\title{
The role of lifestyle factors in primary prevention of dementia
}

Citation for published version (APA):

Deckers, K. (2017). The role of lifestyle factors in primary prevention of dementia: an epidemiological perspective. [Doctoral Thesis, Maastricht University]. NeuroPsych Publishers.

https://doi.org/10.26481/dis.20170511kd

Document status and date:

Published: 01/01/2017

DOI:

10.26481/dis.20170511kd

Document Version:

Publisher's PDF, also known as Version of record

\section{Please check the document version of this publication:}

- A submitted manuscript is the version of the article upon submission and before peer-review. There can be important differences between the submitted version and the official published version of record.

People interested in the research are advised to contact the author for the final version of the publication, or visit the DOI to the publisher's website.

- The final author version and the galley proof are versions of the publication after peer review.

- The final published version features the final layout of the paper including the volume, issue and page numbers.

Link to publication

\footnotetext{
General rights rights.

- You may freely distribute the URL identifying the publication in the public portal. please follow below link for the End User Agreement:

www.umlib.nl/taverne-license

Take down policy

If you believe that this document breaches copyright please contact us at:

repository@maastrichtuniversity.nl

providing details and we will investigate your claim.
}

Copyright and moral rights for the publications made accessible in the public portal are retained by the authors and/or other copyright owners and it is a condition of accessing publications that users recognise and abide by the legal requirements associated with these

- Users may download and print one copy of any publication from the public portal for the purpose of private study or research.

- You may not further distribute the material or use it for any profit-making activity or commercial gain

If the publication is distributed under the terms of Article $25 \mathrm{fa}$ of the Dutch Copyright Act, indicated by the "Taverne" license above, 


\section{THE ROLE OF LIFESTYLE FACTORS IN PRIMARY}

PREVENTION OF DEMENTIA

An epidemiological perspective

Kay Deckers 
(c) Kay Deckers, Maastricht, 2017

All rights reserved. No part of this book may be reproduced or transmitted in any form or by any means, without prior permission in writing by the author, or when appropriate, by the publishers of the publication.

Cover design \& Lay out: Design Your Thesis .com, Rotterdam

Printing:

Ridderprint BV, Ridderkerk

Publisher:

NeuroPsych Publishers

ISBN:

978-94-6299-547-5 


\title{
THE ROLE OF LIFESTYLE FACTORS IN PRIMARY PREVENTION OF DEMENTIA
}

\author{
An epidemiological perspective
}

PROEFSCHRIFT

Ter verkrijging van de graad van doctor aan de Universiteit Maastricht, op gezag van Rector Magnificius, Prof. dr. Rianne M. Letschert, volgens het besluit van het college van Decanen, in het openbaar te verdedigen op donderdag 11 mei 2017 om 14:00 uur

door

\section{Kay Deckers}

Geboren op 10 november 1988 te Brunssum 


\section{Promotor:}

Prof. dr. F.R.J. Verhey

\section{Co-promotores:}

Dr. M.P.J. van Boxtel

Dr. S. Köhler

\section{Beoordelingscommissie:}

Prof. dr. R.W.H.M. Ponds (voorzitter)

Prof. dr. J.F.M. Metsemakers

Prof. dr. M.H. Prins

Dr. E. Richard (Radboud UMC, Nijmegen)

Prof. dr. ir. W.M.M. Verschuren (RIVM, Bilthoven)

The research described in this thesis was performed at the Department of Psychiatry \& Neuropsychology, School for Mental Health and Neuroscience, Maastricht University, Alzheimer Center Limburg, Maastricht, the Netherlands; and Cambridge Institute of Public Health, University of Cambridge, Cambridge, United Kingdom.

The research presented in this thesis was supported by the Fellowship Exchange Program of Alzheimer Nederland and Alzheimer's Society UK; and the In-MINDD (Innovative Midlife Intervention for Dementia Deterrence) project. In-MINDD is funded by the European Union's Framework Programme Seven (FP7) under contract number 304979.

Printing of this thesis was kindly supported by Alzheimer Nederland and the Dutch Heart Foundation.
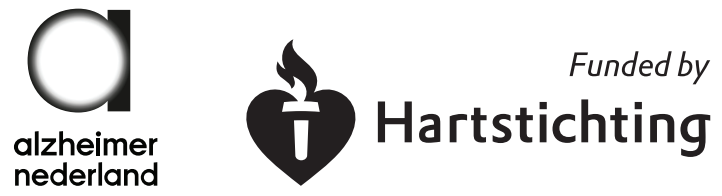


\section{CONTENTS}

1. General introduction, thesis aim and outline 7

PART I: SYSTEMATIC REVIEWS AND META-ANALYSES INTO DEMENTIA EPIDEMIOLOGY

2. Target risk factors for dementia prevention: a systematic review and Delphi

consensus study on the evidence from observational studies

International Journal of Geriatric Psychiatry, 2015

3. Dementia risk in renal dysfunction: a systematic review and meta-analysis of prospective studies

Neurology, 2017

4. Coronary heart disease and risk for cognitive impairment or dementia: a systematic review and meta-analysis

Submitted

5. Obesity and cognitive decline in adults: effect of methodological choices and confounding by age in a longitudinal study Journal of Nutrition, Health and Aging, 2016

6. Prediction of mild cognitive impairment and dementia with a multifactorial environmental risk score: a 30-year follow-up of the CAIDE population-based study

Submitted

7. Lack of associations between modifiable risk factors and dementia in the very old: Findings from the Cambridge City over-75s Cohort Study

Aging \& Mental Health, 2017

8. General discussion

Summary

Nederlandse samenvatting (Dutch summary)

Knowledge valorization

Dankwoord (Acknowledgements)

Thesis defenses from MHeNS (School for Mental Health and Neuroscience)

List of publications

Curriculum vitae 



\section{CHAPTER 1}

GENERAL INTRODUCTION THESIS AIM AND OUTLINE 



\section{GENERAL INTRODUCTION}

\section{Dementia as public health problem}

Although older age is the greatest risk factor for the development of cognitive impairment or dementia later in life, ${ }^{1-3}$ the general notion of dementia being an inevitable part of normal ageing is incorrect. Dementia is a syndrome that is characterized by a loss of cognitive abilities, which is greater than expected based on calendar age alone. Dementia is defined by multiple distortions in memory, thinking, mood, behavior and activities of daily living. The psychosocial effects of this disease are tremendous since it not only affects the person living with dementia, but also severely impacts the quality of life of the caregiver(s), family and friends. ${ }^{4}$

Alzheimer's disease (AD) is the most common cause of dementia and is characterized by cognitive dysfunctions, most often in the memory domain. Pathological evidence shows a build-up of amyloid plaques and neurofibrillary tangles in the brain which causes neurodegeneration and eventually could lead to cognitive disturbances and dementia.5,6 Unfortunately, the exact etiology of dementia syndromes (including AD) is still unknown, although we can conclude that most forms are of a complex multifactorial nature.

Today, the total number of people worldwide living with dementia is estimated to be 46.8 million. ${ }^{7}$ Due to the double aging phenomenon (e.g. increase in life expectancy and the rapid increase in the proportion of oldest old in comparison with the youngest old) in high income countries and the rising life expectancy and epidemiological transition (e.g. adoption of a Western lifestyle) in low and middle income countries, this number will only increase further in the future and is estimated to be 74.7 million in 2030 and 131.5 million in 2050. ${ }^{7}$ As a consequence, the associated global societal economic cost of dementia in 2015 was estimated at US\$ 818 billion. $^{7}$ This is comparable with a top 20 ranking (based on gross domestic product) in the largest economies in the world. Therefore, the World Health Organization (WHO) recognized dementia as a public health priority in $2012 .{ }^{8}$

\section{Modifiable risk factors of dementia and public awareness}

Findings from a vast number of epidemiological studies suggest that a large amount of genetic, demographic, cardiovascular, lifestyle, environmental and psychosocial factors may contribute to the risk for cognitive impairment or dementia. It is well known that nonmodifiable risk factor such as age, sex and certain genetic factors (e.g. apolipoprotein $\mathrm{E}$ genotype) contribute to the risk of developing dementia. Since these static risk factors are not amendable to change, the focus of dementia research should be shifted to modifiable risk factors, i.e. factors that can be targeted in order to potentially decrease the risk of 
cognitive impairment or dementia. It has been shown that seven common modifiable risk factors (diabetes, midlife hypertension, midlife obesity, smoking, depression, low educational attainment and physical inactivity) together contribute to approximately $30 \%$ of all AD cases worldwide. ${ }^{9}$ Modifiable factors for (and possible prevention of) cognitive decline later in life include a healthy diet (e.g. Mediterranean diet, sufficient intake of fruit and vegetables), diabetes, depression, smoking, physical activity and cognitive engagement. Sufficient evidence from randomized controlled trials and observational studies was found for these factors, but the overall quality of evidence for the majority of the identified risk and protective factors was relatively low. ${ }^{10}$ Next, it is still unclear which specific (combination of) potentially modifiable factors can be targeted and which age provides the best window of opportunity to reduce an individual's dementia risk. The latter is important given that there is variation in the effects of some risk factors during the lifespan. For instance, some factors such as obesity and hypertension have more deleterious effects in midlife than in late-life. ${ }^{11,12}$ Besides, late-life studies show more inconsistent results regarding certain health and lifestyle factors. ${ }^{11-14}$

Despite these encouraging findings suggesting that dementia risk can be influenced, an Australian survey among two thousand randomly selected persons showed there is low public awareness that modifiable risk factors may contribute to the risk of developing dementia. Of the respondents, almost 30\% thought that it was not possible to reduce the risk of developing dementia. Additionally, most people were unaware that health and lifestyle adaptations might help to reduce the risk for dementia. ${ }^{15}$ Similar results were found in a recent survey conducted in the United Kingdom. Just $1 \%$ of the respondents were able to identify all seven modifiable risk and protective factors, whereas almost $60 \%$ of the respondents thought that they could do nothing about their own dementia risk or answered that they did not know. ${ }^{16}$

Based on these observations, it is concluded that further research is required to better understand the role of modifiable risk and protective factors in the etiology of dementia. In addition, future public awareness campaigns should include information on the potential relation between health and lifestyle factors and dementia risk in order to raise more public awareness about the possible preventive effects of certain factors.

\section{Dementia prevention trials}

As to date, causal effective treatments for dementia are lacking. For that reason, prevention of dementia in terms of risk reduction has received increasing attention lately and is rising on the research agenda. Prevention of dementia was on the topic list of the first G8 Dementia Summit in London on 11 December 2013. 
Only a few studies have investigated the effect of single risk factor reduction in order to decrease the incidence of cognitive impairment or dementia in the general population. Additionally, most of these trials were not specifically designed to examine their effects on dementia incidence, but they focused on other diseases such as stroke. For instance, the HYVET-COG trial investigated the effect of antihypertensive treatment on the incidence of dementia. In this group of older adults aged 80 years, blood pressure-lowering medication did not reduce the number of new dementia cases. ${ }^{17}$ There are some large (ongoing) dementia prevention initiatives focusing on multifactorial risk reduction, including the Prevention of Dementia by Intensive Vascular Care (preDIVA) trial, ${ }^{18}$ the Finnish Geriatric Intervention Study to Prevent Cognitive Impairment and Disability (FINGER) trial, ${ }^{19}$ the Multidomain Alzheimer Preventive trials (MAPT), ${ }^{20}$ and the Healthy Aging Through Internet Counselling in the Elderly (HATICE) trial. ${ }^{21}$ Yet, these studies focus on relatively older adults (e.g. > 60 years). Therefore, the In-MINDD (INnovative Midlife INtervention for Dementia Deterrence) project was launched in November 2012.

\section{In-MINDD}

The overall aim of In-MINDD was to reduce dementia risk or at least delay it onset through personalized lifestyle interventions in midlife (40-60 years). ${ }^{22}$ The project consisted of three work packages (WPs). In WP1 ("Risk Prediction Algorithm"), we identified the most important modifiable risk and protective factors for primary prevention of dementia by general practitioners. Based on these findings, we created a multi-factorial model that quantifies an individual's potential for dementia risk reduction. Additionally, we validated this model against several population-based data sets and provided the primary input for WP2. In WP2 ("Profiler and online support environment"), an on-line profiler and support environment was developed to calculate an individual's dementia risk modification profile and to support access to health information and goal setting, respectively. In WP3 ("Feasibility study of the In-MINDD profiler and environment in practice"), the effects of the multifactorial environmental risk score, online profiler and support environment has been tested in a multicenter feasibility trial in primary care across France, Ireland, the Netherlands and Scotland. The studies conducted in this thesis were either part of InMINDD WP1 or were particularly inspired by the project. 


\section{THESIS AIM AND OUTLINE}

The general aim of this thesis was to investigate the role of modifiable risk and protective factors of dementia in the general population. The thesis consists of two parts. In Part $\mathrm{I}$, the current state of the literature regarding modifiable risk and protective factors of dementia is broadly summarized first. Based on these findings, more specific studies focusing on candidate risk factors of dementia were conducted in the remainder of Part I. In Part II, observational studies examining the relation between modifiable risk and protective factors and dementia were object of investigation. In this part, two studies focus on the validation of the 'LIfestyle for BRAin Health' (LIBRA) score, a multifactorial environmental risk score that displays an individual's potential for dementia prevention, which was developed as part of WP1 of the In-MINDD project. More specifically, our study addressed the following questions:

\section{Part I:}

What are established modifiable risk and protective factors for dementia?

Chapter 2 provides a systematic literature review and Delphi expert consensus study that was set up to identify the most important modifiable risk and protective factors for primary prevention of dementia.

Is renal dysfunction associated with an increased risk of cognitive impairment or dementia in the general population?

In Chapter 3 the association between markers of renal dysfunction and risk for cognitive impairment or dementia is investigated in a systematic literature review and meta-analysis of prospective population-based studies.

Is there enough evidence to conclude that coronary heart disease is a risk factor for cognitive impairment or dementia?

Chapter 4 contains a systematic literature review and meta-analysis summarizing the findings of all available population-based studies investigating the relation between coronary heart disease (e.g. angina pectoris, myocardial infarction) and risk for cognitive impairment or dementia. 


\section{Part 2:}

\section{What are the effects of obesity on cognitive change over time?}

In Chapter 5 we examine the effects of prevalent and incident obesity on cognitive change over time in participants from the Maastricht Aging Study (MAAS). Particularly, the focus is on the effect of methodological choices and confounding by age.

\section{What is the predictive validity of the LIBRA score for incident mild cognitive impairment or dementia in midlife and late-life?}

In Chapter $\mathbf{6}$ the predictive accuracy of the LIBRA score in midlife and late-life for subsequent mild cognitive impairment and dementia is investigated in the longitudinal population-based Cardiovascular Risk Factors, Aging and Dementia (CAIDE) study. Additionally, potential differences between persons with high and low genetic risk for dementia (apolipoprotein E genotype carriers versus non-carriers) are examined in relation to LIBRA and risk for mild cognitive impairment or dementia.

\section{What is the relation between modifiable risk factors and dementia in the oldest-old?}

Chapter $\mathbf{7}$ assesses the association between modifiable risk and protective factors and severe cognitive impairment or dementia in participants aged 85 years of older from the Cambridge City over-75s Cohort (CC75C) Study. In addition, the predictive validity of the LIBRA score for incident dementia is tested.

The main findings, clinical and scientific implications of the various chapters, and recommendations for future studies are discussed in Chapter 8. Further, this chapter provides a list of publications, information about the author, and acknowledgements. 


\section{REFERENCES}

1. Kawas C, Gray S, Brookmeyer R, Fozard J, Zonderman A. Age-specific incidence rates of Alzheimer's disease: the Baltimore Longitudinal Study of Aging. Neurology 2000; 54(11): 20727.

2. Kukull WA, Higdon R, Bowen JD, et al. Dementia and Alzheimer disease incidence: a prospective cohort study. Arch Neurol 2002; 59(11): 1737-46.

3. Launer LJ, Andersen K, Dewey ME, et al. Rates and risk factors for dementia and Alzheimer's disease: results from EURODEM pooled analyses. EURODEM Incidence Research Group and Work Groups. European Studies of Dementia. Neurology 1999; 52(1): 78-84.

4. Berr C, Wancata J, Ritchie K. Prevalence of dementia in the elderly in Europe. Eur Neuropsychopharmacol 2005; 15(4): 463-71.

5. Jack CR, Jr., Knopman DS, Jagust WJ, et al. Tracking pathophysiological processes in Alzheimer's disease: an updated hypothetical model of dynamic biomarkers. Lancet Neurol 2013; 12(2): 207-16.

6. Jack CR, Jr., Knopman DS, Jagust WJ, et al. Hypothetical model of dynamic biomarkers of the Alzheimer's pathological cascade. Lancet Neurol 2010; 9(1): 119-28.

7. Prince M, Wimo A, Guerchet M, Ali G-C, Wu Y-T, M. P. World alzheimer report 2015. The global impact of Dementia: an analysis of prevalence, incidence, cost and trends. London: Alzheimer's Disease International (ADI), 2015.

8. World Health Organization and Alzheimer's Disease International. Dementia: A Public Health Priority. Geneva: World Health Organization, 2012.

9. Norton S, Matthews FE, Barnes DE, Yaffe K, Brayne C. Potential for primary prevention of Alzheimer's disease: an analysis of population-based data. Lancet Neurol 2014; 13(8): 788-94.

10. Plassman BL, Williams JW, Jr., Burke JR, Holsinger T, Benjamin S. Systematic review: factors associated with risk for and possible prevention of cognitive decline in later life. Ann Intern Med 2010; 153(3): 182-93.

11. Anstey KJ, Cherbuin N, Budge M, Young J. Body mass index in midlife and late-life as a risk factor for dementia: a meta-analysis of prospective studies. Obes Rev 2011; 12(5): e426-37.

12. Barnes $D E$, Yaffe $K$. The projected effect of risk factor reduction on Alzheimer's disease prevalence. Lancet Neurol 2011; 10(9): 819-28.

13. Anstey KJ, Lipnicki DM, Low LF. Cholesterol as a risk factor for dementia and cognitive decline: a systematic review of prospective studies with meta-analysis. Am J Geriatr Psychiatry 2008; 16(5): 343-54.

14. Power MC, Weuve J, Gagne JJ, McQueen MB, Viswanathan A, Blacker D. The association between blood pressure and incident Alzheimer disease: a systematic review and metaanalysis. Epidemiology 2011; 22(5): 646-59.

15. Low LF, Anstey KJ. Dementia literacy: recognition and beliefs on dementia of the Australian public. Alzheimers Dement 2009; 5(1): 43-9.

16. Marcinkiewicz A, Reid S. Attitudes to dementia: Findings from the 2015 Britisch Social Attitudes survey. London: NatCen Social Research, 2016.

17. Peters R, Beckett N, Forette F, et al. Incident dementia and blood pressure lowering in the Hypertension in the Very Elderly Trial cognitive function assessment (HYVET-COG): a doubleblind, placebo controlled trial. Lancet Neurol 2008; 7(8): 683-9. 
18. Richard E, Van den Heuvel E, Moll van Charante EP, et al. Prevention of dementia by intensive vascular care (PreDIVA): a cluster-randomized trial in progress. Alzheimer Dis Assoc Disord 2009; 23(3): 198-204.

19. Kivipelto M, Solomon A, Ahtiluoto S, et al. The Finnish Geriatric Intervention Study to Prevent Cognitive Impairment and Disability (FINGER): study design and progress. Alzheimers Dement 2013; 9(6): 657-65.

20. Gillette-Guyonnet S, Andrieu S, Dantoine T, Dartigues J-F, Touchon J, Vellas B. Commentary on "A roadmap for the prevention of dementia II. Leon Thal Symposium 2008." The Multidomain Alzheimer Preventive Trial (MAPT): A new approach to the prevention of Alzheimer's disease. Alzheimers Dement 2009; 5(2): 114-21.

21. Richard $\mathrm{E}$, Jongstra $\mathrm{S}$, Soininen $\mathrm{H}$, et al. Healthy Ageing Through Internet Counselling in the Elderly: the HATICE randomised controlled trial for the prevention of cardiovascular disease and cognitive impairment. BMJ Open 2016; 6(6).

22. O'Donnell CA, Browne $S$, Pierce $M$, et al. Reducing dementia risk by targeting modifiable risk factors in mid-life: study protocol for the Innovative Midlife Intervention for Dementia Deterrence (In-MINDD) randomised controlled feasibility trial. Pilot and Feasibility Studies 2015; 1(1): 40 . 



\section{PART I}

\section{SYSTEMATIC REVIEWS AND META-ANALYSES INTO DEMENTIA EPIDEMIOLOGY}



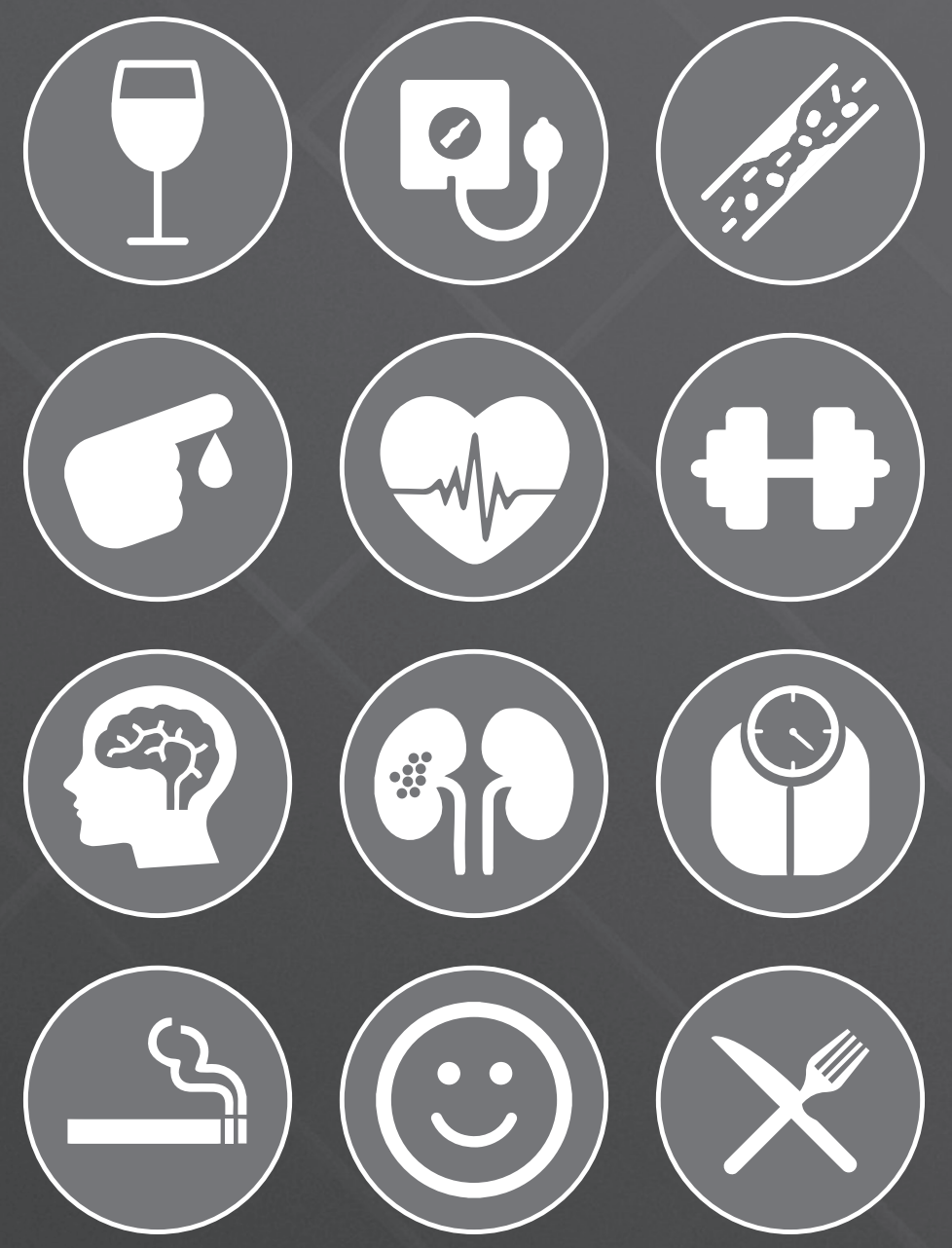


\section{CHAPTER 2}

\section{TARGET RISK FACTORS FOR DEMENTIA PREVENTION: A SYSTEMATIC REVIEW AND DELPHI CONSENSUS STUDY ON THE EVIDENCE FROM OBSERVATIONAL STUDIES}

International Journal of Geriatric Psychiatry 2015;30:234-246

Kay Deckers, Martin PJ van Boxtel, Olga JG Schiepers, Marjolein de Vugt, Juan Luis Muñoz Sánchez, Kaarin J Anstey, Carol Brayne, Jean-Francois Dartigues,

Knut Engedal, Miia Kivipelto, Karen Ritchie, John M Starr, Kristine Yaffe, Kate Irving on behalf of the In-MINDD project team, Frans RJ Verhey, Sebastian Köhler 


\section{ABSTRACT}

Objective: Dementia has a multifactorial etiology, but the importance of individual health and lifestyle related risk factors is often uncertain or based on few studies. The goal of this paper is to identify the major modifiable risk factors for dementia as a first step in developing an effective preventive strategy and promoting healthy late life cognitive functioning.

Methods: A mixed-method approach combined findings from a systematic literature review and a Delphi consensus study. The literature search was conducted in PubMed and updated an earlier review by the United States National Institutes of Health from 2010. We reviewed the available evidence from observational epidemiological studies. The onlineDelphi study asked eight international experts to rank and weigh each risk factor for its importance for dementia prevention.

Results: Out of 3,127 abstracts, 291 were included in the review. There was good agreement between modifiable risk factors identified in the literature review and risk factors named spontaneously by experts. After triangulation of both methods and re-weighting by experts strongest support was found for depression, (midlife) hypertension, physical inactivity, diabetes, (midlife) obesity, hyperlipidemia, and smoking, while more research is needed for coronary heart disease, renal dysfunction, diet and cognitive activity.

Conclusions: Findings provide good support for several somatic and lifestyle factors and will be used to inform the design of a new multicenter trial into dementia prevention. 


\section{INTRODUCTION}

The total number of people with dementia will increase due to the ageing of the population, ${ }^{1,2}$ and so will associated care costs, ${ }^{3}$ despite declining prevalence and incidence rates, ${ }^{4,5}$ making dementia a global public health priority. ${ }^{6}$ Identifying major determinants for dementia is important for understanding disease mechanisms and designing effective preventive strategies in the absence of curative treatment. ${ }^{7}$

Potentially modifiable risk factors for cognitive decline and dementia include depression, diabetes mellitus, smoking, vegetable intake, physical activity, and cognitive training. ${ }^{8,9}$ A recent review suggested that seven major modifiable risk factors (diabetes mellitus, midlife hypertension, midlife obesity, smoking, depression, and cognitive and physical inactivity) account for about $50 \%$ of all cases of Alzheimer's disease (AD) dementia. ${ }^{10}$ Yet, the quality of evidence for several of these factors has been judged to be low because most evidence comes from observational studies. ${ }^{8}$ In the absence of well-designed randomized controlled trials (RCT) for most risk and protective factors, experts' opinion about the evidence from observational studies might offer an alternative approach to weight the current evidence regarding a factor's importance for primary prevention. Therefore, the current study aimed 1) to update the evidence base regarding major risk factors for dementia in a systematic review, and 2) to get a better balanced account of their (relative) importance for dementia prevention in a Delphi expert study. ${ }^{11}$

\section{METHODS}

\section{Phase 1: Systematic review}

\section{Data Sources and Searches}

PubMed was searched using the search strategy of a recent United States NIH report that evaluated all literature between 1984 and 27 October 2009.8,9 However, a more generic search term was used as to be more inclusive and potentially identifying novel risk factors studied only recently.

\section{Study selection}

Inclusion criteria were: population based sample, prospective design (cross-sectional and retrospective case-control studies were excluded), $\geq 200$ participants, aged $\geq 45$ years, $\geq$ 1 year follow-up and published between 28 October 2009 and 5 December 2012. For the full search term see Appendix 1. 


\section{Data extraction}

A single rater (SK) screened abstracts for broad suitability. Two investigators (KD, JLM) then extracted relevant information from full texts such as sample size, age range, followup period, outcome (e.g. dementia, cognitive impairment, cognitive decline), predictors, and association.

\section{Quality Assessment}

Quality aspects of the included cohort studies were assessed with the 8-item Newcastle Ottawa Scale. ${ }^{12}$

\section{Phase 2: Delphi study - first round}

The Delphi study was conducted among experts in dementia epidemiology and prevention. Inclusion criteria for experts were: (1) associate professor or higher; (2) proven track record in the field; (3) board members of professional organizations for dementia research; and (4) leaders of prominent research groups. A dedicated website was constructed hosting an online-survey, thereby blinding participants to contributions from other participants. Experts were provided with a link and unique access code, which allowed blinding of the moderator (SK) when processing participants' responses. Twenty experts were invited, of which eight agreed (40\% response rate), one initially agreed but did not complete the survey, four declined (two lack of time, two referred to colleague), and seven did not respond after three reminders. In the first round (February-March 2013), each participant freely named potential risk factors for all-type dementia in subjective order of importance and indicated potential interactions. Individual responses were then given a 'rank score' (RS) (see Appendix 2 for the formula). Individual experts' RS were then summed across experts for a factor's total RS.

\section{Phase 3: Synthesis of information}

Next, evidence was aggregated by compiling lists with the major modifiable risk factors from both the literature review (the number of encountered studies, consistency in direction of association, effect size) and the first Delphi round (risk factor's total RS). The preliminary risk factor inventory included the highest-ranking factors from both methods.

\section{Phase 4: Delphi study - second round}

In the second round (June-September 2013), the same experts were provided with the results from the systematic review and the aggregated results of the first Delphi round. They were invited to comment on the preliminary risk factor inventory. Experts then 
weighted the risk factors in order of importance for primary prevention of dementia by general practitioners. For this, they were given 100 points, which could be distributed across risk factors (more points = more important). Summation of these points yielded the final ranking and inventory of most important risk factors.

\section{RESULTS}

\section{Systematic review}

The search returned 3,127 abstracts, of which 320 (10.2\%) were included for full-text scrutiny. Of these, 29 were excluded for different reasons (Figure 1). From all encountered risk factors (Appendix 3), we identified the ones studied most extensively and calculated their consistency of association (Table 1). Several factors showed good (i.e. $\geq 80 \%$ ) consistency: depression, diabetes, and smoking. While there was considerable overlap with factors reported in our reference reviews, ${ }^{8,10}$ some were not include before but seemed promising candidates: coronary heart disease, renal dysfunction, and inflammation. Quality assessment of 289 studies showed that all of these were of sufficient quality to include in our analyses ( mean $=7.92, \mathrm{SD}=0.64$, median $=8$, range $=6-9$ ). For two studies sufficient information could be extracted on the basis of the abstract. 


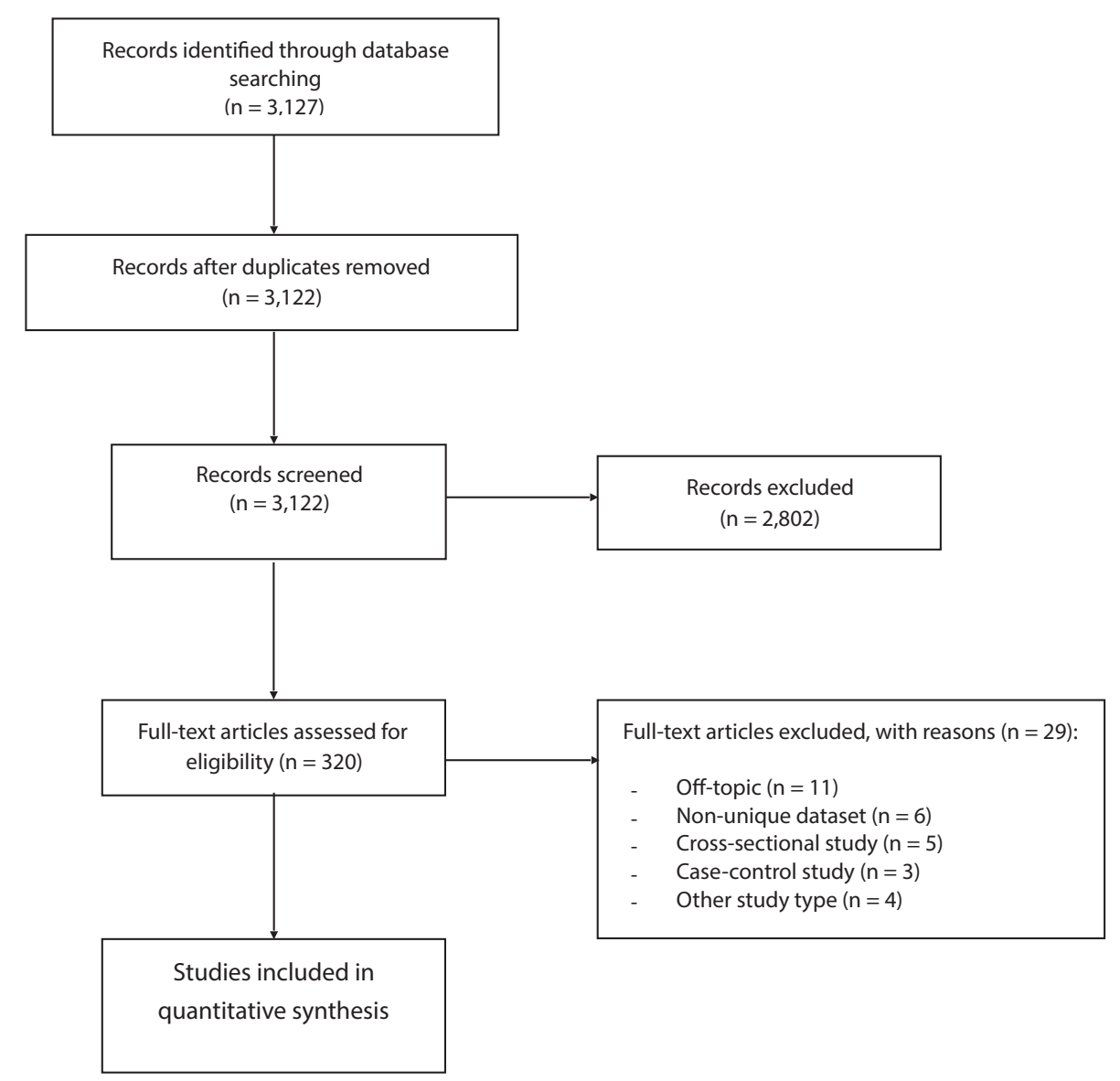

Figure 1. Preferred Reporting Items for Systematic Reviews and Meta-Analyses (PRISMA)-style Flowchart of Study selection and Review 
Table 1. List of best-documented dementia risk and/or protective factors based on review of 291 abstracts (from a total of 3,127)

\begin{tabular}{|c|c|c|c|c|c|}
\hline & $\begin{array}{l}\text { Number of } \\
\text { studies }\end{array}$ & $\begin{array}{l}\text { Higher risk/ } \\
\text { decline }\end{array}$ & $\begin{array}{l}\text { Lower risk/ } \\
\text { decline }\end{array}$ & $\begin{array}{l}\text { No } \\
\text { association }\end{array}$ & $\begin{array}{l}\text { Consistency of } \\
\text { association }\end{array}$ \\
\hline Depression & 21 & 19 & 0 & 2 & $90 \%$ \\
\hline Hypertension $^{a}$ & 21 & 16 & 2 & 3 & $76 \%$ \\
\hline Midlife & 8 & 7 & 0 & 1 & $88 \%$ \\
\hline Late-life & 16 & 12 & 2 & 2 & $75 \%$ \\
\hline Diabetes & 19 & 17 & 0 & 2 & $89 \%$ \\
\hline Obesity & 14 & 7 & 2 & 5 & $50 \%$ \\
\hline Midlife & 6 & 4 & 0 & 2 & $67 \%$ \\
\hline Late-life & 8 & 3 & 2 & 3 & $38 \%$ \\
\hline Smoking & 13 & 10 & 1 & 2 & $77 \%$ \\
\hline Coronary heart disease & 10 & 8 & 0 & 2 & $80 \%$ \\
\hline High cholesterol & 10 & 8 & 0 & 2 & $80 \%$ \\
\hline Renal dysfunction & 9 & 9 & 0 & 0 & $100 \%$ \\
\hline Low physical activity & 7 & 5 & 0 & 2 & $71 \%$ \\
\hline High homocysteine & 5 & 4 & 0 & 1 & $80 \%$ \\
\hline Metabolic syndrome & 5 & 4 & 0 & 1 & $80 \%$ \\
\hline Stroke & 5 & 4 & 0 & 1 & $80 \%$ \\
\hline Inflammation & 5 & 3 & 0 & 2 & $60 \%$ \\
\hline High unsaturated fat intake & 5 & 1 & 4 & 0 & $80 \%$ \\
\hline High cognitive activity & 4 & 0 & 4 & 0 & $100 \%$ \\
\hline
\end{tabular}

${ }^{a}$ Three studies examined both the relation between midlife and late-life hypertension and cognitive decline.

\section{First Delphi round}

Experts named 25 modifiable risk factors (Appendix 4). Table 2 shows those with the highest RS. Also, ten non-modifiable risk factors were named, with the highest RS for age, generic genetic effects, the apolipoprotein E (APOE) gene in particular, sex, and family history of dementia. No interaction between risk factors was named twice.

\section{Second Delphi round}

In this round, experts assigned points (100 in total) to the modifiable risk factors that were most prominent in the review and first Delphi (see also Tables 1 and 2). Most points were given to depression, diabetes, cognitive activity, physical activity, and hypertension. Mediterranean diet, obesity in midlife, smoking, alcohol intake (low/moderate), and cholesterol/hyperlipidemia were considered relatively less important (Table 3). 
Table 2. First Delphi round: list of most important modifiable dementia risk factors

\begin{tabular}{|l|l|l|l|l|}
\hline Modifiable risk factors & Frequency $^{\mathbf{a}}$ & Ranks $^{\mathbf{b}}$ & Score $^{\mathbf{c}}$ & Final Rank $^{\mathbf{d}}$ \\
\hline Hypertension & 5 & $1,1,2,3,9$ & 349 & 1 \\
\hline Diabetes & 6 & $1,2,3,6,7,7$ & 302 & 2 \\
\hline Physical inactivity & 6 & $2,2,3,6,6,7$ & 292 & 3 \\
\hline Depression & 7 & $2,3,5,6,8,9,10$ & 220 & 4 \\
\hline Low cognitive activity & 4 & $2,3,6,7$ & 186 & 5 \\
\hline Obesity & 4 & $4,5,4,7$ & 126 & 6 \\
\hline Alcohol & 3 & $3,6,9$ & 110 & 7 \\
\hline High cholesterol & 2 & 3,6 & 106 & 8 \\
\hline Metabolic syndrome & 1 & 1 & 100 & 9 \\
\hline Diet & 3 & $5,4,10$ & 86 & 10 \\
\hline Smoking & 4 & $4,8,8,10$ & 68 & 11 \\
\hline
\end{tabular}

${ }^{\mathrm{a}}$ Frequency $=$ number of times risk factor is mentioned by the eight Delphi experts.

${ }^{\mathrm{b}}$ Ranks = ranks given to each risk factor by the eight Delphi experts.

' Score $=$ total number of assigned points based on Ranks (see Appendix 2 for the formula).

${ }^{\mathrm{d}}$ Final rank $=$ final rank based on Score.

Table 3. Second Delphi round: ranking of dementia risk and protective factors

\begin{tabular}{|l|l|l|l|}
\hline Risk/protective factors & Frequency $^{\mathbf{a}}$ & Score $^{\mathbf{b}}$ & Final Rank $^{\mathbf{c}}$ \\
\hline Depression & 8 & 120 & 1 \\
\hline Diabetes & 8 & 115 & 2 \\
\hline High cognitive activity & 8 & 113 & 3 \\
\hline (High) physical activity & 8 & 111 & 4 \\
\hline Hypertension & 8 & 108 & 5 \\
\hline Mediterranean diet & 8 & 64 & 6 \\
\hline Obesity (midlife) & 8 & 50 & 7 \\
\hline Smoking & 8 & 46 & 8 \\
\hline Low/ moderate alcohol & 8 & 37 & 9 \\
\hline High cholesterol & 7 & 31 & 10 \\
\hline Coronary heart disease & 1 & 5 & 11 \\
\hline
\end{tabular}

${ }^{a}$ Frequency $=$ number of times risk factor is mentioned by the eight Delphi experts.

${ }^{\mathrm{b}} \mathrm{S}$ core $=$ total number of points assigned by the eight Delphi experts.

' Final rank = final rank based on Score. 


\section{Summary of major modifiable risk factors}

Table 4 shows the final inventory based on the review, Delphi study, and the two reference reviews. ${ }^{8,10}$ Relative risks (RR) for dementia were extracted from existing meta-analyses.

Table 4. Effects of modifiable risk factors for dementia based on all available evidence from Delphi expert survey and systematic reviews

\begin{tabular}{|c|c|c|c|c|c|c|c|}
\hline & $\begin{array}{l}\text { Delphi } \\
\text { ranking } \\
\text { Round } 1\end{array}$ & $\begin{array}{l}\text { Delphi } \\
\text { ranking } \\
\text { Round } 2\end{array}$ & $\begin{array}{l}\text { Sys- } \\
\text { tematic } \\
\text { review, } \\
\text { number } \\
\text { of stud- } \\
\text { ies }\end{array}$ & $\begin{array}{l}\text { Consis- } \\
\text { tency of } \\
\text { associa- } \\
\text { tion }\end{array}$ & $\begin{array}{l}\text { Sys- } \\
\text { tematic } \\
\text { review + } \\
\text { review } \\
\text { of Plass- } \\
\text { man } \\
\text { et al. } \\
(2010) \text {, } \\
\text { number } \\
\text { of stud- } \\
\text { ies }\end{array}$ & $\begin{array}{l}\text { Included } \\
\text { in review } \\
\text { of } \\
\text { Barnes } \\
\text { and } \\
\text { Yaffe } \\
(2011)\end{array}$ & $\begin{array}{l}\text { Relative } \\
\text { risk } \\
\text { extract- } \\
\text { ed from } \\
\text { existing } \\
\text { me- } \\
\text { ta-analy- } \\
\text { ses }\end{array}$ \\
\hline Depression & 4 & 1 & 21 & $90 \%$ & 34 & $x$ & $1.85^{13}$ \\
\hline Diabetes & 2 & 2 & 19 & $89 \%$ & 31 & $x$ & $1.47^{14}$ \\
\hline Cognitive activity & 5 & 3 & 4 & $100 \%$ & 8 & $x$ & $0.38^{15}$ \\
\hline Physical activity & 3 & 4 & 7 & $71 \%$ & 15 & $x$ & $1.39^{16}$ \\
\hline (Midlife) hypertension & 1 & 5 & 21 & $76 \%$ & 40 & $x$ & $1.61^{10}$ \\
\hline Diet $^{\mathrm{a}, \mathrm{c}}$ & 10 & $6^{\mathrm{b}}$ & 5 & $60 \%$ & 7 & - & $0.60^{17}$ \\
\hline (Midlife) obesity & 6 & 7 & 14 & $50 \%$ & 17 & $x$ & $1.60^{10}$ \\
\hline Smoking & 11 & 8 & 13 & $77 \%$ & 27 & $x$ & $1.59^{18}$ \\
\hline Low/moderate alcohol & 7 & 9 & 3 & $33 \%$ & 10 & - & $0.74^{19}$ \\
\hline High cholesterol & 8 & 10 & 10 & $80 \%$ & 15 & - & $1.54^{15}$ \\
\hline $\begin{array}{l}\text { Coronary heart } \\
\text { disease }^{d}\end{array}$ & - & 11 & 10 & $80 \%$ & 10 & - & $1.36^{20}$ \\
\hline Renal dysfunction & - & - & 9 & $100 \%$ & 9 & - & $1.39^{21}$ \\
\hline Low unsaturated fat & - & - & 5 & $80 \%$ & 11 & - & - \\
\hline Inflammation ${ }^{e}$ & - & - & 5 & $60 \%$ & 5 & - & $1.45^{22}$ \\
\hline
\end{tabular}

a Number of studies based on "Mediterranean diet" and "unhealthy diet".

${ }^{\mathrm{b}}$ Mediterranean diet.

'Meta-analysis on Mediterranean diet.

${ }^{\mathrm{d}}$ Meta-analysis on atrial fibrillation.

e Meta-analysis based on pooled effect for C-reactive protein. 


\section{Depression}

In our review, depression increased the risk of cognitive decline or dementia in 19 out of 21 studies. ${ }^{23-41}$ Two studies found no association (90\% consistency). ${ }^{42,43}$ Experts rated depression as the most important risk factor in the second Delphi round. Recent metaanalyses report a $90 \%$ higher risk for $\mathrm{AD}^{4{ }^{4}}$ or $85 \%$ higher risk for all-type dementia. ${ }^{13}$ Whether depression is a causal risk factor or a vulnerability marker is controversial. ${ }^{45} \mathrm{Next}$ to neurodegeneration, cerebrovascular pathology might be involved, ${ }^{30,45}$ which is in line with the notion of a 2.5 times increased risk for vascular dementia. ${ }^{13}$

\section{Diabetes}

Nineteen studies reported on diabetes, of which 17 found an increased effect. ${ }^{33,36,46-60}$ Two studies found no association (89\% consistency). ${ }^{61,62}$ Experts ranked diabetes as the second most important risk factor in both Delphi rounds. In a meta-analysis of six prospective studies, diabetes carried a $47 \%$ increased risk of dementia. ${ }^{14}$ The pathological mechanisms linking diabetes to cognitive decline and dementia are not fully understood, but might include metabolic, vascular and inflammatory processes. Insulin deficiency is linked to the metabolism of the AD pathology including amyloid beta and tau. ${ }^{63,64}$

\section{Cognitive activity}

From four studies on high cognitive activity, ${ }^{65-68}$ all found a decreased risk (100\% consistency). Experts rated cognitive inactivity as the third most important factor. Pooled effect sizes of two large prospective studies suggest a $62 \%$ lower risk of AD in older adults who engage in cognitive stimulating leisure activities. ${ }^{15}$ Yet, another large prospective study found no support. ${ }^{69}$ Engagement in cognitively stimulating activities has generally been associated with a reduced risk for cognitive decline, ${ }^{65,68}$ mild cognitive impairment $(\mathrm{MCl}){ }^{66}$ and dementia. ${ }^{66,67}$ However, the Advanced Cognitive Training for Independent and Vital Elderly (ACTIVE) trial found no effect of cognitive training on dementia risk after five years. ${ }^{70}$ Cognitive activity may delay cognitive decline by increasing an individual's cognitive reserve. ${ }^{66}$

\section{Physical activity}

Out of seven studies on low physical activity, five found an increased risk, ${ }^{71-75}$ while two studies found no association (71\% consistency). ${ }^{76,77}$ Experts rated (high) physical activity as the fourth most important factor. Physical inactivity increased the risk of developing dementia in a meta-analysis of 14 prospective studies by $39 \% .{ }^{16}$ However, another report found insufficient evidence supporting an association between physical inactivity and 
dementia. ${ }^{8}$ Definition of the optimal dose of physical activity is difficult, because studies rarely include measures of both frequency and intensity of exercise. Some studies have shown that physical activity might influence cognition by counteracting vascular risk factors such as hypertension, diabetes and obesity, ${ }^{71,78}$ whereas a large body of animal research has demonstrated that physical activity may directly affect the brain, independent from its cardioprotective effects. ${ }^{79}$

\section{Hypertension}

Out of 21 studies, five focusing on midlife hypertension, 13 on late-life hypertension, and three examined both. Seven studies into midlife hypertension found an increased risk, ${ }^{47,50,53,57,80-82}$ one study found no association ( $88 \%$ consistency). ${ }^{83}$ For late-life, 12 studies found an increased risk, ${ }^{33,53,56,57,82,84-90}$ two a decreased risk, ${ }^{55,91}$ and two no association (75\% consistency). ${ }^{62,80,92}$ Experts ranked hypertension as the fifth most important factor. Midlife hypertension is associated with a $61 \%$ increased risk of developing dementia. ${ }^{10}$ Two metaanalyses from 2011 found no association between hypertension and risk of AD, ${ }^{93,94}$ but they combined studies into midlife and late-life hypertension. ${ }^{95} \mathrm{~A}$ meta-analysis of nine placebo controlled trials showed positive effects of blood pressure-lowering therapies, though interventions were not started in midlife. ${ }^{96}$ Possible mechanisms include atherosclerosis, white matter lesions, increased neuritic plaques and tangles, and atrophy. ${ }^{78}$

\section{Diet}

Out of the three studies, two associated a healthy dietary pattern with a lower risk. ${ }^{97,98}$ One study found no association ( $67 \%$ consistency).$^{73}$ Experts rated healthy diet (i.e. Mediterranean diet) as the sixth most important factor.

Regarding the Mediterranean diet, one study found no association ${ }^{99}$ and another study showed a protective association. ${ }^{100}$ A Mediterranean diet is characterized by (1) a high consumption of olive oil, fruits, vegetables, nuts, seeds, beans, and fish; (2) a moderate consumption of wine or dairy products such as cheese or yoghurt; and (3) a low consumption of meat. ${ }^{99,100}$ Adherence might protect against dementia. ${ }^{17} \mathrm{~A}$ recent systematic review of 12 studies ( 11 observational studies and one RCT) found that higher adherence was associated with less cognitive decline and a reduced risk of AD, but not MCl. ${ }^{101}$

\section{Obesity}

Fourteen studies reported on obesity, of which 6 focused on midlife obesity and eight on late-life obesity. Midlife obesity increased the risk in four studies, ${ }^{80,102-104}$ while two found 
no association (67\% consistency). ${ }^{73,105}$ In late-life, three studies found an increased risk $56,106,107$, two studies found a decreased risk, ${ }^{108,109}$ and three studies found no association (38\% consistency). ${ }^{46,62,108-110}$. Experts ranked midlife obesity as the seventh most important factor. In meta-analyses, midlife obesity has been associated with a $60 \%$ increased risk of dementia. ${ }^{10}$ Overweight and obesity are interrelated and have effects on other risk factors like hypertension, diabetes and hyperlipidemia. ${ }^{111}$ Adiposity may influence brain health through different biological mechanisms including inflammatory cytokines. ${ }^{111,112}$

\section{Smoking}

Thirteen studies reported on smoking. Ten studies found an increased risk, ${ }^{47,56,73,113-119}$ one study suggested that (current and past) smoking may be a protective factor for cognitive decline, ${ }^{120}$ whereas two studies found no association (77\% consistency). ${ }^{52,121}$ Experts rated smoking as the eighth most important one. In a meta-analysis of 8 prospective studies, current smoking was associated with a $59 \%$ increased risk of AD. ${ }^{18}$ Smoking is a catalyst in the process of cognitive decline, although the exact mechanisms are still unknown. Smoking might have (indirect) effects on several vascular, inflammatory and degenerative processes (e.g. oxidative stress) ${ }^{114,115}$ including atherosclerosis. ${ }^{122}$

\section{Alcohol consumption}

Three studies reported on alcohol consumption. One found that low-to-moderate alcohol reduced the risk, ${ }^{123}$ while another study did not confirm this. ${ }^{124}$ The remaining study suggested that daily drinking was associated with an increased risk of dementia. ${ }^{119}$ Experts ranked low-to-moderate alcohol consumption as the ninth most important factor of dementia. A meta-analysis of 7 prospective studies found a $26 \%$ reduced risk in low-tomoderate drinkers. ${ }^{19}$ A putative protective effect has been linked to cardiovascular (e.g. lowering of cholesterol, reducing blood pressure, blood clotting and ischemic attacks) and anti-amyloidogenic effects of wine flavonoids. ${ }^{125,126}$ On the other hand, chronic alcohol abuse is associated with a number of brain-related diseases such as the WernickeKorsakoff's syndrome, alcoholic dementia, stroke, and cerebellar degeneration. ${ }^{127}$ Alcoholrelated brain damage can be caused by neurotoxicity, nutritional deficiency, neuroinflammation and changes in neurotransmitter systems. ${ }^{127}$

\section{Cholesterol/hyperlipidemia}

Ten studies reported on high cholesterol levels, of which eight found an increased risk, ${ }^{47,56,128-133}$ and two studies found no association (80\% consistency). ${ }^{62,134}$ Experts ranked high cholesterol as the tenth most important factor. A meta-analysis of prospective 
studies from 2008 implied that high midlife total serum cholesterol increases the risk of dementia, ${ }^{135}$ whereas late-life cholesterol does not. ${ }^{136,137} \mathrm{~A}$ recent meta-analysis of five prospective studies reported a 54\% increased risk in older adults with high levels of serum cholesterol. ${ }^{15}$ There are several putative mechanisms linking cholesterol and dementia. High levels of brain cholesterol accelerate AD progression by influencing the beta-amyloid metabolism and neurofibrillary tangle formation. ${ }^{138,139}$

\section{Coronary heart disease}

Eight studies of ten found an increased risk in people with coronary heart disease, ${ }^{89,113,140-145}$, and two studies found no association (80\% consistency). ${ }^{56,146}$ Experts did not name coronary heart disease in the first Delphi round, and only one expert suggested to include it in the second round. Several forms of heart disease have been related to cognitive decline, ${ }^{147}$ with atrial fibrillation being studied most extensively. ${ }^{20,148,149} \mathrm{~A}$ meta-analysis of 7 prospective studies found a $36 \%$ higher risk for AD in people with atrial fibrillation. ${ }^{20}$ A large cohort study reported an association between atherosclerosis and dementia. ${ }^{150}$ The association between heart disease and dementia could be (partly) due to shared risk factors (e.g. hypertension, diabetes, high cholesterol levels, smoking, obesity), leading to vascular insufficiency, reduced cerebral blood flow and ischemic brain lesions. ${ }^{20,147}$

\section{Renal dysfunction}

All nine studies on renal dysfunction encountered in the review found an increased risk (100\% consistency). ${ }^{151-159}$ Experts did not name renal dysfunction in first or second Delphi round. Other considered it a new candidate risk factor. ${ }^{160} \mathrm{~A}$ meta-analysis of longitudinal studies in patients with chronic kidney disease found a 39\% increased risk for cognitive impairment. ${ }^{21}$ The underlying mechanisms have not been elucidated, but anemia and cerebral small vessel disease might play a role. ${ }^{161}$

\section{Unsaturated fat intake}

Five studies reported on unsaturated fat intake. Four studies found a decreased risk, ${ }^{162-165}$ one study found an increased risk ( $80 \%$ consistency).${ }^{99}$ Experts did not name fat intake as a specific risk factor. Observational studies suggest that higher intake of omega-3 polyunsaturated fatty acids may be associated with a reduced risk of dementia. ${ }^{166-168}$ A meta-analysis of 10 RCTs found no effect in healthy individuals or patients with AD, but some support for improved memory, attention and processing speed in those with cognitive impairment no dementia. ${ }^{169}$ 


\section{Inflammation}

Five studies reported on serum inflammatory markers. Three studies found a positive association, ${ }^{170-172}$ and two studies found no association (60\% consistency). ${ }^{173,174}$ Different markers of inflammation, e.g. C-reactive protein ${ }^{170-174}$ or interleukin-6 ${ }^{170-173}$ ), make comparisons of individual studies difficult. Inflammation was not named by experts in the Delphi study. Inflammation has been linked to the pathogenesis of dementia. ${ }^{175} \mathrm{~A}$ meta-analysis of observational studies found that high C-reactive protein levels increase dementia risk by $45 \%$, while a $32 \%$ increased risk was found for higher interleukin- 6 levels. ${ }^{22}$ Inflammation might also be a mediator or moderator of the effect of other risk factors, including metabolic changes. ${ }^{176}$

\section{DISCUSSION}

This study weighted the evidence for major dementia risk factors by conducting a systematic literature review on the evidence from epidemiological studies, followed by expert consensus in a Delphi study. Support was found for several somatic and lifestyle factors: depression, (midlife) hypertension, physical inactivity, diabetes, (midlife) obesity, hyperlipidemia, and smoking. In addition, some risk factors were identified that need further validation (few studies, inconsistent results): coronary heart disease, renal dysfunction, diet and cognitive activity. Modifiable risk factors have been estimated to account for $50 \%$ of the prevalence of AD dementia. ${ }^{10}$ Evidence mostly comes from observational studies, ${ }^{8,10}$ which are subject to methodological limitations such as exposure and outcome misclassification, selection and confounding, leading to uncertainty regarding their importance. Our approach of adding experts' opinions to the findings of a systematic review, enriched by existing meta-analyses, make a strong case for targeting these factors in dementia prevention trials.

There is still considerable low public awareness that dementia risk may depend to some extent on modifiable lifestyle factors. ${ }^{177}$ This has important consequences: persons-at-risk do not seek help, they receive insufficient and inaccurate care as well as support from their social environment, and dementia is stigmatized. ${ }^{1}$ The present findings could inform the design of prevention programs or training curricula for health care providers. Recently, the Alzheimer's Association and Centers for Disease Control and Prevention developed such an initiative. ${ }^{178,179}$ Findings hopefully stimulate further research into the identified candidate risk factors.

It is also noteworthy that experts did not agree on possible interactions between risk factors. Several commented on the scarcity of data available to make an 'educated guess'. 
It is becoming increasingly clear that $A D$ and other common types of dementia show a mixed pathology. ${ }^{180-182}$ Risk factors are unlikely to occur in isolation, but might interact in a synergistic or antagonistic way, or form clusters (e.g. metabolic syndrome). Obviously, more research into the etiological complexity of dementia using advanced statistical methods is needed to get a better view of the interrelated action of risk factors. Ongoing and planned dementia prevention initiatives will explore optimal target populations, intervention strategies, and outcome measures that are important for future multi-national clinical trials on dementia prevention. Three large multi-domain dementia prevention studies are ongoing (Prevention of Dementia by Intensive Vascular Care (preDIVA), Finnish Geriatric Intervention Study to Prevent Cognitive Impairment and Disability (FINGER), Multidomain Alzheimer Preventive trails (MAPT)), ${ }^{183-185}$ and together form the European Dementia Prevention Initiative (EPDI). ${ }^{186}$ This initiative developed a new RCT, the Healthy Aging Through Internet Counselling in the Elderly (HATICE), to investigate whether cognitive decline or new cardiovascular disease can be prevented. ${ }^{186}$

The focus of these intervention studies is on older adults ( $>60$ years), while some risk factors show most effect in middle-aged persons (e.g. hypertension, obesity). Identification of midlife modifiable risk factors is crucial in order to intervene at an early stage of the disease process. The In-MINDD (Innovative Midlife Intervention for Dementia Deterrence) project aims to decrease dementia risk and/or delay its onset through lifestyle interventions in midlife. The current findings will then be used to inform the design of a European multicenter trial into dementia prevention in individuals aged 40 to 60 years as part of the In-MINDD project.

The primary strength of our study is the use of both quantitative and qualitative information to identify dementia risk and protective factors. This allowed for cross-validation and triangulation of the findings in order to arrive at what appears as current best evidence. In addition, we compared and pooled our findings with the results and from recent metaanalyses and systematic reviews to arrive at a final risk inventory. Second our broad search term yielded more results and we therefore identified some candidate risk factors (e.g. renal dysfunction) that were not included in previous reviews. ${ }^{8,10}$

Still our study has several limitations. First, we focused only on observational studies due to the nature of this study and research project. For some of the identified factors (e.g. diet, cognitive activity, physical activity), good evidence comes from RCTs (see Appendix 5). We realize that by excluding RCT valuable information was lost and thereby causality between predictors and outcome cannot directly be demonstrated. Second, many of the risk factors encountered are interrelated (e.g. diabetes and obesity). Therefore, it is not possible to state that reduction of a certain risk factor could lead to a lower disease 
incidence due to that specific factor. Well-designed RCTs are needed to assess the effect of risk factor reduction strategies on dementia incidence, ideally targeting multiple modifiable risk factors and assessing possible interactions as well as age-dependent effects. Third, by restricting observational studies to those with a follow-up $>1$ year we excluded studies showing promising short-term results. Fourth, the majority of evidence for our findings (both systematic review and Delphi consensus study) reflects sources from the Western (mostly Caucasian) population, with little evidence from literature as applied to Asians, Blacks, and other minorities. Fifth, various measures were used across studies to define cognitive change (e.g. Mini-Mental State Examination (MMSE) score of 23 or less, 3 points change in MMSE score, incident $\mathrm{MCl}$ ), ${ }^{187-189}$ making direct comparisons of findings difficult. Sixth, the present findings must be interpreted with caution due the existence of publication bias. Finally, it would have been desirable to have more participants in the Delphi exercise. However, we considered the quality of the panel at least as important as quantity.

In summary, there is good support from both the literature and experts' opinions on the role of several modifiable risk and preventive factors for cognitive decline and dementia. These findings flag several important targets for dementia prevention through interventions starting in midlife. 


\section{REFERENCES}

1. Ferri CP, Prince $M$, Brayne $C$, et al. Global prevalence of dementia: a Delphi consensus study. Lancet 2005; 366(9503): 2112-7.

2. Hebert LE, Weuve J, Scherr PA, Evans DA. Alzheimer disease in the United States (2010-2050) estimated using the 2010 census. Neurology 2013; 80(19): 1778-83.

3. Hurd MD, Martorell P, Delavande A, Mullen KJ, Langa KM. Monetary costs of dementia in the United States. N Engl J Med 2013; 368(14): 1326-34.

4. Matthews FE, Arthur A, Barnes LE, et al. A two-decade comparison of prevalence of dementia in individuals aged 65 years and older from three geographical areas of England: results of the Cognitive Function and Ageing Study I and II. Lancet 2013; 382(9902): 1405-12.

5. Schrijvers EM, Verhaaren BF, Koudstaal PJ, Hofman A, Ikram MA, Breteler MM. Is dementia incidence declining?: Trends in dementia incidence since 1990 in the Rotterdam Study. Neurology 2012; 78(19): 1456-63.

6. World Health Organization. Dementia: a public health priority. Geneva: WHO, 2012.

7. Scalco MZ, van Reekum R. Prevention of Alzheimer disease. Encouraging evidence. Can Fam Physician 2006; 52: 200-7.

8. Plassman BL, Williams JW, Jr., Burke JR, Holsinger T, Benjamin S. Systematic review: factors associated with risk for and possible prevention of cognitive decline in later life. Ann Intern Med 2010; 153(3): 182-93.

9. Williams JW, Plassman BL, Burke J, Benjamin S. Preventing Alzheimer's disease and cognitive decline. Evid Rep Technol Assess (Full Rep) 2010; (193): 1-727.

10. Barnes DE, Yaffe K. The projected effect of risk factor reduction on Alzheimer's disease prevalence. Lancet Neurol 2011; 10(9): 819-28.

11. Dalkey N, Helmer O. An Experimental Application of the DELPHI Method to the Use of Experts. Management Science 1963; 9(3): 458-67.

12. Wells G, Shea B, O'connell D, et al. The Newcastle-Ottawa Scale (NOS) for assessing the quality of nonrandomised studies in meta-analyses. 2000. http://www.ohri.ca/programs/clinical_ epidemiology/oxford.htm (accessed 17 June 2013).

13. Diniz BS, Butters MA, Albert SM, Dew MA, Reynolds CF, 3rd. Late-life depression and risk of vascular dementia and Alzheimer's disease: systematic review and meta-analysis of community-based cohort studies. Br J Psychiatry 2013; 202(5): 329-35.

14. Lu FP, Lin KP, Kuo HK. Diabetes and the risk of multi-system aging phenotypes: a systematic review and meta-analysis. PLoS One 2009; 4(1): e4144.

15. Anstey KJ, Cherbuin N, Herath PM. Development of a new method for assessing global risk of Alzheimer's disease for use in population health approaches to prevention. Prev Sci 2013; 14(4): 411-21.

16. Hamer M, Chida Y. Physical activity and risk of neurodegenerative disease: a systematic review of prospective evidence. Psychol Med 2009; 39(1): 3-11.

17. Psaltopoulou T, Sergentanis TN, Panagiotakos DB, Sergentanis IN, Kosti R, Scarmeas N. Mediterranean diet, stroke, cognitive impairment, and depression: A meta-analysis. Ann Neurol 2013; 74(4): 580-91.

18. Peters R, Poulter R, Warner J, Beckett N, Burch L, Bulpitt C. Smoking, dementia and cognitive decline in the elderly, a systematic review. BMC Geriatr 2008; 8: 36. 
19. Anstey KJ, Mack HA, Cherbuin N. Alcohol consumption as a risk factor for dementia and cognitive decline: meta-analysis of prospective studies. Am J Geriatr Psychiatry 2009; 17(7): 54255.

20. Kalantarian S, Stern TA, Mansour M, Ruskin JN. Cognitive impairment associated with atrial fibrillation: a meta-analysis. Ann Intern Med 2013; 158(5 Pt 1): 338-46.

21. Etgen T, Chonchol M, Forstl H, Sander D. Chronic kidney disease and cognitive impairment: a systematic review and meta-analysis. Am J Nephrol 2012; 35(5): 474-82.

22. Koyama A, O'Brien J, Weuve J, Blacker D, Metti AL, Yaffe K. The role of peripheral inflammatory markers in dementia and Alzheimer's disease: a meta-analysis. J Gerontol A Biol Sci Med Sci 2013; 68(4): 433-40.

23. Bielak AA, Gerstorf D, Kiely KM, Anstey KJ, Luszcz M. Depressive symptoms predict decline in perceptual speed in older adulthood. Psychol Aging 2011; 26(3): 576-83.

24. Boyle LL, Porsteinsson AP, Cui X, King DA, Lyness JM. Depression predicts cognitive disorders in older primary care patients. J Clin Psychiatry 2010; 71(1): 74-9.

25. Dotson VM, Beydoun MA, Zonderman AB. Recurrent depressive symptoms and the incidence of dementia and mild cognitive impairment. Neurology 2010; 75(1): 27-34.

26. Goveas JS, Espeland MA, Woods NF, Wassertheil-Smoller S, Kotchen JM. Depressive symptoms and incidence of mild cognitive impairment and probable dementia in elderly women: the Women's Health Initiative Memory Study. J Am Geriatr Soc 2011; 59(1): 57-66.

27. Greendale GA, Wight RG, Huang MH, et al. Menopause-associated symptoms and cognitive performance: results from the study of women's health across the nation. Am J Epidemiol 2010; 171(11): 1214-24.

28. Johansson L, Guo X, Waern M, et al. Midlife psychological stress and risk of dementia: a 35-year longitudinal population study. Brain 2010; 133(Pt 8): 2217-24.

29. Kim JM, Stewart R, Kim SY, et al. Synergistic associations of depression and apolipoprotein E genotype with incidence of dementia. Int J Geriatr Psychiatry 2011; 26(9): 893-8.

30. Kohler S, van Boxtel M, Jolles J, Verhey F. Depressive symptoms and risk for dementia: a 9-year follow-up of the Maastricht Aging Study. Am J Geriatr Psychiatry 2011; 19(10): 902-5.

31. Lenoir H, Dufouil C, Auriacombe S, et al. Depression history, depressive symptoms, and incident dementia: the 3C Study. J Alzheimers Dis 2011; 26(1): 27-38.

32. Li G, Wang LY, Shofer JB, et al. Temporal relationship between depression and dementia: findings from a large community-based 15-year follow-up study. Arch Gen Psychiatry 2011; 68(9): 970-7.

33. Mejia-Arango S, Gutierrez LM. Prevalence and incidence rates of dementia and cognitive impairment no dementia in the Mexican population: data from the Mexican Health and Aging Study. J Aging Health 2011; 23(7): 1050-74.

34. Peters $\mathrm{R}$, Pinto $\mathrm{E}$, Beckett $\mathrm{N}$, et al. Association of depression with subsequent mortality, cardiovascular morbidity and incident dementia in people aged 80 and over and suffering from hypertension. Data from the Hypertension in the Very Elderly Trial (HYVET). Age Ageing 2010; 39(4): 439-45.

35. Potvin O, Forget H, Grenier S, Preville M, Hudon C. Anxiety, depression, and 1-year incident cognitive impairment in community-dwelling older adults. J Am Geriatr Soc 2011; 59(8): 14218. 
36. Ritchie K, Carriere I, Ritchie CW, Berr C, Artero S, Ancelin ML. Designing prevention programmes to reduce incidence of dementia: prospective cohort study of modifiable risk factors. BMJ 2010; 341: c3885.

37. Rosenberg PB, Mielke MM, Xue QL, Carlson MC. Depressive symptoms predict incident cognitive impairment in cognitive healthy older women. Am J Geriatr Psychiatry 2010; 18(3): 204-11.

38. Royall DR, Palmer R, Chiodo LK, Polk MJ. Depressive symptoms predict longitudinal change in executive control but not memory. Int J Geriatr Psychiatry 2012; 27(1): 89-96.

39. Saczynski JS, Beiser A, Seshadri S, Auerbach S, Wolf PA, Au R. Depressive symptoms and risk of dementia: the Framingham Heart Study. Neurology 2010; 75(1): 35-41.

40. Sander K, Bickel H, Forstl H, et al. Carotid- intima media thickness is independently associated with cognitive decline. The INVADE study. Int J Geriatr Psychiatry 2010; 25(4): 389-94.

41. Unverzagt FW, Ogunniyi A, Taler V, et al. Incidence and risk factors for cognitive impairment no dementia and mild cognitive impairment in African Americans. Alzheimer Dis Assoc Disord 2011; 25(1): 4-10.

42. Chodosh J, Miller-Martinez D, Aneshensel CS, Wight RG, Karlamangla AS. Depressive symptoms, chronic diseases, and physical disabilities as predictors of cognitive functioning trajectories in older Americans. J Am Geriatr Soc 2010; 58(12): 2350-7.

43. Jajodia A, Borders A. Memory predicts changes in depressive symptoms in older adults: a bidirectional longitudinal analysis. J Gerontol B Psychol Sci Soc Sci 2011; 66(5): 571-81.

44. Ownby RL, Crocco E, Acevedo A, John V, Loewenstein D. Depression and risk for Alzheimer disease: systematic review, meta-analysis, and metaregression analysis. Arch Gen Psychiatry 2006; 63(5): 530-8.

45. Butters MA, Young JB, Lopez $\mathrm{O}$, et al. Pathways linking late-life depression to persistent cognitive impairment and dementia. Dialogues Clin Neurosci 2008; 10(3): 345-57.

46. Abbatecola AM, Lattanzio F, Spazzafumo L, et al. Adiposity predicts cognitive decline in older persons with diabetes: a 2-year follow-up. PLoS One 2010; 5(4): e10333.

47. Alonso A, Mosley TH, Jr., Gottesman RF, Catellier D, Sharrett AR, Coresh J. Risk of dementia hospitalisation associated with cardiovascular risk factors in midlife and older age: the Atherosclerosis Risk in Communities (ARIC) study. J Neurol Neurosurg Psychiatry 2009; 80(11): 1194-201.

48. Cheng D, Noble J, Tang MX, Schupf N, Mayeux R, Luchsinger JA. Type 2 diabetes and late-onset Alzheimer's disease. Dement Geriatr Cogn Disord 2011; 31(6): 424-30.

49. Christman AL, Matsushita K, Gottesman RF, et al. Glycated haemoglobin and cognitive decline: the Atherosclerosis Risk in Communities (ARIC) study. Diabetologia 2011; 54(7): 1645-52.

50. Creavin ST, Gallacher J, Bayer A, Fish M, Ebrahim S, Ben-Shlomo Y. Metabolic syndrome, diabetes, poor cognition, and dementia in the Caerphilly prospective study. J Alzheimers Dis 2012; 28(4): 931-9.

51. Crowe M, Sartori A, Clay OJ, et al. Diabetes and cognitive decline: investigating the potential influence of factors related to health disparities. J Aging Health 2010; 22(3): 292-306.

52. Gaussoin SA, Espeland MA, Absher J, Howard BV, Jones BM, Rapp SR. Ascertaining dementiarelated outcomes for deceased or proxy-dependent participants: an overview of the Women's Health Initiative Memory Study supplemental case ascertainment protocol. Int J Geriatr Psychiatry 2012; 27(2): 205-14. 
53. Kimm H, Lee PH, Shin YJ, et al. Mid-life and late-life vascular risk factors and dementia in Korean men and women. Arch Gerontol Geriatr 2011; 52(3): e117-22.

54. Ohara T, Doi Y, Ninomiya T, et al. Glucose tolerance status and risk of dementia in the community: the Hisayama study. Neurology 2011; 77(12): 1126-34.

55. Rastas S, Pirttila T, Mattila K, et al. Vascular risk factors and dementia in the general population aged $>85$ years: prospective population-based study. Neurobiol Aging 2010; 31(1): 1-7.

56. Reitz C, Tang MX, Schupf N, Manly JJ, Mayeux R, Luchsinger JA. A summary risk score for the prediction of Alzheimer disease in elderly persons. Arch Neurol 2010; 67(7): 835-41.

57. Ronnemaa E, Zethelius B, Lannfelt L, Kilander L. Vascular risk factors and dementia: 40-year follow-up of a population-based cohort. Dement Geriatr Cogn Disord 2011; 31(6): 460-6.

58. Wang KC, Woung LC, Tsai MT, Liu CC, Su YH, Li CY. Risk of Alzheimer's disease in relation to diabetes: a population-based cohort study. Neuroepidemiology 2012; 38(4): 237-44.

59. Wessels AM, Lane KA, Gao S, Hall KS, Unverzagt FW, Hendrie HC. Diabetes and cognitive decline in elderly African Americans: a 15-year follow-up study. Alzheimers Dement 2011; 7(4): 418-24.

60. Yen $\mathrm{CH}$, Yeh $\mathrm{CJ}$, Wang CC, et al. Determinants of cognitive impairment over time among the elderly in Taiwan: results of the national longitudinal study. Arch Gerontol Geriatr 2010; 50 Suppl 1: S53-7.

61. Euser SM, Sattar N, Witteman JC, et al. A prospective analysis of elevated fasting glucose levels and cognitive function in older people: results from PROSPER and the Rotterdam Study. Diabetes 2010; 59(7): 1601-7.

62. van Vliet P, Westendorp RG, van Heemst D, de Craen AJ, Oleksik AM. Cognitive decline precedes late-life longitudinal changes in vascular risk factors. J Neurol Neurosurg Psychiatry 2010; 81(9): 1028-32.

63. Park SA. A common pathogenic mechanism linking type-2 diabetes and Alzheimer's disease: evidence from animal models. J Clin Neurol 2011; 7(1): 10-8.

64. Qiu WQ, Folstein MF. Insulin, insulin-degrading enzyme and amyloid-beta peptide in Alzheimer's disease: review and hypothesis. Neurobiol Aging 2006; 27(2): 190-8.

65. Marquie JC, Duarte LR, Bessieres P, Dalm C, Gentil C, Ruidavets JB. Higher mental stimulation at work is associated with improved cognitive functioning in both young and older workers. Ergonomics 2010; 53(11): 1287-301.

66. Sattler C, Toro P, Schonknecht P, Schroder J. Cognitive activity, education and socioeconomic status as preventive factors for mild cognitive impairment and Alzheimer's disease. Psychiatry Res 2012; 196(1): 90-5.

67. Valenzuela M, Brayne C, Sachdev P, Wilcock G, Matthews F. Cognitive lifestyle and long-term risk of dementia and survival after diagnosis in a multicenter population-based cohort. Am J Epidemiol 2011; 173(9): 1004-12.

68. Wilson RS, Segawa E, Boyle PA, Bennett DA. Influence of late-life cognitive activity on cognitive health. Neurology 2012; 78(15): 1123-9.

69. Eriksson Sorman D, Sundstrom A, Ronnlund M, Adolfsson R, Nilsson LG. Leisure activity in old age and risk of dementia: a 15-year prospective study. J Gerontol B Psychol Sci Soc Sci 2014; 69(4): 493-501.

70. Unverzagt FW, Guey LT, Jones RN, et al. ACTIVE cognitive training and rates of incident dementia. J Int Neuropsychol Soc 2012; 18(4): 669-77.

71. Angevaren M, Vanhees L, Nooyens AC, Wendel-Vos CG, Verschuren WM. Physical activity and 5-year cognitive decline in the Doetinchem cohort study. Ann Epidemiol 2010; 20(6): 473-9. 
72. Buchman AS, Boyle PA, Yu L, Shah RC, Wilson RS, Bennett DA. Total daily physical activity and the risk of AD and cognitive decline in older adults. Neurology 2012; 78(17): 1323-9.

73. Gelber RP, Petrovitch $\mathrm{H}$, Masaki KH, et al. Lifestyle and the risk of dementia in Japaneseamerican men. J Am Geriatr Soc 2012; 60(1): 118-23.

74. Jedrziewski MK, Ewbank DC, Wang $\mathrm{H}$, Trojanowski JQ. Exercise and cognition: results from the National Long Term Care Survey. Alzheimers Dement 2010; 6(6): 448-55.

75. Kim JM, Stewart R, Bae KY, et al. Role of BDNF val66met polymorphism on the association between physical activity and incident dementia. Neurobiol Aging 2011; 32(3): 551 e5-12.

76. Ku PW, Stevinson C, Chen LJ. Prospective associations between leisure-time physical activity and cognitive performance among older adults across an 11-year period. J Epidemiol 2012; 22(3): 230-7.

77. Sattler C, Erickson Kl, Toro P, Schroder J. Physical fitness as a protective factor for cognitive impairment in a prospective population-based study in Germany. J Alzheimers Dis 2011; 26(4): 709-18.

78. Hughes TF, Ganguli M. Modifiable Midlife Risk Factors for Late-Life Cognitive Impairment and Dementia. Curr Psychiatry Rev 2009; 5(2): 73-92.

79. Voss MW, Vivar C, Kramer AF, van Praag H. Bridging animal and human models of exerciseinduced brain plasticity. Trends Cogn Sci 2013; 17(10): 525-44.

80. Debette S, Seshadri S, Beiser A, et al. Midlife vascular risk factor exposure accelerates structural brain aging and cognitive decline. Neurology 2011;77(5): 461-8.

81. Launer LJ, Hughes T, Yu B, et al. Lowering midlife levels of systolic blood pressure as a public health strategy to reduce late-life dementia: perspective from the Honolulu Heart Program/ Honolulu Asia Aging Study. Hypertension 2010; 55(6): 1352-9.

82. Ninomiya T, Ohara T, Hirakawa $Y$, et al. Midlife and late-life blood pressure and dementia in Japanese elderly: the Hisayama study. Hypertension 2011; 58(1): 22-8.

83. Joas E, Backman K, Gustafson D, et al. Blood pressure trajectories from midlife to late life in relation to dementia in women followed for 37 years. Hypertension 2012; 59(4): 796-801.

84. Bermejo-Pareja F, Benito-Leon J, Louis ED, et al. Risk of incident dementia in drug-untreated arterial hypertension: a population-based study. J Alzheimers Dis 2010; 22(3): 949-58.

85. Hajjar I, Quach L, Yang F, et al. Hypertension, white matter hyperintensities, and concurrent impairments in mobility, cognition, and mood: the Cardiovascular Health Study. Circulation 2011; 123(8): 858-65.

86. Murray AD, Staff RT, McNeil CJ, et al. Brain lesions, hypertension and cognitive ageing in the 1921 and 1936 Aberdeen birth cohorts. Age (Dordr) 2012; 34(2): 451-9.

87. Ogunniyi A, Lane KA, Baiyewu $\mathrm{O}$, et al. Hypertension and incident dementia in communitydwelling elderly Yoruba Nigerians. Acta Neurol Scand 2011; 124(6): 396-402.

88. Thorvaldsson V, Skoog I, Hofer SM, et al. Nonlinear blood pressure effects on cognition in old age: separating between-person and within-person associations. Psychol Aging 2012; 27(2): 375-83.

89. Unverzagt FW, McClure LA, Wadley VG, et al. Vascular risk factors and cognitive impairment in a stroke-free cohort. Neurology 2011; 77(19): 1729-36.

90. Yang $\mathrm{YH}$, Roe CM, Morris JC. Relationship between late-life hypertension, blood pressure, and Alzheimer's disease. Am J Alzheimers Dis Other Demen 2011; 26(6): 457-62. 
91. Benetos A, Watfa G, Hanon O, et al. Pulse wave velocity is associated with 1-year cognitive decline in the elderly older than 80 years: the PARTAGE study. J Am Med Dir Assoc 2012; 13(3): 239-43.

92. Johnson W, Price JF, Rafnsson SB, Deary IJ, Fowkes FG. Ankle--brachial index predicts level of, but not change in, cognitive function: the Edinburgh Artery Study at the 15-year follow-up. Vasc Med 2010; 15(2): 91-7.

93. Guan JW, Huang CQ, Li YH, et al. No association between hypertension and risk for Alzheimer's disease: a meta-analysis of longitudinal studies. J Alzheimers Dis 2011; 27(4): 799-807.

94. Power MC, Weuve J, Gagne JJ, McQueen MB, Viswanathan A, Blacker D. The association between blood pressure and incident Alzheimer disease: a systematic review and metaanalysis. Epidemiology 2011; 22(5): 646-59.

95. Qiu C. Preventing Alzheimer's disease by targeting vascular risk factors: hope and gap. $J$ Alzheimers Dis 2012; 32(3): 721-31.

96. Staessen JA, Thijs L, Richart T, Odili AN, Birkenhager WH. Placebo-controlled trials of blood pressure-lowering therapies for primary prevention of dementia. Hypertension 2011 ; 57(2): e67.

97. Gu Y, Nieves JW, Stern Y, Luchsinger JA, Scarmeas N. Food combination and Alzheimer disease risk: a protective diet. Arch Neurol 2010; 67(6): 699-706.

98. Shatenstein B, Ferland G, Belleville $S$, et al. Diet quality and cognition among older adults from the NuAge study. Exp Gerontol 2012; 47(5): 353-60.

99. Cherbuin N, Anstey KJ. The Mediterranean diet is not related to cognitive change in a large prospective investigation: the PATH Through Life study. Am J Geriatr Psychiatry 2012; 20(7): 6359.

100. Gu Y, Luchsinger JA, Stern Y, Scarmeas N. Mediterranean diet, inflammatory and metabolic biomarkers, and risk of Alzheimer's disease. J Alzheimers Dis 2010; 22(2): 483-92.

101. Lourida I, Soni M, Thompson-Coon J, et al. Mediterranean diet, cognitive function, and dementia: a systematic review. Epidemiology 2013; 24(4): 479-89.

102. Dahl A, Hassing LB, Fransson E, et al. Being overweight in midlife is associated with lower cognitive ability and steeper cognitive decline in late life. J Gerontol A Biol Sci Med Sci 2010; 65(1): 57-62.

103. Hassing LB, Dahl AK, Pedersen NL, Johansson B. Overweight in midlife is related to lower cognitive function 30 years later: a prospective study with longitudinal assessments. Dement Geriatr Cogn Disord 2010; 29(6): 543-52.

104. Xu WL, Atti AR, Gatz M, Pedersen NL, Johansson B, Fratiglioni L. Midlife overweight and obesity increase late-life dementia risk: a population-based twin study. Neurology 2011; 76(18): 156874.

105. Gustafson DR, Backman K, Waern M, et al. Adiposity indicators and dementia over 32 years in Sweden. Neurology 2009; 73(19): 1559-66.

106. Kerwin DR, Gaussoin SA, Chlebowski RT, et al. Interaction between body mass index and central adiposity and risk of incident cognitive impairment and dementia: results from the Women's Health Initiative Memory Study. J Am Geriatr Soc 2011; 59(1): 107-12.

107. Luchsinger JA, Cheng D, Tang MX, Schupf N, Mayeux R. Central obesity in the elderly is related to late-onset Alzheimer disease. Alzheimer Dis Assoc Disord 2012; 26(2): 101-5.

108. Forti P, Pisacane N, Rietti E, et al. Metabolic syndrome and risk of dementia in older adults. J Am Geriatr Soc 2010; 58(3): 487-92. 
109. Power BD, Alfonso H, Flicker L, Hankey GJ, Yeap BB, Almeida OP. Body adiposity in later life and the incidence of dementia: the health in men study. PLoS One 2011; 6(3): e17902.

110. Dolcos S, MacDonald SW, Braslavsky A, Camicioli R, Dixon RA. Mild cognitive impairment is associated with selected functional markers: integrating concurrent, longitudinal, and stability effects. Neuropsychology 2012; 26(2): 209-23.

111. Gustafson D. Adiposity indices and dementia. Lancet Neurol 2006; 5(8): 713-20.

112. Whitmer RA. The epidemiology of adiposity and dementia. Curr Alzheimer Res 2007; 4(2): $117-$ 22.

113. Chen R, Hu Z, Wei L, Ma Y, Liu Z, Copeland JR. Incident dementia in a defined older Chinese population. PLoS One 2011; 6(9): e24817.

114. Collins N, Sachs-Ericsson N, Preacher KJ, Sheffield KM, Markides K. Smoking increases risk for cognitive decline among community-dwelling older Mexican Americans. Am J Geriatr Psychiatry 2009; 17(11): 934-42.

115. Rusanen M, Kivipelto M, Quesenberry CP, Jr., Zhou J, Whitmer RA. Heavy smoking in midlife and long-term risk of Alzheimer disease and vascular dementia. Arch Intern Med 2011; 171(4): 333-9.

116. Rusanen M, Rovio S, Ngandu T, et al. Midlife smoking, apolipoprotein E and risk of dementia and Alzheimer's disease: a population-based cardiovascular risk factors, aging and dementia study. Dement Geriatr Cogn Disord 2010; 30(3): 277-84.

117. Sabia S, Elbaz A, Dugravot A, et al. Impact of smoking on cognitive decline in early old age: the Whitehall II cohort study. Arch Gen Psychiatry 2012; 69(6): 627-35.

118. Weuve J, Tchetgen Tchetgen EJ, Glymour MM, et al. Accounting for bias due to selective attrition: the example of smoking and cognitive decline. Epidemiology 2012; 23(1): 119-28.

119. Zhou R, Deng J, Zhang M, Zhou HD, Wang YJ. Association between bone mineral density and the risk of Alzheimer's disease. J Alzheimers Dis 2011; 24(1): 101-8.

120. Wang CC, Lu TH, Liao WC, et al. Cigarette smoking and cognitive impairment: a 10-year cohort study in Taiwan. Arch Gerontol Geriatr 2010; 51(2): 143-8.

121. Caselli RJ, Dueck AC, Locke DE, et al. Cerebrovascular risk factors and preclinical memory decline in healthy APOE epsilon4 homozygotes. Neurology 2011; 76(12): 1078-84.

122. HHS. The 2004 United States Surgeon General's Report: The Health Consequences of Smoking.: United States Department of Health and Human Services, 2004.

123. Weyerer S, Schaufele M, Wiese B, et al. Current alcohol consumption and its relationship to incident dementia: results from a 3-year follow-up study among primary care attenders aged 75 years and older. Age Ageing 2011; 40(4): 456-63.

124. Lobo E, Dufouil C, Marcos G, et al. Is there an association between low-to-moderate alcohol consumption and risk of cognitive decline? Am J Epidemiol 2010; 172(6): 708-16.

125. Agarwal DP. Cardioprotective effects of light-moderate consumption of alcohol: a review of putative mechanisms. Alcohol Alcohol 2002; 37(5): 409-15.

126. Commenges D, Scotet V, Renaud S, Jacqmin-Gadda H, Barberger-Gateau P, Dartigues JF. Intake of flavonoids and risk of dementia. Eur J Epidemiol 2000; 16(4): 357-63.

127. Zahr NM, Kaufman KL, Harper CG. Clinical and pathological features of alcohol-related brain damage. Nat Rev Neurol 2011; 7(5): 284-94.

128. Beydoun MA, Beason-Held LL, Kitner-Triolo MH, et al. Statins and serum cholesterol's associations with incident dementia and mild cognitive impairment. $J$ Epidemiol Community Health 2011; 65(11): 949-57. 
129. Reitz C, Tang MX, Schupf N, Manly JJ, Mayeux R, Luchsinger JA. Association of higher levels of high-density lipoprotein cholesterol in elderly individuals and lower risk of late-onset Alzheimer disease. Arch Neurol 2010; 67(12): 1491-7.

130. Reynolds CA, Gatz M, Prince JA, Berg S, Pedersen NL. Serum lipid levels and cognitive change in late life. J Am Geriatr Soc 2010; 58(3): 501-9.

131. Song F, Poljak A, Crawford J, et al. Plasma apolipoprotein levels are associated with cognitive status and decline in a community cohort of older individuals. PLoS One 2012; 7(6): e34078.

132. van den Kommer TN, Dik MG, Comijs HC, Jonker C, Deeg DJ. Role of lipoproteins and inflammation in cognitive decline: do they interact? Neurobiol Aging 2012; 33(1): 196 e1-12.

133. Zuliani G, Cavalieri M, Galvani M, et al. Relationship between low levels of high-density lipoprotein cholesterol and dementia in the elderly. The InChianti study. J Gerontol A Biol Sci Med Sci 2010; 65(5): 559-64.

134. Mielke MM, Zandi PP, Shao H, et al. The 32-year relationship between cholesterol and dementia from midlife to late life. Neurology 2010; 75(21): 1888-95.

135. Anstey KJ, Lipnicki DM, Low LF. Cholesterol as a risk factor for dementia and cognitive decline: a systematic review of prospective studies with meta-analysis. Am J Geriatr Psychiatry 2008; 16(5): 343-54.

136. Reitz C, Tang MX, Luchsinger J, Mayeux R. Relation of plasma lipids to Alzheimer disease and vascular dementia. Arch Neurol 2004; 61(5): 705-14.

137. Tan ZS, Seshadri S, Beiser A, et al. Plasma total cholesterol level as a risk factor for Alzheimer disease: the Framingham Study. Arch Intern Med 2003; 163(9): 1053-7.

138. Burns M, Duff K. Cholesterol in Alzheimer's disease and tauopathy. Ann N Y Acad Sci 2002; 977: 367-75.

139. Reid PC, Urano Y, Kodama T, Hamakubo T. Alzheimer's disease: cholesterol, membrane rafts, isoprenoids and statins. J Cell Mol Med 2007; 11(3): 383-92.

140. Bunch TJ, Crandall BG, Weiss JP, et al. Patients treated with catheter ablation for atrial fibrillation have long-term rates of death, stroke, and dementia similar to patients without atrial fibrillation. J Cardiovasc Electrophysiol 2011; 22(8): 839-45.

141. Bunch TJ, Weiss JP, Crandall BG, et al. Atrial fibrillation is independently associated with senile, vascular, and Alzheimer's dementia. Heart Rhythm 2010; 7(4): 433-7.

142. Dublin S, Anderson ML, Haneuse SJ, et al. Atrial fibrillation and risk of dementia: a prospective cohort study. J Am Geriatr Soc 2011; 59(8): 1369-75.

143. Eriksson UK, Bennet AM, Gatz M, Dickman PW, Pedersen NL. Nonstroke cardiovascular disease and risk of Alzheimer disease and dementia. Alzheimer Dis Assoc Disord 2010; 24(3): 213-9.

144. Hjelm C, Dahl A, Brostrom A, Martensson J, Johansson B, Stromberg A. The influence of heart failure on longitudinal changes in cognition among individuals 80 years of age and older. J Clin Nurs 2012; 21(7-8): 994-1003.

145. Kerola T, Nieminen T, Sulkava R, Vuolteenaho O, Hartikainen S, Kettunen R. Inverted mitral inflow pattern in echocardiography among the elderly--a marker of non-cardiovascular mortality and cognitive dysfunction. Int J Cardiol 2012; 155(1): 70-4.

146. Marengoni A, Qiu C, Winblad B, Fratiglioni L. Atrial fibrillation, stroke and dementia in the very old: a population-based study. Neurobiol Aging 2011; 32(7): 1336-7.

147. Justin BN, Turek M, Hakim AM. Heart disease as a risk factor for dementia. Clin Epidemiol 2013; 5: $135-45$. 
148. Kwok CS, Loke YK, Hale R, Potter JF, Myint PK. Atrial fibrillation and incidence of dementia: a systematic review and meta-analysis. Neurology 2011; 76(10): 914-22.

149. Santangeli P, Di Biase $L$, Bai R, et al. Atrial fibrillation and the risk of incident dementia: a metaanalysis. Heart Rhythm 2012; 9(11): 1761-8.

150. van Oijen M, de Jong FJ, Witteman JC, Hofman A, Koudstaal PJ, Breteler MM. Atherosclerosis and risk for dementia. Ann Neurol 2007; 61 (5): 403-10.

151. Barzilay Jl, Gao P, O'Donnell M, et al. Albuminuria and decline in cognitive function: The ONTARGET/TRANSCEND studies. Arch Intern Med 2011; 171(2): 142-50.

152. Feng $L$, Yap KB, Yeoh LY, Ng TP. Kidney function and cognitive and functional decline in elderly adults: findings from the Singapore longitudinal aging study. J Am Geriatr Soc 2012; 60(7): 1208-14.

153. Helmer C, Stengel B, Metzger M, et al. Chronic kidney disease, cognitive decline, and incident dementia: the 3C Study. Neurology 2011; 77(23): 2043-51.

154. Jassal SK, Kritz-Silverstein D, Barrett-Connor E. A prospective study of albuminuria and cognitive function in older adults: the Rancho Bernardo study. Am J Epidemiol 2010; 171(3): 277-86.

155. Khatri M, Nickolas T, Moon YP, et al. CKD associates with cognitive decline. J Am Soc Nephrol 2009; 20(11): 2427-32.

156. Kurella Tamura M, Muntner P, Wadley V, et al. Albuminuria, kidney function, and the incidence of cognitive impairment among adults in the United States. Am J Kidney Dis 2011; 58(5): 756-63.

157. Sajjad I, Grodstein F, Kang JH, Curhan GC, Lin J. Kidney dysfunction and cognitive decline in women. Clin J Am Soc Nephrol 2012; 7(3): 437-43.

158. Sasaki Y, Marioni R, Kasai M, Ishii H, Yamaguchi S, Meguro K. Chronic kidney disease: a risk factor for dementia onset: a population-based study. The Osaki-Tajiri Project. J Am Geriatr Soc 2011; 59(7): 1175-81.

159. Wang F, Zhang L, Liu L, Wang H. Level of kidney function correlates with cognitive decline. Am J Nephrol 2010; 32(2): 117-21.

160. Bugnicourt JM, Godefroy O, Chillon JM, Choukroun G, Massy ZA. Cognitive disorders and dementia in CKD: the neglected kidney-brain axis. J Am Soc Nephrol 2013; 24(3): 353-63.

161. Ikram MA, Vernooij MW, Hofman A, Niessen WJ, van der Lugt A, Breteler MM. Kidney function is related to cerebral small vessel disease. Stroke 2008; 39(1): 55-61.

162. Gao Q, Niti M, Feng L, Yap KB, Ng TP. Omega-3 polyunsaturated fatty acid supplements and cognitive decline: Singapore Longitudinal Aging Studies. J Nutr Health Aging 2011; 15(1): 32-5.

163. Lopez LB, Kritz-Silverstein D, Barrett Connor E. High dietary and plasma levels of the omega-3 fatty acid docosahexaenoic acid are associated with decreased dementia risk: the Rancho Bernardo study. J Nutr Health Aging 2011; 15(1): 25-31.

164. Naqvi AZ, Harty B, Mukamal KJ, Stoddard AM, Vitolins M, Dunn JE. Monounsaturated, trans, and saturated Fatty acids and cognitive decline in women. J Am Geriatr Soc 2011; 59(5): 837-43.

165. Samieri C, Feart C, Proust-Lima C, et al. omega-3 fatty acids and cognitive decline: modulation by ApoEepsilon4 allele and depression. Neurobiol Aging 2011; 32(12): 2317 e13-22.

166. Devore EE, Grodstein F, van Rooij FJ, et al. Dietary intake of fish and omega-3 fatty acids in relation to long-term dementia risk. Am J Clin Nutr 2009; 90(1): 170-6.

167. Morris MC, Evans DA, Bienias JL, et al. Consumption of fish and n-3 fatty acids and risk of incident Alzheimer disease. Arch Neurol 2003; 60(7): 940-6. 
168. Sydenham E, Dangour AD, Lim WS. Omega 3 fatty acid for the prevention of cognitive decline and dementia. Cochrane Database Syst Rev 2012; 6: CD005379.

169. Mazereeuw G, Lanctot KL, Chau SA, Swardfager W, Herrmann N. Effects of omega-3 fatty acids on cognitive performance: a meta-analysis. Neurobiol Aging 2012; 33(7): 1482 e17-29.

170. Dlugaj $M$, Gerwig $M$, Wege N, et al. Elevated levels of high-sensitivity C-reactive protein are associated with mild cognitive impairment and its subtypes: results of a population-based case-control study. J Alzheimers Dis 2012; 28(3): 503-14.

171. Jenny NS, French B, Arnold AM, et al. Long-term assessment of inflammation and healthy aging in late life: the Cardiovascular Health Study All Stars. J Gerontol A Biol Sci Med Sci 2012; 67(9): 970-6.

172. Mooijaart SP, Sattar N, Trompet S, et al. C-reactive protein and genetic variants and cognitive decline in old age: the PROSPER study. PLoS One 2011; 6(9): e23890.

173. Gallacher J, Bayer A, Lowe G, et al. Is sticky blood bad for the brain?: Hemostatic and inflammatory systems and dementia in the Caerphilly Prospective Study. Arterioscler Thromb Vasc Biol 2010; 30(3): 599-604.

174. Laurin D, David Curb J, Masaki KH, White LR, Launer LJ. Midlife C-reactive protein and risk of cognitive decline: a 31-year follow-up. Neurobiol Aging 2009; 30(11): 1724-7.

175. McGeer EG, McGeer PL. Neuroinflammation in Alzheimer's disease and mild cognitive impairment: a field in its infancy. J Alzheimers Dis 2010; 19(1): 355-61.

176. Yaffe $K$, Kanaya $A$, Lindquist $K$, et al. The metabolic syndrome, inflammation, and risk of cognitive decline. JAMA 2004; 292(18): 2237-42.

177. Farrow M. Dementia risk reduction: what do Australians know? 2008. http://www. yourbrainmatters.org.au/sites/default/files/Dementia\%20Risk\%20Reduction-What\%20 do\%20Australians\%20know.pdf (accessed 30 July 2013).

178. Alzheimer's Association and Centers for Disease Control and Prevention. The Healthy Brain Initiative: The Public Health Road Map for State and National Partnerships, 2013-2018. Chicago, IL: Alzheimer's Association, 2013.

179. The Lancet Neurology. The road map to integrated dementia prevention and care. Lancet Neurol 2013; 12(9): 839.

180. MRC-CFAS. Pathological correlates of late-onset dementia in a multicentre, community-based population in England and Wales. Neuropathology Group of the Medical Research Council Cognitive Function and Ageing Study (MRC-CFAS). Lancet 2001; 357(9251): 169-75.

181. Bennett DA, Wilson RS, Arvanitakis Z, Boyle PA, de Toledo-Morrell L, Schneider JA. Selected findings from the Religious Orders Study and Rush Memory and Aging Project. J Alzheimers Dis 2013; 33 Suppl 1: S397-403.

182. Provenzano FA, Muraskin J, Tosto G, et al. White matter hyperintensities and cerebral amyloidosis: necessary and sufficient for clinical expression of Alzheimer disease? JAMA Neurol 2013; 70(4): 455-61.

183. Gillette-Guyonnet S, Andrieu S, Dantoine T, Dartigues JF, Touchon J, Vellas B. Commentary on "A roadmap for the prevention of dementia II. Leon Thal Symposium 2008." The Multidomain Alzheimer Preventive Trial (MAPT): a new approach to the prevention of Alzheimer's disease. Alzheimers Dement 2009; 5(2): 114-21.

184. Kivipelto M, Solomon A, Ahtiluoto S, et al. The Finnish Geriatric Intervention Study to Prevent Cognitive Impairment and Disability (FINGER): study design and progress. Alzheimers Dement 2013; 9(6): 657-65. 
185. Richard E, Van den Heuvel E, Moll van Charante EP, et al. Prevention of dementia by intensive vascular care (PreDIVA): a cluster-randomized trial in progress. Alzheimer Dis Assoc Disord 2009; 23(3): 198-204.

186. Richard E, Andrieu S, Solomon A, et al. Methodological challenges in designing dementia prevention trials - the European Dementia Prevention Initiative (EDPI). J Neurol Sci 2012; 322(12): 64-70.

187. Folstein MF, Folstein SE, McHugh PR. "Mini-mental state". A practical method for grading the cognitive state of patients for the clinician. J Psychiatr Res 1975; 12(3): 189-98.

188. Graham JE, Rockwood K, Beattie BL, et al. Prevalence and severity of cognitive impairment with and without dementia in an elderly population. Lancet 1997; 349(9068): 1793-6.

189. Petersen RC, Smith GE, Waring SC, Ivnik RJ, Tangalos EG, Kokmen E. Mild cognitive impairment: clinical characterization and outcome. Arch Neurol 1999; 56(3): 303-8. 


\section{SUPPLEMENTAL DATA}

\section{APPENDIX 1: PubMed search term}

(risk factor[ALL] OR epidemiologic factors[mesh] OR exposure*[ALL] OR exposed[TW] OR determinant*[ALL] OR predict*[ALL]) AND ((dementia[mesh] OR dementia[all fields] OR Alzheimer* OR alzheimer disease[mesh]) OR (((cognitiv* OR cognition OR memory) AND (declin* OR impair* OR deteriora* OR change* OR deficit* OR complaint*)) OR "Cognition Disorders"[Mesh:noexp]) OR ("pre- clinical AD" OR "preclinical AD")) AND (((Epidemiologic Studies[Mesh:noexp] OR case-control studies[Mesh] OR cohort studies[Mesh] OR seroepidemiologic studies[Mesh]) OR cohort OR cohorts OR observ* OR case-control OR non-randomized $O R$ nonrandomized $O R$ unrandomised $O R$ prospectiv* OR retrospectiv* OR follow* OR longitudinal OR (cases AND controls)) AND (odds ratio[Mesh] OR "odds ratio" OR "relative risk" OR risk OR risks OR associat* OR causality OR etiology OR epidemiology OR ethnology OR probability OR inciden*)) NOT ((schizophrenia[mesh] OR schizophrenia[all fields] OR "down syndrome"[mesh] OR "down syndrome"[all fields] OR "psychotic disorders"[mesh] OR "psychosis"[all fields] OR "substance-related disorders"[MeSH Terms] OR "substance abuse"[all fields] OR epilepsy[mesh] OR epilepsy[all fields] OR "seizure disorder"[all fields] OR "Parkinson Disease[Mesh]" OR "Parkinson disease"[ALL] OR "Bipolar Disorder[Mesh]" OR "bipolar disorder"[ALL])) NOT (letter[PT:noexp] OR review[PT:noexp]) AND (("2009/10/28"[PDAT] : "2012/12/05"[PDAT]) AND "humans"[MeSH Terms] AND (Dutch[lang] OR English[lang] OR German[lang]) AND ("middle aged"[MeSH Terms] OR "aged"[MeSH Terms])) NOT (depression[ALL] AND ("cognitive therapy"[ALL] OR "cognitive behavioral therapy"[ALL]))

\section{APPENDIX 2: Formula first Delphi round}

In the first Delphi round, each participant freely named potential risk factors for all-type dementia in subjective order of importance. Individual responses were given a'rank score'. This rank score is constructed by using the following quadratic scale:

rank $1=100$ points $(10 \wedge 2)$

rank $2=81$ points $(9 \wedge 2)$

rank $3=64$ points $(8 \wedge 2)$

rank $4=49$ points $(7 \wedge 2)$

rank $5=36$ points $(6 \wedge 2)$

rank $6=25$ points $(5 \wedge 2)$

$\operatorname{rank} 7=16$ points $(4 \wedge 2)$

rank $8=9$ points $\left(3^{\wedge} 2\right)$ 
rank $9=4$ points $(2 \wedge 2)$

rank $10=2$ points $(1 \wedge 2)$.

Individual experts' RS were then summed for a total RS.

\section{Example}

As illustrated in Table 2, hypertension was mentioned five times by the Delphi experts and was given the following ranks: 1, 1, 2, 3, 9. This results in the following rank scores: rank $1=$ 100 points $\left(10^{\wedge} 2\right)$; rank $1=100$ points $\left(10^{\wedge} 2\right)$; rank $2=81$ points $(9 \wedge 2)$; rank $3=64$ points $(8 \wedge 2)$, rank $9=4$ points $(2 \wedge 2)$. The total rank score for hypertension is 349 points.

\section{APPENDIX 3: Full list of modifiable and non-modifiable risk factors encountered in systematic literature review}

\begin{tabular}{|c|c|c|}
\hline Domain & Modifiable risk factor & Number of studies \\
\hline \multirow[t]{16}{*}{ Vascular factors } & Hypertension (1-21) & 21 \\
\hline & Cholesterol/hyperlipidemia $(16,17,20,22-28)$ & 10 \\
\hline & (Coronary) Heart disease $(3,16,29-36)$ & 10 \\
\hline & Stroke $(31,37-40)$ & 5 \\
\hline & Vascular risk factors/disease in general $(8,41-43)$ & 4 \\
\hline & Retinopathy (44-46) & 3 \\
\hline & D-dimer levels (47-49) & 3 \\
\hline & Arterial stiffness $(10,50)$ & 2 \\
\hline & High Framingham risk score $(51,52)$ & 2 \\
\hline & Hypotension (53) & 1 \\
\hline & Diastolic blood pressure (54) & 1 \\
\hline & Ventricular hypertrophy (3) & 1 \\
\hline & Carotid intima media thickness (55) & 1 \\
\hline & Blood viscosity (56) & 1 \\
\hline & Fibrinogen (56) & 1 \\
\hline & Hematocrit (56) & 1 \\
\hline \multirow[t]{8}{*}{ Other medical } & Depression $(5,39,55,57-74)$ & 21 \\
\hline & Diabetes $(2,5,8,14,16,17,20,21,40,67,75-83)$ & 19 \\
\hline & Overweight/obesity $(7,16,17,54,80,84-92)$ & 14 \\
\hline & Renal dysfunction (93-101) & 9 \\
\hline & Metabolic syndrome $(90,102-105)$ & 5 \\
\hline & Inflammation (106-110) & 5 \\
\hline & Gait problems/ speed (111-115) & 5 \\
\hline & Frailty $(114,116-119)$ & 5 \\
\hline
\end{tabular}




\begin{tabular}{|c|c|c|}
\hline Domain & Modifiable risk factor & Number of studies \\
\hline \multirow[t]{25}{*}{ Other medical } & Self-report cognitive impairment (120-124) & 5 \\
\hline & Poor dental health (125-128) & 4 \\
\hline & Functional impairment $(39,40,129,130)$ & 4 \\
\hline & Low handgrip strength $(115,131-133)$ & 4 \\
\hline & Poor general health (134-136) & 3 \\
\hline & Lung function (137-139) & 3 \\
\hline & Poor sleep $(72,140,141)$ & 3 \\
\hline & Anxiety $(59,72)$ & 2 \\
\hline & Weight loss $(142,143)$ & 2 \\
\hline & Head injury $(66,144)$ & 2 \\
\hline & Mobility $(145,146)$ & 2 \\
\hline & Cancer (147) & 1 \\
\hline & Muscle strength (148) & 1 \\
\hline & Hypoglycemia (149) & 1 \\
\hline & Apathy (150) & 1 \\
\hline & Weight gain (142) & 1 \\
\hline & Low circadian rhythm (151) & 1 \\
\hline & Osteoporosis (152) & 1 \\
\hline & Parkinsonism (114) & 1 \\
\hline & Terminal pathology (153) & 1 \\
\hline & Sepsis (154) & 1 \\
\hline & Essential tremor (155) & 1 \\
\hline & Hysterectomy and oophorectomy (156) & 1 \\
\hline & Posttraumatic stress disorder (157) & 1 \\
\hline & Migraine (158) & 1 \\
\hline \multirow[t]{12}{*}{ General lifestyle } & Smoking $(16,20,29,41,83,84,152,159-164)$ & 13 \\
\hline & Low physical activity $(84,113,165-169)$ & 7 \\
\hline & Low cognitive activity (170-173) & 4 \\
\hline & Low leisure time activity $(54,174,175)$ & 3 \\
\hline & Occupational stress (176-178) & 3 \\
\hline & Adverse life events $(179,180)$ & 2 \\
\hline & Low social engagement $(181,182)$ & 2 \\
\hline & Purpose in life $(183,184)$ & 2 \\
\hline & Unhealthy lifestyle $(185,186)$ & 2 \\
\hline & Religious attendance $(185,187)$ & 2 \\
\hline & Social vulnerability (188) & 1 \\
\hline & Self-maintenance activities (54) & 1 \\
\hline
\end{tabular}




\begin{tabular}{|c|c|c|}
\hline Domain & Modifiable risk factor & Number of studies \\
\hline \multirow[t]{4}{*}{ General lifestyle } & Novel information processing (54) & 1 \\
\hline & Worriness (189) & 1 \\
\hline & Positive affect (54) & 1 \\
\hline & Negative affect (54) & 1 \\
\hline \multirow[t]{16}{*}{ Diet } & Low unsaturated fat intake (190-194) & 5 \\
\hline & Low vitamin B and folic acid (195-197) & 3 \\
\hline & Low fruit and vegetable intake $(67,198,199)$ & 3 \\
\hline & High alcohol intake $(152,200,201)$ & 3 \\
\hline & Unhealthy diet $(84,202,203)$ & 3 \\
\hline & Low vitamin D $(204,205)$ & 2 \\
\hline & Low vitamin E $(206,207)$ & 2 \\
\hline & Low leptin $(152,208)$ & 2 \\
\hline & High caloric intake $(190,209)$ & 2 \\
\hline & Fish intake $(192,193)$ & 2 \\
\hline & Mediterranean diet $(190,210)$ & 2 \\
\hline & Coffee intake (211) & 1 \\
\hline & Caffeine intake (212) & 1 \\
\hline & Low flavonoids (213) & 1 \\
\hline & Dietary inflammation score (214) & 1 \\
\hline & Daily supplementation of vitamins B12, B6, and folic acid (215) & 1 \\
\hline \multirow[t]{13}{*}{ Drug use } & Anticholinergica (216-219) & 4 \\
\hline & Statin use $(25,220,221)$ & 3 \\
\hline & Lipid lowering agents (222) & 1 \\
\hline & Fibrate use (220) & 1 \\
\hline & Antidepressants (223) & 1 \\
\hline & Sedatives (224) & 1 \\
\hline & Non-steroidal anti-inflammatory drugs (225) & 1 \\
\hline & Antihistamines (226) & 1 \\
\hline & Polypharmacy (227) & 1 \\
\hline & Gonadal steroids (228) & 1 \\
\hline & Benzodiazepines (229) & 1 \\
\hline & Hormone therapy (83) & 1 \\
\hline & Angiotensin converting enzyme inhibitors (230) & 1 \\
\hline \multirow[t]{2}{*}{ Environmental } & Air pollution, particles (231) & 1 \\
\hline & Exposure to extreme low-frequency magnetic fields (232) & 1 \\
\hline
\end{tabular}




\begin{tabular}{|c|c|c|}
\hline Domain & Modifiable risk factor & Number of studies \\
\hline \multirow{18}{*}{$\begin{array}{l}\text { Molecular } \\
\text { (non-disease) } \\
\text { markers }\end{array}$} & High homocysteine $(197,233-236)$ & 5 \\
\hline & Cortisol $(118,237)$ & 2 \\
\hline & Sex-hormone binding globulin $(238,239)$ & 2 \\
\hline & Telomere length $(240,241)$ & 2 \\
\hline & Fibrinogen $(49,109)$ & 2 \\
\hline & Low testosterone $(238,242)$ & 2 \\
\hline & Estradiol $(238,243)$ & 2 \\
\hline & High Triglycerides (27) & 1 \\
\hline & Methylglyoxal (244) & 1 \\
\hline & 3-methoxy-4-hydroxyphenylglycol (245) & 1 \\
\hline & Thyroid-stimulating hormone (246) & 1 \\
\hline & F-2 isoprostanes (oxidative stress) (247) & 1 \\
\hline & Low B-type nutriuretic peptide (248) & 1 \\
\hline & Estrone (243) & 1 \\
\hline & Factor V (109) & 1 \\
\hline & Plasminogen (109) & 1 \\
\hline & von Willebrand factor (49) & 1 \\
\hline & Parathyroid hormone (249) & 1 \\
\hline \multirow[t]{5}{*}{ Other } & Poor vision (250) & 1 \\
\hline & Poor odor identification (251) & 1 \\
\hline & Hearing loss (252) & 1 \\
\hline & Perceived performance difficulty (57) & 1 \\
\hline & High nontraditional risk factors (253) & 1 \\
\hline
\end{tabular}

\begin{tabular}{|l|l|l|}
\hline Domain & Non-modifiable risk factor & Number of studies \\
\hline \multirow{5}{*}{ Demographics } & Low education $(3,5,16,21,29,40,66,126,129,145,171,254-268)$ & 26 \\
\cline { 2 - 3 } & $\begin{array}{l}\text { Older age }(3,5,16,29,40,43,55,66,121,122,129,181,254,255, \\
257,258,263,265,266,269-271)\end{array}$ & 22 \\
\cline { 2 - 3 } & Male sex $(3,5,29,40,145,181,217,254-257,260,265,266,272)$ & 15 \\
\cline { 2 - 3 } & Low socioeconomic status $(171,181,272-274)$ & 5 \\
\hline & Ethnicity $(3,16,268)$ & 3 \\
\hline & Low occupational level (29, 275) & 2 \\
\hline & Positive family history dementia (217) & 1 \\
\cline { 2 - 3 } & Large household size (29) & 1 \\
\cline { 2 - 3 } & High job-related physical demand (262) & 1 \\
\cline { 2 - 3 } & Low motivation-related occupational activities (276) & 1 \\
\cline { 2 - 3 } & Minority status (258) & 1 \\
\hline
\end{tabular}




\begin{tabular}{|c|c|c|}
\hline Domain & Non-modifiable risk factor & Number of studies \\
\hline \multirow[t]{5}{*}{ Demographics } & Rural residence (181) & 1 \\
\hline & Parental longevity (277) & 1 \\
\hline & Non-native language use (278) & 1 \\
\hline & Marital status (254) & 1 \\
\hline & Living situation (254) & 1 \\
\hline \multirow[t]{4}{*}{ Personality } & High neuroticism (279-282) & 4 \\
\hline & Lower openness to experience $(279,282,283)$ & 3 \\
\hline & Lower conscientiousness $(279,282)$ & 2 \\
\hline & Extraversion (279) & 1 \\
\hline \multirow[t]{7}{*}{ Genetics } & Apolipoprotein E (APOE) E4 allele $(16,43,58,67,284-287)$ & 8 \\
\hline & $\begin{array}{l}\text { Brain-derived neurotrophic factor (BDNF) val66met polymorphism } \\
\text { (169) }\end{array}$ & 1 \\
\hline & $\begin{array}{l}\text { Interleukin-1 alpha (IL-1a) rs1800587 single nucleotide } \\
\text { polymorphism (288) }\end{array}$ & 1 \\
\hline & $\begin{array}{l}\text { Interleukin-1 beta (IL-1ß) rs3087258 single nucleotide } \\
\text { polymorphism (288) }\end{array}$ & 1 \\
\hline & $\begin{array}{l}\text { Tumor necrosis factor alpha (TNF-a) rs1799724 single nucleotide } \\
\text { polymorphism (288) }\end{array}$ & 1 \\
\hline & Fat mass and obesity associated gene (FTO-gene) (289) & 1 \\
\hline & $\begin{array}{l}\text { NOS1 Ex1f-VNTR ( functional promoter polymorphism of nitric } \\
\text { oxide (NO) synthase (NOS-I) gene) (290) }\end{array}$ & 1 \\
\hline \multirow[t]{4}{*}{ Other } & Low birth weight (291) & 1 \\
\hline & Small head circumference (105) & 1 \\
\hline & Menopause transition stage (72) & 1 \\
\hline & Age at menopause (83) & 1 \\
\hline
\end{tabular}




\section{REFERENCES}

1 Joas $E$, Bäckman K, Gustafson D, et al. Blood pressure trajectories from midlife to late life in relation to dementia in women followed for 37 years. Hypertension 2012;59:796-801.

2 Creavin ST, Gallacher J, Bayer A, Fish M, Ebrahim S, Ben-Shlomo Y. Metabolic syndrome, diabetes, poor cognition, and dementia in the Caerphilly prospective study. J Alzheimers Dis 2012;28:931-9.

3 Unverzagt FW, McClure LA, Wadley VG, et al. Vascular risk factors and cognitive impairment in a stroke-free cohort. Neurology 2011;77:1729-36.

4 Thorvaldsson V, Skoog I, Hofer SM, et al. Nonlinear blood pressure effects on cognition in old age: separating between-person and within-person associations. Psychol Aging 2012;27:37583.

5 Mejia-Arango S, Gutierrez LM. Prevalence and incidence rates of dementia and cognitive impairment no dementia in the Mexican population: data from the Mexican Health and Aging Study. J Aging Health 2011;23:1050-74.

6 Yang YH, Roe CM, Morris JC. Relationship between late-life hypertension, blood pressure, and Alzheimer's disease. Am J Alzheimers Dis Other Demen 2011;26:457-62.

7 Debette S, Seshadri S, Beiser A, et al. Midlife vascular risk factor exposure accelerates structural brain aging and cognitive decline. Neurology 2011;77:461-8.

8 Rönnemaa E, Zethelius B, Lannfelt L, Kilander L. Vascular risk factors and dementia: 40-year follow-up of a population-based cohort. Dement Geriatr Cogn Disord 2011;31:460-6.

9 Ninomiya T, Ohara T, Hirakawa Y, et al. Midlife and late-life blood pressure and dementia in Japanese elderly: the Hisayama study. Hypertension 2011;58:22-8.

10 Benetos A, Watfa G, Hanon O, et al. Pulse wave velocity is associated with 1-year cognitive decline in the elderly older than 80 years: the PARTAGE study. J Am Med Dir Assoc 2012;13:23943.

11 Murray AD, Staff RT, McNeil CJ, et al. Brain lesions, hypertension and cognitive ageing in the 1921 and 1936 Aberdeen birth cohorts. Age 2012;34:451-9.

12 Hajjar I, Quach L, Yang F, et al. Hypertension, white matter hyperintensities, and concurrent impairments in mobility, cognition, and mood: the Cardiovascular Health Study. Circulation 2011;123:858-65.

13 Ogunniyi A, Lane KA, Baiyewu O, et al. Hypertension and incident dementia in communitydwelling elderly Yoruba Nigerians. Acta Neurol Scand 2011;124:396-402.

$14 \mathrm{Kimm} \mathrm{H}$, Lee PH, Shin YJ, et al. Mid-life and late-life vascular risk factors and dementia in Korean men and women. Arch Gerontol Geriatr 2011;52:e117-22.

15 Bermejo-Pareja F, Benito-León J, Louis ED, et al. Risk of incident dementia in drug-untreated arterial hypertension: a population-based study. J Alzheimers Dis 2010;22:949-58.

16 Reitz C, Tang MX, Schupf N, Manly JJ, Mayeux R, Luchsinger JA. A summary risk score for the prediction of Alzheimer disease in elderly persons. Arch Neurol 2010;67:835-41.

17 van Vliet P, Westendorp RG, van Heemst D, de Craen AJ, Oleksik AM. Cognitive decline precedes late-life longitudinal changes in vascular risk factors. J Neurol Neurosurg Psychiatry 2010;81:1028-32.

18 Launer LJ, Hughes T, Yu B, et al. Lowering midlife levels of systolic blood pressure as a public health strategy to reduce late-life dementia: perspective from the Honolulu Heart Program/ Honolulu Asia Aging Study. Hypertension 2010;55:1352-9. 
19 Johnson W, Price JF, Rafnsson SB, Deary IJ, Fowkes FG. Ankle--brachial index predicts level of, but not change in, cognitive function: the Edinburgh Artery Study at the 15-year follow-up. Vasc Med 2010;15:91-7.

20 Alonso A, Mosley TH Jr, Gottesman RF, Catellier D, Sharrett AR, Coresh J. Risk of dementia hospitalisation associated with cardiovascular risk factors in midlife and older age: the Atherosclerosis Risk in Communities (ARIC) study. J Neurol Neurosurg Psychiatry 2009;80:1194201.

21 Rastas S, Pirttilä T, Mattila K, et al. Vascular risk factors and dementia in the general population aged $>85$ years: prospective population-based study. Neurobiol Aging 2010;31:1-7.

22 Song F, Poljak A, Crawford J, et al. Plasma apolipoprotein levels are associated with cognitive status and decline in a community cohort of older individuals. PLoS One 2012;7:e34078.

23 Reitz C, Tang MX, Schupf N, Manly JJ, Mayeux R, Luchsinger JA. Association of higher levels of high-density lipoprotein cholesterol in elderly individuals and lower risk of late-onset Alzheimer disease. Arch Neurol 2010;67:1491-7.

24 Mielke MM, Zandi PP, Shao H, et al. The 32-year relationship between cholesterol and dementia from midlife to late life. Neurology 2010;75:1888-95.

25 Beydoun MA, Beason-Held LL, Kitner-Triolo MH, et al. Statins and serum cholesterol's associations with incident dementia and mild cognitive impairment. J Epidemiol Community Health 2011;65:949-57.

26 van den Kommer TN, Dik MG, Comijs HC, Jonker C, Deeg DJ. Role of lipoproteins and inflammation in cognitive decline: do they interact? Neurobiol Aging 2012;33:196.e1-12.

27 Reynolds CA, Gatz M, Prince JA, Berg S, Pedersen NL. Serum lipid levels and cognitive change in late life. J Am Geriatr Soc 2010;58:501-9.

28 Zuliani G, Cavalieri M, Galvani M, et al. Relationship between low levels of high-density lipoprotein cholesterol and dementia in the elderly. The InChianti study. J Gerontol A Biol Sci Med Sci 2010;65:559-64.

29 Chen R, Hu Z, Wei L, Ma Y, Liu Z, Copeland JR. Incident dementia in a defined older Chinese population. PLoS One 2011;6:e24817.

30 Hjelm C, Dahl A, Broström A, Mårtensson J, Johansson B, Strömberg A. The influence of heart failure on longitudinal changes in cognition among individuals 80 years of age and older. $J$ Clin Nurs 2012;21:994-1003.

31 Dublin S, Anderson ML, Haneuse SJ, et al. Atrial fibrillation and risk of dementia: a prospective cohort study. J Am Geriatr Soc 2011;59:1369-75.

32 Bunch TJ, Crandall BG, Weiss JP, et al. Patients treated with catheter ablation for atrial fibrillation have long-term rates of death, stroke, and dementia similar to patients without atrial fibrillation. $J$ Cardiovasc Electrophysiol 2011;22:839-45.

33 Kerola T, Nieminen T, Sulkava R, Vuolteenaho O, Hartikainen S, Kettunen R. Inverted mitral inflow pattern in echocardiography among the elderly--a marker of non-cardiovascular mortality and cognitive dysfunction. Int J Cardiol 2012;155:70-4.

34 Eriksson UK, Bennet AM, Gatz M, Dickman PW, Pedersen NL. Nonstroke cardiovascular disease and risk of Alzheimer disease and dementia. Alzheimer Dis Assoc Disord 2010;24:213-9.

35 Bunch TJ, Weiss JP, Crandall BG, et al. Atrial fibrillation is independently associated with senile, vascular, and Alzheimer's dementia. Heart Rhythm 2010;7:433-7.

36 Marengoni A, Qiu C, Winblad B, Fratiglioni L. Atrial fibrillation, stroke and dementia in the very old: a population-based study. Neurobiol Aging 2011;32:1336-7. 
37 Divani AA, Majidi S, Barrett AM, Noorbaloochi S, Luft AR. Consequences of stroke in communitydwelling elderly: the health and retirement study, 1998 to 2008. Stroke 2011;42:1821-5.

38 Dodge HH, Chang CC, Kamboh IM, Ganguli M. Risk of Alzheimer's disease incidence attributable to vascular disease in the population. Alzheimers Dement 2011;7:356-60.

39 Chodosh J, Miller-Martinez D, Aneshensel CS, Wight RG, Karlamangla AS. Depressive symptoms, chronic diseases, and physical disabilities as predictors of cognitive functioning trajectories in older Americans. J Am Geriatr Soc 2010;58:2350-7.

40 Yen $\mathrm{CH}$, Yeh CJ, Wang CC, et al. Determinants of cognitive impairment over time among the elderly in Taiwan results of the national longitudinal study. Arch Gerontol Geriatr 2010;50:S537.

41 Caselli RJ, Dueck AC, Locke DE, et al. Cerebrovascular risk factors and preclinical memory decline in healthy APOE $\varepsilon$ homozygotes. Neurology 2011;76:1078-84.

42 Qiu C, Xu W, Winblad B, Fratiglioni L. Vascular risk profiles for dementia and Alzheimer's disease in very old people: a population-based longitudinal study. J Alzheimers Dis 2010;20:293-300.

43 Luck T, Riedel-Heller SG, Luppa M, et al. Risk factors for incident mild cognitive impairmentresults from the German Study on Ageing, Cognition and Dementia in Primary Care Patients (AgeCoDe). Acta Psychiatr Scand 2010;121:260-72.

44 Schrijvers EM, Buitendijk GH, Ikram MK et al. Retinopathy and risk of dementia: the Rotterdam Study. Neurology 2012;79:365-70.

45 Haan M, Espeland MA, Klein BE, et al. Cognitive function and retinal and ischemic brain changes: the Women's Health Initiative. Neurology 2012;78:942-9.

46 de Jong FJ, Schrijvers EM, Ikram MK et al. Retinal vascular caliber and risk of dementia: the Rotterdam study. Neurology 2011;76:816-21.

47 Marti H, Carcaillon L, Chavance M. Multiple imputation for estimating hazard ratios and predictive abilities in case-cohort surveys. BMC Med Res Methodol 2012;12:24.

48 Stott DJ, Robertson M, Rumley A, et al. Activation of hemostasis and decline in cognitive function in older people. Arterioscler Thromb Vasc Biol 2010;30:605-11.

49 Carcaillon L, Gaussem P, Ducimetière $P$, et al. Elevated plasma fibrin D-dimer as a risk factor for vascular dementia: the Three-City cohort study. J Thromb Haemost 2009;7:1972-8.

50 Watson NL, Sutton-Tyrrell K, Rosano C, et al. Arterial stiffness and cognitive decline in wellfunctioning older adults. J Gerontol A Biol Sci Med Sci 2011;66:1336-42.

51 Laughlin GA, McEvoy LK, von Mühlen D, et al. Sex differences in the association of Framingham Cardiac Risk Score with cognitive decline in community-dwelling elders without clinical heart disease. Psychosom Med 2011;73:683-9.

52 Kaffashian S, Dugravot A, Nabi H, et al. Predictive utility of the Framingham general cardiovascular disease risk profile for cognitive function: evidence from the Whitehall II study. Eur Heart J 2011;32:2326-32.

53 Rose KM, Couper D, Eigenbrodt ML, Mosley TH, Sharrett AR, Gottesman RF. Orthostatic hypotension and cognitive function: the Atherosclerosis Risk in Communities Study. Neuroepidemiology 2010;34:1-7.

54 Dolcos S, MacDonald SW, Braslavsky A, Camicioli R, Dixon RA. Mild cognitive impairment is associated with selected functional markers: integrating concurrent, longitudinal, and stability effects. Neuropsychology 2012;26:209-23.

55 Sander K, Bickel H, Förstl H, et al. Carotid- intima media thickness is independently associated with cognitive decline. The INVADE study. Int J Geriatr Psychiatry 2010;25:389-94. 
56 Rafnsson S, Deary IJ, Whiteman MC, Rumley A, Lowe GD, Fowkes FG. Haemorheological predictors of cognitive decline: the Edinburgh Artery Study. Age Ageing 2010;39:217-22.

57 Li G, Wang LY, Shofer JB, et al. Temporal relationship between depression and dementia: findings from a large community-based 15-year follow-up study. Arch Gen Psychiatry 2011;68:970-7.

58 Kim JM, Stewart R, Kim SY, et al. Synergistic associations of depression and apolipoprotein E genotype with incidence of dementia. Int J Geriatr Psychiatry 2011;26:893-8.

59 Potvin O, Forget H, Grenier S, Préville M, Hudon C. Anxiety, depression, and 1-year incident cognitive impairment in community-dwelling older adults. J Am Geriatr Soc 2011;59:1421-8.

60 Jajodia A, Borders A. Memory predicts changes in depressive symptoms in older adults: a bidirectional longitudinal analysis. J Gerontol B Psychol Sci Soc Sci 2011;66:571-81.

61 Lenoir H, Dufouil C, Auriacombe S, et al. Depression history, depressive symptoms, and incident dementia: the 3C Study. J Alzheimers Dis 2011;26:27-38.

62 Köhler S, van Boxtel M, Jolles J, Verhey F. Depressive symptoms and risk for dementia: a 9-year follow-up of the Maastricht Aging Study. Am J Geriatr Psychiatry 2011;19:902-5.

63 Bielak AA, Gerstorf D, Kiely KM, Anstey KJ, Luszcz M. Depressive symptoms predict decline in perceptual speed in older adulthood. Psychol Aging 2011;26:576-83.

64 Royall DR, Palmer R, Chiodo LK, Polk MJ. Depressive symptoms predict longitudinal change in executive control but not memory. Int J Geriatr Psychiatry 2012;27:89-96.

65 Goveas JS, Espeland MA, Woods NF, Wassertheil-Smoller S, Kotchen JM. Depressive symptoms and incidence of mild cognitive impairment and probable dementia in elderly women: the Women's Health Initiative Memory Study. J Am Geriatr Soc 2011;59:57-66.

66 Unverzagt FW, Ogunniyi A, Taler V, et al. Incidence and risk factors for cognitive impairment no dementia and mild cognitive impairment in African Americans. Alzheimer Dis Assoc Disord. 2011;25:4-10.

67 Ritchie K, Carrière I, Ritchie CW, Berr C, Artero S, Ancelin ML. Designing prevention programmes to reduce incidence of dementia: prospective cohort study of modifiable risk factors. $B M J$ 2010;341:c3885.

68 Saczynski JS, Beiser A, Seshadri S, Auerbach S, Wolf PA, Au R. Depressive symptoms and risk of dementia: the Framingham Heart Study. Neurology 2010;75:35-41.

69 Dotson VM, Beydoun MA, Zonderman AB. Recurrent depressive symptoms and the incidence of dementia and mild cognitive impairment. Neurology 2010;75:27-34.

70 Peters R, Pinto E, Beckett N, et al. Association of depression with subsequent mortality, cardiovascular morbidity and incident dementia in people aged 80 and over and suffering from hypertension. Data from the Hypertension in the Very Elderly Trial (HYVET). Age Ageing 2010;39:439-45.

71 Johansson L, Guo X, Waern M, et al. Midlife psychological stress and risk of dementia: a 35-year longitudinal population study. Brain 2010;133:2217-24.

72 Greendale GA, Wight RG, Huang MH, et al. Menopause-associated symptoms and cognitive performance: results from the study of women's health across the nation. Am J Epidemiol 2010;171:1214-24.

73 Rosenberg PB, Mielke MM, Xue QL, Carlson MC. Depressive symptoms predict incident cognitive impairment in cognitive healthy older women. Am J Geriatr Psychiatry 2010;18:20411.

74 Boyle LL, Porsteinsson AP, Cui X, King DA, Lyness JM. Depression predicts cognitive disorders in older primary care patients. J Clin Psychiatry 2010;71:74-9. 
75 Wang KC, Woung LC, Tsai MT, Liu CC, Su YH, Li CY. Risk of Alzheimer's disease in relation to diabetes: a population-based cohort study. Neuroepidemiology 2012;38:237-44.

76 Ohara T, Doi Y, Ninomiya T, et al. Glucose tolerance status and risk of dementia in the community: the Hisayama study. Neurology 2011;77:1126-34.

77 Wessels AM, Lane KA, Gao S, Hall KS, Unverzagt FW, Hendrie HC. Diabetes and cognitive decline in elderly African Americans: a 15-year follow-up study. Alzheimers Dement 2011;7:418-24.

78 Cheng D, Noble J, Tang MX, Schupf N, Mayeux R, Luchsinger JA. Type 2 diabetes and late-onset Alzheimer's disease. Dement Geriatr Cogn Disord 2011;31:424-30.

79 Christman AL, Matsushita K, Gottesman RF, et al. Glycated haemoglobin and cognitive decline: the Atherosclerosis Risk in Communities (ARIC) study. Diabetologia 2011;54:1645-52.

80 Abbatecola AM, Lattanzio F, Spazzafumo L, et al. Adiposity predicts cognitive decline in older persons with diabetes: a 2-year follow-up. PLoS One 2010;5:e10333.

81 Euser SM, Sattar N, Witteman JC, et al. A prospective analysis of elevated fasting glucose levels and cognitive function in older people: results from PROSPER and the Rotterdam Study. Diabetes 2010;59:1601-7.

82 Crowe M, Sartori A, Clay OJ, et al. Diabetes and cognitive decline: investigating the potential influence of factors related to health disparities. J Aging Health 2010;22:292-306.

83 Gaussoin SA, Espeland MA, Absher J, Howard BV, Jones BM, Rapp SR. Ascertaining dementiarelated outcomes for deceased or proxy-dependent participants: an overview of the Women's Health Initiative Memory Study supplemental case ascertainment protocol. Int J Geriatr Psychiatry 2012;27:205-214.

84 Gelber RP, Petrovitch $\mathrm{H}$, Masaki $\mathrm{KH}$, et al. Lifestyle and the risk of dementia in Japaneseamerican men. J Am Geriatr Soc 2012;60:118-23.

85 Luchsinger JA, Cheng D, Tang MX, Schupf N, Mayeux R. Central obesity in the elderly is related to late-onset Alzheimer disease. Alzheimer Dis Assoc Disord 2012;26:101-5.

86 Xu WL, Atti AR, Gatz M, Pedersen NL, Johansson B, Fratiglioni L. Midlife overweight and obesity increase late-life dementia risk: a population-based twin study. Neurology 2011;76:1568-74.

87 Power BD, Alfonso H, Flicker L, Hankey GJ, Yeap BB, Almeida OP. Body adiposity in later life and the incidence of dementia: the health in men study. PLoS One 2011;6:e17902.

88 Kerwin DR, Gaussoin SA, Chlebowski RT, et al. Interaction between body mass index and central adiposity and risk of incident cognitive impairment and dementia: results from the Women's Health Initiative Memory Study. J Am Geriatr Soc 2011;59:107-12.

89 Hassing LB, Dahl AK, Pedersen NL, Johansson B. Overweight in midlife is related to lower cognitive function 30 years later: a prospective study with longitudinal assessments. Dement Geriatr Cogn Disord 2010;29:543-52.

90 Forti P, Pisacane N, Rietti E, et al. Metabolic syndrome and risk of dementia in older adults. J Am Geriatr Soc 2010;58:487-92.

91 Gustafson DR, Bäckman K, Waern M, et al. Adiposity indicators and dementia over 32 years in Sweden. Neurology 2009;73:1559-66.

92 Dahl A, Hassing LB, Fransson E, et al. Being overweight in midlife is associated with lower cognitive ability and steeper cognitive decline in late life. J Gerontol A Biol Sci Med Sci 2010;65:57-62.

93 Feng L, Yap KB, Yeoh LY, Ng TP. Kidney function and cognitive and functional decline in elderly adults: findings from the Singapore longitudinal aging study. J Am Geriatr Soc 2012;60:120814. 
94 Sajjad I, Grodstein F, Kang JH, Curhan GC, Lin J. Kidney dysfunction and cognitive decline in women. Clin J Am Soc Nephrol 2012;7:437-43.

95 Helmer C, Stengel B, Metzger M, et al. Chronic kidney disease, cognitive decline, and incident dementia: the 3C Study. Neurology 2011;77:2043-51.

96 Kurella Tamura M, Muntner P, Wadley V, et al. Albuminuria, kidney function, and the incidence of cognitive impairment among adults in the United States. Am J Kidney Dis 2011;58:756-63.

97 Sasaki Y, Marioni R, Kasai M, Ishii H, Yamaguchi S, Meguro K. Chronic kidney disease: a risk factor for dementia onset: a population-based study. The Osaki-Tajiri Project. J Am Geriatr Soc 2011;59:1175-81.

98 Barzilay Jl, Gao P, O'Donnell M, et al. Albuminuria and decline in cognitive function: The ONTARGET/TRANSCEND studies. Arch Intern Med 2011;171:142-50.

99 Wang F, Zhang L, Liu L, Wang H. Level of kidney function correlates with cognitive decline. Am J Nephrol 2010;32:117-21.

100 Jassal SK, Kritz-Silverstein D, Barrett-Connor E. A prospective study of albuminuria and cognitive function in older adults: the Rancho Bernardo study. Am J Epidemio/ 2010;171:277-86.

101 Khatri M, Nickolas T, Moon YP, et al. CKD associates with cognitive decline. J Am Soc Nephrol 2009;20:2427-32.

102 McEvoy LK, Laughlin GA, Barrett-Connor E, et al. Metabolic syndrome and 16-year cognitive decline in community-dwelling older adults. Ann Epidemiol 2012;22:310-7.

103 Raffaitin C, Féart C, Le Goff M, et al. Metabolic syndrome and cognitive decline in French elders: the Three-City Study. Neurology 2011;76:518-25.

104 Solfrizzi V, Scafato E, Capurso C, et al. Metabolic syndrome and the risk of vascular dementia: the Italian Longitudinal Study on Ageing. J Neurol Neurosurg Psychiatry 2010;81:433-40.

105 Lee KS, Eom JS, Cheong HK, Oh BH, Hong CH. Effects of head circumference and metabolic syndrome on cognitive decline. Gerontology 2010;56:32-8.

106 Jenny NS, French B, Arnold AM, et al. Long-term assessment of inflammation and healthy aging in late life: the Cardiovascular Health Study All Stars. J Gerontol A Biol Sci Med Sci 2012;67:970-6.

107 Dlugaj M, Gerwig M, Wege N, et al. Elevated levels of high-sensitivity C-reactive protein are associated with mild cognitive impairment and its subtypes: results of a population-based case-control study. J Alzheimers Dis 2012;28:503-14.

108 Mooijaart SP, Sattar N, Trompet S, et al. C-reactive protein and genetic variants and cognitive decline in old age: the PROSPER study. PLoS One 2011;6:e23890.

109 Gallacher J, Bayer A, Lowe G, et al. Is sticky blood bad for the brain?: Hemostatic and inflammatory systems and dementia in the Caerphilly Prospective Study. Arterioscler Thromb Vasc Biol 2010;30:599-604.

110 Laurin D, David Curb J, Masaki KH, White LR, Launer LJ. Midlife C-reactive protein and risk of cognitive decline: a 31-year follow-up. Neurobiol Aging 2009;30:1724-7.

111 Taniguchi Y, Yoshida H, Fujiwara Y, Motohashi Y, Shinkai S. A prospective study of gait performance and subsequent cognitive decline in a general population of older Japanese. $J$ Gerontol A Biol Sci Med Sci 2012;67:796-803.

112 Abellan van Kan G, Rolland Y, Gillette-Guyonnet S, et al. Gait speed, body composition, and dementia. The EPIDOS-Toulouse cohort. J Gerontol A Biol Sci Med Sci 2012;67:425-32.

113 Sattler C, Erickson Kl, Toro P, Schröder J. Physical fitness as a protective factor for cognitive impairment in a prospective population-based study in Germany. J Alzheimers Dis 2011;26:70918. 
114 Buchman AS, Leurgans SE, Boyle PA, Schneider JA, Arnold SE, Bennett DA. Combinations of motor measures more strongly predict adverse health outcomes in old age: the rush memory and aging project, a community-based cohort study. BMC Med 2011;9:42.

115 Atkinson HH, Rapp SR, Williamson JD, et al. The relationship between cognitive function and physical performance in older women: results from the women's health initiative memory study. J Gerontol A Biol Sci Med Sci 2010;65:300-6.

116 Mitnitski A, Fallah N, Rockwood MR, Rockwood K. Transitions in cognitive status in relation to frailty in older adults: a comparison of three frailty measures. J Nutr Health Aging 2011;15:8637.

117 Auyeung TW, Lee JS, KwokT, Woo J. Physical frailty predicts future cognitive decline - a four-year prospective study in 2737 cognitively normal older adults. J Nutr Health Aging 2011;15:690-4.

118 Comijs HC, Gerritsen L, Penninx BW, Bremmer MA, Deeg DJ, Geerlings MI. The association between serum cortisol and cognitive decline in older persons. Am J Geriatr Psychiatry 2010;18:42-50.

119 Boyle PA, Buchman AS, Wilson RS, Leurgans SE, Bennett DA. Physical frailty is associated with incident mild cognitive impairment in community-based older persons. J Am Geriatr Soc 2010;58:248-55.

120 Rabin LA, Wang C, Katz MJ, Derby CA, Buschke H, Lipton RB. Predicting Alzheimer's disease: neuropsychological tests, self-reports, and informant reports of cognitive difficulties. $J \mathrm{Am}$ Geriatr Soc 2012;60:1128-34.

121 Jessen $\mathrm{F}$, Wiese $\mathrm{B}$, Bickel $\mathrm{H}$, et al. Prediction of dementia in primary care patients. PLoS One 2011;6:e16852.

122 Luck T, Luppa M, Briel S, et al. Mild cognitive impairment: incidence and risk factors: results of the Leipzig longitudinal study of the aged. J Am Geriatr Soc 2010;58:1903-10.

123 Reisberg B, Shulman MB, Torossian C, Leng L, Zhu W. Outcome over seven years of healthy adults with and without subjective cognitive impairment. Alzheimers Dement 2010;6:11-24.

124 Jessen F, Wiese B, Bachmann C, et al. Prediction of dementia by subjective memory impairment: effects of severity and temporal association with cognitive impairment. Arch Gen Psychiatry 2010;67:414-22.

125 Yamamoto T, Kondo K, Hirai H, Nakade M, Aida J, Hirata Y. Association between self-reported dental health status and onset of dementia: a 4-year prospective cohort study of older Japanese adults from the Aichi Gerontological Evaluation Study (AGES) Project. Psychosom Med 2012;74:241-8.

126 Arrivé $E$, Letenneur L, Matharan F, et al. Oral health condition of French elderly and risk of dementia: a longitudinal cohort study. Community Dent Oral Epidemiol 2012;40:230-8.

127 Kaye EK, Valencia A, Baba N, Spiro A 3rd, Dietrich T, Garcia RI. Tooth loss and periodontal disease predict poor cognitive function in older men. J Am Geriatr Soc 2010;58:713-8.

128 Stein PS, Kryscio RJ, Desrosiers M, Donegan SJ, Gibbs MB. Tooth loss, apolipoprotein E, and decline in delayed word recall. J Dent Res 2010;89:473-7.

129 Farias ST, Mungas D, Hinton L, Haan M. Demographic, neuropsychological, and functional predictors of rate of longitudinal cognitive decline in Hispanic older adults. Am J Geriatr Psychiatry 2011;19:440-50.

130 LuckT, Luppa M, Angermeyer MC, Villringer A, König HH, Riedel-Heller SG. Impact of impairment in instrumental activities of daily living and mild cognitive impairment on time to incident dementia: results of the Leipzig Longitudinal Study of the Aged. Psychol Med 2011;41:1087-97. 
131 Taekema DG, Ling CH, Kurrle SE, et al. Temporal relationship between handgrip strength and cognitive performance in oldest old people. Age Ageing 2012;41:506-12.

132 Deary IJ, Johnson W, Gow AJ, et al. Losing one's grip: a bivariate growth curve model of grip strength and nonverbal reasoning from age 79 to 87 years in the Lothian Birth Cohort 1921. $J$ Gerontol B Psychol Sci Soc Sci 2011;66:699-707.

133 Taekema DG, Gussekloo J, Maier AB, Westendorp RG, de Craen AJ. Handgrip strength as a predictor of functional, psychological and social health. A prospective population-based study among the oldest old. Age Ageing 2010;39:331-7.

134 Montlahuc C, Soumaré A, Dufouil C, et al. Self-rated health and risk of incident dementia: a community-based elderly cohort, the 3C study. Neurology 2011;77:1457-64.

135 Sargent-Cox K, Cherbuin N, Sachdev P, Anstey KJ. Subjective health and memory predictors of mild cognitive disorders and cognitive decline in ageing: the Personality and Total Health (PATH) through Life Study. Dement Geriatr Cogn Disord 2011;31:45-52.

136 Ford K, Sowers M, Seeman TE, Greendale GA, Sternfeld B, Everson-Rose SA. Cognitive functioning is related to physical functioning in a longitudinal study of women at midlife. Gerontology 2010;56:250-8.

137 Weuve J, Glymour MM, Hu H, et al. Forced expiratory volume in 1 second and cognitive aging in men. J Am Geriatr Soc 2011;59:1283-92.

138 Pathan SS, Gottesman RF, Mosley TH, Knopman DS, Sharrett AR, Alonso A. Association of lung function with cognitive decline and dementia: the Atherosclerosis Risk in Communities (ARIC) Study. Eur J Neurol 2011;18:888-98.

139 Giltay EJ, Nissinen A, Giampaoli S, Kromhout D. Apolipoprotein E genotype modifies the association between midlife lung function and cognitive function in old age. Dement Geriatr Cogn Disord 2009;28:433-41.

140 Potvin $\mathrm{O}$, Lorrain $\mathrm{D}$, Forget $\mathrm{H}$, et al. Sleep quality and 1-year incident cognitive impairment in community-dwelling older adults. Sleep 2012;35:491-9.

141 Elwood PC, Bayer AJ, Fish M, Pickering J, Mitchell C, Gallacher JE. Sleep disturbance and daytime sleepiness predict vascular dementia. J Epidemiol Community Health 2011;65:820-4.

142 Lo AH, Pachana NA, Byrne GJ, Sachdev PS, Woodman RJ. Relationship between changes in body weight and cognitive function in middle-aged and older women. Int J Geriatr Psychiatry 2012;27:863-72.

143 Ogunniyi A, Gao S, Unverzagt FW, et al. Weight loss and incident dementia in elderly Yoruba Nigerians: a 10-year follow-up study. Int Psychogeriatr 2011;23:387-94.

144 Helmes E, Østbye T, Steenhuis RE. Incremental contribution of reported previous head injury to the prediction of diagnosis and cognitive functioning in older adults. Brain Inj 201 1;25:338-47.

145 Muniz-Terrera G, Matthews FE, Stephan B, Brayne C, CC75C Collaboration Group. Are terminal decline and its potential indicators detectable in population studies of the oldest old? Int $J$ Geriatr Psychiatry 2011;26:584-92.

146 James BD, Boyle PA, Buchman AS, Barnes LL, Bennett DA. Life space and risk of Alzheimer disease, mild cognitive impairment, and cognitive decline in old age. Am J Geriatr Psychiatry 2011;19:961-9.

147 Driver JA, Beiser A, Au R, et al. Inverse association between cancer and Alzheimer's disease: results from the Framingham Heart Study. BMJ 2012;344:e1442. 
148 Boyle PA, Buchman AS, Wilson RS, Leurgans SE, Bennett DA. Association of muscle strength with the risk of Alzheimer disease and the rate of cognitive decline in community-dwelling older persons. Arch Neurol 2009;66:1339-44.

149 Aung PP, Strachan MW, Frier BM, et al. Severe hypoglycaemia and late-life cognitive ability in older people with Type 2 diabetes: the Edinburgh Type 2 Diabetes Study. Diabet Med 2012;29:328-36.

150 Clarke DE, Ko JY, Lyketsos C, Rebok GW, Eaton WW. Apathy and cognitive and functional decline in community-dwelling older adults: results from the Baltimore ECA longitudinal study. Int Psychogeriatr 2010;22:819-29.

151 Tranah GJ, Blackwell T, Stone KL, et al. Circadian activity rhythms and risk of incident dementia and mild cognitive impairment in older women. Ann Neurol 2011;70:722-32.

152 Zhou R, Deng J, Zhang M, Zhou HD, Wang YJ. Association between bone mineral density and the risk of Alzheimer's disease. J Alzheimers Dis 2011;24:101-8.

153 Rabbitt P, Lunn M, Pendleton N, Yardefagar G. Terminal pathologies affect rates of decline to different extents and age accelerates the effects of terminal pathology on cognitive decline. $J$ Gerontol B Psychol Sci Soc Sci 2011;66:325-34.

154 Iwashyna TJ, Ely EW, Smith DM, Langa KM. Long-term cognitive impairment and functional disability among survivors of severe sepsis. JAMA 2010;304:1787-94.

155 Louis ED, Benito-León J, Vega-Quiroga S, Bermejo-Pareja F; Neurological Disorders in Central Spain (NEDICES) Study Group. Faster rate of cognitive decline in essential tremor cases than controls: a prospective study. Eur J Neurol 2010;17:1291-7.

156 Rocca WA, Grossardt BR, Shuster LT, Stewart EA. Hysterectomy, oophorectomy, estrogen, and the risk of dementia. Neurodegener Dis 2012;10:175-8.

157 Qureshi SU, Kimbrell T, Pyne JM, et al. Greater prevalence and incidence of dementia in older veterans with posttraumatic stress disorder. J Am Geriatr Soc 2010;58:1627-33.

158 Baars MA, van Boxtel MP, Jolles J. Migraine does not affect cognitive decline: results from the Maastricht aging study. Headache 2010;50:176-84.

159 Sabia S, Elbaz A, Dugravot A, et al. Impact of smoking on cognitive decline in early old age: the Whitehall Il cohort study. Arch Gen Psychiatry 2012;69:627-35.

160 Weuve J, Tchetgen Tchetgen EJ, Glymour MM, et al. Accounting for bias due to selective attrition: the example of smoking and cognitive decline. Epidemiology 2012;23:119-28.

161 Rusanen M, Kivipelto M, Quesenberry CP Jr, Zhou J, Whitmer RA. Heavy smoking in midlife and long-term risk of Alzheimer disease and vascular dementia. Arch Intern Med 2011;171:333-9.

162 Rusanen M, Rovio S, Ngandu T, et al. Midlife smoking, apolipoprotein E and risk of dementia and Alzheimer's disease: a population-based cardiovascular risk factors, aging and dementia study. Dement Geriatr Cogn Disord 2010;30:277-84.

163 Collins N, Sachs-Ericsson N, Preacher KJ, Sheffield KM, Markides K. Smoking increases risk for cognitive decline among community-dwelling older Mexican Americans. Am J Geriatr Psychiatry 2009;17:934-42.

164 Wang CC, Lu TH, Liao WC, et al. Cigarette smoking and cognitive impairment: a 10-year cohort study in Taiwan. Arch Gerontol Geriatr 2010;51:14-38.

165 Buchman AS, Boyle PA, Yu L, Shah RC, Wilson RS, Bennett DA. Total daily physical activity and the risk of $A D$ and cognitive decline in older adults. Neurology 2012;78:1323-9. 
166 Ku PW, Stevinson C, Chen LJ. Prospective associations between leisure-time physical activity and cognitive performance among older adults across an 11-year period. $J$ Epidemiol 2012;22:230-7.

167 Jedrziewski MK, Ewbank DC, Wang H, Trojanowski JQ. Exercise and cognition: results from the National Long Term Care Survey. Alzheimers Dement 2010;6:448-55.

168 Angevaren M, Vanhees L, Nooyens AC, Wendel-Vos CG, Verschuren WM. Physical activity and 5-year cognitive decline in the Doetinchem cohort study. Ann Epidemiol 2010;20:473-9.

169 Kim JM, Stewart R, Bae KY, et al. Role of BDNF val66met polymorphism on the association between physical activity and incident dementia. Neurobiol Aging 2011;32:551.e5-12.

170 Wilson RS, Segawa E, Boyle PA, Bennett DA. Influence of late-life cognitive activity on cognitive health. Neurology 2012;78:1123-9.

171 Sattler C, Toro P, Schönknecht P, Schröder J. Cognitive activity, education and socioeconomic status as preventive factors for mild cognitive impairment and Alzheimer's disease. Psychiatry Res 2012;196:90-5.

172 Valenzuela M, Brayne C, Sachdev P, Wilcock G, Matthews F; Medical Research Council Cognitive Function and Ageing Study. Cognitive lifestyle and long-term risk of dementia and survival after diagnosis in a multicenter population-based cohort. Am J Epidemiol 2011;173:1004-12.

173 Marquie JC, Duarte LR, Bessières P, Dalm C, Gentil C, Ruidavets JB. Higher mental stimulation at work is associated with improved cognitive functioning in both young and older workers. Ergonomics 2010;53:1287-301.

174 Iwasa H, Yoshida Y, Kai I, Suzuki T, Kim H, Yoshida H. Leisure activities and cognitive function in elderly community-dwelling individuals in Japan: a 5-year prospective cohort study. $J$ Psychosom Res 2012;72:159-64.

175 Hughes TF, Chang CC, Vander Bilt J, Ganguli M. Engagement in reading and hobbies and risk of incident dementia: the MoVIES project. Am J Alzheimers Dis Other Demen 2010;25:432-8.

176 Wang HX, Wahlberg M, Karp A, Winblad B, Fratiglioni L. Psychosocial stress at work is associated with increased dementia risk in late life. Alzheimers Dement 2012;8:114-20.

177 Andel R, Crowe M, Hahn EA, et al. Work-related stress may increase the risk of vascular dementia. J Am Geriatr Soc 2012;60:60-7.

178 Elovainio M, Singh-Manoux A, Ferrie JE, et al. Organisational justice and cognitive function in middle-aged employees: the Whitehall II study. J Epidemiol Community Health 2012;66:552-6.

179 Deng J, Lian Y, Shen C, et al. Adverse life event and risk of cognitive impairment: a 5-year prospective longitudinal study in Chongqing, China. Eur J Neurol 2012;19:631-7.

180 Ravona-Springer R, Beeri MS, Goldbourt U. Exposure to the Holocaust and World War II concentration camps during late adolescence and adulthood is not associated with increased risk for dementia at old age. J Alzheimers Dis 2011;23:709-16.

181 Gureje O, Ogunniyi A, Kola L, Abiona T. Incidence of and risk factors for dementia in the Ibadan study of aging. J Am Geriatr Soc 2011;59:869-74.

182 Amieva H, Stoykova R, Matharan F, Helmer C, Antonucci TC, Dartigues JF. What aspects of social network are protective for dementia? Not the quantity but the quality of social interactions is protective up to 15 years later. Psychosom Med 2010;72:905-11.

183 Geda YE. A purpose-oriented life: is it potentially neuroprotective? Arch Neurol 2010;67:10101. 
184 Boyle PA, Buchman AS, Barnes LL, Bennett DA. Effect of a purpose in life on risk of incident Alzheimer disease and mild cognitive impairment in community-dwelling older persons. Arch Gen Psychiatry 2010;67:304-10.

185 Norton MC, Dew J, Smith H, et al. Lifestyle behavior pattern is associated with different levels of risk for incident dementia and Alzheimer's disease: the Cache County study. J Am Geriatr Soc 2012;60:405-12.

186 Carlson MC, Parisi JM, Xia J, et al. Lifestyle activities and memory: variety may be the spice of life. The women's health and aging study II. J Int Neuropsychol Soc 2012;18:286-94.

187 Corsentino EA, Collins N, Sachs-Ericsson N, Blazer DG. Religious attendance reduces cognitive decline among older women with high levels of depressive symptoms. J Gerontol A Biol Sci Med Sci 2009;64:1283-9.

188 Andrew MK, Rockwood K. Social vulnerability predicts cognitive decline in a prospective cohort of older Canadians. Alzheimers Dement 2010;6:319-325.e1.

189 Pietrzak RH, Maruff P, Woodward M, et al. Mild worry symptoms predict decline in learning and memory in healthy older adults: a 2-year prospective cohort study. Am J Geriatr Psychiatry 2012;20:266-75.

190 Cherbuin N, Anstey KJ. The Mediterranean diet is not related to cognitive change in a large prospective investigation: the PATH Through Life study. Am J Geriatr Psychiatry 2012;20:635-9.

191 Naqvi AZ, Harty B, Mukamal KJ, Stoddard AM, Vitolins M, Dunn JE. Monounsaturated, trans, and saturated Fatty acids and cognitive decline in women. J Am Geriatr Soc 2011;59:837-43.

192 Gao Q, Niti M, Feng L, Yap KB, Ng TP. Omega-3 polyunsaturated fatty acid supplements and cognitive decline: Singapore Longitudinal Aging Studies. J Nutr Health Aging 2011;15:32-5.

193 Lopez LB, Kritz-Silverstein D, Barrett Connor E. High dietary and plasma levels of the omega-3 fatty acid docosahexaenoic acid are associated with decreased dementia risk: the Rancho Bernardo study. J Nutr Health Aging 2011;15:25-31.

194 Samieri C, Féart C, Proust-Lima C, et al. $\omega-3$ fatty acids and cognitive decline: modulation by ApoE\&4 allele and depression. Neurobiol Aging 2011;32:2317.e13-22.

195 Morris MS, Selhub J, Jacques PF. Vitamin B-12 and folate status in relation to decline in scores on the mini-mental state examination in the framingham heart study. J Am Geriatr Soc 2012;60:1457-64.

196 Brown B, Huang MH, Karlamangla A, Seeman T, Kado D. Do the effects of APOE- $\varepsilon 4$ on cognitive function and decline depend upon vitamin status? MacArthur Studies of Successful Aging. $J$ Nutr Health Aging 2011;15:196-201.

197 Hooshmand B, Solomon A, Kåreholt I, et al. Homocysteine and holotranscobalamin and the risk of Alzheimer disease: a longitudinal study. Neurology 2010;75:1408-14.

198 Nooyens AC, Bueno-de-Mesquita HB, van Boxtel MP, van Gelder BM, Verhagen H, Verschuren WM. Fruit and vegetable intake and cognitive decline in middle-aged men and women: the Doetinchem Cohort Study. Br J Nutr 2011;106:752-61.

199 Hughes TF, Andel R, Small BJ, et al. Midlife fruit and vegetable consumption and risk of dementia in later life in Swedish twins. Am J Geriatr Psychiatry 2010;18:413-20.

200 Weyerer S, Schäufele M, Wiese B, et al. Current alcohol consumption and its relationship to incident dementia: results from a 3-year follow-up study among primary care attenders aged 75 years and older. Age Ageing 2011;40:456-63.

201 Lobo E, Dufouil C, Marcos G, et al. Is there an association between low-to-moderate alcohol consumption and risk of cognitive decline? Am J Epidemiol 2010;172:708-16. 
202 Shatenstein B, Ferland G, Belleville S, et al. Diet quality and cognition among older adults from the NuAge study. Exp Gerontol 2012;47:353-60.

203 Gu Y, Nieves JW, Stern Y, Luchsinger JA, Scarmeas N. Food combination and Alzheimer disease risk: a protective diet. Arch Neurol 2010;67:699-706.

204 Slinin Y, Paudel M, Taylor BC, et al. Association between serum 25(OH) vitamin D and the risk of cognitive decline in older women. J Gerontol A Biol Sci Med Sci 2012;67:1092-8.

205 Llewellyn DJ, Lang IA, Langa KM, et al. Vitamin D and risk of cognitive decline in elderly persons. Arch Intern Med 2010;170:1135-41.

206 Devore EE, Grodstein F, van Rooij FJ, et al. Dietary antioxidants and long-term risk of dementia. Arch Neurol 2010;67:819-25.

207 Mangialasche F, Kivipelto M, Mecocci P, et al. High plasma levels of vitamin E forms and reduced Alzheimer's disease risk in advanced age. J Alzheimers Dis 2010;20:1029-37.

208 Gustafson DR, Bäckman K, Lissner L, et al. Leptin and dementia over 32 years-The Prospective Population Study of Women. Alzheimers Dement 2012;8:272-7.

209 Creavin ST, Gallacher J, Pickering J, et al. High caloric intake, poor cognition and dementia: the Caerphilly Prospective Study. Eur J Epidemiol 2012;27:197-203.

$210 \mathrm{Gu}$ Y, Luchsinger JA, Stern Y, Scarmeas N. Mediterranean diet, inflammatory and metabolic biomarkers, and risk of Alzheimer's disease. J Alzheimers Dis 2010;22:483-92.

211 Gelber RP, Petrovitch H, Masaki KH, Ross GW, White LR. Coffee intake in midlife and risk of dementia and its neuropathologic correlates. J Alzheimers Dis 2011;23:607-15.

212 Santos C, Lunet N, Azevedo A, de Mendonça A, Ritchie K, Barros H. Caffeine intake is associated with a lower risk of cognitive decline: a cohort study from Portugal. $J$ Alzheimers Dis 2010;20:S175-85.

213 Butchart C, Kyle J, McNeill G, et al. Flavonoid intake in relation to cognitive function in later life in the Lothian Birth Cohort 1936. Br J Nutr 2011;106:141-8.

214 Gu Y, Nieves JW, Luchsinger JA, Scarmeas N. Dietary inflammation factor rating system and risk of Alzheimer disease in elders. Alzheimer Dis Assoc Disord 2011;25:149-54.

215 Ford AH, Flicker L, Alfonso H, et al. Vitamins B(12), B(6), and folic acid for cognition in older men. Neurology 2010;75:1540-7.

216 Jessen F, Kaduszkiewicz H, Daerr M, et al. Anticholinergic drug use and risk for dementia: target for dementia prevention. Eur Arch Psychiatry Clin Neurosci 2010;260:S111-5.

217 Whalley LJ, Sharma S, Fox HC, et al. Anticholinergic drugs in late life: adverse effects on cognition but not on progress to dementia. J Alzheimers Dis 2012;30:253-61.

218 Fox C, Richardson K, Maidment ID, et al. Anticholinergic medication use and cognitive impairment in the older population: the medical research council cognitive function and ageing study. J Am Geriatr Soc 2011;59:1477-83.

219 Campbell NL, Boustani MA, Lane KA, et al. Use of anticholinergics and the risk of cognitive impairment in an African American population. Neurology 2010;75:152-9.

220 Ancelin ML, Carrière I, Barberger-Gateau P, et al. Lipid lowering agents, cognitive decline, and dementia: the three-city study. J Alzheimers Dis 2012;30:629-37.

$221 \mathrm{Li} \mathrm{G}$, Shofer JB, Rhew IC, et al. Age-varying association between statin use and incident Alzheimer's disease. J Am Geriatr Soc 2010;58:1311-7.

222 Solomon A, Sippola R, Soininen $\mathrm{H}$, et al. Lipid-lowering treatment is related to decreased risk of dementia: a population-based study (FINRISK). Neurodegener Dis 2010;7:180-2. 
223 Goveas JS, Hogan PE, Kotchen JM, et al. Depressive symptoms, antidepressant use, and future cognitive health in postmenopausal women: the Women's Health Initiative Memory Study. Int Psychogeriatr 2012;24:1252-64.

224 Desplenter F, Lavikainen P, Hartikainen S, Sulkava R, Bell JS. Sedative use and incident cognitive decline among persons aged 75 years and older: a population-based longitudinal study. Int Psychogeriatr 2012;24:48-54.

225 Côté S, Carmichael PH, Verreault R, Lindsay J, Lefebvre J, Laurin D. Nonsteroidal antiinflammatory drug use and the risk of cognitive impairment and Alzheimer's disease. Alzheimers Dement 2012;8:219-26.

226 Gray SL, Walker R, Dublin S, et al. Histamine-2 receptor antagonist use and incident dementia in an older cohort. J Am Geriatr Soc 2011;59:251-7.

227 Jyrkkä J, Enlund H, Lavikainen P, Sulkava R, Hartikainen S. Association of polypharmacy with nutritional status, functional ability and cognitive capacity over a three-year period in an elderly population. Pharmacoepidemiol Drug Saf 2011;20:514-22.

228 Whitmer RA, Quesenberry CP, Zhou J, Yaffe K. Timing of hormone therapy and dementia: the critical window theory revisited. Ann Neurol 2011;69:163-9.

229 Boeuf-Cazou O, Bongue B, Ansiau D, Marquié JC, Lapeyre-Mestre M. Impact of long-term benzodiazepine use on cognitive functioning in young adults: the VISAT cohort. Eur J Clin Pharmacol 2011;67:1045-52.

230 Hajjar I, Kritchevsky S, Newman AB, et al. Renin angiotensin system gene polymorphisms modify angiotensin-converting enzyme inhibitors' effect on cognitive function: the health, aging and body composition study. J Am Geriatr Soc 2010;58:1035-42.

231 Weuve J, Puett RC, Schwartz J, Yanosky JD, Laden F, Grodstein F. Exposure to particulate air pollution and cognitive decline in older women. Arch Intern Med 2012;172:219-27.

232 Andel $R$, Crowe $M$, Feychting $M$, et al. Work-related exposure to extremely low-frequency magnetic fields and dementia: results from the population-based study of dementia in Swedish twins. J Gerontol A Biol Sci Med Sci 2010;65:1220-7.

233 Ford $\mathrm{AH}$, Flicker $\mathrm{L}$, Alfonso $\mathrm{H}$, et al. Plasma homocysteine and MTHFRC677T polymorphism as risk factors for incident dementia. J Neurol Neurosurg Psychiatry 2012;83:70-5.

234 Zylberstein DE, Lissner L, Björkelund C, et al. Midlife homocysteine and late-life dementia in women. A prospective population study. Neurobiol Aging 2011;32:380-6.

235 Redéen S, Ryberg A, Petersson F, Eriksson O, Nägga K, Borch K. Homocysteine levels in chronic gastritis and other conditions: relations to incident cardiovascular disease and dementia. Dig Dis Sci 2010;55:351-8.

236 van den Kommer TN, Dik MG, Comijs HC, Jonker C, Deeg DJ. Homocysteine and inflammation: predictors of cognitive decline in older persons? Neurobiol Aging 2010;31:1700-9.

237 Schrijvers EM, Direk N, Koudstaal PJ, et al. Associations of serum cortisol with cognitive function and dementia: the Rotterdam Study. J Alzheimers Dis 2011;25:671-7.

238 LeBlanc ES, Wang PY, Janowsky JS, et al. Association between sex steroids and cognition in elderly men. Clin Endocrinol 2010;72:393-403.

239 Muller M, Schupf N, Manly JJ, Mayeux R, Luchsinger JA. Sex hormone binding globulin and incident Alzheimer's disease in elderly men and women. Neurobiol Aging 2010;31:1758-65.

240 Devore EE, Prescott J, De Vivo I, Grodstein F. Relative telomere length and cognitive decline in the Nurses' Health Study. Neurosci Lett 2011;492:15-8. 
241 Fitzpatrick AL, Kronmal RA, Kimura M, et al. Leukocyte telomere length and mortality in the Cardiovascular Health Study. J Gerontol A Biol Sci Med Sci 2011;66:421-9.

242 Hogervorst E, Matthews FE, Brayne C. Are optimal levels of testosterone associated with better cognitive function in healthy older women and men? Biochim Biophys Acta 2010;1800:114552.

243 Laughlin GA, Kritz-Silverstein D, Barrett-Connor E. Endogenous oestrogens predict 4-year decline in verbal fluency in postmenopausal women: the Rancho Bernardo Study. Clin Endocrinol 2010;72:99-106.

244 Beeri MS, Moshier E, Schmeidler J, et al. Serum concentration of an inflammatory glycotoxin, methylglyoxal, is associated with increased cognitive decline in elderly individuals. Mech Ageing Dev 2011;132:583-7.

245 Watanabe I, Li GY, Imamura Y, et al. Baseline saliva level of 3-methoxy-4-hydroxyphenylglycole (MHPG) associates with a consequent cognitive decline in non-demented elderly subjects: three-years follow-up study. Psychiatry Res 2012;195:125-8.

246 Forti P, Olivelli V, Rietti E, et al. Serum thyroid-stimulating hormone as a predictor of cognitive impairment in an elderly cohort. Gerontology 2012;58:41-9.

247 Fiocco AJ, Kanaya AM, Lindquist KM, et al. Plasma F2-isoprostane level and cognitive function over eight years in non-demented older adults: Findings from the Health ABC Study. Prostaglandins Leukot Essent Fatty Acids 2011;84:57-61.

248 Kerola T, Nieminen T, Hartikainen S, Sulkava R, Vuolteenaho O, Kettunen R. B-type natriuretic peptide as a predictor of declining cognitive function and dementia--a cohort study of an elderly general population with a 5-year follow-up. Ann Med 2010;42:207-15.

249 Björkman MP, Sorva AJ, Tilvis RS. Does elevated parathyroid hormone concentration predict cognitive decline in older people? Aging Clin Exp Res 2010;22:164-9.

250 Rogers MA, Langa KM. Untreated poor vision: a contributing factor to late-life dementia. Am J Epidemiol 2010;171:728-35.

251 Finkel D, Reynolds CA, Larsson M, Gatz M, Pedersen NL. Both odor identification and ApoE- $\varepsilon 4$ contribute to normative cognitive aging. Psychol Aging 2011;26:872-83.

252 Lin FR, Metter EJ, O'Brien RJ, Resnick SM, Zonderman AB, Ferrucci L. Hearing loss and incident dementia. Arch Neurol 2011;68:214-20.

253 Song X, Mitnitski A, Rockwood K. Nontraditional risk factors combine to predict Alzheimer disease and dementia. Neurology 2011;77:227-34.

254 Ehreke L, Luppa M, König HH, Villringer A, Riedel-Heller SG. Does the clock drawing test predict dementia? Results of the Leipzig longitudinal study of the aged (LEILA 75+). Dement Geriatr Cogn Disord 2011;31:89-97.

255 Tierney MC, Moineddin R, McDowell I. Prediction of all-cause dementia using neuropsychological tests within 10 and 5 years of diagnosis in a community-based sample. $J$ Alzheimers Dis 2010;22:1231-40.

256 Roberts RO, Geda YE, Knopman DS, et al. The incidence of MCI differs by subtype and is higher in men: the Mayo Clinic Study of Aging. Neurology 2012;78:342-51.

257 Castro-Costa E, Dewey ME, Uchôa E, Firmo JO, Lima-Costa MF, Stewart R. Trajectories of cognitive decline over 10 years in a Brazilian elderly population: the Bambuí Cohort Study of Aging. Cad Saude Publica 2011;27:S345-50.

258 Wolinsky FD, Bentler SE, Hockenberry J, et al. A prospective cohort study of long-term cognitive changes in older Medicare beneficiaries. BMC Public Health 2011;11:710. 
259 Zahodne LB, Glymour MM, Sparks C, et al. Education does not slow cognitive decline with aging: 12-year evidence from the victoria longitudinal study. J Int Neuropsychol Soc 2011;17:1039-46.

260 Lobo A, Lopez-Anton R, Santabárbara J, et al. Incidence and lifetime risk of dementia and Alzheimer's disease in a Southern European population. Acta Psychiatr Scand 2011;124:372-83.

261 Batterham PJ, Mackinnon AJ, Christensen $\mathrm{H}$. The effect of education on the onset and rate of terminal decline. Psychol Aging 2011;26:339-50.

262 Marengoni A, Fratiglioni L, Bandinelli S, Ferrucci L. Socioeconomic status during lifetime and cognitive impairment no-dementia in late life: the population-based aging in the Chianti Area (InCHIANTI) Study. J Alzheimers Dis 2011;24:559-68.

263 Roe CM, Fagan AM, Williams MM, et al. Improving CSF biomarker accuracy in predicting prevalent and incident Alzheimer disease. Neurology 2011;76:501-10.

264 EClipSE Collaborative Members, Brayne C, Ince PG, et al. Education, the brain and dementia: neuroprotection or compensation? Brain 2010;133:2210-6.

265 Anstey KJ, Burns RA, Birrell CL, Steel D, Kiely KM, Luszcz MA. Estimates of probable dementia prevalence from population-based surveys compared with dementia prevalence estimates based on meta-analyses. BMC Neurol 2010;10:62.

266 Mitnitski A, Fallah N, Wu Y, Rockwood K, Borenstein AR. Changes in cognition during the course of eight years in elderly Japanese Americans: a multistate transition model. Ann Epidemiol 2010;20:480-6.

267 Terrera GM, Brayne C, Matthews F; CC75C Study Collaboration Group. One size fits all? Why we need more sophisticated analytical methods in the explanation of trajectories of cognition in older age and their potential risk factors. Int Psychogeriatr 2010;22:291-9.

268 Masel MC, Peek MK. Ethnic differences in cognitive function over time. Ann Epidemiol 2009; 19: 778-83.

269 Jochemsen HM, Muller M, van der Graaf Y, Geerlings MI. APOE $\varepsilon 4$ differentially influences change in memory performance depending on age. The SMART-MR study. Neurobiol Aging 2012;33:832.e15-22.

270 Corrada MM, Brookmeyer R, Paganini-Hill A, Berlau D, Kawas CH. Dementia incidence continues to increase with age in the oldest old: the 90+ study. Ann Neurol 2010;67:114-21.

271 Oulhaj A, Wilcock GK, Smith AD, de Jager CA. Predicting the time of conversion to $\mathrm{MCl}$ in the elderly: role of verbal expression and learning. Neurology 2009;73:1436-42.

272 De Deyn PP, Goeman J, Vervaet A, Dourcy-Belle-Rose B, Van Dam D, Geerts E. Prevalence and incidence of dementia among 75-80-year-old community-dwelling elderly in different districts of Antwerp, Belgium: the Antwerp Cognition (ANCOG) Study. Clin Neurol Neurosurg 2011;113:736-45.

273 Haan MN, Zeki Al-Hazzouri A, Aiello AE. Life-span socioeconomic trajectory, nativity, and cognitive aging in Mexican Americans: the Sacramento Area Latino Study on Aging. J Gerontol B Psychol Sci Soc Sci 2011;66:i102-10.

274 Zeki Al Hazzouri A, Haan MN, Kalbfleisch JD, Galea S, Lisabeth LD, Aiello AE. Life-course socioeconomic position and incidence of dementia and cognitive impairment without dementia in older Mexican Americans: results from the Sacramento area Latino study on aging. Am J Epidemiol 2011;173:1148-58.

275 Roberts BA, Fuhrer R, Marmot M, Richards M. Does retirement influence cognitive performance? The Whitehall II Study. J Epidemiol Community Health 2011;65:958-63. 
276 Forstmeier S, Maercker A, Maier W, et al. Motivational reserve: motivation-related occupational abilities and risk of mild cognitive impairment and Alzheimer disease. Psychol Aging 2012;27:353-63.

277 Lipton RB, Hirsch J, Katz MJ, et al. Exceptional parental longevity associated with lower risk of Alzheimer's disease and memory decline. J Am Geriatr Soc 2010;58:1043-9.

278 Sanders AE, Hall CB, Katz MJ, Lipton RB. Non-native language use and risk of incident dementia in the elderly. J Alzheimers Dis 2012;29:99-108.

279 Chapman B, Duberstein P, Tindle HA, et al. Personality predicts cognitive function over 7 years in older persons. Am J Geriatr Psychiatry 2012;20:612-21.

280 Hagger-Johnson GE, Shickle DA, Roberts BA, Deary IJ. Neuroticism combined with slower and more variable reaction time: synergistic risk factors for 7-year cognitive decline in females. $J$ Gerontol B Psychol Sci Soc Sci 2012;67:572-81.

281 Wilson RS, Begeny CT, Boyle PA, Schneider JA, Bennett DA. Vulnerability to stress, anxiety, and development of dementia in old age. Am J Geriatr Psychiatry 2011;19:327-34.

282 Duberstein PR, Chapman BP, Tindle HA, et al. Personality and risk for Alzheimer's disease in adults 72 years of age and older: a 6-year follow-up. Psychol Aging 2011;26:351-62.

283 Sharp ES, Reynolds CA, Pedersen NL, Gatz M. Cognitive engagement and cognitive aging: is openness protective? Psychol Aging 2010;25:60-73.

284 Ohara T, Ninomiya T, Kubo M, et al. Apolipoprotein genotype for prediction of Alzheimer's disease in older Japanese: the Hisayama Study. J Am Geriatr Soc 2011;59:1074-9.

285 Köhler S, van Boxtel MP, van Os J, et al. Depressive symptoms and cognitive decline in community-dwelling older adults. J Am Geriatr Soc 2010;58:873-9.

286 Beydoun MA, Boueiz A, Abougergi MS, et al. Sex differences in the association of the apolipoprotein E epsilon 4 allele with incidence of dementia, cognitive impairment, and decline. Neurobiol Aging 2012;33:720-731.e4.

287 Boardman JD, Barnes LL, Wilson RS, Evans DA, Mendes de Leon CF. Social disorder, APOE-E4 genotype, and change in cognitive function among older adults living in Chicago. Soc Sci Med 2012;74:1584-90.

288 Albani D, Tettamanti M, Batelli $S$, et al. Interleukin-1a, interleukin-1 $\beta$ and tumor necrosis factor-a genetic variants and risk of dementia in the very old: evidence from the "Monzino 80plus" prospective study. Age 2012;34:519-26.

289 Keller L, Xu W, Wang HX, Winblad B, Fratiglioni L, Graff C. The obesity related gene, FTO, interacts with APOE, and is associated with Alzheimer's disease risk: a prospective cohort study. J Alzheimers Dis 2011;23:461-9.

290 Reif A, Grünblatt E, Herterich S, et al. Association of a functional NOS1 promoter repeat with Alzheimer's disease in the VITA cohort. J Alzheimers Dis 2011;23:327-33.

291 Costa AJ, Kale PL, Luiz RR, De Moraes SA, Mosley TH, Szklo M. Association between birth weight and cognitive function in middle age: the atherosclerosis risk in communities study. Ann Epidemiol 2011;21:851-6. 
APPENDIX 4: Full list of modifiable, non-modifiable risk factors and their interactions as identified by the expert panel during the first Delphi round

\begin{tabular}{|l|l|l|l|l|}
\hline Modifiable risk factors & Frequency & Ranks & $\begin{array}{l}\text { Rank } \\
\text { score }\end{array}$ & $\begin{array}{l}\text { Final } \\
\text { rank }\end{array}$ \\
\hline Formal education & 6 & $1,1,1,2,4,5$ & 466 & 1 \\
\hline Hypertension / high blood pressure & 5 & $1,1,2,3,9$ & 349 & 2 \\
\hline Diabetes & 6 & $1,2,3,6,7,7$ & 302 & 3 \\
\hline Physical inactivity & 6 & $2,2,3,6,6,7$ & 292 & 4 \\
\hline Psychosocial stress / Depression & 7 & $2,3,5,6,8,9,10$ & 220 & 5 \\
\hline Low cognitive activity & 4 & $2,3,6,7$ & 186 & 6 \\
\hline Obesity & 4 & $4,5,4,7$ & 126 & 7 \\
\hline Alcohol & 3 & $3,6,9$ & 110 & 8 \\
\hline High cholesterol & 2 & 3,6 & 106 & 9 \\
\hline Metabolic syndrome & 1 & 1 & 100 & 10 \\
\hline Head Injury & 3 & $2,8,8$ & 99 & 11 \\
\hline Diet & 3 & $5,4,10$ & 86 & 12 \\
\hline Intelligence quotient (IQ) & 1 & 3 & 81 & 13 \\
\hline Smoking & 4 & $4,8,8,10$ & 68 & 14 \\
\hline Other vascular risk factors and disease & 3 & $4,7,10$ & 66 & 15 \\
\hline $\begin{array}{l}\text { Infectious disease (human immunodeficiency virus (HIV) } \\
\text { malaria, Prion disease) }\end{array}$ & 2 & 4,7 & 65 & 16 \\
\hline Other stimulating leisure activities & & & & \\
\hline Low social engagement & 1 & 4 & 49 & 17 \\
\hline Rural residence & 2 & 5,10 & 37 & 18 \\
\hline High homocysteine & 1 & 5 & 36 & 19 \\
\hline Stroke & 1 & 5 & 36 & 19 \\
\hline Parkinson's disease & 1 & 5 & 36 & 19 \\
\hline Noxious substances and drugs & 2 & 6 & 25 & 22 \\
\hline Sleep quality & 1 & 9,9 & 8 & 23 \\
\hline Fetal and childhood nutrition & 1 & 10 & 2 & 24 \\
\hline & 2 & & 1 & 25 \\
\hline
\end{tabular}

\begin{tabular}{|l|l|l|l|l|}
\hline Non-modifiable risk factors & Frequency & Ranks & $\begin{array}{l}\text { Rank } \\
\text { score }\end{array}$ & $\begin{array}{l}\text { Final } \\
\text { rank }\end{array}$ \\
\hline Age & 7 & $1,1,1,1,2,1,1$ & 681 & 1 \\
\hline Genes & 7 & $2,2,2,3,1,5,4$ & 492 & 2 \\
\hline Apolipoprotein E (APOE) $\varepsilon 4$ allele & 5 & $2,3,2,3,3$ & 354 & 3 \\
\hline Sex & 4 & $1,5,5,4$ & 197 & 4 \\
\hline
\end{tabular}




\begin{tabular}{|l|l|l|l|l|}
\hline Non-modifiable risk factors & Frequency & Ranks & $\begin{array}{l}\text { Rank } \\
\text { score }\end{array}$ & $\begin{array}{l}\text { Final } \\
\text { rank }\end{array}$ \\
\hline Family history & 2 & 2,2 & 162 & 5 \\
\hline Head trauma & 2 & 3,3 & 128 & 6 \\
\hline Terminal decline; end of life dysfunction & 2 & 3,4 & 113 & 7 \\
\hline Stroke & 1 & 4 & 49 & 8 \\
\hline Socioeconomic status & 1 & 4 & 49 & 8 \\
\hline Down syndrome and other intellectual disability & 1 & 6 & 25 & 10 \\
\hline
\end{tabular}

\begin{tabular}{|l|l|}
\hline Interactions & Frequency \\
\hline Age * Family history & 1 \\
\hline Age * APOE E4 & 1 \\
\hline Age * Genes & 1 \\
\hline Physical inactivity * Age & 1 \\
\hline Hypertension * Genes & 1 \\
\hline Obesity * Age & 1 \\
\hline Diabetes * Genes & 1 \\
\hline Head trauma * Genetics & 1 \\
\hline Head trauma * Age & 1 \\
\hline Physical inactivity * APOE E4 & 1 \\
\hline Diet * APOE E4 & 1 \\
\hline Alcohol * APOE E4 & 1 \\
\hline Smoking * APOE E4 & 1 \\
\hline Low cognitive activity * APOE E4 & 1 \\
\hline Head trauma * APOE E4 & 1 \\
\hline Diabetes * Hypertension & 1 \\
\hline Diabetes * Physical inactivity & 1 \\
\hline Hypertension * APOE E4 & 1 \\
\hline Physical inactivity * Low cognitive activity & 1 \\
\hline & \\
\hline
\end{tabular}




\section{APPENDIX 5: Examples of existing randomized controlled trials (RCT) per risk factor}

\section{Depression}

A RCT in 63 depressed older adults investigated the effects of antidepressants (sertraline or nortriptyline) on cognitive test performances. Participants in the sertraline condition improved significantly on verbal learning abilities independent of the responder status (response to medication yes or no). In comparison, participants in the nortriptyline condition showed no improvement in all cognitive domains. ${ }^{1}$ It remains unclear whether this improvement in memory could be entirely explained by sertraline use or whether it could be attributed to other factor such as the small sample size or learning and expectancy effects.

\section{Diabetes}

No RCT examined the effect of treatment on dementia prevalence or cognitive outcomes.

\section{Cognitive activity}

A recent RCT evaluated the effects of a computerized brain exercise program ( 5 days a week for 20-25 minutes each day) on cognitive abilities in healthy older adults. Participants in the intervention group improved significantly on delayed memory, but not on language and immediate memory. All participants who achieved more than 40 sessions improved on all three cognitive domains over the 6 month period. ${ }^{2}$

\section{Physical activity}

A RCT in 120 older adults investigated the effects of aerobic exercise training on hippocampal volume and memory. Participants were randomized to a moderate-intensity aerobic exercise (3days per week) group (intervention) or stretching and toning exercises group (control). Hippocampal volume was increased by $2 \%$ in the 1 -year aerobic exercise group compared to a $1.4 \%$ decline in the stretching control group over a 1 -year period. In addition, both groups showed an improvement in spatial memory. ${ }^{3}$

\section{Cognitive activity/physical activity}

The Mental Activity and eXercise (MAX) trial investigated the combined effects of physical and cognitive activity on cognition in 126 community-residing older adults with cognitive complaints. All participants followed class-based physical activity and home-based mental activity and were randomized to a mental activity intervention or control group 
plus a physical activity or control group. Global cognition improved significantly over time with no difference between intervention and active control groups. ${ }^{4}$

\section{Hypertension}

The Ongoing Telmisartan Alone and in Combination With Ramipril Global End Point Trial (ONTARGET) and the Telmisartan Randomized Assessment Study in ACE [AngiotensinConverting Enzyme]-Intolerant Subjects With Cardiovascular Disease (TRANSCEND) in more than 25,000 patients with vascular disease or diabetes mellitus investigated the effects of telmisartan (angiotensin-receptor blocker) and Ramipril (angiotensin-converting enzyme (ACE) inhibitor) and a combination of these two drugs on cognitive functioning. Over several years of treatment, no beneficial cognitive outcomes were found in all bloodpressure lowering medication groups. ${ }^{5}$

\section{Diet}

The PREDIMED-NAVARRA trial randomized 1,055 adults aged 55-80 years to either a control group (advice to adhere to a low-fat diet), or one of two interventions groups with advice how to cook a Mediterranean diet plus a) 30 grams nuts each day, or b) free allotments of extra-virgin olive oil. After 6.5 years of follow-up, the two treatment groups performed modestly better than the control group on the Mini-Mental State Examination (0.5-0.6 point difference). However, only $50 \%$ of the original sample could be tested due to loss to follow-up. ${ }^{6}$

\section{Obesity}

No RCT examined the effect of treatment on dementia prevalence or cognitive outcomes.

\section{Smoking}

No RCT examined the effect of treatment on dementia prevalence or cognitive outcomes.

\section{Alcohol consumption}

No RCT examined the effect of treatment on dementia prevalence or cognitive outcomes.

\section{Cholesterol/hyperlipidemia}

The PROspective Study of Pravastatin in the Elderly at Risk (PROSPER) investigated the effects of a lipid-lower agent (pravastatin) on cognitive function in 5,804 elderly subjects with pre-existing vascular disease or increased risk of such disease. During the 3-year follow-up period, participants in the pravastatin condition did not perform better on all 
cognitive domains compared to the placebo condition. ${ }^{7}$ Similar results were found in two RCTs evaluating the effects of statin use in participants with mild to moderate dementia. ${ }^{8,9}$

\section{Coronary heart disease}

No RCT examined the effect of treatment on dementia prevalence or cognitive outcomes.

\section{Renal dysfunction}

No RCT examined the effect of treatment on dementia prevalence or cognitive outcomes.

\section{Unsaturated fat intake}

A number of RCTs have investigated the effects of unsaturated fat intake on cognition, but the results are divergent. ${ }^{10,11}$ For instance, a recent RCT in 40 healthy older adults (5172 years) evaluated the effects of intake of long-chain plasma n-3 polyunsaturated fatty acids ( 3 grams on a daily basis) on cognitive test performance. After a period of 5 weeks, participants who were supplemented with $n-3$ polyunsaturated fatty acids performed better on a working memory test in comparison with the control group. ${ }^{10}$

\section{Inflammation}

The Alzheimer's Disease Anti-inflammatory Prevention Trial (ADAPT) investigated whether non-steroidal anti-inflammatory drugs (celecoxib or naproxen) could be used to delay the onset of dementia ${ }^{12}$ among 2,528 volunteers aged 70 years and older. Initial results were contradictive and not very promising. ${ }^{13-15}$ Similarly, the 7-year follow-up study of this trial found no evidence for the protective effects of celecoxib or naproxen ${ }^{16}$ 


\section{REFERENCES}

1. Culang-Reinlieb ME, Sneed JR, Keilp JG, Roose SP. Change in cognitive functioning in depressed older adults following treatment with sertraline or nortriptyline. Int J Geriatr Psychiatry 2012; 27(8): 777-84.

2. Miller KJ, Dye RV, Kim J, et al. Effect of a computerized brain exercise program on cognitive performance in older adults. Am J Geriatr Psychiatry 2013; 21 (7): 655-63.

3. Erickson Kl, Voss MW, Prakash RS, et al. Exercise training increases size of hippocampus and improves memory. Proc Natl Acad Sci U S A 2011; 108(7): 3017-22.

4. Barnes DE, Santos-Modesitt W, Poelke G, et al. The Mental Activity and eXercise (MAX) trial: a randomized controlled trial to enhance cognitive function in older adults. JAMA Intern Med 2013; 173(9): 797-804.

5. Anderson C, Teo K, Gao P, et al. Renin-angiotensin system blockade and cognitive function in patients at high risk of cardiovascular disease: analysis of data from the ONTARGET and TRANSCEND studies. Lancet Neurol 2011; 10(1): 43-53.

6. Martinez-Lapiscina EH, Clavero P, Toledo E, et al. Mediterranean diet improves cognition: the PREDIMED-NAVARRA randomised trial. J Neurol Neurosurg Psychiatry 2013; 84(12): 1318-25.

7. Trompet $\mathrm{S}$, van Vliet $\mathrm{P}$, de Craen $\mathrm{AJ}$, et al. Pravastatin and cognitive function in the elderly. Results of the PROSPER study. J Neurol 2010; 257(1): 85-90.

8. Feldman HH, Doody RS, Kivipelto M, et al. Randomized controlled trial of atorvastatin in mild to moderate Alzheimer disease: LEADe. Neurology 2010; 74(12): 956-64.

9. Sano $M$, Bell KL, Galasko D, et al. A randomized, double-blind, placebo-controlled trial of simvastatin to treat Alzheimer disease. Neurology 2011; 77(6): 556-63.

10. Nilsson A, Radeborg K, Salo I, Bjorck I. Effects of supplementation with n-3 polyunsaturated fatty acids on cognitive performance and cardiometabolic risk markers in healthy 51 to 72 years old subjects: a randomized controlled cross-over study. Nutr J 2012; 11: 99.

11. Yurko-Mauro K, McCarthy D, Rom D, et al. Beneficial effects of docosahexaenoic acid on cognition in age-related cognitive decline. Alzheimers Dement 2010; 6(6): 456-64.

12. Martin BK, Meinert CL, Breitner JCS, the ARG. Double placebo design in a prevention trial for Alzheimer's disease. Controlled Clinical Trials 2002; 23(1): 93-9.

13. Breitner JC, Baker LD, Montine TJ, et al. Extended results of the Alzheimer's disease antiinflammatory prevention trial. Alzheimers Dement 2011; 7(4): 402-11.

14. ADAPT Research Group. Naproxen and celecoxib do not prevent AD in early results from a randomized controlled trial. Neurology 2007; 68(21): 1800-8.

15. Martin BK, Szekely C, Brandt J, et al. Cognitive function over time in the Alzheimer's Disease Anti-inflammatory Prevention Trial (ADAPT): results of a randomized, controlled trial of naproxen and celecoxib. Arch Neurol 2008; 65(7): 896-905.

16. ADAPT Research Group. Results of a follow-up study to the randomized Alzheimer's Disease Anti-inflammatory Prevention Trial (ADAPT). Alzheimers Dement 2013; 9(6): 714-23. 
(in) 


\section{CHAPTER 3}

\section{DEMENTIA RISK IN RENAL DYSFUNCTION: A SYSTEMATIC REVIEW AND META- ANALYSIS OF PROSPECTIVE STUDIES}

Neurology 2017;88(2):198-208

Kay Deckers, Ileana Camerino, Martin PJ van Boxtel, Frans RJ Verhey, Kate Irving, Carol Brayne, Miia Kivipelto, John M Starr, Kristine Yaffe, Peter W de Leeuw, Sebastian Köhler 


\section{ABSTRACT}

Objective: Renal dysfunction has been linked with increased risk for cognitive impairment and dementia, but studies are conflicting. For that reason, the aim of the present systematic review and meta-analysis is to summarize the best available evidence on the prospective association between potential markers of renal dysfunction and development of cognitive impairment or dementia.

Methods: Medline, Embase and Cochrane Database of Systematic Reviews were searched for potential publications until 1 August 2016. Studies were eligible if they fulfilled the following criteria: population-based study, prospective design, $\geq 100$ participants, aged $\geq 45$ years, $\geq 1$ year follow-up, and cognition/dementia outcomes. Where appropriate, random effects meta-analyses were conducted yielding pooled odds ratio's (OR) and 95\% confidence intervals $(\mathrm{Cl})$.

Results: Twenty-two out of 8,494 abstracts fulfilled the eligibility criteria. Sufficient evidence was found for albuminuria, mixed results for estimated glomerular filtration rate (eGFR), insufficient support for cystatin C, and tentative evidence for serum creatinine and creatinine clearance. Meta-analyses of five studies representing 27,805 persons showed a $35 \%$ increased risk of cognitive impairment or dementia in those with albuminuria (OR = $1.35,95 \% \mathrm{Cl} 1.06-1.73, \mathrm{p}=0.015$, whereas eGFR $<60 \mathrm{~mL} / \mathrm{min} / 1.73 \mathrm{~m}^{2}$ showed no significant association ( $\mathrm{OR}=1.28,95 \% \mathrm{Cl} 0.99-1.65, \mathrm{p}=0.063)$. No meta-analyses could be done for serum creatinine, creatinine clearance and cystatin $C$.

Conclusions: The overall evidence for an association between renal dysfunction and cognitive impairment or dementia is modest. Evidence suggests that albuminuria is associated with higher odds of developing cognitive impairment or dementia. 


\section{INTRODUCTION}

Renal dysfunction has been considered a candidate risk factor for cognitive impairment and dementia. ${ }^{1-3}$ The kidneys and the brain, both being end organs, are susceptible to vascular damage due to broadly similar anatomic and hemodynamic features. ${ }^{4}$ Chronic kidney disease (CKD) and dementia share a similar risk factor profile including hypertension, diabetes mellitus, or hyperlipidemia, and in both conditions a high prevalence of small vessel disease, silent brain infarcts, white matter pathology and microbleeds was reported. ${ }^{2,3,5-8}$ Hence, several pathways may underlie the association between CKD and cognitive impairment, including shared vascular factors or a direct neurotoxic effect of uremia. ${ }^{2,9}$

Worldwide, the number of people with dementia increases. ${ }^{10}$ Identification of determinants of dementia is important given the absence of effective treatments. There is sufficient evidence to support the associations between modifiable risk factors and cognitive decline or dementia later in life..$^{11,12}$ The global prevalence of CKD in the general population is estimated to be $8-16 \%$, with the highest prevalence in older people..$^{13}$ Both CKD and dementia are important public health problems with associated poor health outcomes and rising health care costs for our society. ${ }^{14,15}$

A previous meta-analysis found a $39 \%$ increased odds for cognitive impairment in subjects with CKD. ${ }^{16}$ Yet, this study included only six prospective studies and only reported on estimated glomerular filtration rate (eGFR) as a marker of renal dysfunction, potentially excluding relevant studies using other markers like albuminuria or cystatin $\mathrm{C}$. Therefore, we took a broader approach and systematically reviewed the best available evidence on the prospective association between potential markers of renal dysfunction and development of cognitive impairment or dementia.

\section{METHODS}

\section{Data Sources and Searches}

The literature search was conducted in Medline, Embase and Cochrane Database of Systematic Reviews. A deliberate choice was made for a broad search with minimal restrictions in order to harvest all potentially interesting publications. Some markers of renal function were specified within the search term due to their wide use in clinical practice. ${ }^{17}$ The search strategy included 1) terms related to predictors (e.g. "renal", "kidney", "albuminuria", "creatinine", "cystatin"), 2) terms for the outcomes (e.g. "dementia", 
"Alzheimer's disease", "cognitive impairment"), and 3) specific limitations (i.e. humans, language restrictions). See Appendix 1 for the complete search strategy.

\section{Study Selection}

All publications until $1^{\text {st }}$ August 2016 were included that fulfilled the following inclusion criteria: population-based study, prospective design, $\geq 100$ participants, aged $\geq 45$ years, $\geq 1$ year follow-up, cognition/dementia outcomes. Secondary literature (review articles, conference abstracts) and reference lists of publications were also scrutinized.

\section{Data Extraction and Quality Assessment}

The selection process followed the PRISMA guidelines. Firstly, two independent raters (SK, KD) screened titles and abstracts for broad suitability and eligibility criteria. Secondly, two independent investigators (IC, KD) reviewed the full text versions of potentially relevant citations and extracted information such as sample size, setting, age range, follow-up period, outcome (dementia, cognitive impairment, or cognitive decline), predictors (marker of renal dysfunction), and effect estimate, according to a standardized data collection form. Discrepancies were resolved through consensus and discussion with the third reviewer (SK). Corresponding authors were contacted if full-text articles were not available or additional information was required (with two reminders in case of nonresponse). Quality aspects were assessed with the Newcastle-Ottawa Scale (NOS). ${ }^{18}$

\section{Markers of renal dysfunction}

eGFR is expressed as milliliter blood filtered per minute by the functioning nephrons in the kidney, with $<60 \mathrm{~mL} / \mathrm{min} / 1.73 \mathrm{~m}^{2}$ as moderately impaired and $<45 \mathrm{~mL} / \mathrm{min} / 1.73 \mathrm{~m}^{2}$ as moderate to severely impaired kidney function. Yet, an eGFR of $60-90 \mathrm{~mL} / \mathrm{min} / 1.73$ $\mathrm{m}^{2}$ represents mildly reduced kidney function (stage 2 CKD). In the present study, we will look at more advanced stages of CKD, namely eGFR levels $<45,45-59$ and $<60 \mathrm{~mL} /$ $\mathrm{min} / 1.73 \mathrm{~m}^{2}$. eGFR $<60 \mathrm{~mL} / \mathrm{min} / 1.73 \mathrm{~m}^{2}$ is the most common indicator of CKD. ${ }^{19}$ eGFR can be derived according to different formulas usually from serum creatinine (SCr). ${ }^{20}$ Albuminuria or proteinuria refers to an abnormal amount of proteins (e.g. albumin) present in the urine. ${ }^{21}$ Normally, proteins are retained during the filtration process in the kidneys. Microalbuminuria is defined as excretion of $30-300 \mathrm{mg}$ of albumin per 24 hours, whereas macroalbuminuria is defined as an excretion of more than $300 \mathrm{mg}$ of albumin a day. ${ }^{22}$ The value of acceptable albumin excretion lies between 2 and $30 \mathrm{mg}$ per 24 hours. ${ }^{23}$ In addition, albuminuria can be measured by using an albumin-to-creatinine ratio on a random (spot) urine sample. An albumin-to-creatinine ratio of $30 \mathrm{mg} / \mathrm{g}$ is considered 
clinically significant. ${ }^{24}$ Cystatin $C$, a cysteine proteinase inhibitor, is a very small protein produced by all nucleated cells. It is freely filtered by the glomerulus and then metabolized in the tubules. Normal kidney functioning is characterized by a steady cystatin $\mathrm{C}$ blood level, whereas high levels of cystatin C indicate kidney dysfunction. ${ }^{25}$ Creatinine is a waste product of creatine phosphate in muscles, and is relatively stable over time. An elevated level of $\mathrm{SCr}$ (for men $>1.2 \mathrm{mg} / \mathrm{dL}$; for women $1.0 \mathrm{mg} / \mathrm{dL}$ ) may indicate that the kidneys are not working properly. ${ }^{7}$ However, $\mathrm{SCr}$ does not correlate linearly with eGFR and is a relatively poor measure of renal function. ${ }^{19}$ Creatinine clearance $(\mathrm{CCl})$ is the measurement of the amount of creatinine excreted in the urine per unit of time (usually based on a 24hour urine collection). ${ }^{17}$

\section{Data Synthesis and Analysis}

Random effects meta-analysis was used to generate pooled odds ratios (OR) and their $95 \%$ confidence intervals (Cl). Tests were two-sided at an alpha-level of 0.05 . Estimates from crude as well as most fully-adjusted models available were used. Heterogeneity among studies was assessed using the $P^{2}$ statistic. Possible publication bias was assessed by funnel plots and Egger's test. Separate meta-analyses were only conducted for different levels of eGFR and albuminuria. All analyses were done with Stata 13.1.

\section{RESULTS}

We identified 8,494 abstracts, of which 86 (1\%) were included for full-text scrutiny. Of these, 64 were excluded due to article type (e.g. review, editorial), study design (e.g. crosssectional study) or they were conference abstracts or duplicate records. We contacted seventeen authors to obtain full-text articles that were not available to us. Of these, eleven authors responded. The six unavailable full-text articles were patient-based studies, conference abstracts or review articles. In addition, we contacted authors of twenty studies for additional information that was not included in full-texts, and ten authors responded. This resulted in 22 prospective population-based studies (see Figure 1). One additional study was found from cross-references, but this study was excluded after fulltext screening. Quality assessment of 22 prospective studies was sufficient (mean NOS score $=8.00, \mathrm{SD}=0.62$, range $=7-9$ ).

Renal dysfunction in the population-based studies was based on eGFR, albuminuria, cystatin $\mathrm{C}, \mathrm{SCr}$ and $\mathrm{CCl}$. Cognitive functioning was most often defined as a decline in cognition between two time points (e.g. change in Mini-Mental State Examination (MMSE) scores). Other outcome measures such as cognitive impairment or dementia 
were diagnosed based on findings from neuropsychological examinations, clinical evaluations, diagnostic criteria (e.g. Diagnostic and Statistical Manual of Mental Disorders, fourth edition(DSM-IV ${ }^{26}$ ) and review of medical records. If studies investigated dementia subtypes, this was generally based on different criteria for Alzheimer's disease (AD) dementia (NINCDS-ADRDA criteria ${ }^{27}$ ) and vascular dementia (NINDS-AIREN criteria ${ }^{28}$ ). All 22 studies and their results are summarized in Table 1 and Appendix 2.

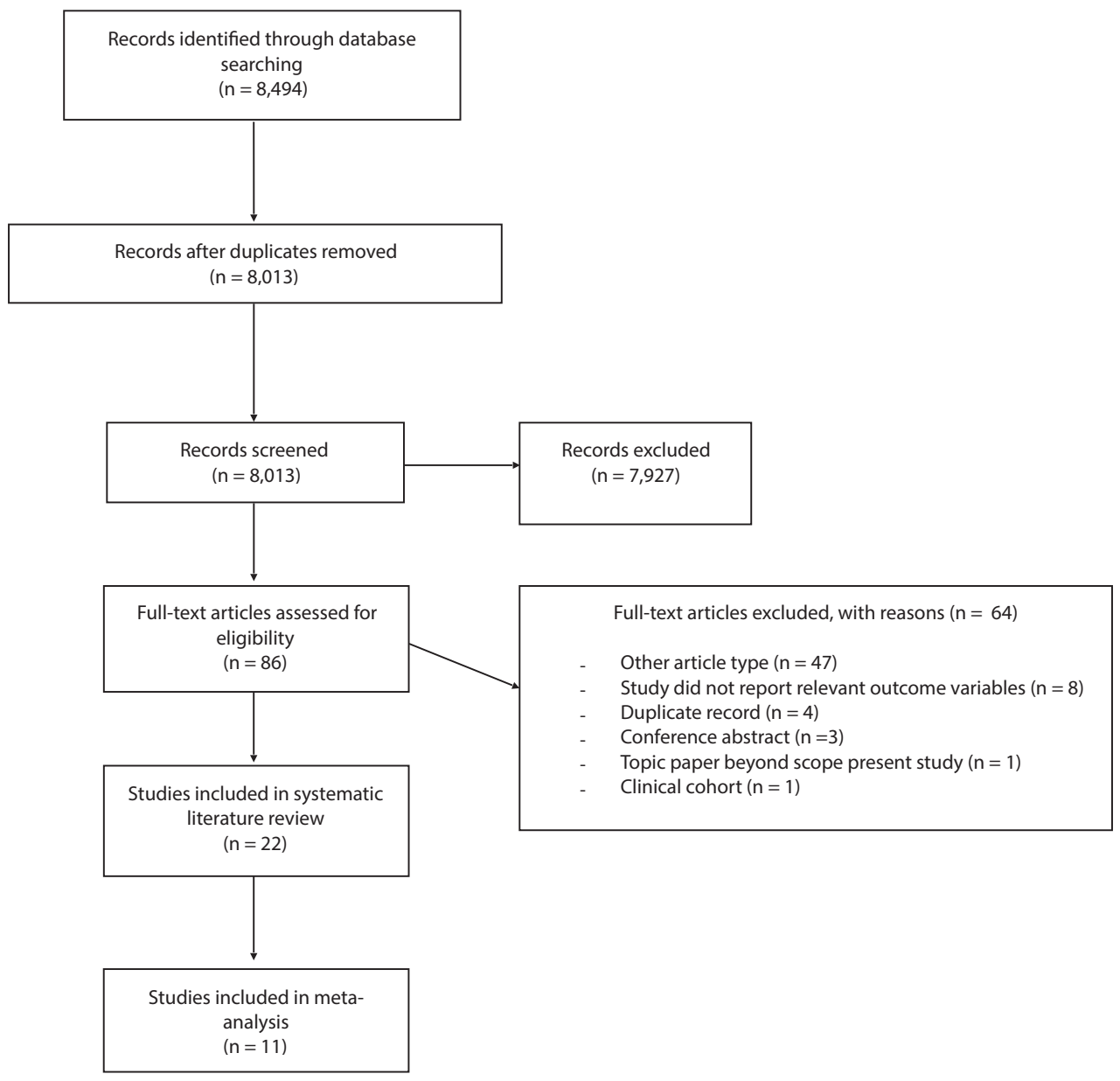

Figure 1. Flow diagram 


\section{eGFR}

Seventeen studies investigated the association between (change in) eGFR and cognitive decline or risk of cognitive impairment/dementia. Ten studies focused on cognitive decline, of which five found more decline in cognitive capacity with lower eGFR as time progresses, ${ }^{29-33}$ and five studies found no effect. ${ }^{34-38}$ Two of these studies and one additional study looked at the association between longitudinal changes in eGFR and cognitive decline. ${ }^{34,35,39}$ One study found that faster eGFR decline was associated with cognitive decline and incident dementia with a vascular component, ${ }^{35}$ one study reported an association between declining eGFR and a decline in several cognitive domains, ${ }^{34}$ and one study found that higher eGFR was associated with slower cognitive decline. ${ }^{39}$ Five studies focused on cognitive impairment, of which one study found an increased risk, ${ }^{40}$ and four studies found no association. ${ }^{41-44}$ Three studies examined the relation between eGFR and dementia risk, two studies found no association between eGFR and dementia risk, ${ }^{35,45}$ while one study found an increased risk of all-cause dementia. ${ }^{46}$ Rather than eGFR at baseline, age-related change in eGFR and type of dementia might play a role.

In the meta-analysis, a total of eight studies, representing 36,636 persons, could be included. ${ }^{31,33,35,37,40,42,43,46}$ For this, four studies reporting both eGFR $<45 \mathrm{~mL} / \mathrm{min} / 1.73 \mathrm{~m}^{2}$ and eGFR $45-59 \mathrm{~mL} / \mathrm{min} / 1.73 \mathrm{~m}^{2}$ levels were pooled individually (within one study) in order to be included in the eGFR $<60 \mathrm{~mL} / \mathrm{min} / 1.73 \mathrm{~m}^{2}$ meta-analysis. ${ }^{35,40,42,43} \mathrm{eGFR}<60 \mathrm{~mL} / \mathrm{min} / 1.73$ $\mathrm{m}^{2}$ was not associated with risk of cognitive impairment or dementia $(p=0.063$; see Figure 2). There were signs of heterogeneity based on the $I^{2}$ statistic $\left(I^{2}=69.0 \%, p=0.002\right)$. The funnel plot of the adjusted estimates was broadly symmetrical (see Figure 1 of Appendix 3 ) and the Egger's test ( $p=0.105$ ) was not significant, suggesting no signs of publication bias. Exclusion of two relatively small influential studies (logarithm of standard error $>0.4$ ) reduced heterogeneity modestly $\left(\mathrm{OR}=1.13,95 \% \mathrm{Cl} 0.91-1.40, \mathrm{p}=0.258 ; \mathrm{I}^{2}=58.8 \%, \mathrm{p}=\right.$ 0.033). Separate meta-analyses were conducted for eGFR $<45 \mathrm{~mL} / \mathrm{min} / 1.73 \mathrm{~m}^{2}$ and eGFR $45-59 \mathrm{~mL} / \mathrm{min} / 1.73 \mathrm{~m}^{2}$. No significant associations were observed in these analyses (see Appendix 4). It was not possible to perform a meta-analysis for eGFR $60-89 \mathrm{~mL} / \mathrm{min} / 1.73$ $\mathrm{m}^{2}$ since there were only two studies. ${ }^{33,42}$ Overall, heterogeneity in outcomes across studies was reduced in all analyses for adjusted estimates in comparison with unadjusted estimates (e.g. eGFR $<60 \mathrm{~mL} / \mathrm{min} / 1.73 \mathrm{~m}^{2}: \mathrm{I}^{2}=69.0 \%$ versus $\mathrm{I}^{2}=91.6 \%$, respectively). See Figure 1, 2, and 3 of Appendix 5 for the results of the unadjusted estimates. 


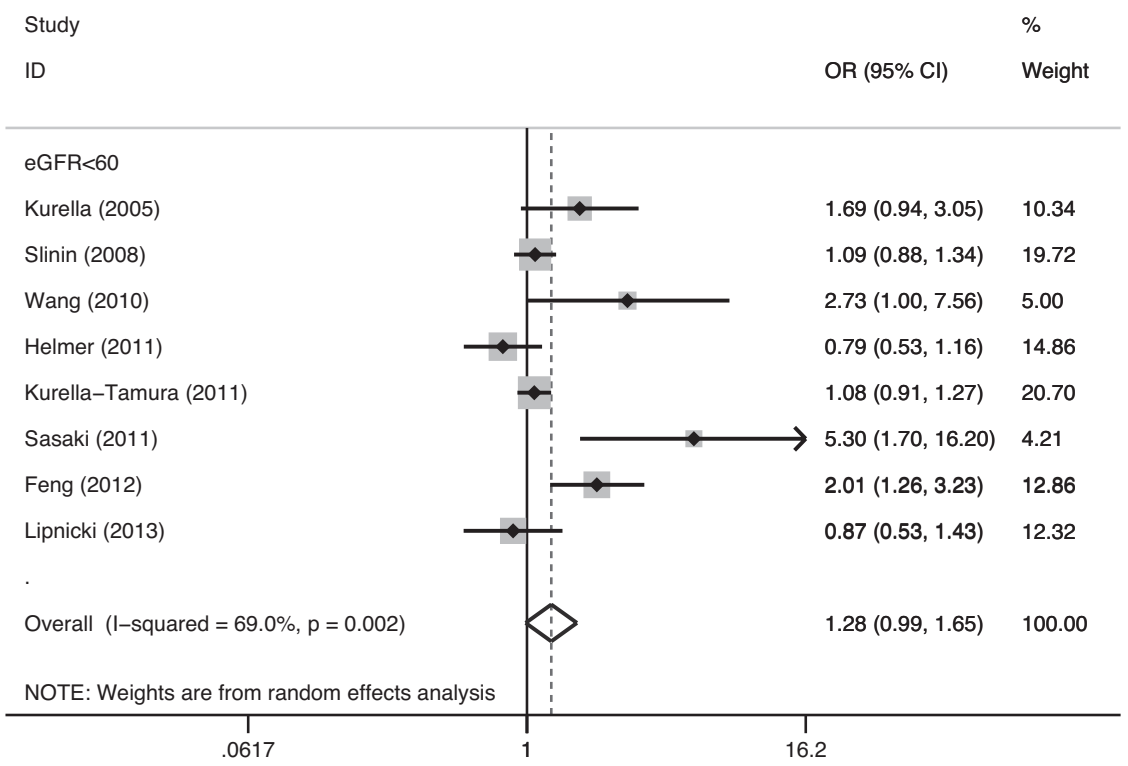

Figure 2. Forest plot of population-based prospective studies assessing the relation between eGFR $<60 \mathrm{~mL} / \mathrm{min} / 1.73 \mathrm{~m}^{2}$ and cognitive impairment or dementia (fully-adjusted estimates)

\section{Albuminuria}

Seven studies reported on albuminuria, of which four found a faster rate of cognitive decline, ${ }^{33,36,38,47}$ one study found an increased risk of cognitive impairment, ${ }^{42}$ and three studies showed mixed results for incident dementia. ${ }^{35,45,47}$

In the meta-analysis, five studies, representing 27,805 persons, could be included. ${ }^{33,35,42,45,47}$ Based on the fully-adjusted estimates, albuminuria was associated with a $35 \%$ increased risk of cognitive impairment or dementia ( $p=0.015$; see Figure 3 ). There was mild to moderate heterogeneity $\left(I^{2}=38.2 \%\right)$. There were no signs of publication bias based on visual inspection of the funnel plot (see Figure 2 of Appendix 3) and the Egger's test ( $p$ $=0.274$ ). Four of these studies reported unadjusted estimates (see Figure 4 of Appendix 5). Heterogeneity in outcomes across studies was reduced for adjusted estimates in comparison with unadjusted estimates $\left(\mathrm{I}^{2}=38.2 \%\right.$ versus $\mathrm{I}^{2}=74.8 \%$, respectively). 
Study

ID
$\%$

OR $(95 \% \mathrm{Cl}) \quad$ Weight

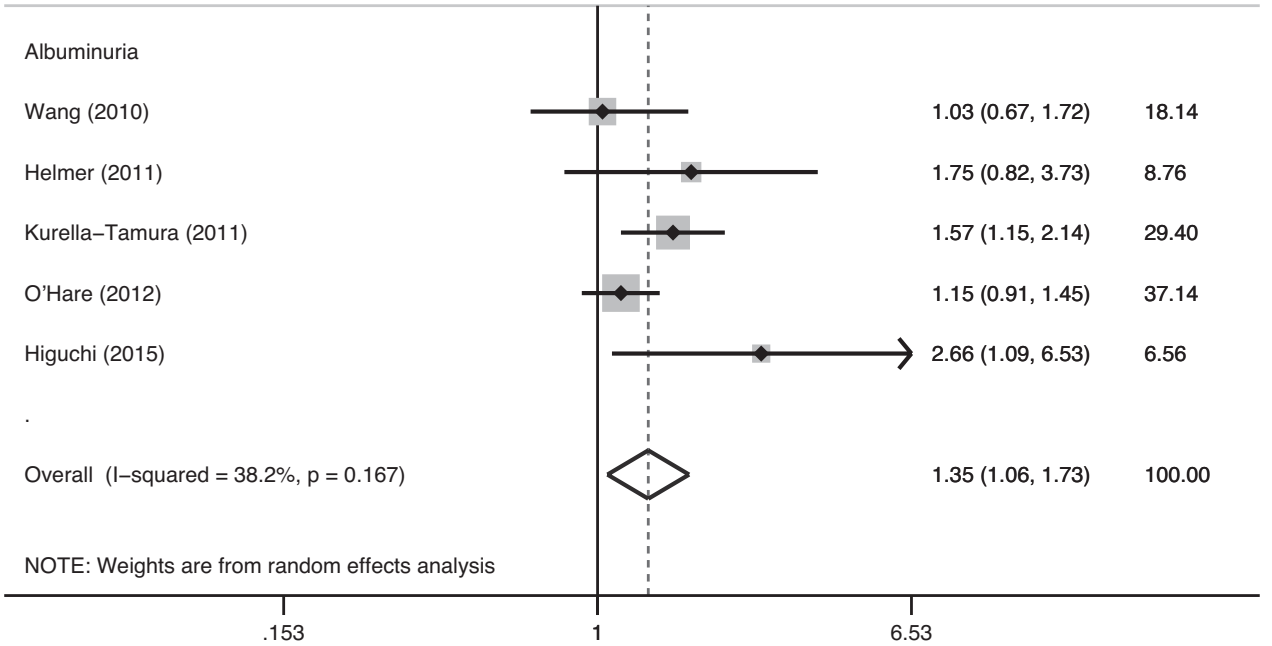

Figure 3. Forest plot of population-based prospective studies assessing the relation between albuminuria and cognitive impairment or dementia (fully-adjusted estimates)

\section{Creatinine}

Five studies reported on $\mathrm{SCr}$, of which two found an increased risk of cognitive impairment, ${ }^{40,41}$ one found an increased risk of dementia, ${ }^{48}$ one study found a faster rate of cognitive decline, ${ }^{32}$ and one study found that an increase in $\mathrm{SCr}$ was associated with more rapid cognitive decline. ${ }^{39}$ No meta-analysis could be conducted for this association due to different methods of exposure and outcome formulations across studies.

\section{Creatinine clearance}

Three studies investigated the association between $\mathrm{CCl}$ and cognitive decline or cognitive impairment. The Northern Manhattan Study in 2,172 community-dwelling participants found that persons with a baseline $\mathrm{CCl}<60 \mathrm{ml} / \mathrm{min}$ showed significantly more decline compared with individuals with a $\mathrm{CCl}>90 \mathrm{ml} / \mathrm{min}$ over the 2.9 years of follow-up. ${ }^{32}$ The Health $A B C$ Study in 2,406 elderly individuals found a significant association between $\mathrm{CCl}$ (45-59 and $<45 \mathrm{ml} / \mathrm{min}$ per $1.73 \mathrm{~m}^{2}$ ) and cognitive impairment. ${ }^{40}$ The INVADE study demonstrated a significant association between $\mathrm{CCl}<45 \mathrm{ml} / \mathrm{min}$ per $1.73 \mathrm{~m}^{2}$ and cognitive 
impairment after 2 years of follow-up. ${ }^{41}$ No meta-analysis could be conducted because of differences in exposure and outcome definitions between studies.

\section{Cystatin C}

Three studies focused on cystatin $C$ and cognitive impairment or dementia. The Health $A B C$ Study found an increased risk of cognitive impairment among 3,030 older adults if they had high levels of cystatin C. ${ }^{49}$ In contrast, in men aged 70 and 77 years from the Uppsala Longitudinal Study of Adult Men high levels of serum cystatin C were associated with a decreased risk of AD.50 The Study of Osteoporotic Fractures in 1,332 elderly women found a U-shape association between cystatin $C$ and cognitive impairment, but after adjustment for covariates these associations were no longer significant. ${ }^{44}$ No valid metaanalysis could be conducted due to different methods of exposure (e.g. cut-offs, tertiles, quartiles) and outcome formulations across studies. 


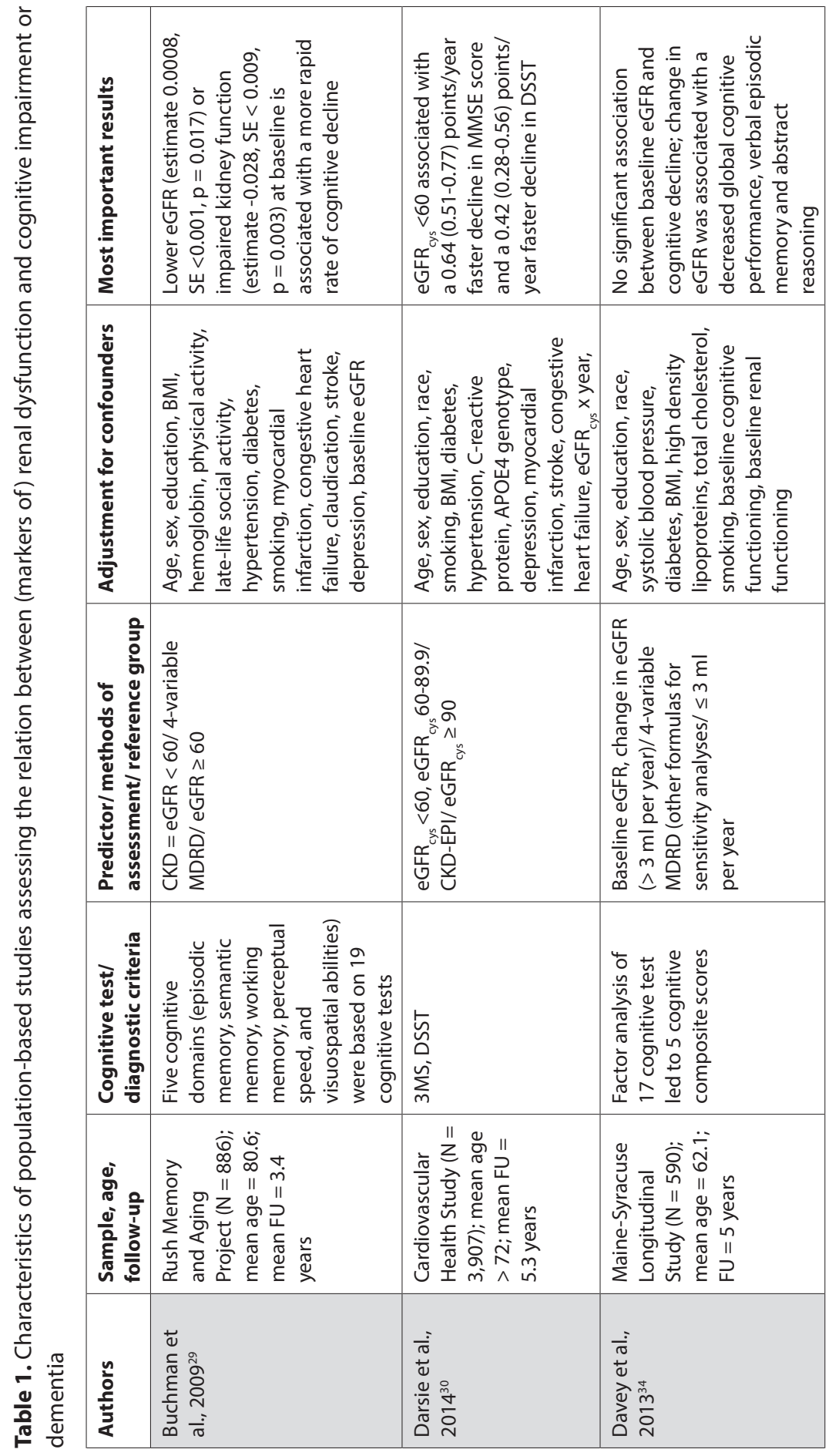




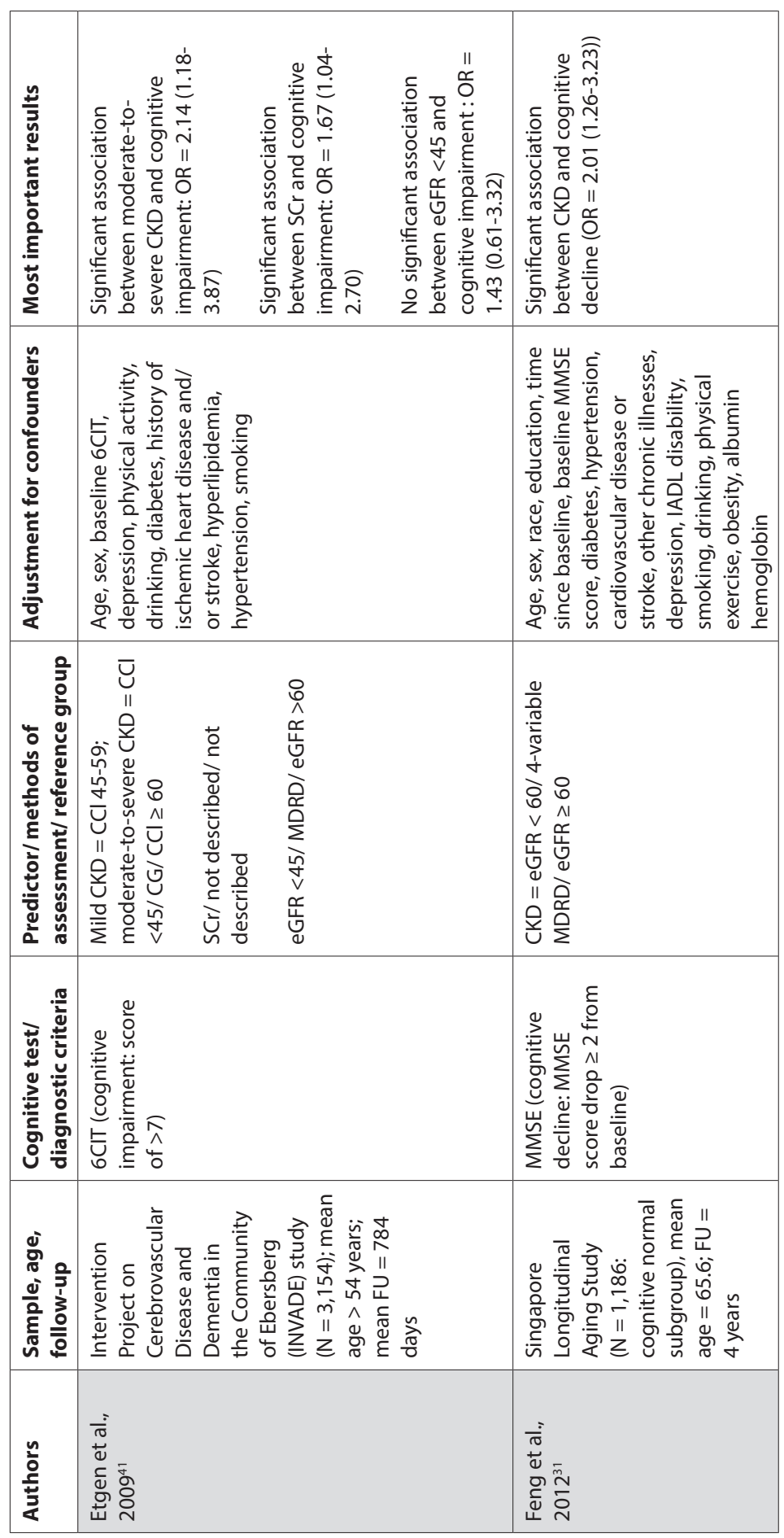




\begin{tabular}{|c|c|c|c|c|}
\hline 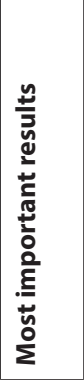 & 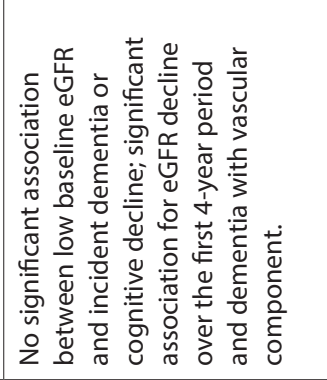 & 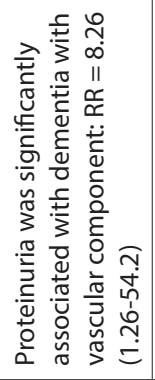 & 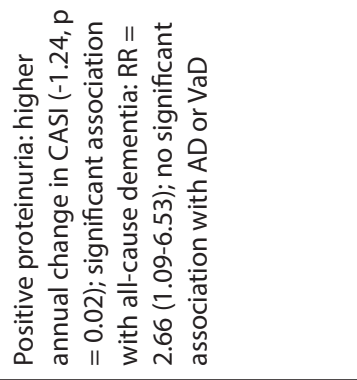 & 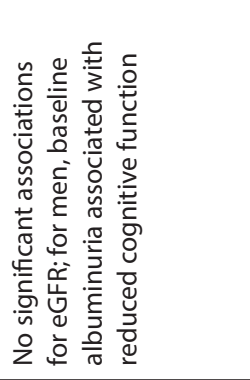 \\
\hline 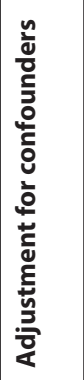 & 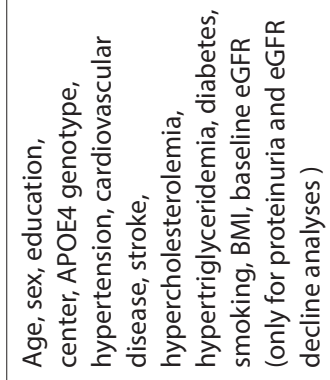 & & 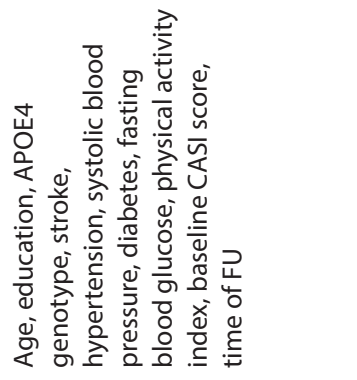 & 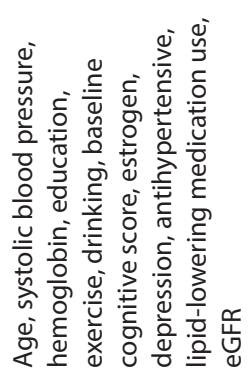 \\
\hline 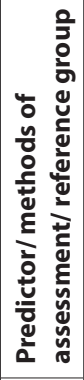 & 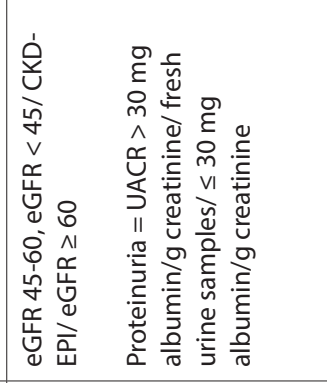 & & 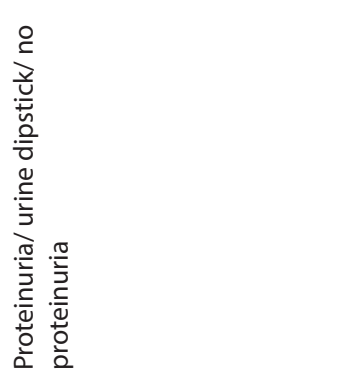 & 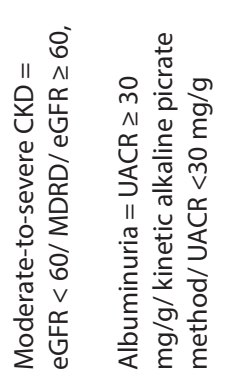 \\
\hline 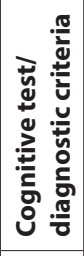 & 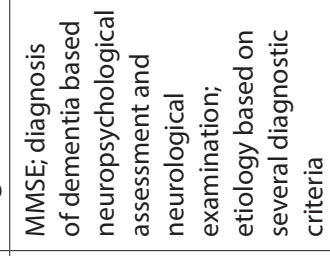 & & 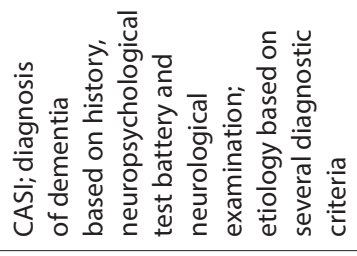 & 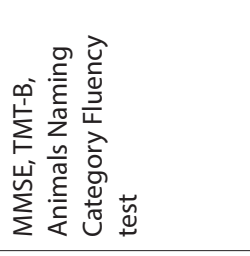 \\
\hline 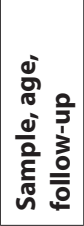 & 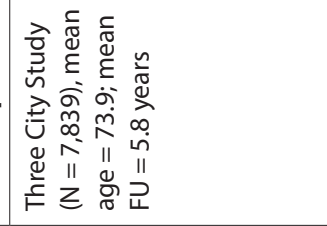 & & 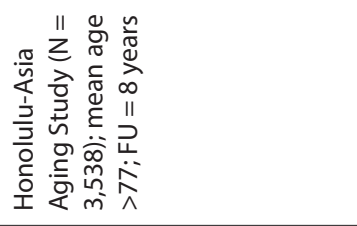 & 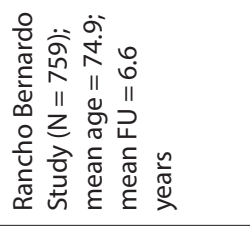 \\
\hline 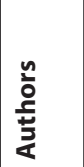 & 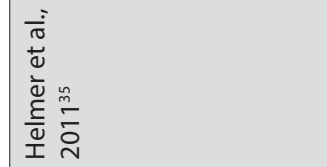 & & 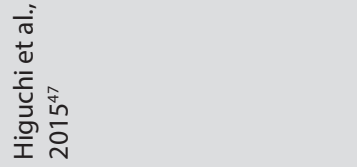 & 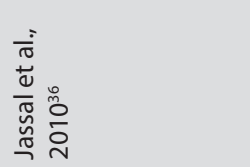 \\
\hline
\end{tabular}




\begin{tabular}{|c|c|c|c|c|c|c|}
\hline 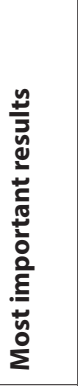 & 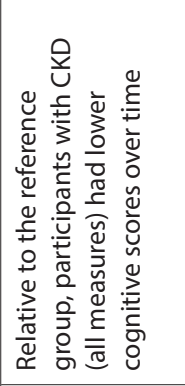 & & 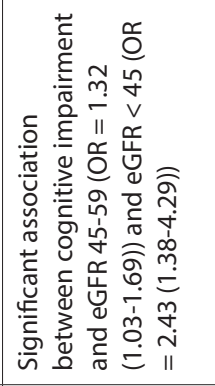 & 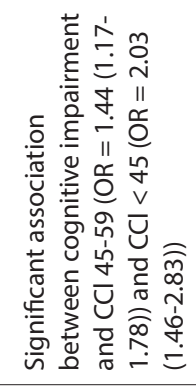 & 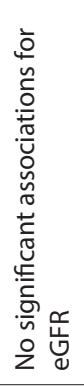 & 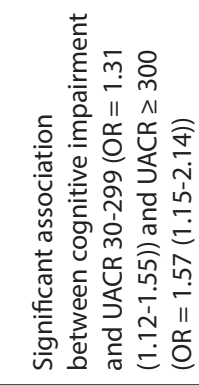 \\
\hline 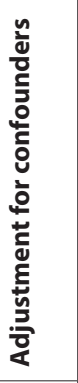 & \multicolumn{2}{|l|}{ 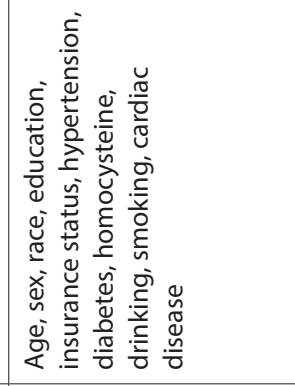 } & \multicolumn{2}{|l|}{ 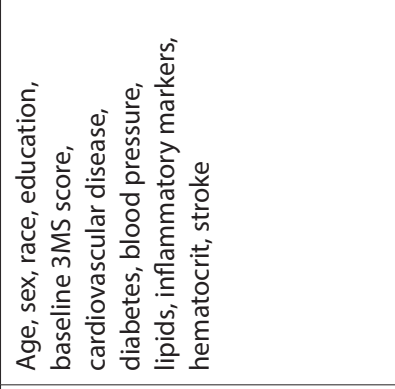 } & \multicolumn{2}{|c|}{ 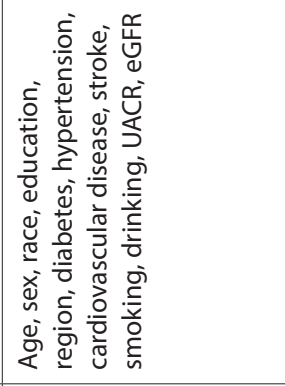 } \\
\hline 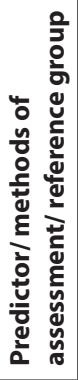 & 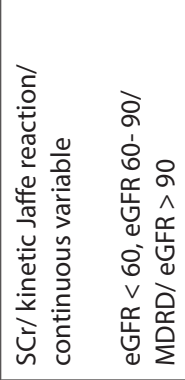 & 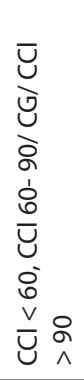 & 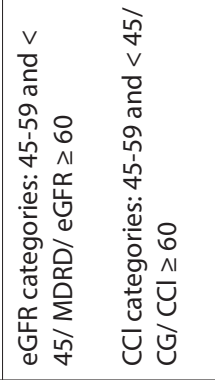 & 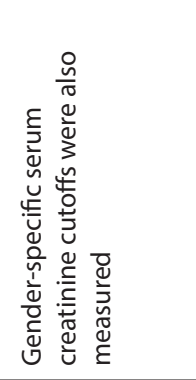 & 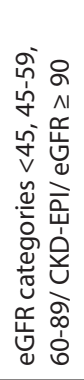 & 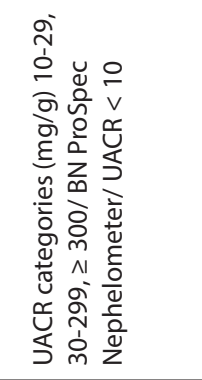 \\
\hline 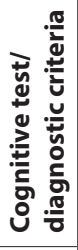 & 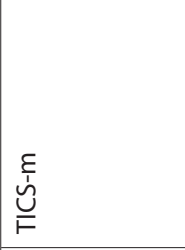 & & 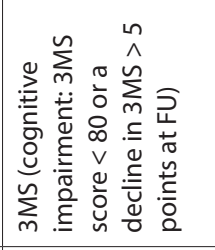 & & 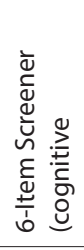 & $\begin{array}{l}\mathrm{q} \\
\mathrm{vI}\end{array}$ \\
\hline 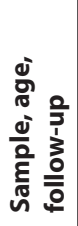 & 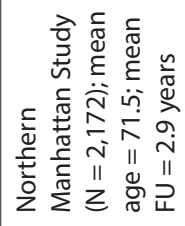 & & 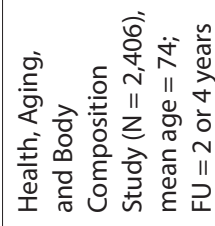 & & 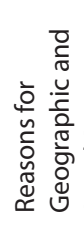 & 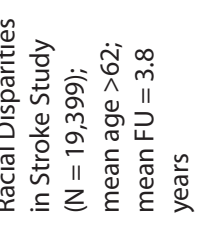 \\
\hline 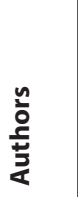 & 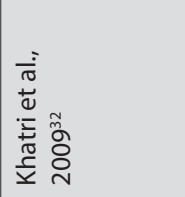 & & 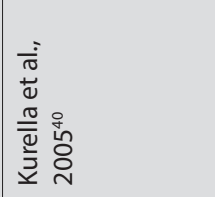 & & 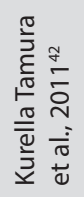 & \\
\hline
\end{tabular}




\begin{tabular}{|c|c|c|c|c|c|}
\hline 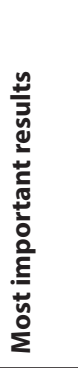 & 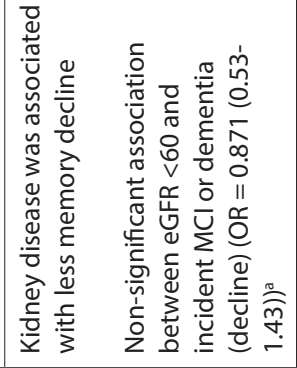 & \multicolumn{2}{|c|}{ 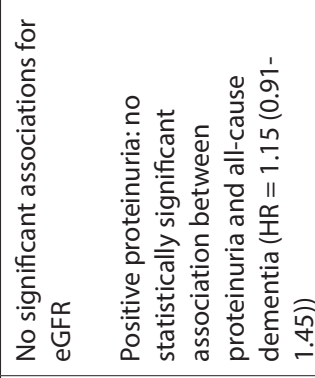 } & 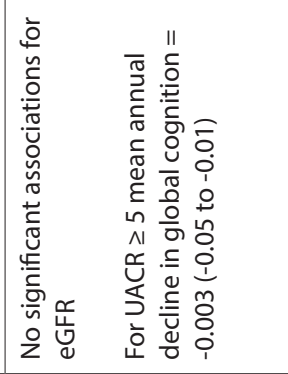 & 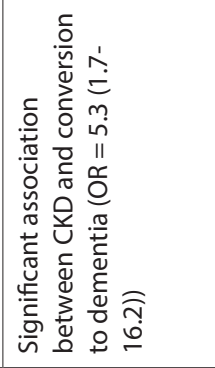 \\
\hline 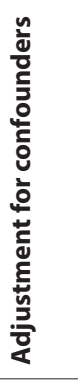 & 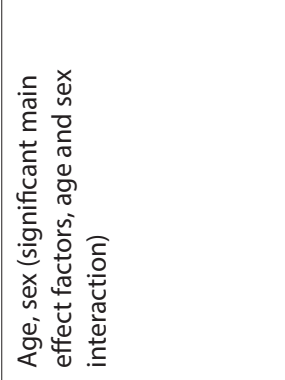 & \multicolumn{2}{|c|}{ 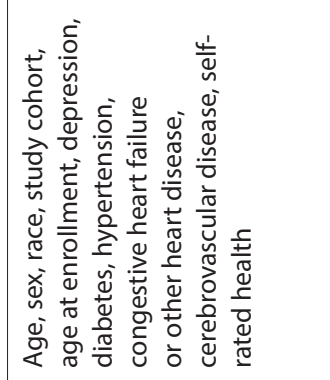 } & 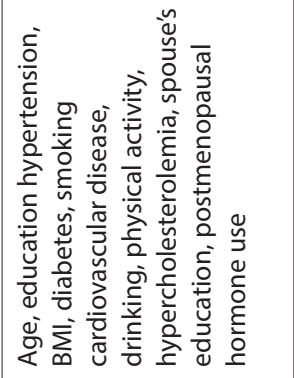 & 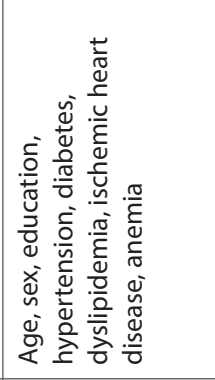 \\
\hline 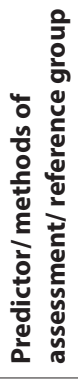 & 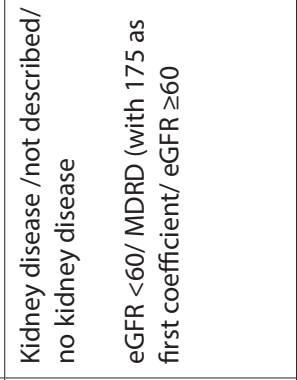 & 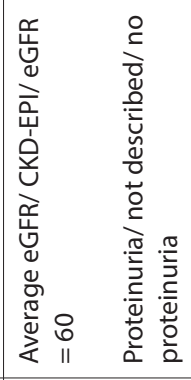 & 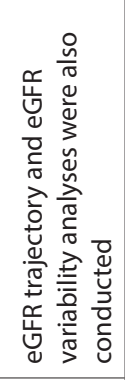 & 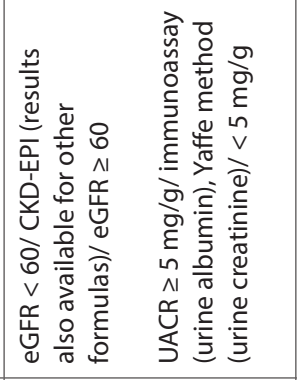 & 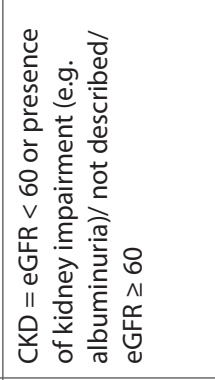 \\
\hline 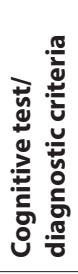 & 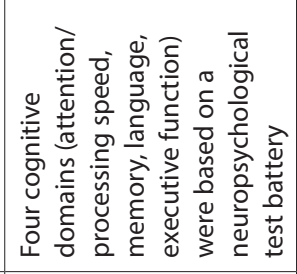 & 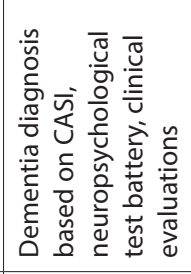 & & 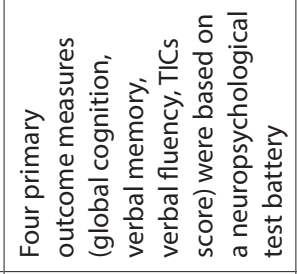 & 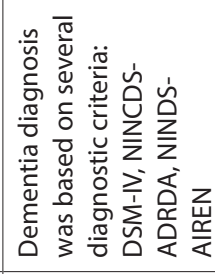 \\
\hline 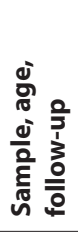 & 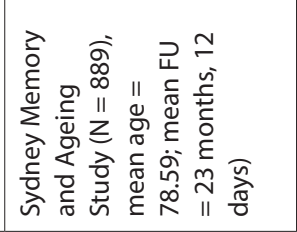 & 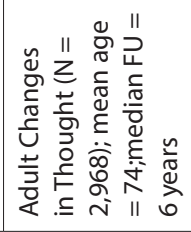 & & 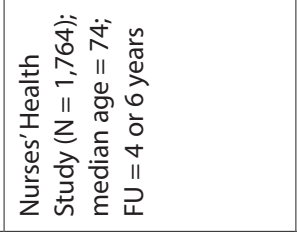 & 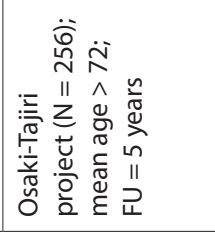 \\
\hline $\begin{array}{l}\frac{n}{2} \\
\frac{2}{2} \\
\frac{5}{2}\end{array}$ & 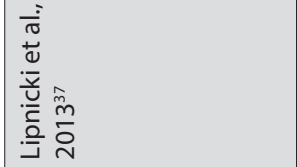 & 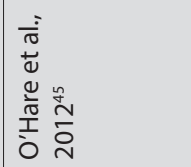 & & 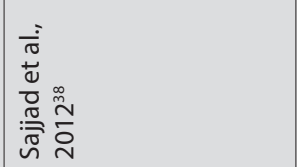 & 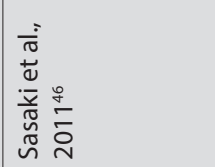 \\
\hline
\end{tabular}




\begin{tabular}{|c|c|c|c|}
\hline 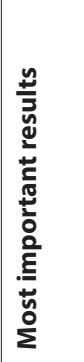 & 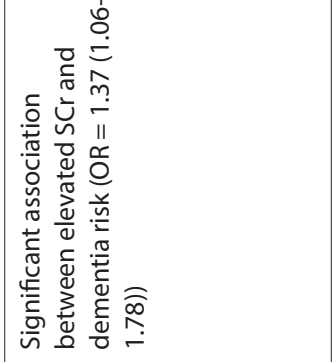 & 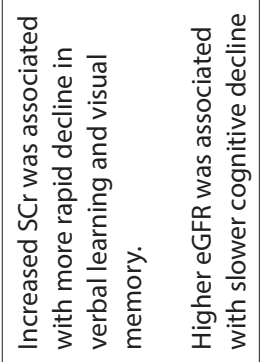 & 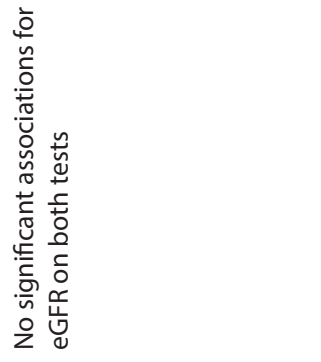 \\
\hline 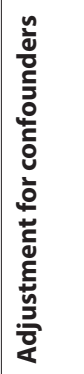 & 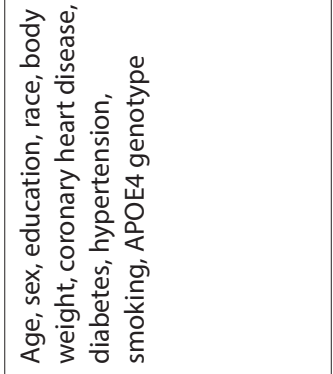 & 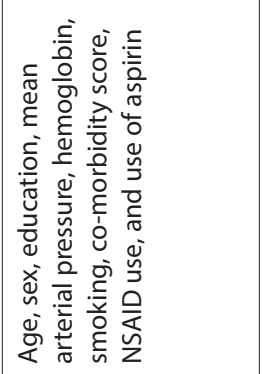 & 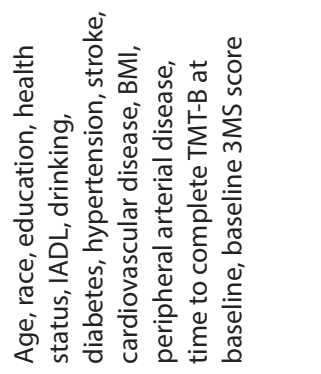 \\
\hline 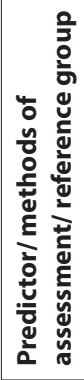 & 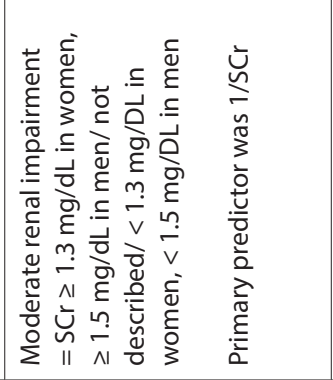 & 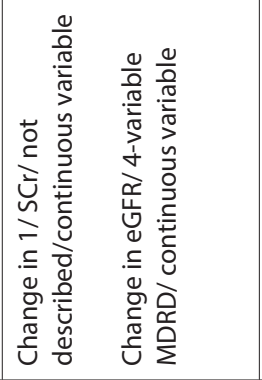 & 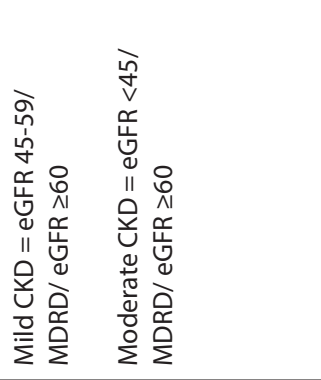 \\
\hline 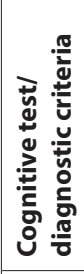 & 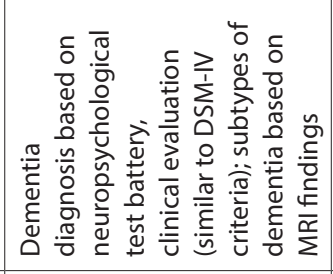 & 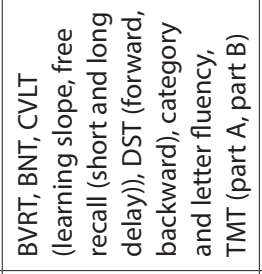 & 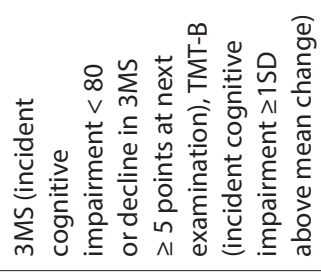 \\
\hline 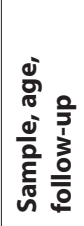 & 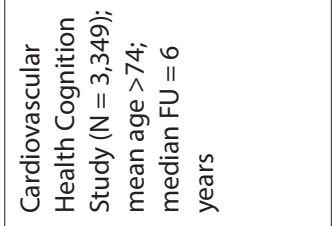 & 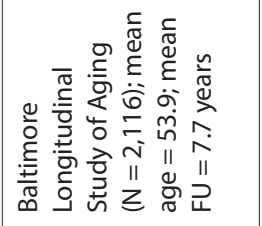 & 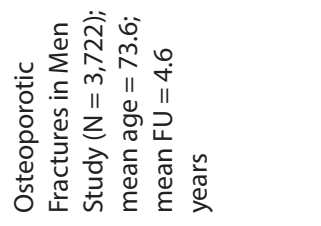 \\
\hline 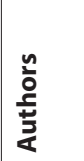 & 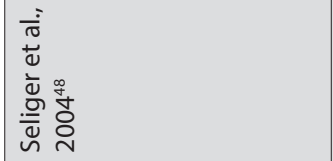 & 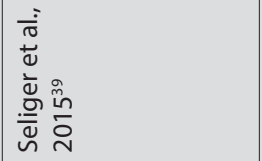 & 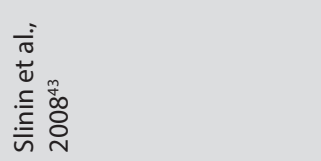 \\
\hline
\end{tabular}




\begin{tabular}{|c|c|c|c|c|c|c|}
\hline \multirow{2}{*}{ 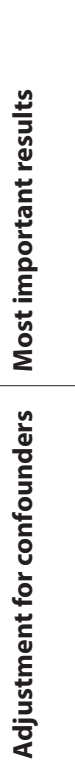 } & \multicolumn{3}{|c|}{ 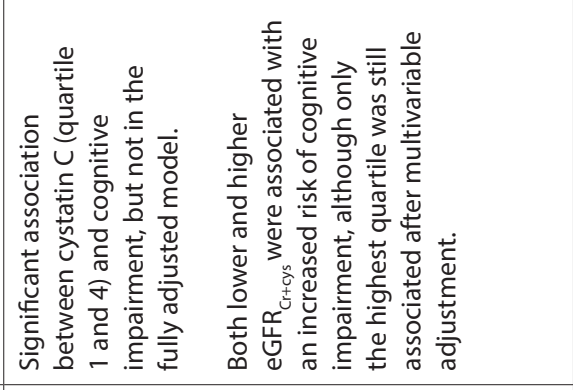 } & 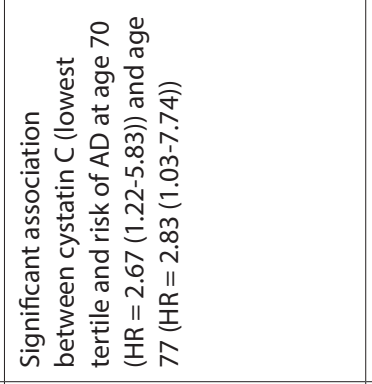 & \multicolumn{2}{|c|}{ 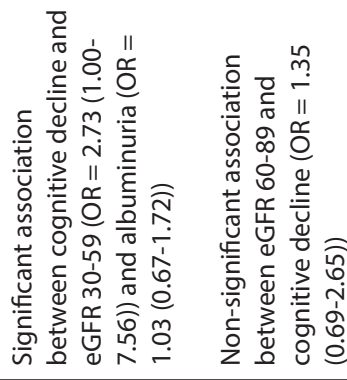 } \\
\hline & 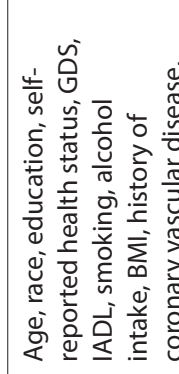 & 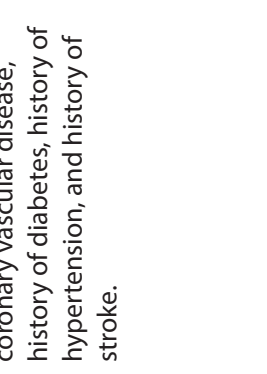 & & 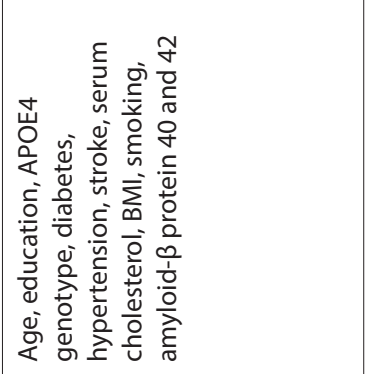 & 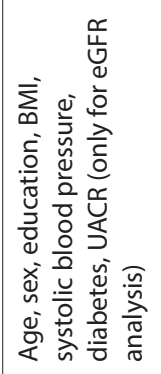 & \\
\hline 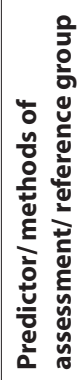 & 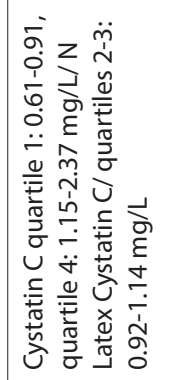 & 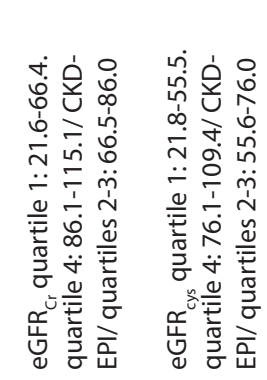 & 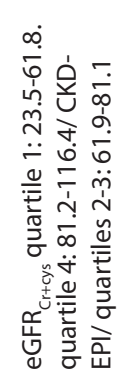 & 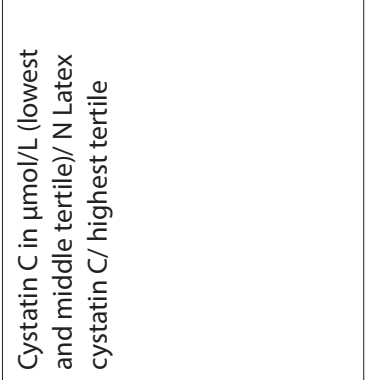 & 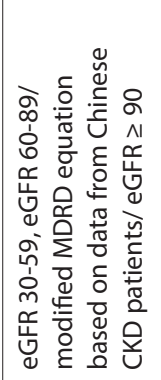 & 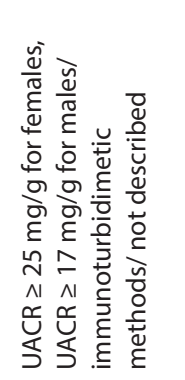 \\
\hline 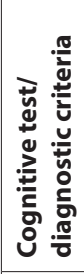 & 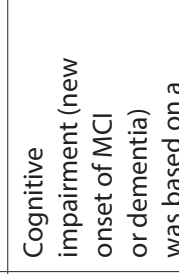 & 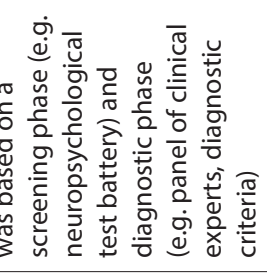 & & 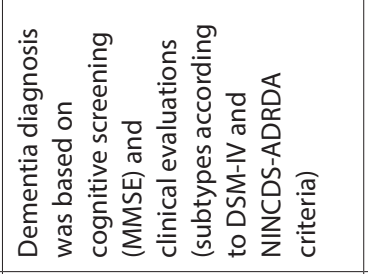 & 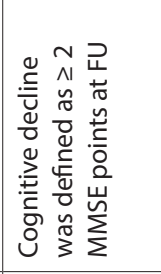 & \\
\hline 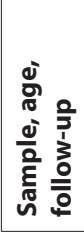 & 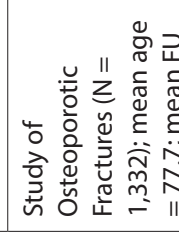 & 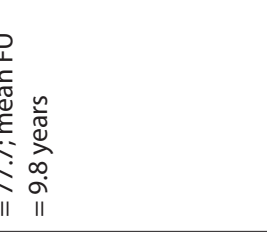 & & 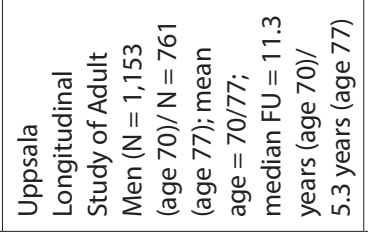 & 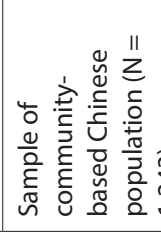 & \\
\hline 崩 & 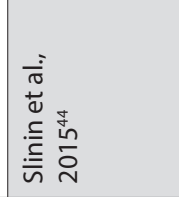 & & & 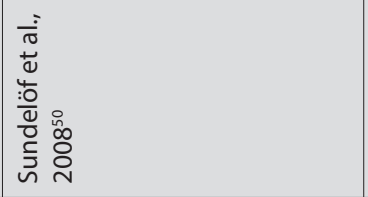 & 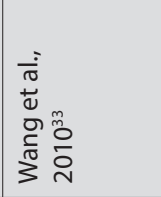 & \\
\hline
\end{tabular}




\begin{tabular}{|c|c|c|c|}
\hline 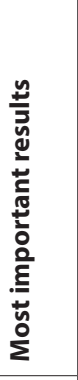 & 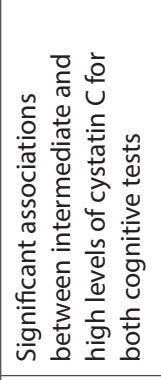 & 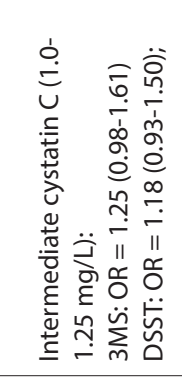 & 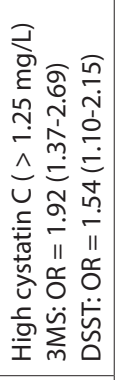 \\
\hline 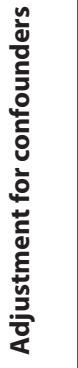 & 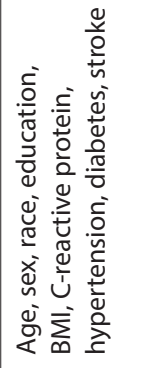 & & \\
\hline 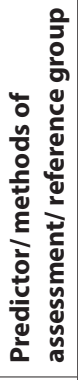 & 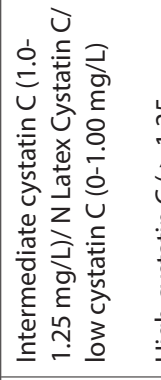 & 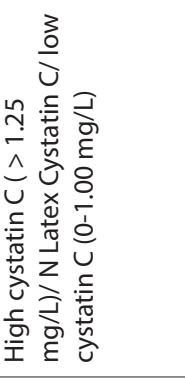 & \\
\hline 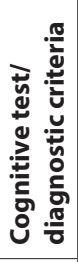 & 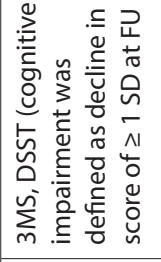 & & \\
\hline 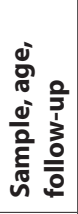 & 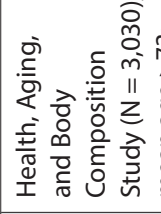 & 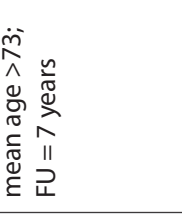 & \\
\hline 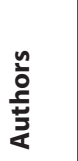 & 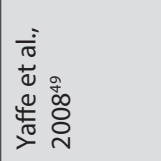 & & \\
\hline
\end{tabular}




\section{DISCUSSION}

This systematic review and meta-analysis suggested that individuals with albuminuria have, on average, a $35 \%$ increased risk of cognitive impairment or dementia. Separate meta-analyses for different levels of eGFR yielded non-significant results, possibly due to substantial heterogeneity among studies. The literature on eGFR is mixed in general, with studies showing a positive or no association between low levels of eGFR with cognitive decline or dementia risk. For $\mathrm{SCr}$, tentative evidence suggests an association between elevated $\mathrm{SCr}$ levels with faster cognitive decline and higher risk for dementia, but too few high-quality studies exist for meta-analysis. In contrast, the review on cystatin $\mathrm{C}$ yielded only three studies with different methodology and contradictory results.

The substantial heterogeneity observed in the meta-analyses of eGFR might be due to several methodological issues such as (1) the difference in formulas used to measure kidney function (e.g. Modification of Diet in Renal Disease formula (MDRD), Chronic Kidney Disease Epidemiology Collaboration equation (CKD-EPI)); (2) the variation in study population (e.g. gender specific, age-range, concurrent medication); (3) the inclusion of possible confounders (e.g. including a few (sociocultural demographics) or the choice of covariates (exercise, depression, genotype); and (4) the assessment of cognitive functioning (e.g. generic screening (MMSE), multi-domain test battery, dementia diagnosis).,2,

The exact mechanisms relating renal dysfunction to dementia are not fully understood, but may include shared risk factors of which some are better documented than others. ${ }^{9}$ Traditional risk factors include cardiovascular disease (e.g. myocardial infarction, atrial fibrillation), stroke, type-2 diabetes mellitus, isolated systolic hypertension, age, smoking and hypercholesterolemia. ${ }^{9,51}$ Other factors include anemia, albumin, and hyperhomocysteinemia, whereas inflammation, oxidative stress, cerebral small vessel disease, silent brain infarcts, microbleeds, and white matter lesions are possible underlying mechanisms leading to cognitive impairment or dementia., ${ }^{2,9}$ It seems not surprising that the prevalence of the abovementioned risk factors is higher in CKD patients than in the general population. ${ }^{23,36-8}$ On the other hand, CKD also appears to be a risk factor for cardiovascular or cerebrovascular diseases. For instance, persons with renal insufficiency have an increased risk of stroke or carotid atherosclerosis. ${ }^{52,53}$ In addition, a recent magnetic resonance imaging study found that renal dysfunction was associated with poor cognitive performance and volume deficits in the brain's white matter. ${ }^{7} \mathrm{~A}$ recent longitudinal study in 600 patients with vascular risk factors found that CKD related to all-cause dementia independent from vascular risk factors and baseline cerebral small 
vessel disease. ${ }^{54}$ These findings suggest that vascular damage is not the only possible explanation of the association.

Unfortunately, we were not able to pool enough studies that reported on cystatin C. A growing body of evidence demonstrated the involvement of cystatin $C$ in neuroprotective processes in the brain, including its colocalization with amyloid- $\beta(A \beta)$ in parenchymal and vascular amyloid deposits, and the inhibition of $A \beta$ aggregation and deposition by binding to the amyloid precursor protein or the $A \beta 40$ and $A \beta 42$ peptides. ${ }^{55}$ In addition, the Icelandic form of the hereditary cystatin $C$ amyloid angiopathy is caused by a mutation in the cystatin $C$ gene and is characterized by low levels of serum and cerebral spinal fluid (CSF) cystatin C, intracerebral hemorrhages, stroke, dementia and death before the age of 40 years. ${ }^{56}$ The study of Yaffe et al. found that individuals with high levels of serum cystatin $C$ had a $92 \%$ increased risk of developing cognitive impairment over 7 years of followup. $^{49}$ This is in line with results from the Cardiovascular Health Study Cognition Study, which found that high serum levels of cystatin $C$ were associated with poorer cognitive performance six years later, greater prevalence of brain infarcts, more white matter lesions and lower grey matter volume. However, this study only measured cognition at a single time point. ${ }^{57}$

In contrast, the study of Sundelöf et al. indicated that lower serum levels of cystatin $C$ were associated with increased odds of $A D .{ }^{50} \mathrm{~A}$ recent study demonstrated the presence of low CSF levels of cystatin $C$ in patients with $A D$ in comparison with healthy controls..$^{58}$ Although serum levels of cystatin $C$ are presumably more related to renal dysfunction and CSF levels of cystatin C more to AD pathology, it is difficult to establish a one-to-one relationship due to intercorrelations.

On the other hand, it is also possible that a direct neuronal toxicity of the uremic state is involved. ${ }^{9}$ Concentrations of uremic toxins in brain areas related to cognition (e.g. thalamus, cerebral cortex) are about ten times higher in CKD patient than in healthy subjects. ${ }^{59}$ The aforementioned association with cystatin $C$ might also support the idea of a direct neural toxic effect. ${ }^{60}$ Yet, it is important to note that the pathways linking CKD and dementia are not mutually exclusive but might work additive or even synergistically. Clearly, more studies into plausible underlying pathways are needed.

The present results for various eGFR levels differ substantially from the findings of a previous meta-analysis by Etgen et al. ${ }^{16}$ This inconsistency in findings can be explained by the fact that we only included the most rigorously adjusted model for each study in our analysis of fully-adjusted estimates, while some of the risk estimates reported by Etgen and colleagues were based on crude data, 35,41 including the large study by Helmer et al., which found almost a significant protective effect of eGFR. 
Our study has a number of strengths. By using large population-based studies with prospective designs including long follow-up periods and adjustment for a large number of known confounders, our study adds to the growing evidence that renal dysfunction is an independent risk factor for cognitive impairment or dementia. A number of limitations in this study must also be mentioned. First, most of the included studies used different methods for estimating renal function (e.g. formulas, equations or gender specific cutoffs), probably increasing heterogeneity among studies. In addition, most studies assessed kidney function only once, usually at study entry. Yet, renal function is complex and dynamic (e.g. day-to-day variability) and cannot be fully captured at one point in time, potentially leading to exposure misclassification. Since such misclassification is likely non-differential (i.e. independent from dementia outcome), this might have diluted stronger associations in the population. Future studies should use multiple baselines. In addition, it would be informative to study longitudinal changes in renal functioning in relation to changes in cognitive performance to learn how trajectories correlate over time. Unfortunately, we could identify only three prospective studies that reported on longitudinal measures of renal function, but due to the differences in applied methodology (e.g. annual eGFR decline, change in logged eGFR) we were unable to pool these results. ${ }^{34,35,39}$ Second, studies adjusted for different sets of possible confounders (all adjusted minimally for age, gender and education). For instance, some studies reporting on non-eGFR markers adjusted for eGFR levels while others did not. However, adjusting for eGFR levels had virtually no effect on risk estimates within individual studies. Third, we were unable to include six studies (30\% of the total included studies) that incorporated markers of renal function as continuous variables in the meta-analyses because of the differences in scaling exposure (e.g. per $0.1 \mathrm{mg} / \mathrm{dL}$ increase, decrease of one standard deviation), and outcomes (e.g. beta-coefficients, change per unit increase), next to diversity in cognitive domains tested (e.g. MMSE, Trail-Making Test B). Fourth, various measures were used across studies to operationalize the dichotomous cognitive impairment or dementia outcomes (e.g. MMSE cut-offs, diagnostic criteria). Fifth, although we used fully-adjusted models it is possible that the association is influenced by residual confounding. Sixth, we did not contact authors to conduct additional analyses (e.g. to provide results for specific cut-offs of markers of renal dysfunction not provided in the original manuscript). While this could have increased the number of studies for pooling of data, using only reported estimates increases transparency. Finally, both renal function and cognition may decline with age, making it very hard to separate the effects of aging from a direct effect of renal function on cognition. 
In sum, albuminuria was associated with a modestly increased risk of cognitive impairment or dementia. Results for different levels of eGFR were non-significant, probably due to heterogeneity across studies. More research is needed to examine whether the association with albuminuria is causal or due to shared mechanisms, and to establish the underlying pathophysiology. 


\section{REFERENCES}

1. Deckers K, van Boxtel MP, Schiepers OJ, et al. Target risk factors for dementia prevention: a systematic review and Delphi consensus study on the evidence from observational studies. Int J Geriatr Psychiatry 2015; 30(3): 234-46.

2. Madero M, Gul A, Sarnak MJ. Cognitive function in chronic kidney disease. Semin Dial 2008; 21(1): 29-37.

3. Murray AM. Cognitive impairment in the aging dialysis and chronic kidney disease populations: an occult burden. Adv Chronic Kidney Dis 2008; 15(2): 123-32.

4. Mogi M, Horiuchi M. Clinical Interaction between Brain and Kidney in Small Vessel Disease. Cardiol Res Pract 2011; 2011: 306189.

5. Barnes DE, Yaffe K. The projected effect of risk factor reduction on Alzheimer's disease prevalence. Lancet Neurol 2011; 10(9): 819-28.

6. Ikram MA, Vernooij MW, Hofman A, Niessen WJ, van der Lugt A, Breteler MM. Kidney function is related to cerebral small vessel disease. Stroke 2008; 39(1): 55-61.

7. Rajagopalan $\mathrm{P}$, Refsum $\mathrm{H}$, Hua X, et al. Mapping creatinine- and cystatin C-related white matter brain deficits in the elderly. Neurobiol Aging 2013; 34(4): 1221-30.

8. Seliger SL, Sarnak MJ. Subclinical vascular disease of the brain in dialysis patients. Am J Kidney Dis 2007; 50(1): 8-10.

9. Bugnicourt JM, Godefroy O, Chillon JM, Choukroun G, Massy ZA. Cognitive disorders and dementia in CKD: the neglected kidney-brain axis. J Am Soc Nephrol 2013; 24(3): 353-63.

10. Ferri CP, Prince $M$, Brayne $C$, et al. Global prevalence of dementia: a Delphi consensus study. The Lancet 2005; 366(9503): 2112-7.

11. Norton S, Matthews FE, Barnes DE, Yaffe K, Brayne C. Potential for primary prevention of Alzheimer's disease: an analysis of population-based data. Lancet Neuro/ 2014; 13(8): 788-94.

12. Plassman BL, Williams JW, Jr., Burke JR, Holsinger T, Benjamin S. Systematic review: factors associated with risk for and possible prevention of cognitive decline in later life. Ann Intern Med 2010; 153(3): 182-93.

13. Jha V, Garcia-Garcia G, Iseki K, et al. Chronic kidney disease: global dimension and perspectives. Lancet 2013; 382(9888): 260-72.

14. World Health Organization. Dementia: a public health priority. Geneva: WHO, 2012.

15. Tonelli M, Riella M. Chronic kidney disease and the ageing population. Lancet 2014; 383(9925): 1278-9.

16. Etgen $\mathrm{T}$, Chonchol M, Forstl H, Sander D. Chronic kidney disease and cognitive impairment: a systematic review and meta-analysis. Am J Nephrol 2012; 35(5): 474-82.

17. Traynor J, Mactier R, Geddes CC, Fox JG. How to measure renal function in clinical practice. $B M J$ 2006; 333(7571): 733-7.

18. Wells G, Shea B, O'connell D, et al. The Newcastle-Ottawa Scale (NOS) for assessing the quality of nonrandomised studies in meta-analyses. 2000.

19. O'Riordan P, Stevens PE, Lamb EJ. Estimated glomerular filtration rate. BMJ 2014; 348: g264.

20. Levey AS, Stevens LA, Schmid CH, et al. A new equation to estimate glomerular filtration rate. Ann Intern Med 2009; 150(9): 604-12.

21. Browne OT, Bhandari S. Interpreting and investigating proteinuria. BMJ 2012; 344.

22. Barzilay Jl, Gao P, O'Donnell M, et al. Albuminuria and decline in cognitive function: The ONTARGET/TRANSCEND studies. Arch Intern Med 2011; 171(2): 142-50. 
23. Chavan VU, Sayyed AK, Durgawale PP, Sontakke AV, Nilakhe SD. Practical Aspects of Calculation, Expression and Interpretation Of Urine Albumin Measurement. NJIRM 2011; 2(1): 29-34.

24. Keane WF, Eknoyan G. Proteinuria, albuminuria, risk, assessment, detection, elimination (PARADE): a position paper of the National Kidney Foundation. Am J Kidney Dis 1999; 33(5): 1004-10.

25. Mussap M, Plebani M. Biochemistry and clinical role of human cystatin C. Crit Rev Clin Lab Sci 2004; 41(5-6): 467-550.

26. American Psychiatric Association. Diagnostic and statistical manual of mental disorders (4th edition). Washington, DC: American Psychiatric Association; 1994.

27. McKhann G, Drachman D, Folstein M, Katzman R, Price D, Stadlan EM. Clinical diagnosis of Alzheimer's disease: report of the NINCDS-ADRDA Work Group under the auspices of Department of Health and Human Services Task Force on Alzheimer's Disease. Neurology 1984; 34(7): 939-44.

28. Román GC, Tatemichi TK, Erkinjuntti T, et al. Vascular dementia: Diagnostic criteria for research studies: Report of the NINDS-AIREN International Workshop*. Neurology 1993; 43(2): 250.

29. Buchman AS, Tanne D, Boyle PA, Shah RC, Leurgans SE, Bennett DA. Kidney function is associated with the rate of cognitive decline in the elderly. Neurology 2009; 73(12): 920-7.

30. Darsie B, Shlipak MG, Sarnak MJ, Katz R, Fitzpatrick AL, Odden MC. Kidney function and cognitive health in older adults: the Cardiovascular Health Study. Am J Epidemiol 2014; 180(1): 68-75.

31. Feng $L$, Yap KB, Yeoh LY, Ng TP. Kidney function and cognitive and functional decline in elderly adults: findings from the Singapore longitudinal aging study. J Am Geriatr Soc 2012; 60(7): 1208-14.

32. Khatri M, Nickolas T, Moon YP, et al. CKD associates with cognitive decline. J Am Soc Nephrol 2009; 20(11): 2427-32.

33. Wang F, Zhang L, Liu L, Wang $\mathrm{H}$. Level of kidney function correlates with cognitive decline. Am J Nephrol 2010; 32(2): 117-21.

34. Davey A, Elias MF, Robbins MA, Seliger SL, Dore GA. Decline in renal functioning is associated with longitudinal decline in global cognitive functioning, abstract reasoning and verbal memory. Nephrol Dial Transplant 2013; 28(7): 1810-9.

35. Helmer C, Stengel B, Metzger M, et al. Chronic kidney disease, cognitive decline, and incident dementia: the 3C Study. Neurology 2011; 77(23): 2043-51.

36. Jassal SK, Kritz-Silverstein D, Barrett-Connor E. A prospective study of albuminuria and cognitive function in older adults: the Rancho Bernardo study. Am J Epidemiol 2010; 171(3): 277-86.

37. Lipnicki DM, Sachdev PS, Crawford J, et al. Risk factors for late-life cognitive decline and variation with age and sex in the Sydney Memory and Ageing Study. PLoS One 2013; 8(6): e65841.

38. Sajjad I, Grodstein F, Kang JH, Curhan GC, Lin J. Kidney dysfunction and cognitive decline in women. Clin J Am Soc Nephrol 2012; 7(3): 437-43.

39. Seliger SL, Wendell CR, Waldstein SR, Ferrucci L, Zonderman AB. Renal function and long-term decline in cognitive function: the Baltimore Longitudinal Study of Aging. Am J Nephrol 2015; 41(4-5): 305-12.

40. Kurella M, Chertow GM, Fried LF, et al. Chronic kidney disease and cognitive impairment in the elderly: the health, aging, and body composition study. J Am Soc Nephrol 2005; 16(7): 2127-33. 
41. Etgen T, Sander D, Chonchol M, et al. Chronic kidney disease is associated with incident cognitive impairment in the elderly: the INVADE study. Nephrol Dial Transplant 2009; 24(10): 3144-50.

42. Kurella Tamura $M$, Muntner $P$, Wadley $V$, et al. Albuminuria, kidney function, and the incidence of cognitive impairment among adults in the United States. Am J Kidney Dis 2011; 58(5): 756-63.

43. Slinin $Y$, Paudel ML, Ishani A, et al. Kidney function and cognitive performance and decline in older men. J Am Geriatr Soc 2008; 56(11): 2082-8.

44. Slinin $Y$, Peters KW, Ishani $A$, et al. Cystatin $C$ and cognitive impairment 10 years later in older women. J Gerontol A Biol Sci Med Sci 2015; 70(6): 771-8.

45. O'Hare AM, Walker R, Haneuse $S$, et al. Relationship between longitudinal measures of renal function and onset of dementia in a community cohort of older adults. J Am Geriatr Soc 2012; 60(12): 2215-22.

46. Sasaki Y, Marioni R, Kasai M, Ishii $\mathrm{H}$, Yamaguchi S, Meguro K. Chronic kidney disease: a risk factor for dementia onset: a population-based study. The Osaki-Tajiri Project. J Am Geriatr Soc 2011; 59(7): 1175-81.

47. Higuchi M, Chen R, Abbott RD, et al. Mid-life proteinuria and late-life cognitive function and dementia in elderly men: the Honolulu-Asia Aging Study. Alzheimer Dis Assoc Disord 2015; 29(3): 200-5.

48. Seliger SL, Siscovick DS, Stehman-Breen CO, et al. Moderate renal impairment and risk of dementia among older adults: the Cardiovascular Health Cognition Study. J Am Soc Nephrol 2004; 15(7): 1904-11.

49. Yaffe $K$, Lindquist $K$, Shlipak MG, et al. Cystatin $C$ as a marker of cognitive function in elders: findings from the health ABC study. Ann Neurol 2008; 63(6): 798-802.

50. Sundelof J, Arnlov J, Ingelsson E, et al. Serum cystatin $C$ and the risk of Alzheimer disease in elderly men. Neurology 2008; 71(14): 1072-9.

51. Collins AJ, Kasiske B, Herzog C, et al. Excerpts from the United States Renal Data System 2006 Annual Data Report. Am J Kidney Dis 2007; 49(1 Suppl 1): A6-7, S1-296.

52. Wannamethee SG, Shaper AG, Perry IJ. Serum creatinine concentration and risk of cardiovascular disease: a possible marker for increased risk of stroke. Stroke 1997; 28(3): 557-63.

53. Ishimura $\mathrm{E}$, Shoji T, Emoto $\mathrm{M}$, et al. Renal insufficiency accelerates atherosclerosis in patients with type 2 diabetes mellitus. Am J Kidney Dis 2001; 38(4 Suppl 1): S186-90.

54. Miwa K, Tanaka M, Okazaki S, et al. Chronic kidney disease is associated with dementia independent of cerebral small-vessel disease. Neurology 2014; 82(12): 1051-7.

55. Sastre M, Calero M, Pawlik M, et al. Binding of cystatin C to Alzheimer's amyloid beta inhibits in vitro amyloid fibril formation. Neurobiol Aging 2004; 25(8): 1033-43.

56. Ghiso J, Jensson O, Frangione B. Amyloid fibrils in hereditary cerebral hemorrhage with amyloidosis of Icelandic type is a variant of gamma-trace basic protein (cystatin C). Proc Natl Acad Sci U S A 1986; 83(9): 2974-8.

57. Riverol M, Becker JT, Lopez OL, et al. Relationship between Systemic and Cerebral Vascular Disease and Brain Structure Integrity in Normal Elderly Individuals. J Alzheimers Dis 2015; 44(1): 319-28.

58. Zhong XM, Hou L, Luo XN, et al. Alterations of CSF cystatin C levels and their correlations with CSF Alphabeta40 and Alphabeta42 levels in patients with Alzheimer's disease, dementia with lewy bodies and the atrophic form of general paresis. PLoS One 2013; 8(1): e55328. 
59. De Deyn PP, Vanholder R, Eloot S, Glorieux G. Guanidino compounds as uremic (neuro)toxins. Semin Dial 2009; 22(4): 340-5.

60. Nagai A, Ryu JK, Terashima $M$, et al. Neuronal cell death induced by cystatin $C$ in vivo and in cultured human CNS neurons is inhibited with cathepsin B. Brain Res 2005; 1066(1-2): 120-8. 


\section{SUPPLEMENTAL DATA}

\section{APPENDIX 1: Search term used in three databases}

1. (renal or kidney or microalbumi* albumi* $^{*}$ or creatinine or cystatin).af.

2. (dementia or Alzheim* or cognitive impair* or cognitive decline).af

3. 1 AND 2

4. 3 limited to ((Dutch or English or French or German) and humans)

Search done on $1^{\text {st }}$ August 2016 (all literature until then).

\section{APPENDIX 2: Overview of population-based studies assessing the relation between (markers of) renal dysfunction and cognitive impairment or dementia}

\begin{tabular}{|c|c|c|c|}
\hline Authors & Predictor & Outcome & $\begin{array}{l}\text { Included in meta- } \\
\text { analysis? (If yes, which } \\
\text { meta-analysis? If no, } \\
\text { reason of exclusion?) }\end{array}$ \\
\hline Buchman et al., $2009^{29}$ & eGFR & Cognitive decline & $\begin{array}{l}\text { No, only continuous } \\
\text { outcome measures }\end{array}$ \\
\hline Darsie et al., $2014^{30}$ & $\mathrm{eGFR}_{\text {cys }}$ & Cognitive decline & $\begin{array}{l}\text { No, only continuous } \\
\text { outcome measures }\end{array}$ \\
\hline Davey et al., $2013^{34}$ & eGFR, change in eGFR & Cognitive decline & $\begin{array}{l}\text { No, only continuous } \\
\text { outcome measures }\end{array}$ \\
\hline Etgen et al., $2009^{41}$ & $\mathrm{CCl}, \mathrm{SCr}$, eGFR & Cognitive impairment & Yes, eGFR meta-analysis \\
\hline Feng et al., $2012^{31}$ & eGFR & Cognitive decline & Yes, eGFR meta-analysis \\
\hline Helmer et al., $2011^{35}$ & $\begin{array}{l}\text { eGFR, annual eGFR } \\
\text { decline, albuminuria }\end{array}$ & $\begin{array}{l}\text { Dementia (all-cause, AD, } \\
\text { VaD), cognitive decline }\end{array}$ & $\begin{array}{l}\text { Yes, eGFR and } \\
\text { albuminuria meta- } \\
\text { analyses }\end{array}$ \\
\hline Higuchi et al., $2015^{47}$ & Albuminuria & $\begin{array}{l}\text { Cognitive decline, } \\
\text { dementia (all-cause, } \\
\text { AD, VaD) }\end{array}$ & $\begin{array}{l}\text { Yes, albuminuria meta- } \\
\text { analysis }\end{array}$ \\
\hline Jassal et al., $2010^{36}$ & eGFR, albuminuria & Cognitive decline & $\begin{array}{l}\text { No, only continuous } \\
\text { outcome measures }\end{array}$ \\
\hline Khatri et al., $2009^{32}$ & $\mathrm{SCr}$, eGFR, CCl & Cognitive decline & $\begin{array}{l}\text { No, only continuous } \\
\text { outcome measures }\end{array}$ \\
\hline Kurella et al., $2005^{40}$ & eGFR, $\mathrm{CCL}, \mathrm{SCr}$ & Cognitive impairment & Yes, eGFR meta-analysis \\
\hline Kurella Tamura et al., $2011^{42}$ & eGFR, albuminuria & Cognitive impairment & $\begin{array}{l}\text { Yes, eGFR and } \\
\text { albuminuria meta- } \\
\text { analyses }\end{array}$ \\
\hline Lipnicki et al., $2013^{37}$ & eGFR & Cognitive decline & Yes, eGFR meta-analysis \\
\hline
\end{tabular}




\begin{tabular}{|c|c|c|c|}
\hline Authors & Predictor & Outcome & $\begin{array}{l}\text { Included in meta- } \\
\text { analysis? (If yes, which } \\
\text { meta-analysis? If no, } \\
\text { reason of exclusion?) }\end{array}$ \\
\hline $\mathrm{O}^{\prime}$ Hare et al., $2012^{45}$ & $\begin{array}{l}\text { Average eGFR, } \\
\text { eGFR trajectory and } \\
\text { variability, albuminuria }\end{array}$ & $\begin{array}{l}\text { Dementia (all-cause, } \\
\text { AD) }\end{array}$ & $\begin{array}{l}\text { Yes, albuminuria meta- } \\
\text { analysis }\end{array}$ \\
\hline Sajjad et al., $2012^{38}$ & eGFR, albuminuria & Cognitive decline & $\begin{array}{l}\text { No, only continuous } \\
\text { outcome measures }\end{array}$ \\
\hline Sasaki et al., $2011^{46}$ & eGFR & Dementia (all-cause) & Yes, eGFR meta-analysis \\
\hline Seliger et al., $2004^{48}$ & $\mathrm{SCr}$ & $\begin{array}{l}\text { Dementia (all-cause, } \\
A D, V a D)\end{array}$ & $\begin{array}{l}\text { No, too few studies on } \\
\text { SCr in order to pool data }\end{array}$ \\
\hline Seliger et al., $2015^{39}$ & $\begin{array}{l}\text { Change in } \mathrm{SCr} \text {, change } \\
\text { in eGFR }\end{array}$ & Cognitive decline & $\begin{array}{l}\text { No, only continuous } \\
\text { outcome measures }\end{array}$ \\
\hline Slinin et al., $2008^{43}$ & eGFR & Cognitive impairment & Yes, eGFR meta-analysis \\
\hline Slinin et al., $2015^{44}$ & $\begin{array}{l}\text { Cystatin C, eGFR }{ }_{\text {cr' }} \\
\text { eGFR }_{\text {cys' }} \text { eGFR } \text { cr+cys }\end{array}$ & Cognitive impairment & $\begin{array}{l}\text { No, too few studies on } \\
\text { cystatin } C \text { in order to } \\
\text { pool data and different } \\
\text { methodology (quartiles) } \\
\text { regarding eGFR }\end{array}$ \\
\hline Sundelöf et al., $2008^{50}$ & Cystatin C & Dementia (AD) & $\begin{array}{l}\text { No, too few studies on } \\
\text { cystatin } C \text { in order to } \\
\text { pool data }\end{array}$ \\
\hline Wang et al., $2010^{33}$ & eGFR, albuminuria & Cognitive decline & $\begin{array}{l}\text { Yes, eGFR and } \\
\text { albuminuria meta- } \\
\text { analyses }\end{array}$ \\
\hline Yaffe et al., $2008^{49}$ & Cystatin C & Cognitive impairment & $\begin{array}{l}\text { No, too few studies on } \\
\text { cystatin C in order to } \\
\text { pool data }\end{array}$ \\
\hline
\end{tabular}

Abbreviations: AD - Alzheimer's disease; $C C l$ - creatinine clearance; eGFR - estimated glomerular filtration rate; eGFR cys $_{\text {s }}$ eGFR

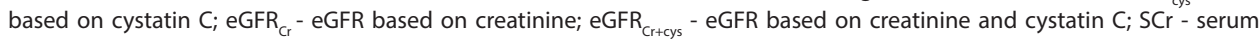
creatinine; $\mathrm{VaD}$ - vascular dementia. 


\section{APPENDIX 3: Funnel plots}

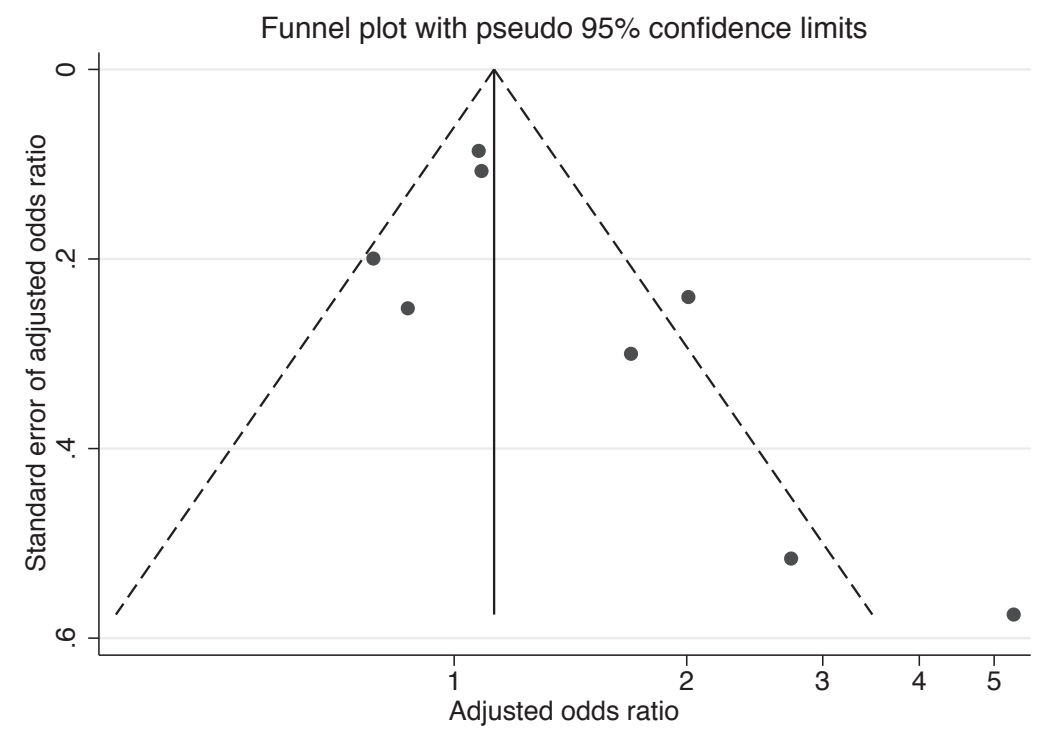

Figure 1. Funnel plot of eGFR $<60 \mathrm{~mL} / \mathrm{min} / 1.73 \mathrm{~m}^{2}$ studies included in the meta-analysis showing the effect estimates by their standard errors (fully-adjusted estimates)

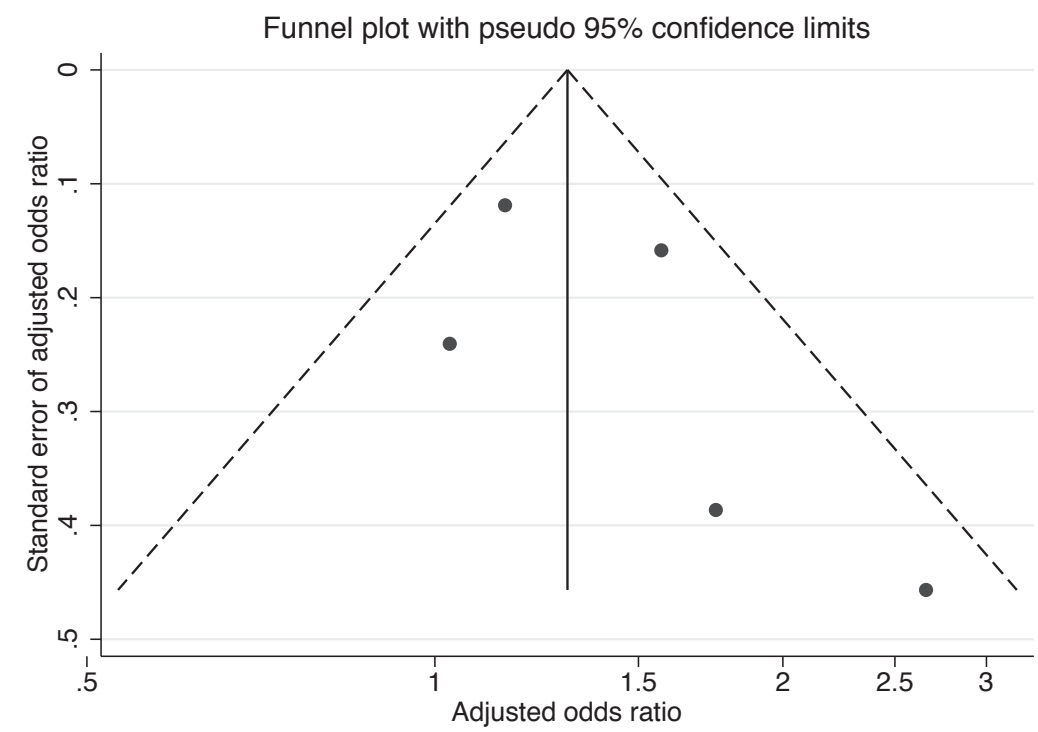

Figure 2. Funnel plot of albuminuria studies included in the meta-analysis showing the effect estimates by their standard errors (fully-adjusted estimates) 


\section{APPENDIX 4: Forest plots of eGFR $<45$ and eGFR $45-59 \mathrm{~mL} / \mathrm{min} / 1.73 \mathrm{~m}^{2}$}

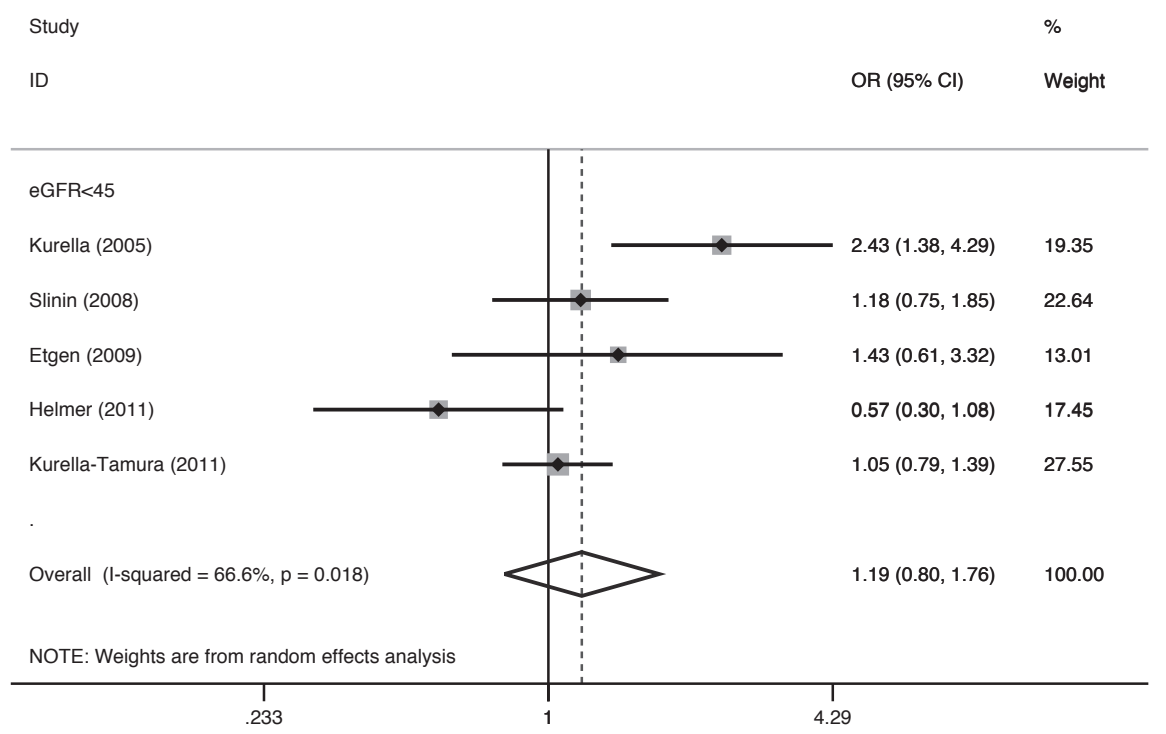

Figure 1. Forest plot of population-based prospective studies assessing the relation between eGFR $<45 \mathrm{~mL} / \mathrm{min} / 1.73 \mathrm{~m}^{2}$ and cognitive impairment or dementia (fully-adjusted estimates)

$$
\text { Study }
$$

ID

D

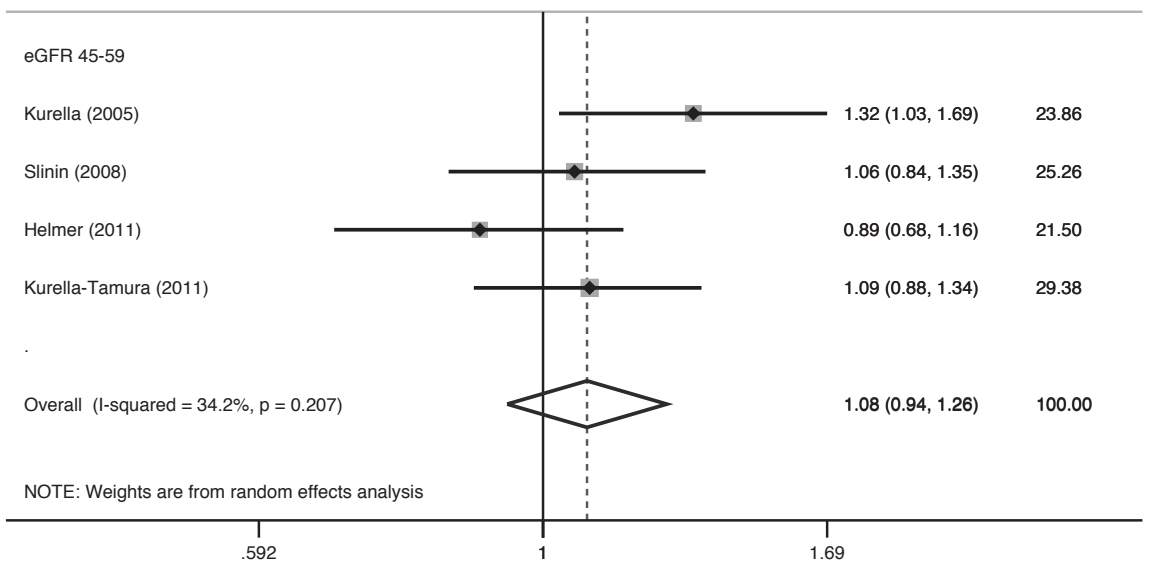

Figure 2. Forest plot of population-based prospective studies assessing the relation between eGFR $45-59 \mathrm{~mL} / \mathrm{min} / 1.73 \mathrm{~m}^{2}$ and cognitive impairment or dementia (fully-adjusted estimates) 


\section{APPENDIX 5: Forest plots of unadjusted estimates}

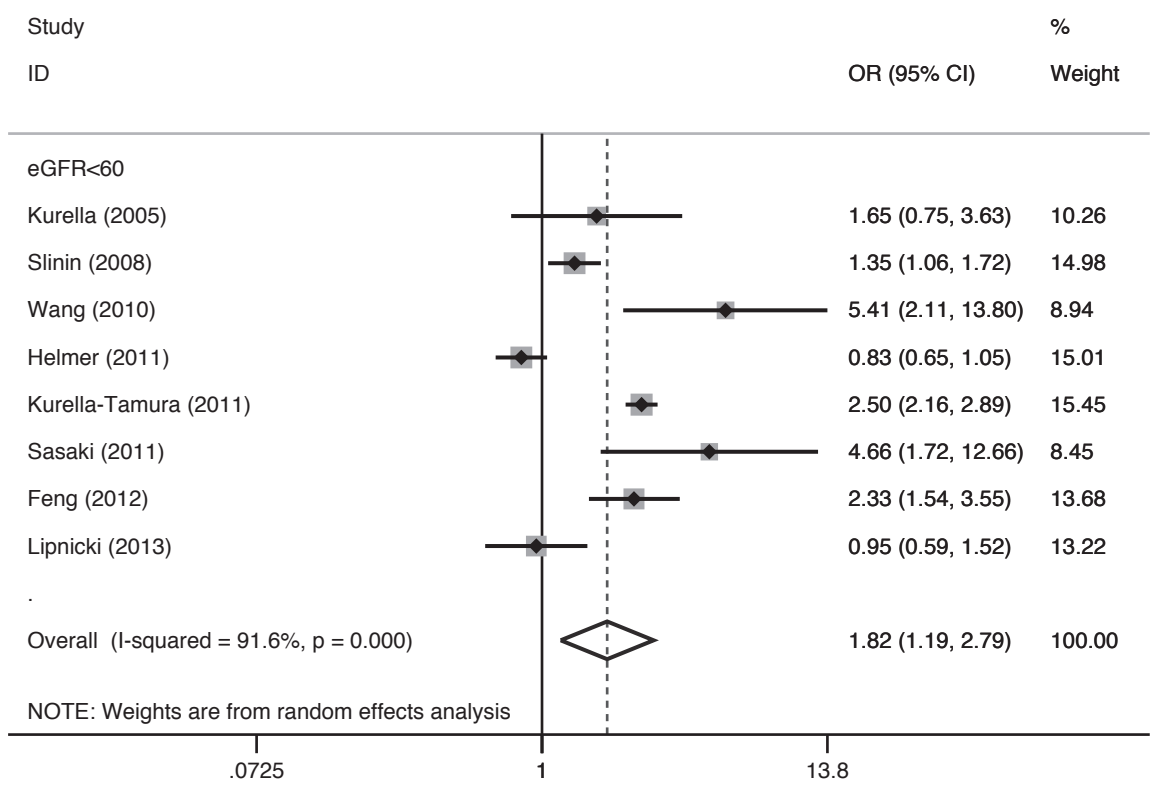

Figure 1. Forest plot of population-based prospective studies assessing the relation between eGFR $<60 \mathrm{~mL} / \mathrm{min} / 1.73 \mathrm{~m}^{2}$ and cognitive impairment or dementia (unadjusted estimates)

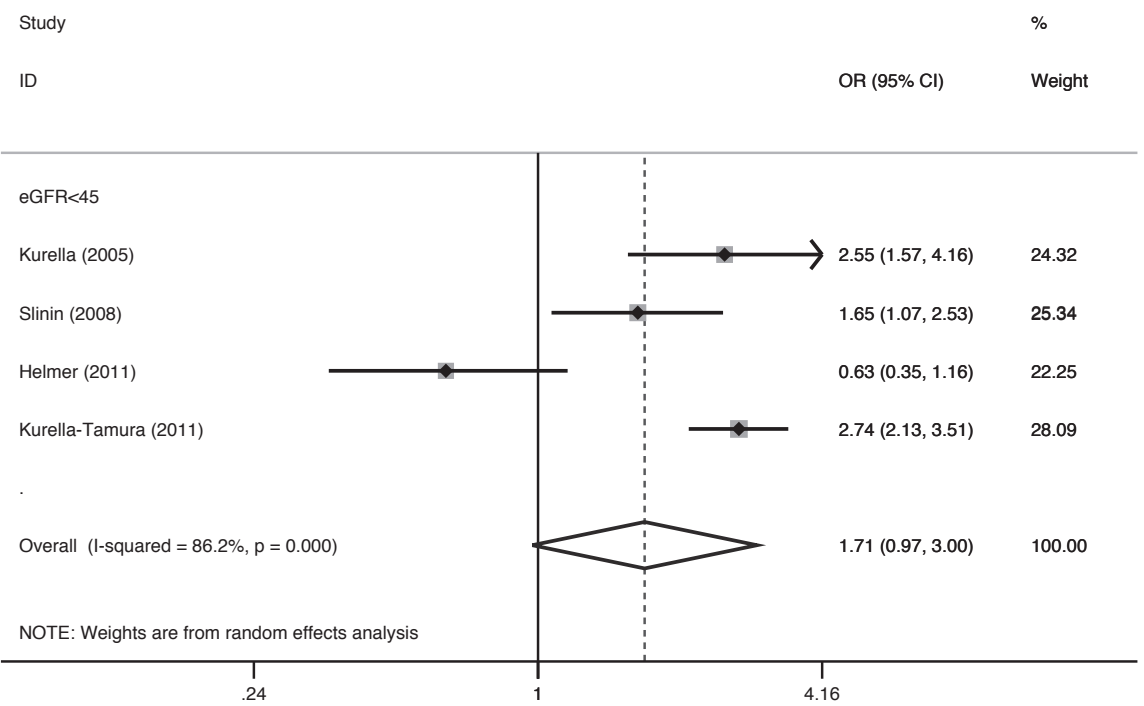

Figure 2. Forest plot of population-based prospective studies assessing the relation between eGFR $<45 \mathrm{~mL} / \mathrm{min} / 1.73 \mathrm{~m}^{2}$ and cognitive impairment or dementia (unadjusted estimates) 
Study

ID
$\%$

OR $(95 \% \mathrm{Cl}) \quad$ Weight

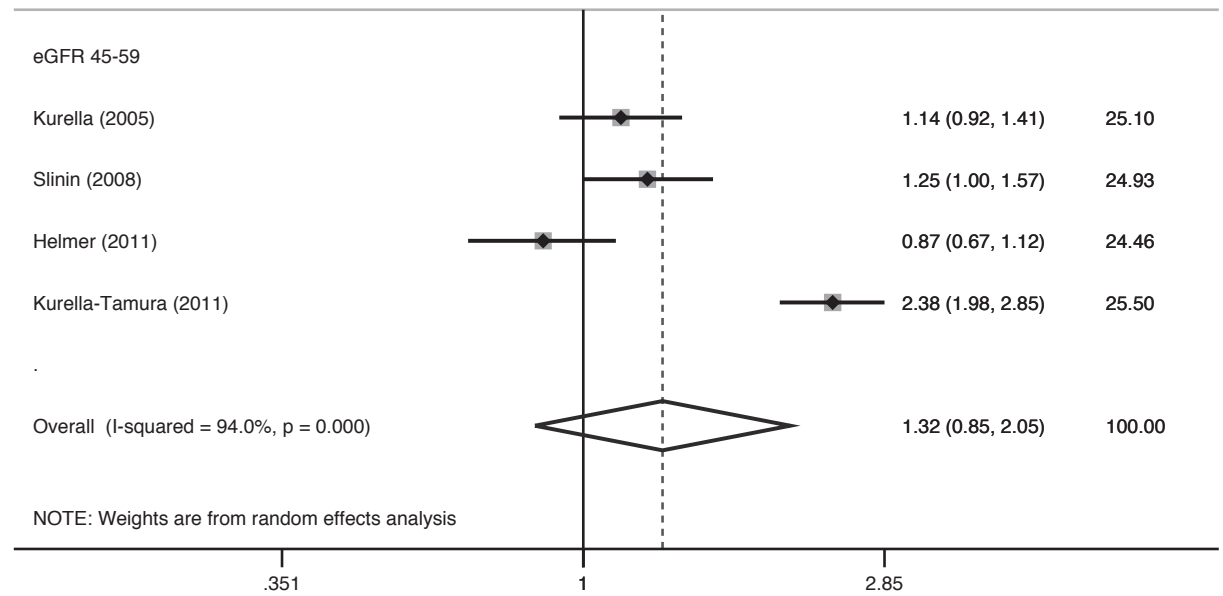

Figure 3. Forest plot of population-based prospective studies assessing the relation between eGFR $45-59 \mathrm{~mL} / \mathrm{min} / 1.73 \mathrm{~m}^{2}$ and cognitive impairment or dementia (unadjusted estimates)

Study

ID
$\%$

OR $(95 \% \mathrm{Cl}) \quad$ Weight

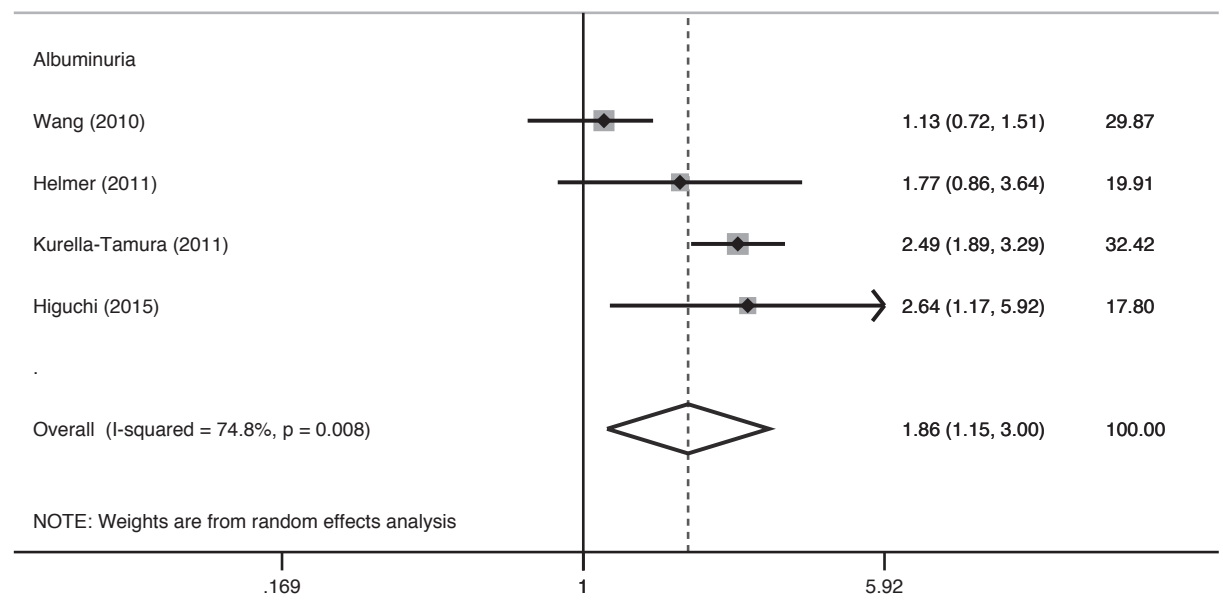

Figure 4. Forest plot of population-based prospective studies assessing the relation between albuminuria and cognitive impairment or dementia (unadjusted estimates) 



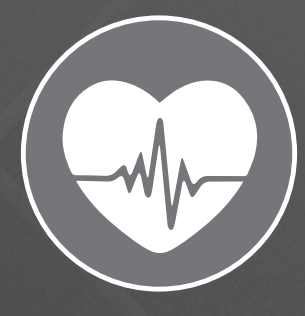




\section{CHAPTER 4}

\section{CORONARY HEART DISEASE AND RISK FOR COGNITIVE IMPAIRMENT OR DEMENTIA: A SYSTEMATIC REVIEW AND META-ANALYSIS}

Submitted

Kay Deckers, Syenna HJ Schievink, Maria MF Rodriquez, Robert J van Oostenbrugge, Martin PJ van Boxtel, Frans RJ Verhey, Sebastian Köhler 


\section{ABSTRACT}

Background: Accumulating evidence suggests an association between coronary heart disease and risk for cognitive impairment or dementia, but no study has systematically reviewed this association. To summarize the available evidence on the association between coronary heart disease and risk for cognitive impairment or dementia.

Methods: Medline, Embase, PsycINFO, and CINAHL were searched for all publications until $8^{\text {th }}$ January 2016. Articles were included if the fulfilled the inclusion criteria: (1) myocardial infarction, angina pectoris or coronary heart disease (combination of both) as predictor variable; (2) cognition, cognitive impairment or dementia as outcome; (3) populationbased study; (4) prospective ( $\geq 1$ year follow-up), cross-sectional or case-control study design; (5) $\geq 100$ participants; and (6) aged $\geq 45$ years. Two reviewers independently screened all abstracts and extracted information from potential relevant full-text articles. We pooled estimates from the most fully adjusted model using random-effects metaanalysis.

Results: We identified 6,132 abstracts, of which 24 studies were included. A meta-analysis of 10 prospective cohort studies showed that coronary heart disease was associated with increased risk of cognitive impairment or dementia $(\mathrm{OR}=1.45,95 \% \mathrm{Cl}=1.21-1.74$, $\mathrm{p}<0.001)$. Between-study heterogeneity was low $\left(l^{2}=25.7 \%, 95 \% \mathrm{Cl}=0-64, \mathrm{p}=0.207\right)$. Similar significant associations were found in separate meta-analyses of prospective cohort studies for the individual predictors (myocardial infarction, angina pectoris). In contrast, meta-analyses of cross-sectional and case-control studies were inconclusive.

Conclusion: This meta-analysis suggests that coronary heart disease is prospectively associated with increased odds of developing cognitive impairment or dementia. Given the projected worldwide increase in the number of people affected by coronary heart disease and dementia, insight into causal mechanisms or common pathways underlying the heart-brain connection is needed. 


\section{INTRODUCTION}

Coronary heart disease (CHD) is the leading cause of death worldwide ${ }^{1}$. An estimated 7.4 million people died from CHD in 2012. ${ }^{2}$ CHD is a broad disease category and consists of several conditions with myocardial infarction (MI) and angina pectoris (AP) being the most prevalent ones. CHD affects the vascular system supplying the heart muscle due to build-up of atheromatous plaques that cover the lining of the coronary arteries. ${ }^{3}$

At the same time, dementia is an important health problem due to increasing incidence rates and its impact on health and daily life. ${ }^{4}$ Major modifiable risk factors for cognitive impairment and dementia relate to or impact the vascular system including hypertension, smoking, obesity, diabetes, hypercholesterolemia and lack of physical exercise.,5 Notably, these factors are also risk factors for CHD. ${ }^{7}$ While CHD is a candidate risk factor for dementia or cognitive impairment, the evidence base has not been established to a similar extent, yet. ${ }^{8}$ In a recent systematic review of the literature on modifiable risk factors, several studies on heart disease were identified, of which the majority reported a higher risk for cognitive impairment or dementia. ${ }^{8}$ Some other types of heart disease have been related to cognitive decline or dementia risk, too, with most substantial evidence for atrial fibrillation. ${ }^{9-11}$ A meta-analysis of 7 prospective studies found that individuals with atrial fibrillation had a 36 percent increased risk of developing cognitive impairment or dementia. ${ }^{9}$ To date, no meta-analysis exists for major heart diseases such as $\mathrm{MI}$ and AP. Therefore, the aim of the present study is to summarize the outcome of all available population-based studies investigating the relation between CHD, notably Ml, and AP, and risk for cognitive impairment or dementia in a systematic review and meta-analysis.

\section{METHODS}

\section{Data Sources and Searches}

The literature search was conducted in Medline, Embase, PsycINFO, and CINAHL. The search string consisted of predictor-related terms (e.g. myocardial infarction, angina pectoris), outcome-related terms (e.g. dementia, Alzheimer, cognition), as well as some specific limitations (e.g. only studies in human, language restrictions). The complete search strategy is provided in Appendix 1.

\section{Study Selection}

All publications until $8^{\text {th }}$ January 2016 were included if they fulfilled the following eligibility criteria: 1) Ml, AP, or a CHD variable that is a combination of $\mathrm{Ml}$ and $\mathrm{AP}$ (e.g. ischemic heart 
disease (IHD)) as predictor variable; 2) cognition, cognitive impairment or dementia as outcome; 3 ) population-based study; 4) prospective ( $\geq 1$ year follow-up), cross-sectional or case-control study design; 5) $\geq 100$ participants; and 6) aged $\geq 45$ years. Reference lists of publications and secondary literature (review articles, editorials, book chapters, etc.) were hand-searched for possible missing articles.

\section{Data Extraction and Quality Assessment}

The selection process followed the PRISMA (Preferred Reporting Items for Systematic reviews and Meta-Analyses) and MOOSE (Meta-analysis Of Observational Studies in Epidemiology) guidelines. ${ }^{12,13}$ Titles and abstracts were screened by two independent assessors (KD, MFR) based on the abovementioned eligibility criteria. Next, full text articles of potentially relevant citations were scrutinized by two independent investigators (KD, MFR). A standardized data collection form was used to extract information such as study design, study cohort, demographics, predictor variable, outcome, and effect estimate. In case of discrepancy, discussion with a third reviewer (SK) took place. Corresponding authors were contacted by e-mail if full-text articles were not available or information was missing (e.g. effect estimates, sample sizes, definition of CHD) or ambiguous (with maximum three reminders in case of non-response). The Newcastle-Ottawa Scale (NOS) was used to asses study quality. ${ }^{14}$ For cross-sectional studies, an adapted version of the NOS was applied (see Appendix 2).

\section{Data Synthesis and Analysis}

Studies qualifying for pooling in meta-analyses were analyzed with random effects models to estimate the pooled odds ratios (OR) and their $95 \%$ confidence intervals $(\mathrm{Cl})$. Estimates from the most fully adjusted model were used. Meta-analyses were conducted for each exposure separately, i.e. for MI, AP, and CHD. The latter includes all studies that report a risk estimate for $\mathrm{MI}, \mathrm{AP}$ or a combination of $\mathrm{MI}$ and $\mathrm{AP}$. In case a study reports risk estimates for multiple exposures the combination estimate (first choice) or the effect estimate with the smallest standard error (i.e. largest sample size; second choice) was chosen. Studies with overlapping study populations were only included if they used other study designs (e.g. cross-sectional and prospective). Heterogeneity among studies was assessed using the $R^{2}$ statistic and the $95 \% \mathrm{Cl}$ for ${ }^{2}$ was calculated using the non-central $X^{2}$ approach. Potential sources of heterogeneity (including mean age at baseline, mean follow-up duration, percentage of women, outcome measurement and study quality) were explored by meta-regression. The $95 \%$ prediction interval was estimated for each meta-analysis including at least 3 observational studies. This measure takes into account 
the between-study heterogeneity and provides an interval for the expected estimate of a future observational study and has been recommended to be standardly included in meta-analysis. ${ }^{15}$ Potential publication bias (i.e. small study effects) was assessed by visual inspection of funnel plots and Egger's test. All tests were two-sided at an alpha-level of 0.05 and all analyses were done with Stata 13.1 (StataCorp, TX).

\section{RESULTS}

The search yielded 6,132 abstracts, of which 142 (2.3\%) were included for full-text review. Of these, 119 were excluded due to different reasons based on the exclusion criteria (see Figure 1). Six authors were contacted to obtain full-text articles that were not available to us, of which 5 responded to our request. Additionally, 10 authors were contacted for missing or ambiguous information, of whom 7 responded. Two additional studies were found from cross-references, ${ }^{16,17}$ of which one could be included. ${ }^{16}$ This resulted in 8 crosssectional studies, 5 case-control studies, 10 prospective cohort studies and 1 study with both cross-sectional and prospective analyses (designated as cross-sectional regarding study quality). Quality assessment of all 24 included studies was sufficient (overall mean NOS score $=6.8, \mathrm{SD}=1.29$, range $=3-9$ ). Separate analyses for each study design showed similar results for prospective (mean NOS score $=6.91$, SD $=1.04$, range $=5-8$ ) and crosssectional studies (mean NOS score $=7.22, \mathrm{SD}=0.97$, range $=6-9$ ), but the quality of casecontrol studies was somewhat lower (mean NOS score $=5.8, \mathrm{SD}=1.92$, range $=3-8$ ), mainly due to the effects of one particular study with a score of 3 . All 24 studies and their details and results are summarized in detail in Table 1-3 and Appendix 3.

\section{Cross-sectional studies}

Out of nine cross-sectional studies, six studies reported on $\mathrm{Ml}^{18-23}$ three on $\mathrm{AP}^{19,21,22}$ and five on the CHD compound (MI+AP). ${ }^{22-26}$ Of the six studies investigating Ml, four found a significant relation with poor cognitive functioning, ${ }^{18,19,22,23}$ and two studies found no association with prevalent cognitive impairment. ${ }^{20,21}$ For AP, two studies found a significant association with poor cognitive functioning, ${ }^{19,22}$ whereas one study found no association with mild cognitive impairment. ${ }^{21}$ For the CHD compound studies, three studies found a significant association with poor cognitive functioning, ${ }^{22,23,26}$ one study found no relation with cognitive function or cognitive impairment, ${ }^{24}$ and one study found a significant association with dementia risk. ${ }^{25}$

In the meta-analysis, four studies representing 623,588 persons could be included. 20,21,24,25 CHD was not significantly associated with an increased risk of cognitive impairment or 


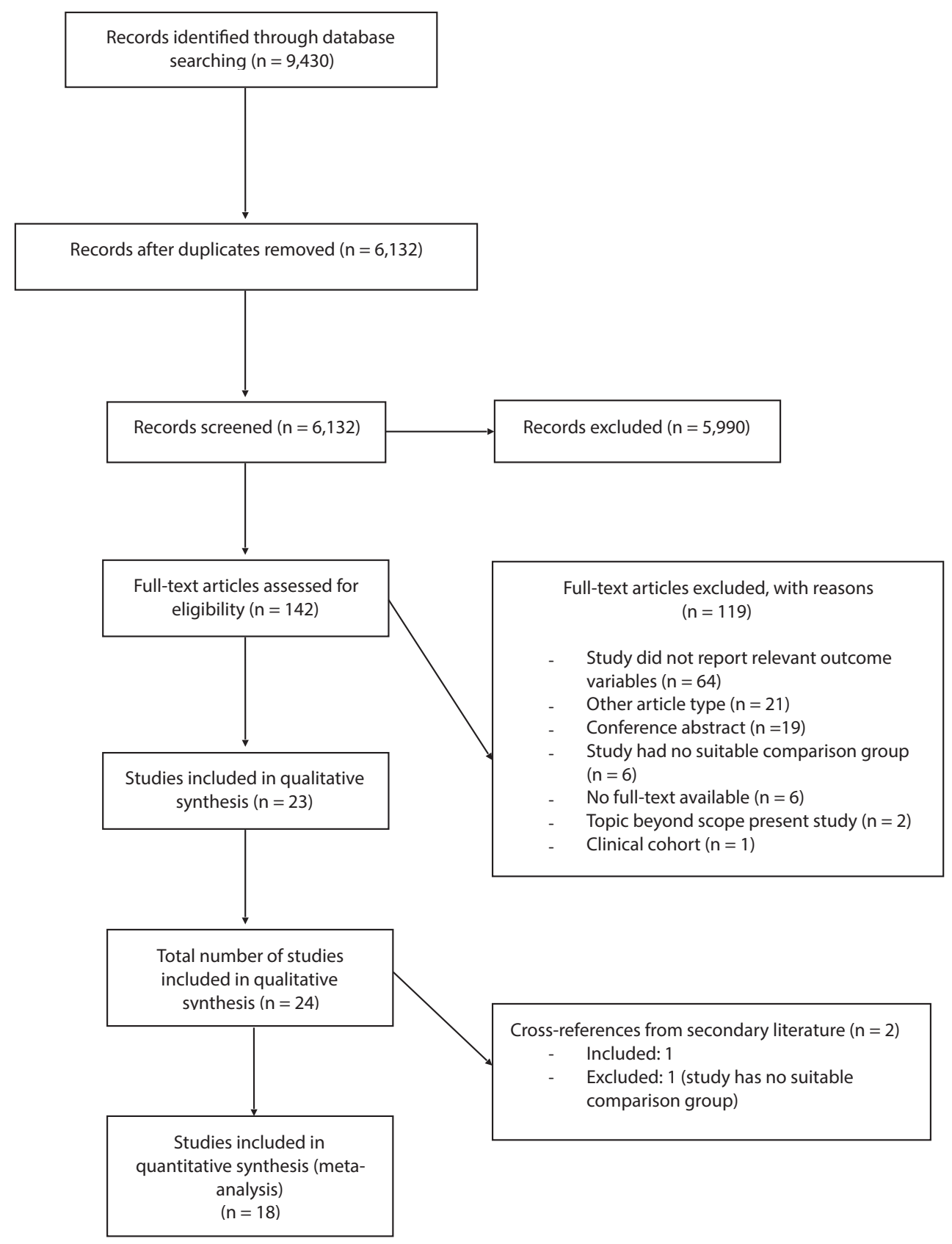

Figure 1. Literature search and selection. 
dementia $(\mathrm{OR}=1.23,95 \% \mathrm{Cl}=0.76-1.97, \mathrm{p}=0.398$; see Figure 1 of Appendix 4). In the CHD meta-analysis, substantial heterogeneity was observed $\left(I^{2}=81.2 \%, 95 \% \mathrm{Cl}=26-91\right.$, $p=0.001)$. No statistically significant source of heterogeneity was identified in a metaregression analysis, although inclusion of some study characteristics (e.g. mean age at baseline, outcome measurement and study quality) led to a reduction in $P^{2}$ (e.g. mean age at baseline: $81.2 \%$ to $53.1 \%$ ). There was no evidence for small-study effects based on the Egger's test $(p=0.407)$ and visual inspection of the funnel plot (see Figure 2 of Appendix 4). Similar non-significant results were found for $\mathrm{MI}(\mathrm{OR}=1.11,95 \% \mathrm{Cl}=0.79-1.57, \mathrm{p}=$ 0.548; see Figure 3 of Appendix 4). It was not possible to perform a meta-analysis for AP since there was only one study. ${ }^{21}$

\section{Case-control studies}

Four out of five case-control studies reported on MI. Three of these found no association between $\mathrm{Ml}$ and dementia or Alzheimer's disease, ${ }^{27-29}$ whereas one nested case-control study did find a significant association between $\mathrm{Ml}$ and dementia risk. ${ }^{30}$ Two case-control studies investigated the relation between AP and risk for dementia, Alzheimer's disease or vascular dementia. Both studies showed no significant associations. 29,31

Four studies representing 6,397 individuals could be included in the meta-analysis. ${ }^{27,29-31}$ CHD was not significantly associated with risk of total or vascular dementia $(O R=1.14$, $95 \% \mathrm{Cl}=0.79-1.64, \mathrm{p}=0.482$; see Figure 1 of Appendix 5). There were signs of moderate heterogeneity $\left(I^{2}=60.3 \%, 95 \% \mathrm{Cl}=0-85, \mathrm{p}=0.056\right)$. There was no strong evidence for small-study effects based on the Egger's test $(p=0.062)$ and visual inspection of the funnel plot (see Figure 2 of Appendix 5). No statistically significant source of heterogeneity was identified in a meta-regression analysis. Separate meta-analyses for MI and AP showed comparable non-significant results ( $\mathrm{Ml}: \mathrm{OR}=1.32,95 \% \mathrm{Cl}=0.78-2.21, \mathrm{p}=0.302$, see Figure 3 of Appendix 5; AP: OR $=0.98,95 \% C l=0.71-1.36, p=0.911$, see Figure 4 of Appendix 5).

\section{Prospective cohort studies}

From the eleven prospective cohort studies, seven focused on $\mathrm{MI}^{16,32-37}$ four on $\mathrm{AP}^{33,36-38}$, and four studies on the CHD compound. $23,36,39,40$ Of those focusing on $\mathrm{Ml}$, four studies did not find an association with dementia, Alzheimer's disease, vascular dementia or decline to mild cognitive impairment or dementia. ${ }^{34-37}$ Three studies did find a significant association between $\mathrm{Ml}$ and dementia, ${ }^{32}$ Alzheimer's disease and Alzheimer's disease/vascular dementia (but only for MI ascertained at the late-life visit) ${ }^{16}$, and possible dementia/mild cognitive impairment. ${ }^{33}$ Two out of the four AP studies did find that AP increased the risk of dementia or possible dementia/mild cognitive impairment, ${ }^{33,38}$ whereas the other two 
studies did not find an association. ${ }^{36,37}$ For the CHD compound, three studies did not find a relation with cognitive decline or decline to dementia/mild cognitive impairment, ${ }^{23,36,39}$ whereas one study found that CHD was a significant predictor of vascular dementia. ${ }^{40}$ In the meta-analysis, a total of ten studies representing 24,801 persons could be included. ${ }^{16,32-40} \mathrm{CHD}$ was associated with a $45 \%$ increased risk of dementia, cognitive impairment or cognitive decline $(\mathrm{OR}=1.45,95 \% \mathrm{Cl}=1.21-1.74, \mathrm{p}<0.001$; see Figure 2$)$. Heterogeneity was low $\left(I^{2}=25.7 \%, 95 \% \mathrm{Cl}=0-64, \mathrm{p}=0.207\right)$, without suggestion of smallstudy effects (Egger's test, $p=0.739$; for the funnel plot, see Figure 1 of Appendix 6). Associations were slightly stronger in studies $(n=7)$ focusing on dementia $(O R=1.55$, $\left.95 \% \mathrm{Cl}=1.20-2.00, \mathrm{p}=0.001 ; P^{2}=40.6 \%, 95 \% \mathrm{Cl}=0-74, \mathrm{p}=0.121\right) .{ }^{16,32,34,35,37,38,40}$ There were too few studies to conduct separate meta-analyses for the different subtypes of dementia. Similar significant results were found for $\mathrm{MI}(\mathrm{OR}=1.46,95 \% \mathrm{Cl}=1.16-1.84, \mathrm{p}=0.001$, see Figure 2 of Appendix 6$)$ and $A P(O R=1.36,95 \% C l=1.12-1.65, p=0.002$, see Figure 3 of Appendix 6) separately. 


\begin{tabular}{|c|c|c|c|c|c|c|}
\hline 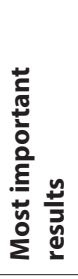 & 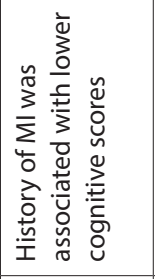 & 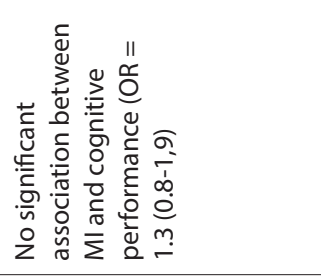 & \multicolumn{2}{|c|}{ 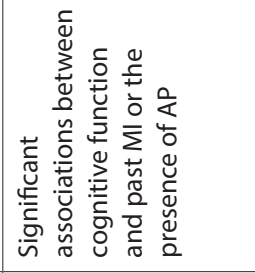 } & \multicolumn{2}{|l|}{ 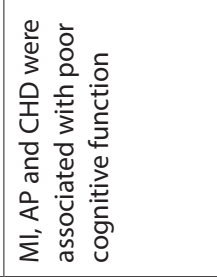 } \\
\hline 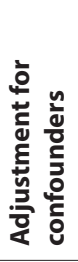 & 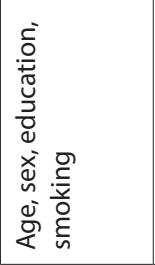 & 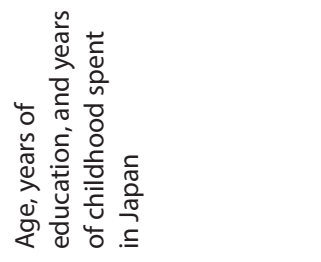 & 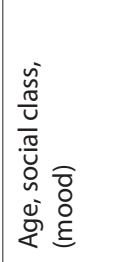 & & 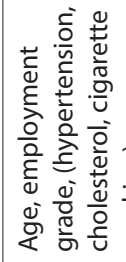 & \\
\hline 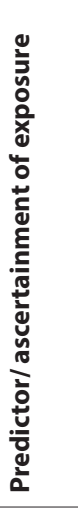 & 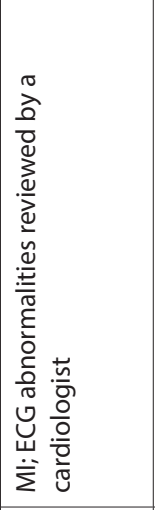 & 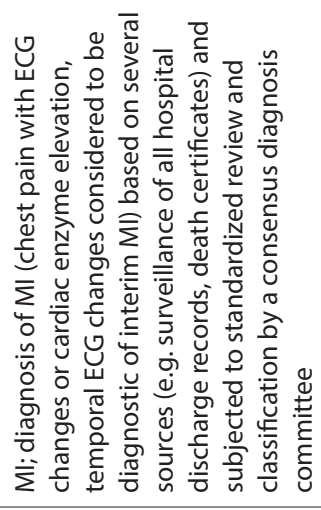 & 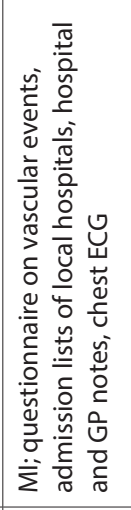 & 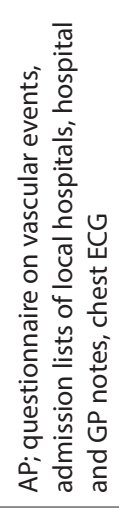 & 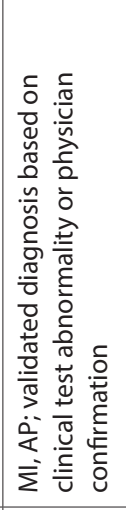 & 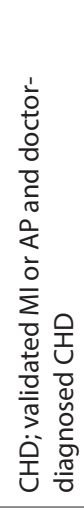 \\
\hline 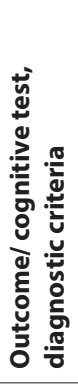 & 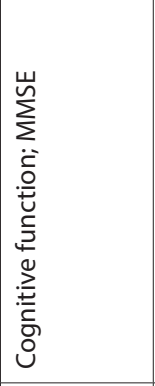 & 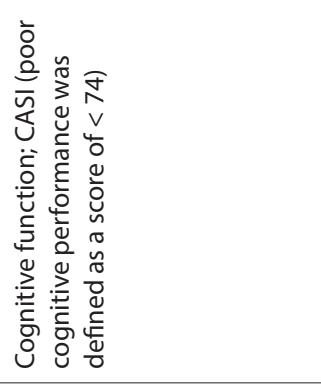 & 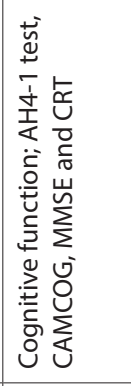 & & 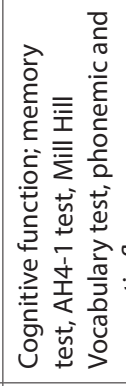 & \\
\hline 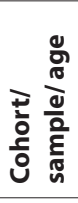 & 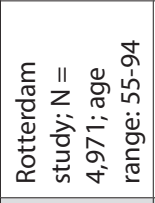 & 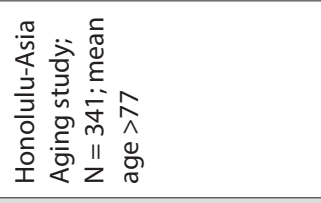 & 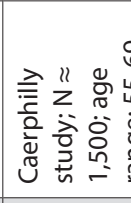 & & 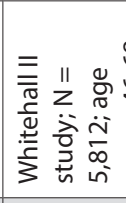 & \\
\hline $\begin{array}{l}\frac{n}{0} \\
\frac{ \pm}{z} \\
\frac{1}{2}\end{array}$ & 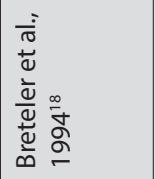 & 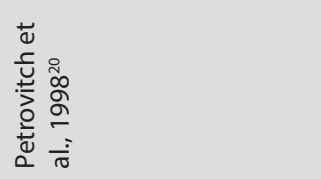 & 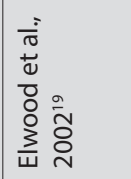 & & 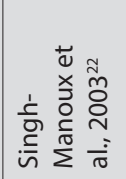 & \\
\hline
\end{tabular}




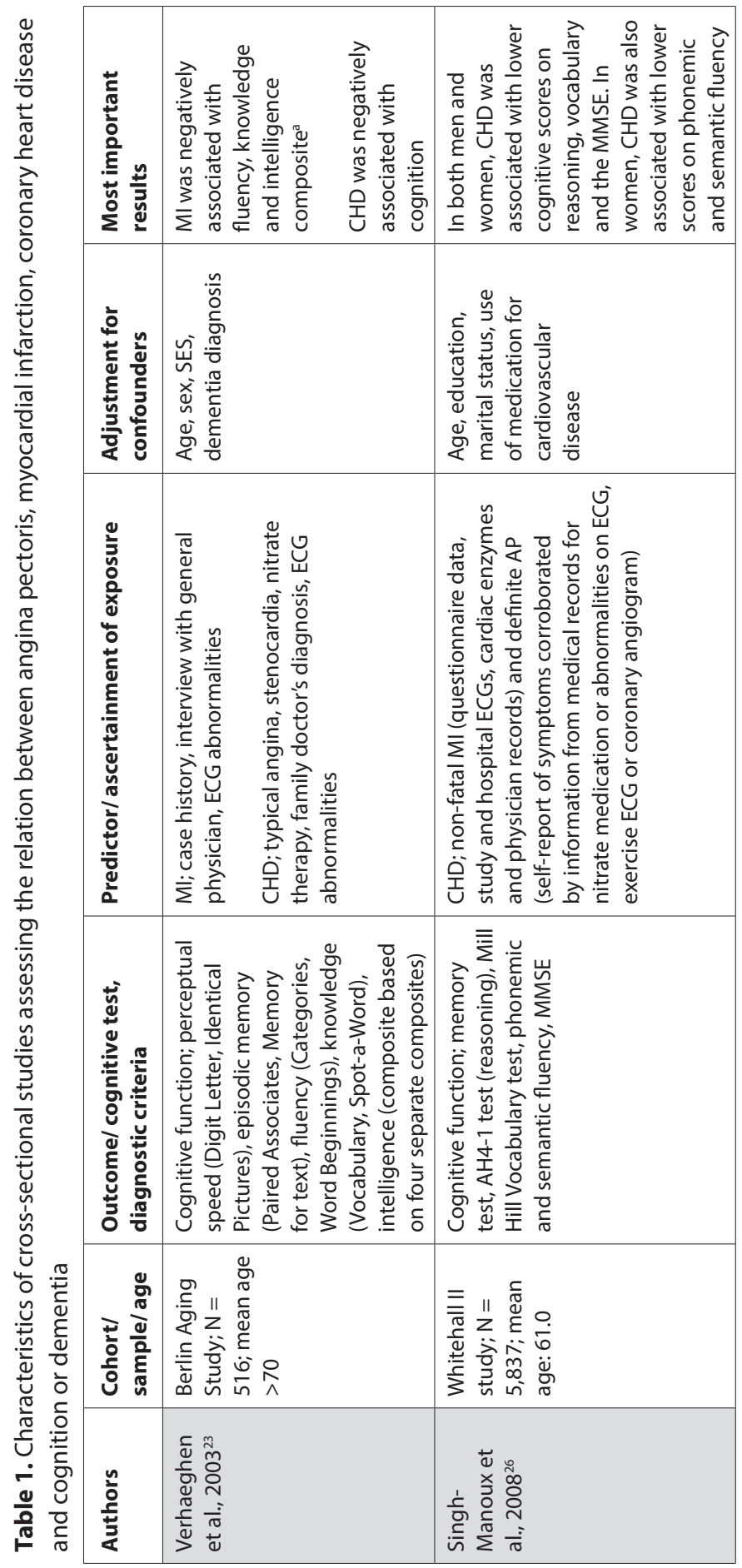




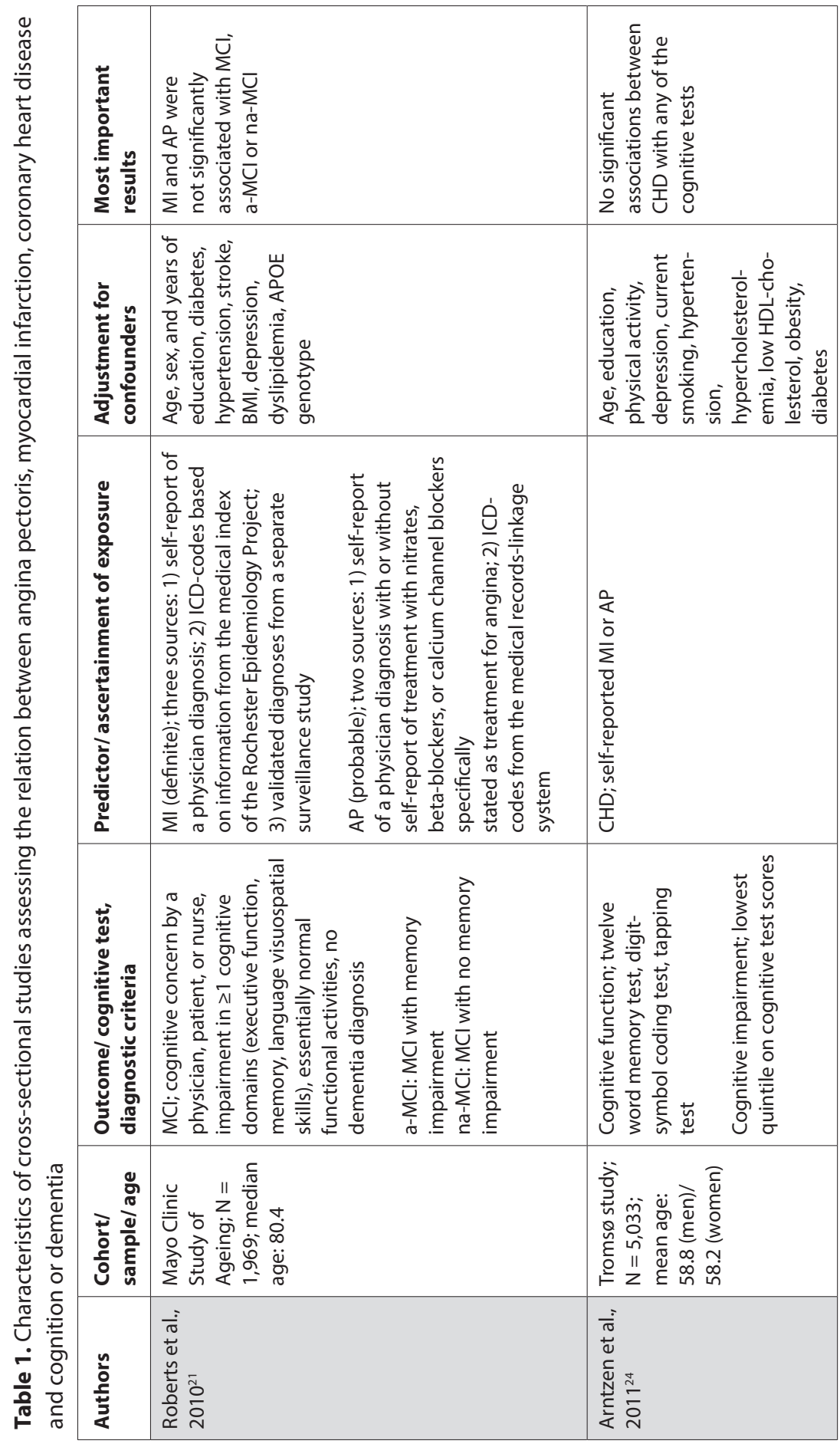




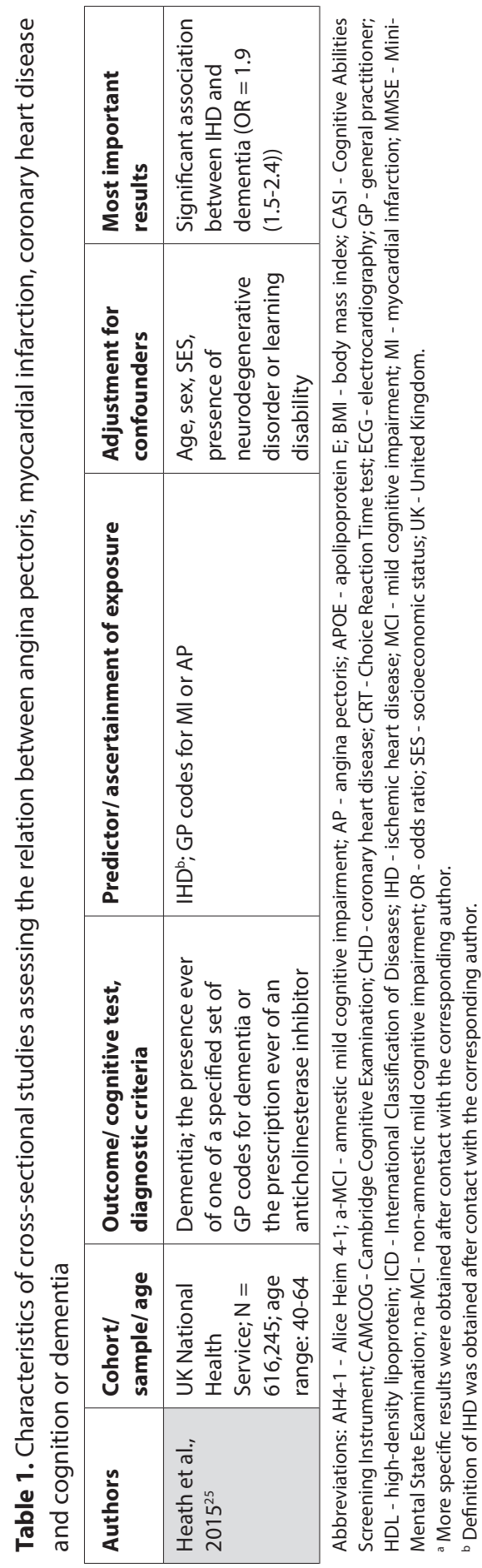




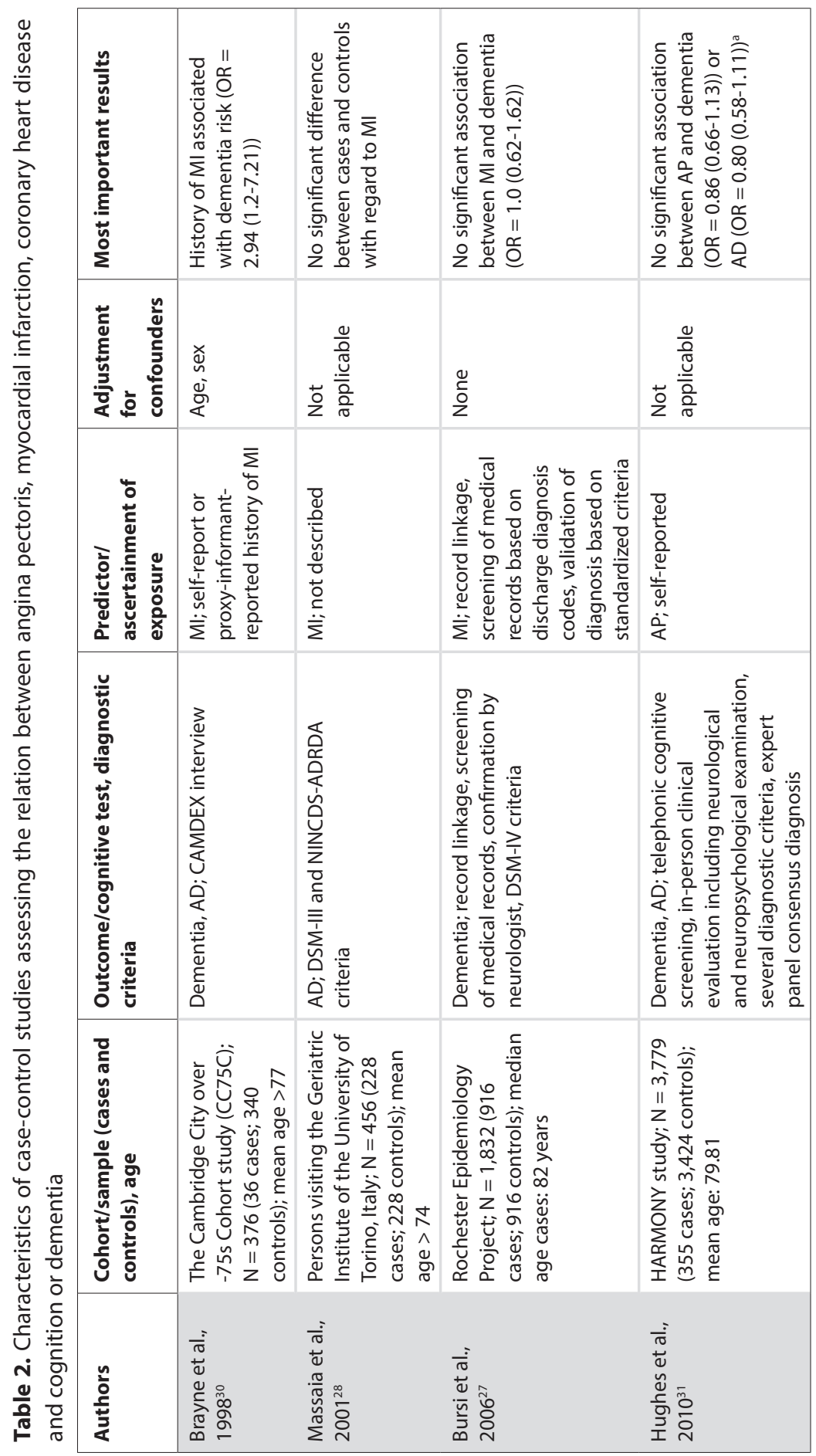




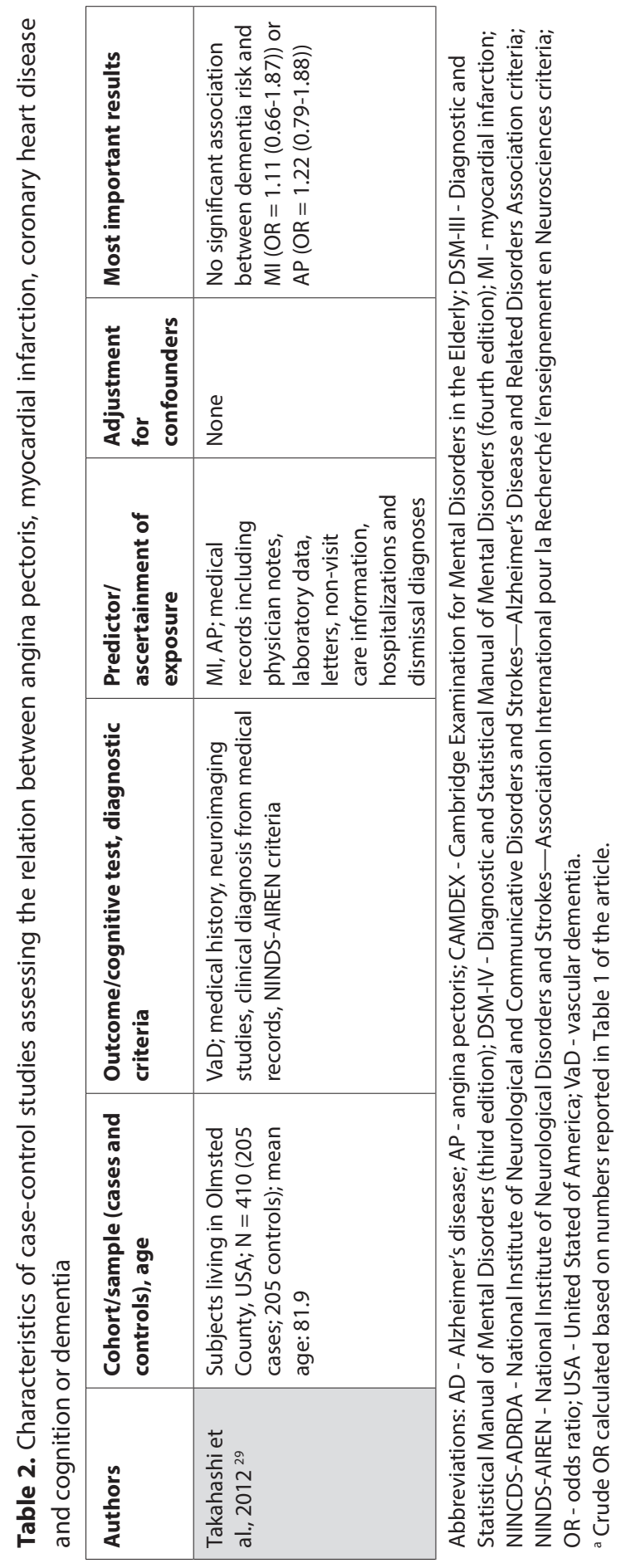




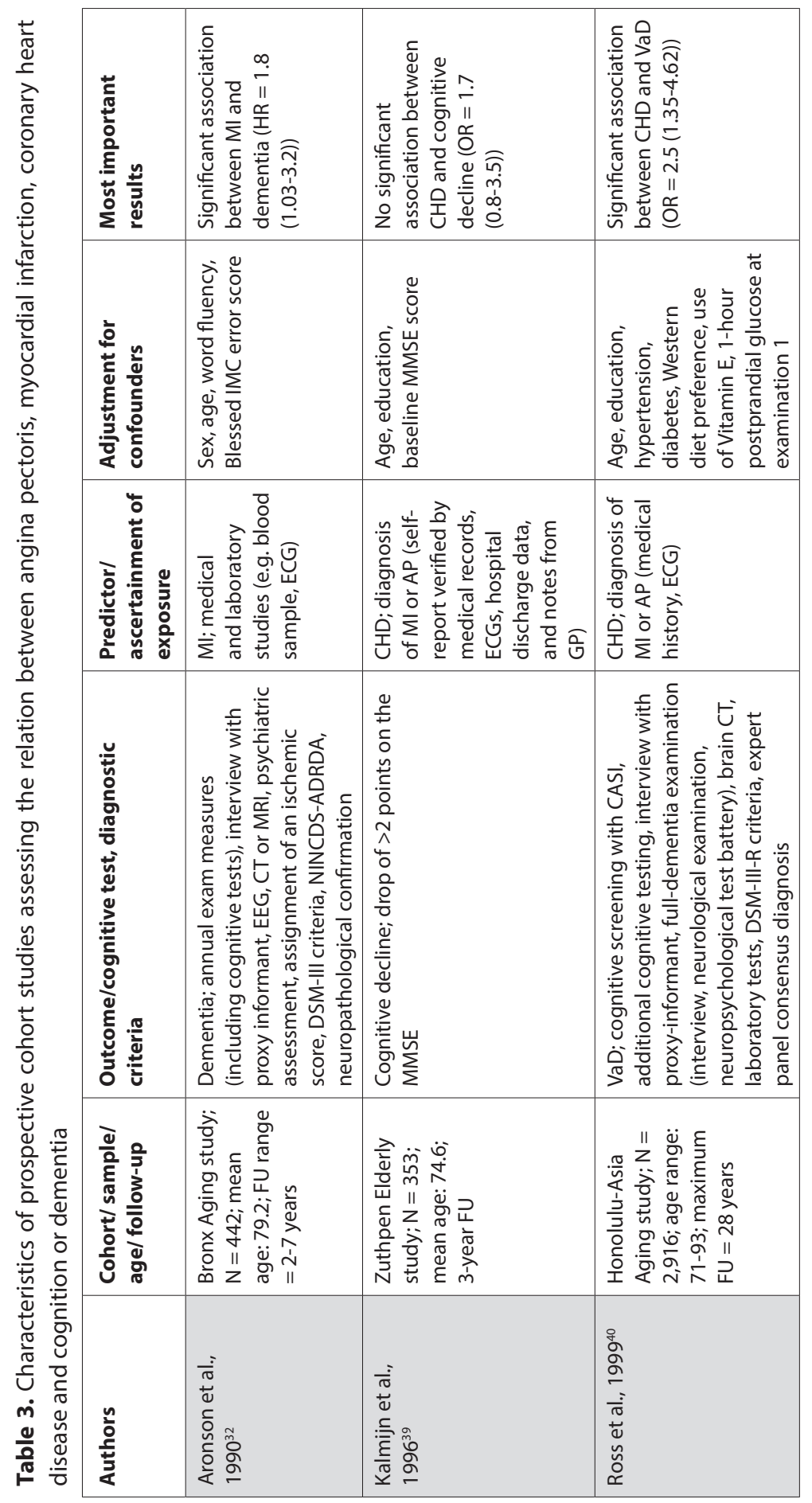




\begin{tabular}{|c|c|c|c|}
\hline 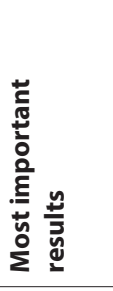 & 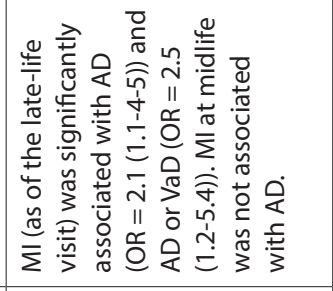 & 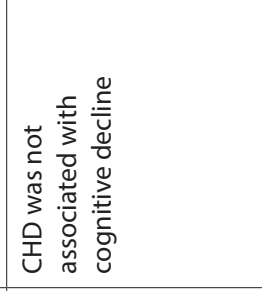 & 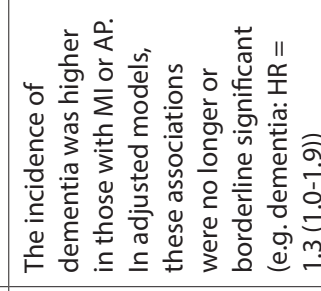 \\
\hline 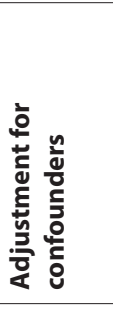 & 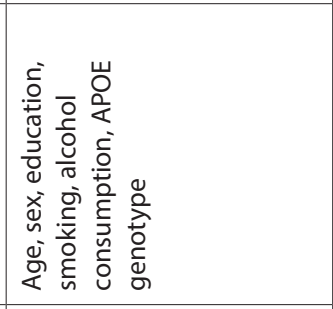 & 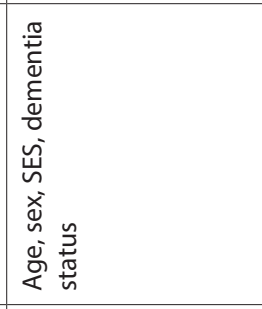 & 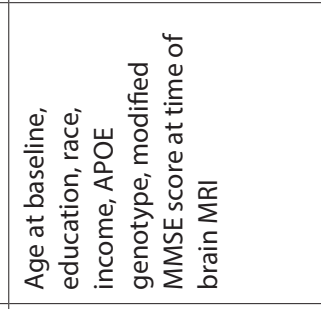 \\
\hline 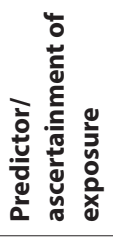 & 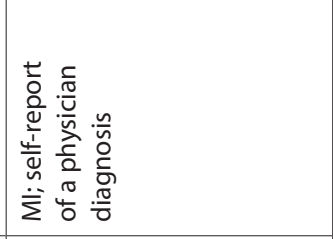 & 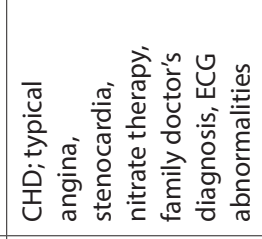 & 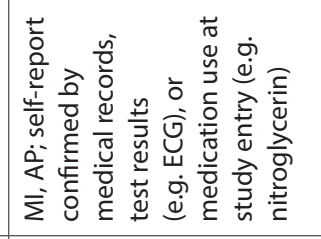 \\
\hline 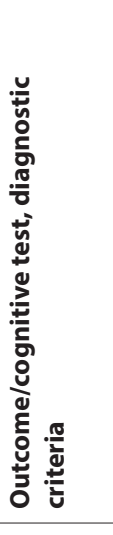 & 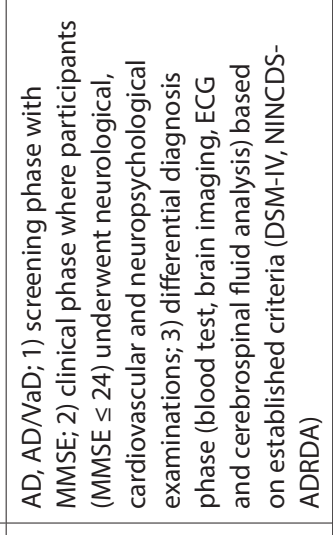 & 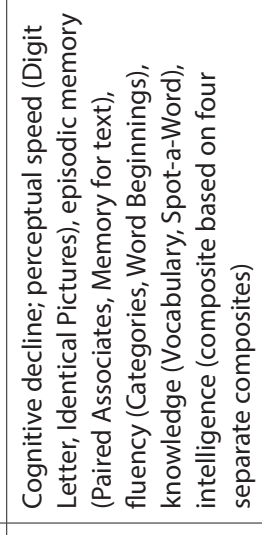 & 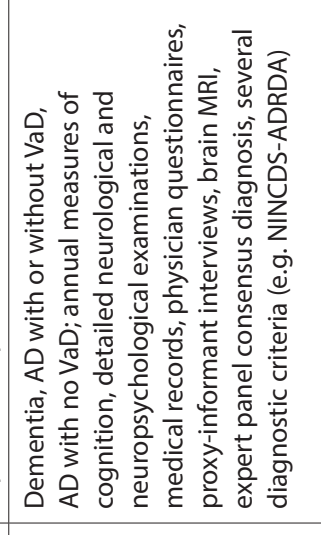 \\
\hline 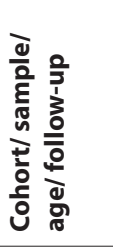 & 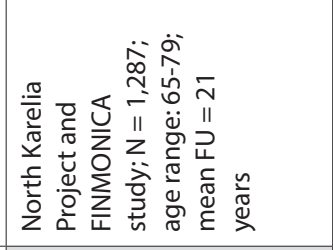 & 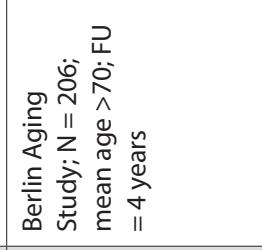 & 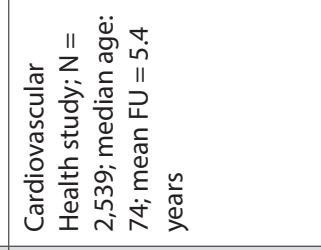 \\
\hline $\begin{array}{l}\frac{n}{2} \\
\frac{c}{\tilde{z}} \\
\end{array}$ & 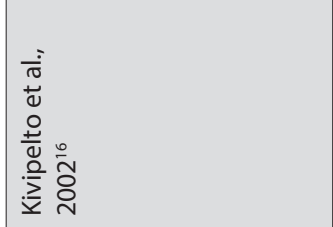 & 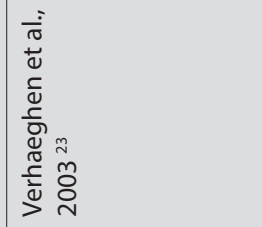 & 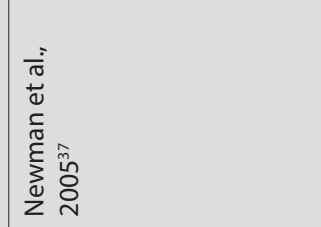 \\
\hline
\end{tabular}




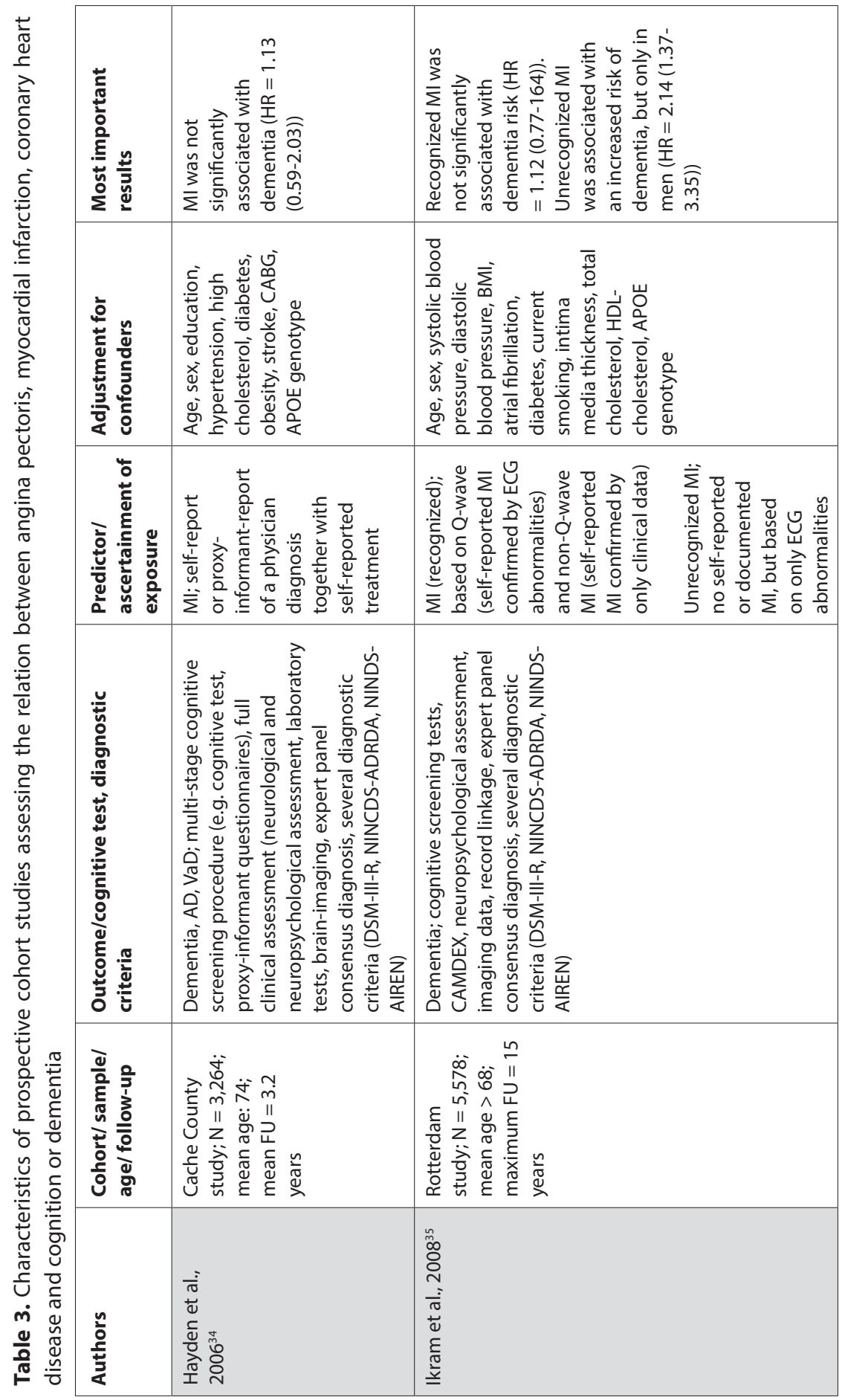




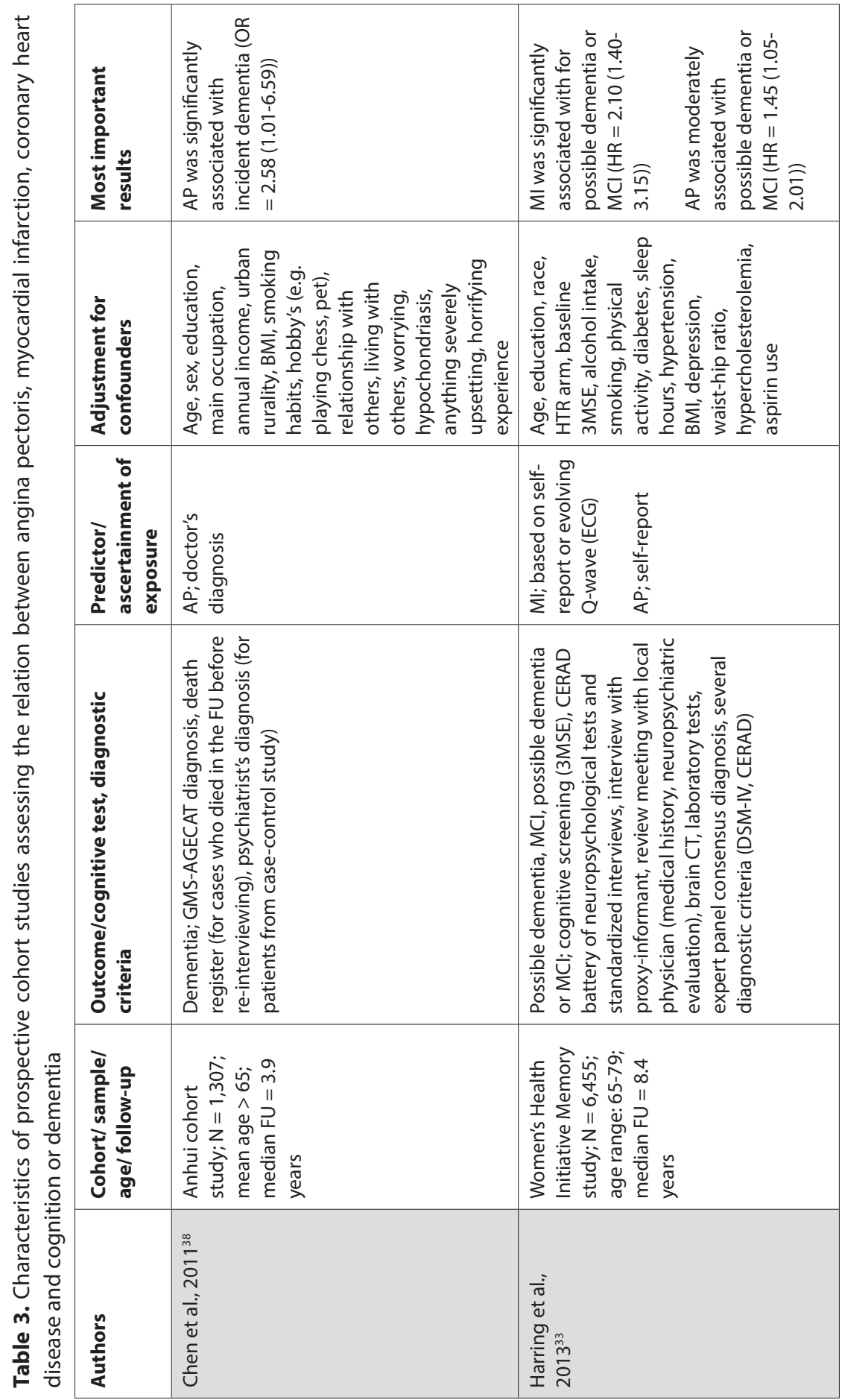




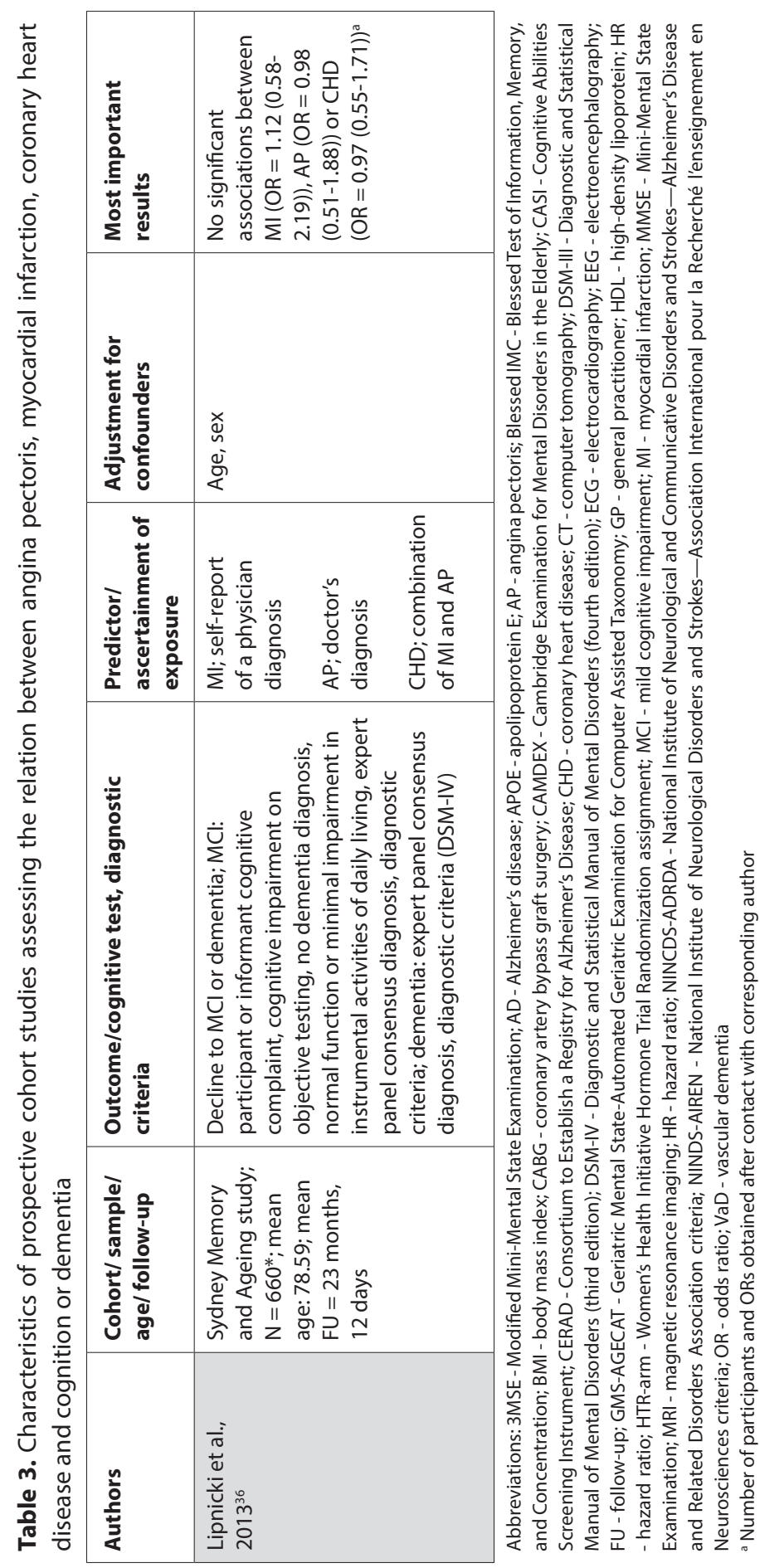




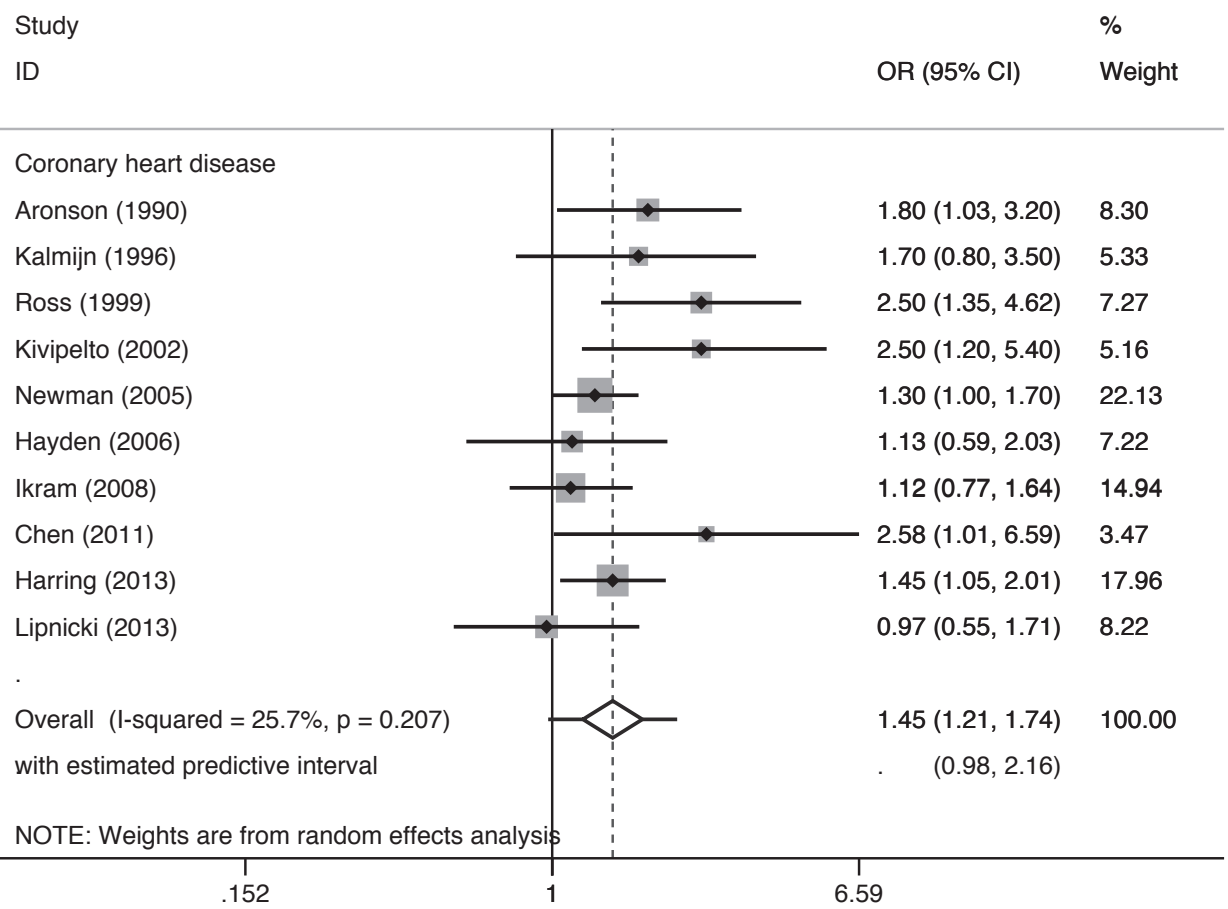

Figure 2. Forest plot of prospective cohort studies assessing the relation between coronary heart disease and cognitive impairment or dementia

\section{DISCUSSION}

The results of this systematic literature review and meta-analysis indicate that individuals with CHD have, on average, a $45 \%$ increased risk of cognitive impairment or dementia. Separate meta-analyses of prospective cohort studies for the individual predictors (MI, AP) showed similar significant results. In contrast, meta-analyses of cross-sectional and case-control studies yielded no significant results, possibly due to the low number of studies included within these analyses and the moderate to substantial heterogeneity among studies. It has to be noted that, for cross-sectional studies, those studies that could not be included in the meta-analysis (those using different continuous outcome measures of cognitive functioning), majorly found lower cognitive abilities in CHD. The literature on CHD is mixed in general, with the majority of prospective and cross-sectional studies 
demonstrating a significant association with cognition or dementia, and most of the casecontrol studies showed no association.

The exact biological mechanism by which $\mathrm{CHD}$ is related to risk of cognitive impairment or dementia is still unknown, but several candidate pathways exist. CHD and dementia share common risk factors such as obesity, type-2 diabetes, smoking, hypertension, physical inactivity, and hypercholesterolemia. ${ }^{7,8} \mathrm{CHD}$ can be associated with cardiac complications (atrial fibrillation, heart failure), whose association with cognitive impairment or dementia is well-established. ${ }^{7,9}$ Additionally, CHD and accompanying vascular insufficiency can lead to cerebrovascular changes such as reduced cerebral blood flow (which can lead to hypoperfusion), ${ }^{41}$ white matter lesions and brain infarctions, ${ }^{35}$ which in turn are associated with reduced cognitive functioning and risk of dementia. ${ }^{42,43} \mathrm{CHD}$ might however not itself be causally related to cognition, but brain-effects (e.g. cognitive impairment with vascular origin) might be due to underlying atherosclerosis, which increases both the risk of $\mathrm{CHD}$ and dementia. ${ }^{44,45}$

Given the present results, public health campaigns focusing on preventing CHD or dementia should join forces and consider placing a greater emphasis on targeting shared risk factors (e.g. obesity, hypercholesterolemia, physical inactivity, hypertension, smoking). Studies have shown that targeting these modifiable risk factors can be effective in reducing incidence rates and disease burden. ${ }^{5,46}$ Concerted actions focusing on the heart-brain connection might be key to fostering healthy aging.

The strengths of this study include the use of large population-based studies with different study designs and the use of risk estimates that were pre-adjusted for confounding variables. Nevertheless, a number of limitations have to be mentioned. First, some studies based the ascertainment of the predictors on self-report or proxy-report, which can be prone to recall bias and underreporting, particularly given the relative older age of the included cohorts. This is particularly problematic in case-control studies, in which differential reporting bias may lead to exposure misclassification and diluted or even biased estimates. Fortunately, the majority of the included studies used validated or combined (e.g. self-report verified by validated) measurements to establish the exposure status. Second, substantial heterogeneity was observed in both cross-sectional and casecontrol studies. This can be related to differences in methodology across studies (e.g. assessment of dementia or cognitive functioning, ascertainment of exposure, variation between cohorts (e.g. gender specific) selection of study participants, follow-up duration and adjustment for important covariates). While meta-regression analyses did not identify any statistically significant source of heterogeneity, other methodological differences not included in the analyses might explain the between-study difference in effect estimates. 
By using a random-effects meta-analysis we have tried to account for variability within and between studies. Third, the observed effects could probably be attributed to residual confounding in the original studies, although we used the most fully adjusted models. Fourth, studies were excluded if their CHD exposure was not a combination of purely MI and AP. For instance, studies reporting on IHD based on the the International Classification of Diseases and Related Health Problems (ICD-10) codes for IHD (I20-I25) were excluded because some of the codes also include coronary atherosclerosis and coronary artery aneurysm which are more causes of IHD. ${ }^{47}$ While this has led to the exclusion of studies affirming the association between CHD and cognitive impairment or dementia, our focus was on MI and AP as the most prevalent conditions. Using a broader search strategy that includes all causes of IHD led to more than 12,000 search hits (now 6,132), which was considered unfeasible.

In conclusion, CHD was associated with an increased risk of cognitive impairment or dementia in prospective cohort studies. Nonetheless, mechanistic studies are needed that focus on the underlying biological pathways (e.g. left ventricular dysfunction, cerebral small vessel disease due to hypoperfusion) and shared risks (e.g. hypertension, arterial stiffness, common genetic variants) that link CHD and risk of cognitive impairment or dementia. In addition, policy makers and health workers must become more aware that identification of individuals at high risk for CHD or dementia is essential to intervene at an early stage by targeting these shared modifiable risk factors. Future public health campaigns have to anticipate on these new insights. 


\section{REFERENCES}

1. Collaborators GMaCoD. Global, regional, and national life expectancy, all-cause mortality, and cause-specific mortality for 249 causes of death, 1980-2015: a systematic analysis for the Global Burden of Disease Study 2015. Lancet 2016; 388(10053): 1459-544.

2. World Health Organization. Cardiovascular diseases - Fact sheet $N^{\circ} 317.2015$ January. http:// www.who.int/mediacentre/factsheets/fs317/en/.

3. Mendis S, Puska P, Norrving B. Global Atlas on Cardiovascular Disease Prevention and Control. Geneva: World Health Organization, 2011.

4. Ferri $C P$, Prince $M$, Brayne $C$, et al. Global prevalence of dementia: a Delphi consensus study. Lancet 2005; 366(9503): 2112-7.

5. Norton S, Matthews FE, Barnes DE, Yaffe K, Brayne C. Potential for primary prevention of Alzheimer's disease: an analysis of population-based data. Lancet Neurol 2014; 13(8): 788-94.

6. Plassman BL, Williams JW, Jr., Burke JR, Holsinger T, Benjamin S. Systematic review: factors associated with risk for and possible prevention of cognitive decline in later life. Ann Intern Med 2010; 153(3): 182-93.

7. Justin BN, Turek M, Hakim AM. Heart disease as a risk factor for dementia. Clin Epidemiol 2013; 5: $135-45$.

8. Deckers K, van Boxtel MP, Schiepers OJ, et al. Target risk factors for dementia prevention: a systematic review and Delphi consensus study on the evidence from observational studies. Int J Geriatr Psychiatry 2015; 30(3): 234-46.

9. Kalantarian S, Stern TA, Mansour M, Ruskin JN. Cognitive impairment associated with atrial fibrillation: a meta-analysis. Ann Intern Med 2013; 158(5 Pt 1): 338-46.

10. Kwok CS, Loke YK, Hale R, Potter JF, Myint PK. Atrial fibrillation and incidence of dementia: a systematic review and meta-analysis. Neurology 2011; 76(10): 914-22.

11. Santangeli $P$, Di Biase $L, B a i R$, et al. Atrial fibrillation and the risk of incident dementia: a metaanalysis. Heart Rhythm 2012; 9(11): 1761-8.

12. Moher D, Liberati A, Tetzlaff J, Altman DG. Preferred reporting items for systematic reviews and meta-analyses: the PRISMA statement. BMJ 2009; 339: b2535.

13. Stroup DF, Berlin JA, Morton SC, et al. Meta-analysis of observational studies in epidemiology: a proposal for reporting. Meta-analysis Of Observational Studies in Epidemiology (MOOSE) group. JAMA 2000; 283(15): 2008-12.

14. Wells G, Shea B, O'connell D, et al. The Newcastle-Ottawa Scale (NOS) for assessing the quality of nonrandomised studies in meta-analyses. 2000.

15. IntHout J, loannidis JP, Rovers MM, Goeman JJ. Plea for routinely presenting prediction intervals in meta-analysis. BMJ Open 2016; 6(7): e010247.

16. Kivipelto M, Helkala EL, Laakso MP, et al. Apolipoprotein E epsilon4 allele, elevated midlife total cholesterol level, and high midlife systolic blood pressure are independent risk factors for latelife Alzheimer disease. Ann Intern Med 2002; 137(3): 149-55.

17. Sparks DL, Hunsaker JC, 3rd, Scheff SW, Kryscio RJ, Henson JL, Markesbery WR. Cortical senile plaques in coronary artery disease, aging and Alzheimer's disease. Neurobiol Aging 1990; 11(6): 601-7.

18. Breteler MM, Claus JJ, Grobbee DE, Hofman A. Cardiovascular disease and distribution of cognitive function in elderly people: the Rotterdam Study. BMJ 1994; 308(6944): 1604-8. 
19. Elwood PC, Pickering J, Bayer A, Gallacher JE. Vascular disease and cognitive function in older men in the Caerphilly cohort. Age Ageing 2002; 31(1): 43-8.

20. Petrovitch $\mathrm{H}$, White $\mathrm{L}$, Masaki $\mathrm{KH}$, et al. Influence of myocardial infarction, coronary artery bypass surgery, and stroke on cognitive impairment in late life. Am J Cardiol 1998; 81(8): 101721.

21. Roberts RO, Knopman DS, Geda YE, Cha RH, Roger VL, Petersen RC. Coronary heart disease is associated with non-amnestic mild cognitive impairment. Neurobiol Aging 2010; 31(11): 1894902.

22. Singh-Manoux A, Britton AR, Marmot M. Vascular disease and cognitive function: evidence from the Whitehall II Study. J Am Geriatr Soc 2003; 51(10): 1445-50.

23. Verhaeghen $\mathrm{P}$, Borchelt $\mathrm{M}, \mathrm{Smith} \mathrm{J}$. Relation between cardiovascular and metabolic disease and cognition in very old age: cross-sectional and longitudinal findings from the berlin aging study. Health Psychol 2003; 22(6): 559-69.

24. Arntzen KA, Schirmer H, Wilsgaard T, Mathiesen EB. Impact of cardiovascular risk factors on cognitive function: the Tromso study. Eur J Neurol 2011; 18(5): 737-43.

25. Heath CA, Mercer SW, Guthrie B. Vascular comorbidities in younger people with dementia: a cross-sectional population-based study of 616245 middle-aged people in Scotland. J Neurol Neurosurg Psychiatry 2015; 86(9): 959-64.

26. Singh-Manoux A, Sabia S, Lajnef $M$, et al. History of coronary heart disease and cognitive performance in midlife: the Whitehall II study. Eur Heart $J$ 2008; 29(17): 2100-7.

27. Bursi F, Rocca WA, Killian JM, et al. Heart disease and dementia: a population-based study. Am J Epidemiol 2006; 163(2): 135-41.

28. Massaia M, Pallavicino Di Ceva A, Bo M, et al. Risk factors for dementia of Alzheimer's type: a case-control, retrospective evaluation. Arch Gerontol Geriatr Suppl 2001; 7: 253-9.

29. Takahashi PY, Caldwell CR, Targonski PV. Effect of vascular burden as measured by vascular indexes upon vascular dementia: a matched case-control study. Clin Interv Aging 2012; 7: 2733.

30. Brayne C, Gill C, Huppert FA, et al. Vascular risks and incident dementia: results from a cohort study of the very old. Dement Geriatr Cogn Disord 1998; 9(3): 175-80.

31. Hughes TF, Andel R, Small BJ, et al. Midlife fruit and vegetable consumption and risk of dementia in later life in Swedish twins. Am J Geriatr Psychiatry 2010; 18(5): 413-20.

32. Aronson MK, Ooi WL, Morgenstern $\mathrm{H}$, et al. Women, myocardial infarction, and dementia in the very old. Neurology 1990; 40(7): 1102-6.

33. Haring B, Leng X, Robinson J, et al. Cardiovascular disease and cognitive decline in postmenopausal women: results from the Women's Health Initiative Memory Study. J Am Heart Assoc 2013; 2(6): e000369.

34. Hayden KM, Zandi PP, Lyketsos CG, et al. Vascular risk factors for incident Alzheimer disease and vascular dementia: the Cache County study. Alzheimer Dis Assoc Disord 2006; 20(2): 93-100.

35. Ikram MA, van Oijen $\mathrm{M}$, de Jong FJ, et al. Unrecognized myocardial infarction in relation to risk of dementia and cerebral small vessel disease. Stroke 2008; 39(5): 1421-6.

36. Lipnicki DM, Sachdev PS, Crawford J, et al. Risk factors for late-life cognitive decline and variation with age and sex in the Sydney Memory and Ageing Study. PLoS One 2013; 8(6): e65841. 
37. Newman AB, Fitzpatrick AL, Lopez $\mathrm{O}$, et al. Dementia and Alzheimer's disease incidence in relationship to cardiovascular disease in the Cardiovascular Health Study cohort. J Am Geriatr Soc 2005; 53(7): 1101-7.

38. Chen R, Hu Z, Wei L, Ma Y, Liu Z, Copeland JR. Incident dementia in a defined older Chinese population. PLoS One 2011; 6(9): e24817.

39. Kalmijn S, Feskens EJ, Launer LJ, Kromhout D. Cerebrovascular disease, the apolipoprotein e4 allele, and cognitive decline in a community-based study of elderly men. Stroke 1996; 27(12): 2230-5.

40. Ross GW, Petrovitch $\mathrm{H}$, White LR, et al. Characterization of risk factors for vascular dementia: the Honolulu-Asia Aging Study. Neurology 1999; 53(2): 337-43.

41. Gruhn N, Larsen FS, Boesgaard S, et al. Cerebral Blood Flow in Patients With Chronic Heart Failure Before and After Heart Transplantation. Stroke 2001; 32(11): 2530-3.

42. de la Torre JC. Cardiovascular risk factors promote brain hypoperfusion leading to cognitive decline and dementia. Cardiovasc Psychiatry Neurol 2012; 2012: 367516.

43. Debette $S$, Markus HS. The clinical importance of white matter hyperintensities on brain magnetic resonance imaging: systematic review and meta-analysis. BMJ 2010; 341: c3666.

44. Roeters van Lennep JE, Westerveld HT, Erkelens DW, van der Wall EE. Risk factors for coronary heart disease: implications of gender. Cardiovascular Research 2002; 53(3): 538-49.

45. van Oijen M, de Jong FJ, Witteman JC, Hofman A, Koudstaal PJ, Breteler MM. Atherosclerosis and risk for dementia. Ann Neurol 2007; 61(5): 403-10.

46. Manuel DG, Lim J, Tanuseputro $P$, et al. Revisiting Rose: strategies for reducing coronary heart disease. BMJ 2006; 332(7542): 659-62.

47. World Health Organization. International Statistical Classification of Diseases and Related Health Problems, 10th Revision. Geneva:World Health Organization, 1992. 


\section{SUPPLEMENTAL DATA}

\section{APPENDIX 1: Complete search strategy}

\section{Medline}

S1: (dement* or Alzheimer* or cognit* or neuropsychol*).af.

S2: (((ischemic or ischaemic or coronary) and (heart OR artery)) or myocardium or myocardial or angina).af.

S3: 1 and 2

S4: limit 3 to (humans and (dutch or english or french or german))

\section{Embase}

S1: (dement* or Alzheimer* or cognit* or neuropsychol*).ti,ab.

S2: (((ischemic or ischaemic or coronary) and (heart or artery)) or myocardium or myocardial or angina).ti,ab.

S3: 1 and 2

S4: limit 3 to (humans and (dutch or english or French or german))

\section{PsycINFO}

S1: dement\# OR Alzheimer OR cognit\# OR neuropsychol\#

S2: (((ischaemic OR ischemic OR coronary) AND (heart OR artery)) OR myocardium OR myocardial OR angina)

S3: S1 AND S2

\section{CINAHL}

S1: (((ischaemic OR ischemic OR coronary) AND (heart OR artery)) OR myocardium OR myocardial OR angina)

S2: dement\# OR Alzheimer OR cognit\# OR neuropsychol\#

S3: S1 and S2 


\section{APPENDIX 2: Newcastle-Ottawa quality assessment scale adapted for cross- sectional studies}

Note: A study can be awarded a maximum of one star for each numbered item within the Selection and Outcome categories, with the exception for 'Assessment for outcome' from the Outcome category. A maximum of two stars can be given for Comparability.

Selection (Maximum 4 stars)

Representativeness of the exposed cohort

a) Truly representative of the general population (random sampling) *

b) Somewhat representative of general population (non-random sampling) *

c) Selected group of users (e.g. nurses, volunteers)

d) No description of the sampling strategy

Sample size, response rate, and comparability between respondent and non-respondents

a) Sample size is justified, response rate AND the comparability between respondents and non-respondents characteristics are described*

b) Sample size is justified and the response rate $\mathrm{OR}$ the comparability between respondents and non-respondents characteristics is described *

c) Sample size is justified, but no description of the response rate and the characteristics of the responders and non-responders

d) Sample size is not justified, and there is no description of the response rate or the characteristics of the responders and non-responders

Selection of the non-exposed cohort
a) Drawn from the same community as the exposed cohort *
b) Drawn from a different source
c) No description of the derivation of the non-exposed cohort

Ascertainment of exposure
a) Validated measurement tool *
b) Non-validated measurement tool, but the tool is available or described *
c) Self-report
d) No description 


\section{Comparability (Maximum 2 stars)}

Comparability of cohorts on the basis of the design or analysis
a) Study controls for the most important factor *
b) Study controls for any additional factor *
c) No control for any important factor

Outcome (Maximum 3 stars)

\section{Assessment of outcome}
a) Independent blind assessment **
b) Record linkage **
c) Self-report
d) No description

Statistical test
a) The statistical test used to analyze the data is clearly described and appropriate, and the measurement of the association is presented, including confidence intervals and the probability level ( $p$ value)*
b) The statistical test is not appropriate, not described or incomplete 


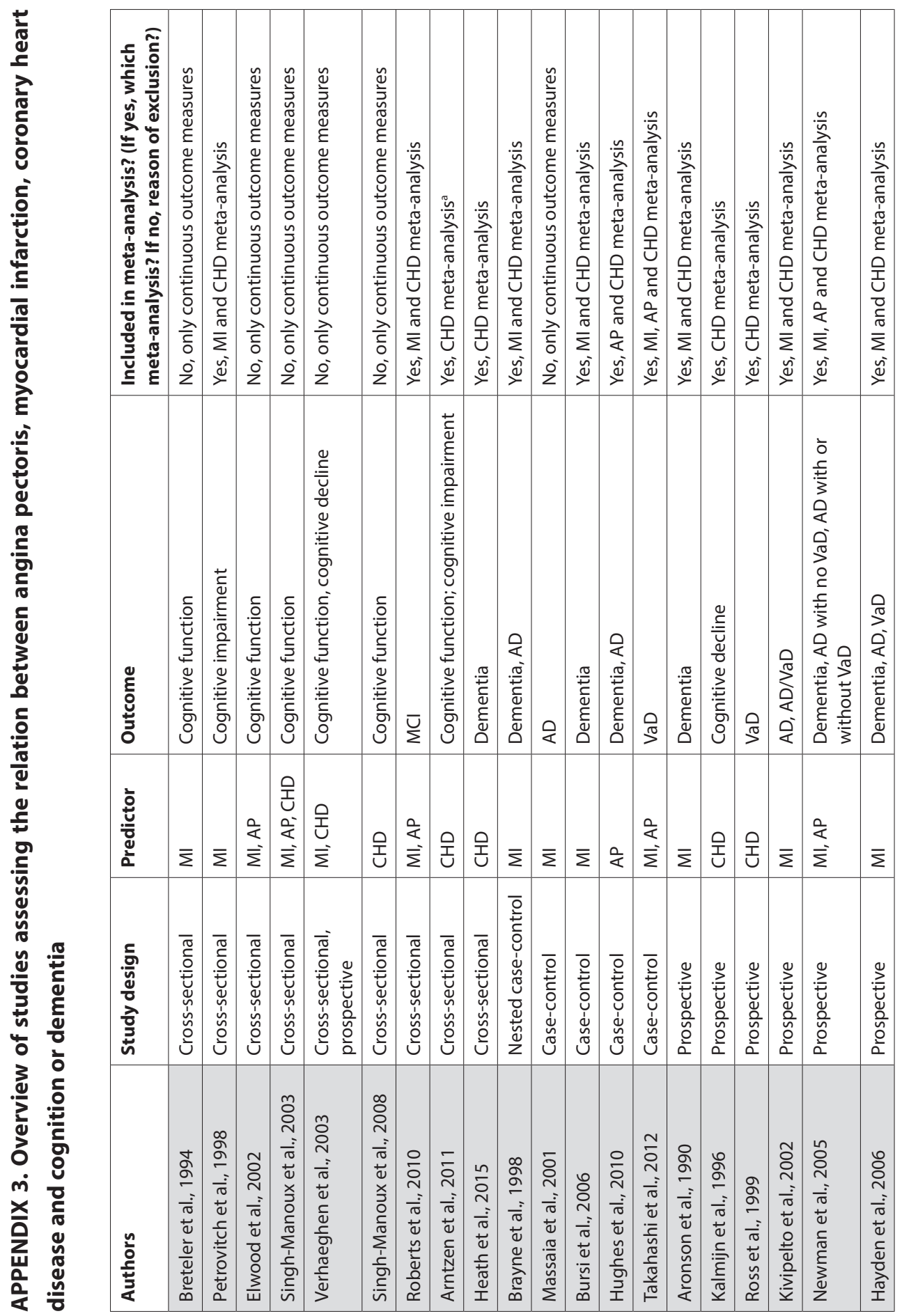




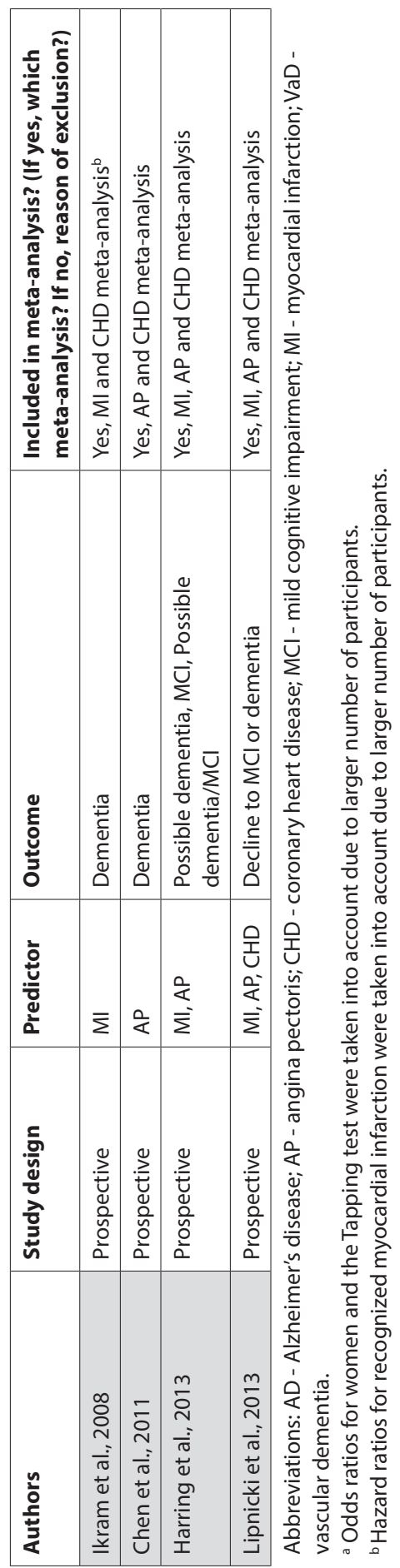




\section{APPENDIX 4: Cross-sectional studies}

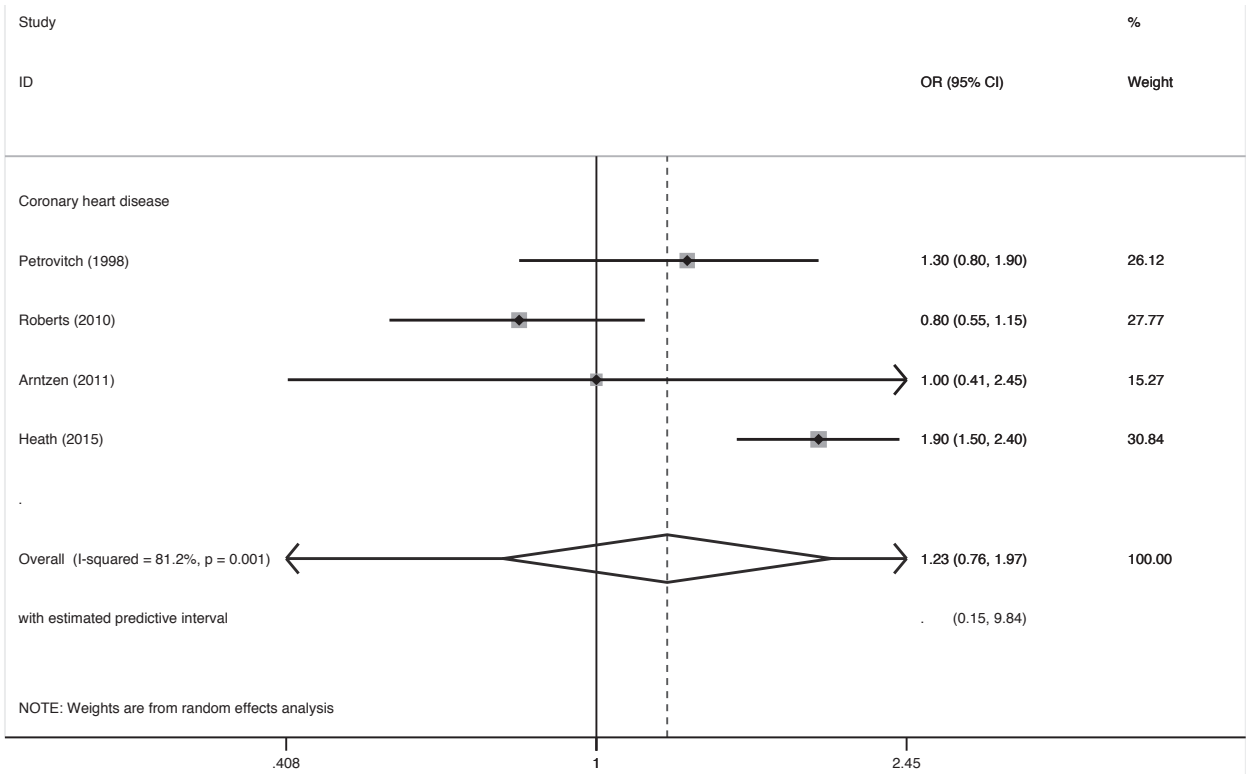

Figure 1: Forest plot of cross-sectional studies assessing the relation between coronary heart disease and cognitive impairment or dementia

Funnel plot with pseudo 95\% confidence limits

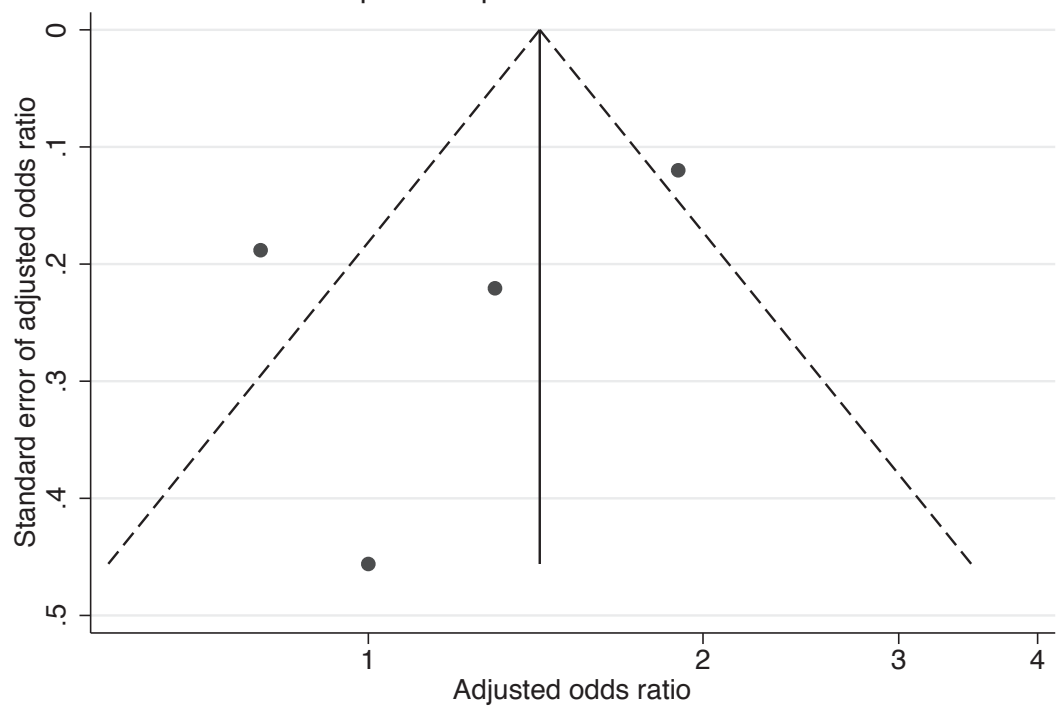

Figure 2: Funnel plot of cross-sectional studies included in the coronary heart disease metaanalysis showing the effect estimates by their standard errors 
Study

ID

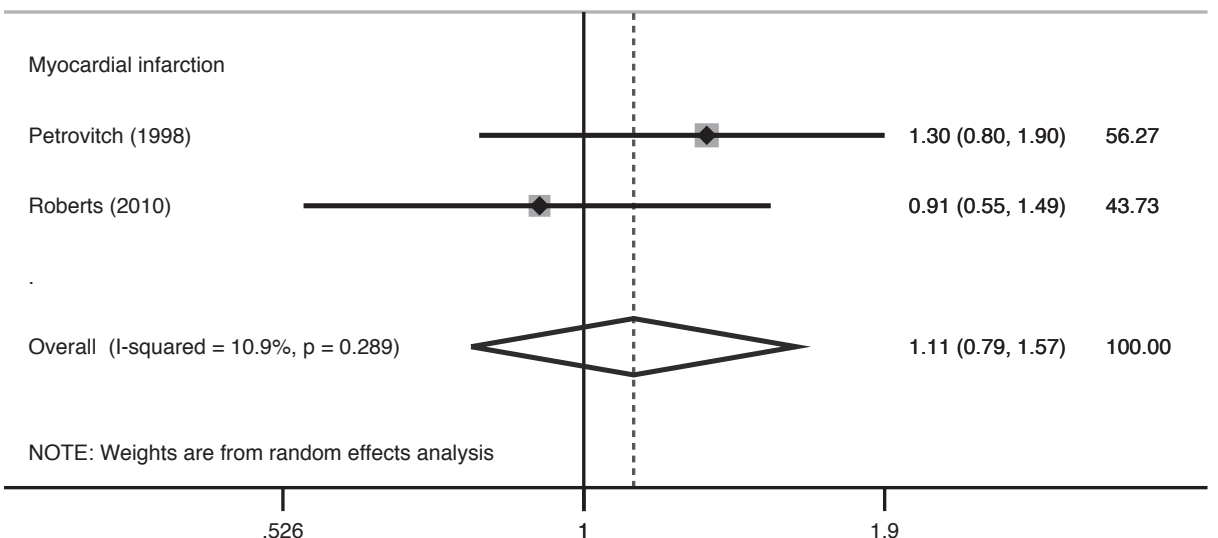

Figure 3: Forest plot of cross-sectional studies assessing the relation between myocardial infarction and cognitive impairment or dementia 


\section{APPENDIX 5: Case-control studies}

Study

ID

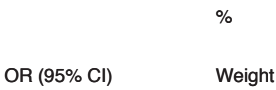

$2.94(1.20,7.21) \quad 12.04$

$1.00(0.62,1.62) \quad 25.02$

$0.86(0.66,1.13) \quad 35.73$

$1.22(0.79,1.88) \quad 27.20$

$1.14(0.79,1.64) \quad 100.00$

$(0.27,4.84)$

with estimated predictive interval

NOTE: Weights are from random effects analysis

.139

Figure 1: Forest plot of case-control studies assessing the relation between coronary heart disease and cognitive impairment or dementia

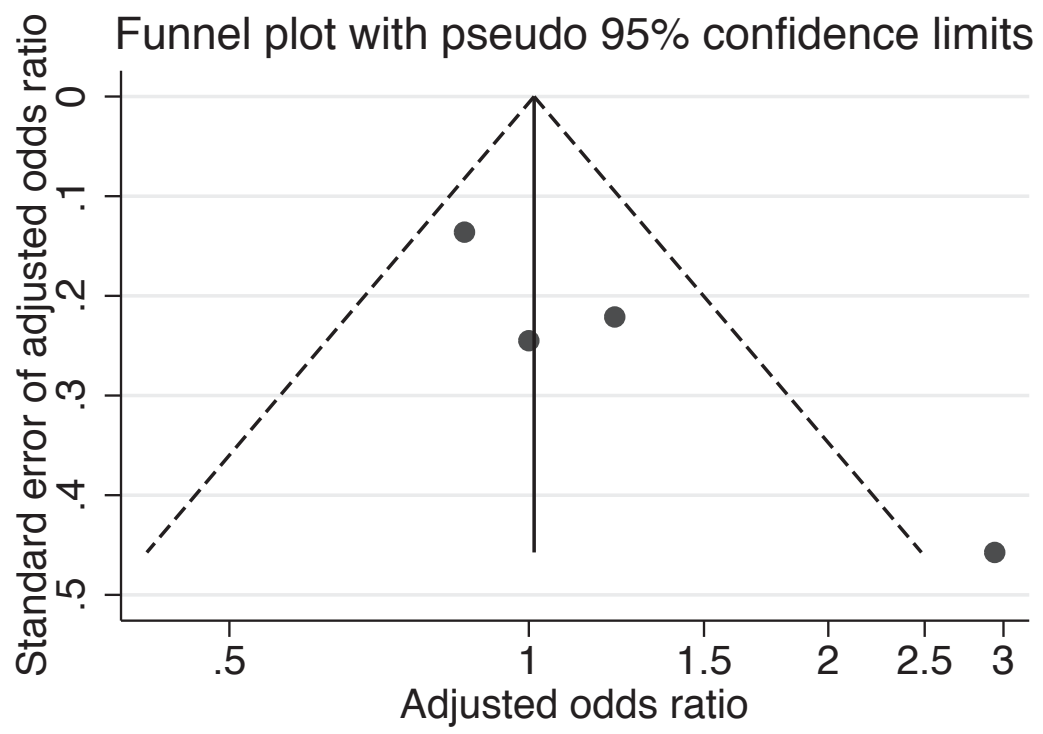

Figure 2: Funnel plot of case-control studies included in the coronary heart disease meta-analysis showing the effect estimates by their standard errors 


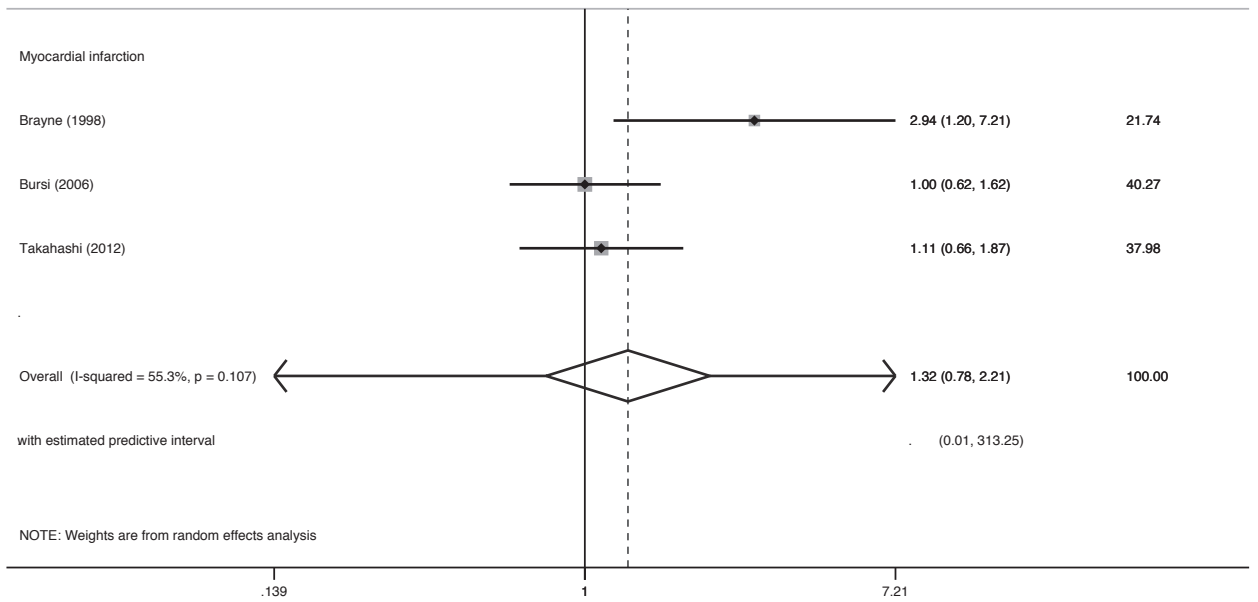

Figure 3: Forest plot of case-control studies assessing the relation between myocardial infarction and cognitive impairment or dementia

Study

ID
$\%$

OR $(95 \% \mathrm{Cl}) \quad$ Weight

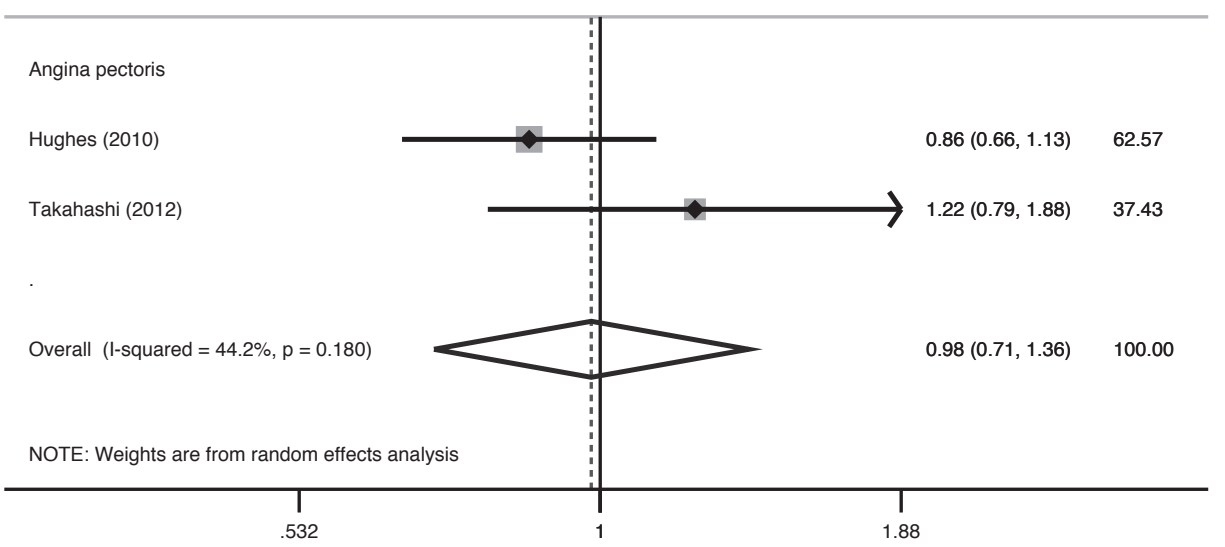

Figure 4: Forest plot of case-control studies assessing the relation between angina pectoris and cognitive impairment or dementia 


\section{APPENDIX 6: Prospective cohort studies}

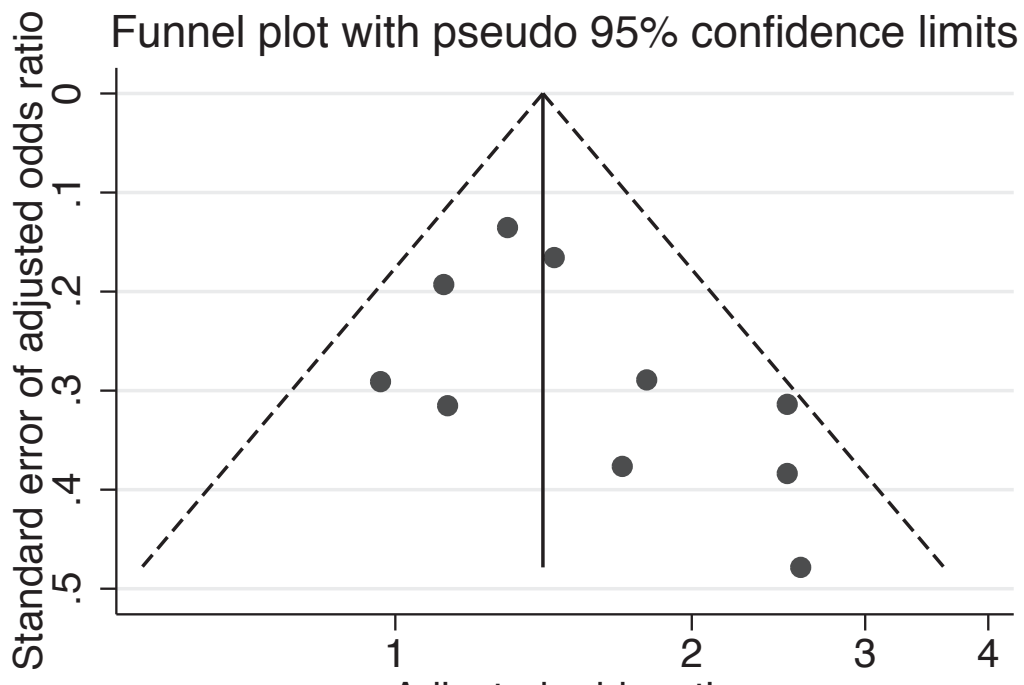

Figure 1: Funnel plot of prospective cohort studies included in the coronary heart disease metaanalysis showing the effect estimates by their standard errors

Study

ID

Myocardial infarction

Aronson (1990)

Kivipelto (2002)

Newman (2005)

Hayden (2006)

Ikram (2008)

Harring (2013)

Lipnicki (2013)

Overall (I-squared $=34.7 \%, p=0.163$ )

with estimated predictive interval

NOTE: Weights are from random effects analy\$is

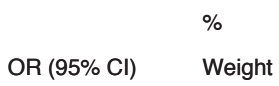

OR $(95 \% \mathrm{Cl}) \quad$ Weight

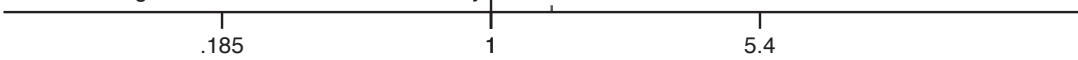

Figure 2: Forest plot of prospective cohort studies assessing the relation between myocardial infarction and cognitive impairment or dementia 
Study

ID

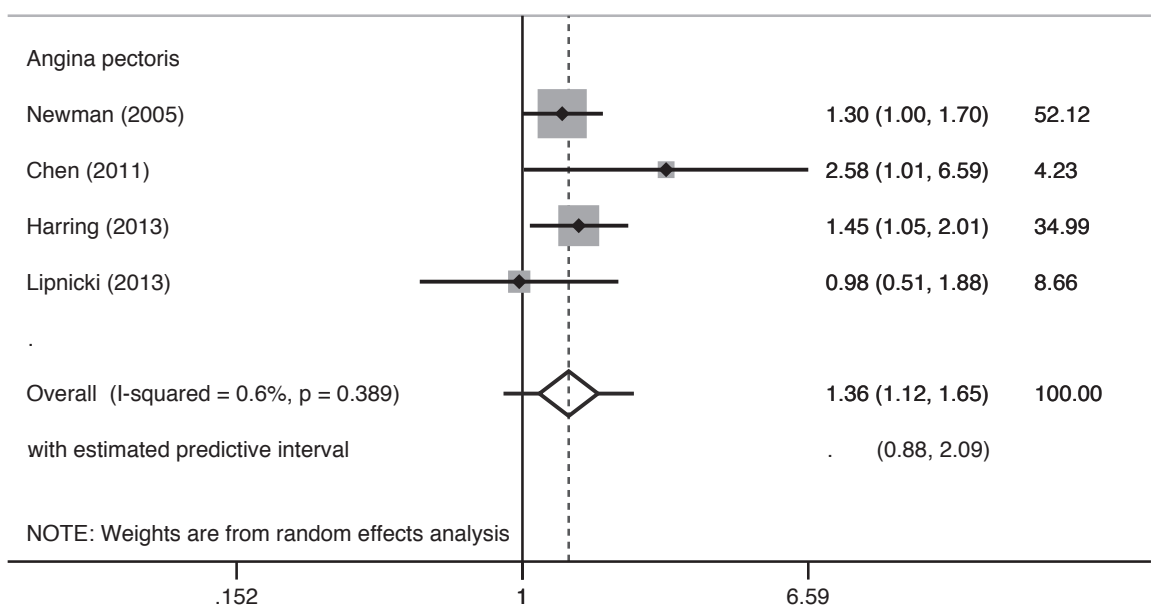

Figure 3: Forest plot of prospective cohort studies assessing the relation between angina pectoris and cognitive impairment or dementia 




\section{PART II}

PROSPECTIVE COHORT STUDIES INTO DEMENTIA EPIDEMIOLOGY 


\section{CHAPTER 5}

\section{OBESITY AND COGNITIVE DECLINE IN ADULTS: EFFECT OF METHODOLOGICAL \\ CHOICES AND CONFOUNDING BY AGE IN A LONGITUDINAL STUDY}

Journal of Nutrition, Health and Aging 2016

Kay Deckers, Martin PJ van Boxtel, Frans RJ Verhey, Sebastian Köhler 


\section{ABSTRACT}

Background and Objectives: Obesity has been associated with increased risk of cognitive impairment or dementia, but recent findings are contradictory, possibly due to methodological differences. The present study tries to clarify these inconsistencies by following the cognitive trajectories of individuals with obesity over 12 years and studying the effect of obesity status (obesity at baseline versus incident obesity at follow-up), chronicity, definition, potential confounding (e.g. age, cardiovascular factors), and nonlinear associations.

Design: Longitudinal study with 12 years follow-up.

Setting: Community based.

Participants: 1,807 cognitively healthy individuals (aged 24-83) from the Maastricht Aging Study (1992-2004).

Measurements: Memory, executive function and processing speed were assessed at baseline and at 6- and 12-year follow-up. Obesity was defined as having a body mass index (BMI) of $\geq 30.0 \mathrm{~kg} / \mathrm{m}^{2}$ or waist circumference (WC) of $>102 \mathrm{~cm}$ for men and $>88 \mathrm{~cm}$ for women.

Results: At baseline, 545 persons were obese (BMI: 329 (18\%); WC: 494 (27\%); both: 278 (15\%). They showed faster decline in memory, executive function, and processing speed. Chronic obese showed less widespread impairment than those who regained normal weight. Associations across cognitive domains were weaker for obesity defined by BMI than for WC. At follow-up, 190 developed obesity, and they performed worse on executive function at baseline, but showed less decline compared with participants with normal weight. Yet, age-stratification and post-hoc analyses showed that most of these associations were confounded by age.

Conclusions: This study shows that the association between obesity and cognitive decline was confounded by the effect of age on rate of decline. Future studies should take this into account. 


\section{INTRODUCTION}

The incidence of dementia is steadily increasing with 4.6 million new cases of dementia every year. ${ }^{1}$ In the absence of a treatment for dementia, identification of modifiable dementia risk factors is important to implement risk management strategies. ${ }^{2}$ Simultaneously, global age-standardized prevalence of obesity doubled from $6.4 \%$ in 1980 to $12 \%$ in 2008 , with the highest absolute numbers found in women and industrialized countries, ${ }^{3-6}$ while the relative increase is largest for low- and middle-income countries. ${ }^{1}$

Midlife obesity has been associated with a faster cognitive decline and a $60 \%$ increased risk of dementia. ${ }^{3,5}$ However, results of prospective studies are inconsistent ${ }^{7}$. Four recent studies found no evidence that midlife obesity increases dementia risk, ${ }^{8-11}$ or suggested that it might even be a protective factor, while underweight individuals might be at risk. ${ }^{11}$ Discrepancies in findings partly reflect differences in the measurement of obesity, residual confounding, demography and age at obesity assessment or duration. To date, few studies have investigated the age-dependent effects of obesity on cognitive change. Next, it is unclear whether this association might be mediated by obesity-related comorbidities such as hyperlipidemia, hypertension or type 2 diabetes. ${ }^{12,13}$

Therefore, the current study investigates the influence of a range of methodological choices in the analysis of the association between obesity and cognitive decline. More specifically, the studies assesses 1) the association between baseline and incident obesity and cognitive decline; 2 ) whether this association is independent of age and other important covariates (e.g. cardiovascular risk factors); 3) the effect of chronic obesity on cognition; 4) the impact of obesity measure (body mass index (BMI) versus waist circumference (WC)); and 5) the effect of accounting for both linear and non-linear associations between body weight and cognitive decline.

\section{METHODS}

\section{Participants}

The Maastricht Aging Study (MAAS) is a prospective cohort study examining the determinants of cognitive aging. ${ }^{14}$ A total of 10,801 patients without major neurological conditions or psychiatric disorders were sampled from Registration Network Family Practices, a collaborative network of general practices in the south of the Netherlands, ${ }^{15}$ and were invited to participate in MAAS. The Registration Network Family Practices represents the general population with respect to demographic characteristics. ${ }^{14}$ Exclusion criteria were medical conditions that may interfere with normal cognitive 
function: (e.g. coma, epilepsy, dementia). All eligible participants were screened in a semistructured interview by telephone for medical conditions that were not documented in the Registration Network Family Practices database such as history of transient ischemic attacks or brain surgery. For inclusion in MAAS, a sub-sample of 1823 individuals was drawn from the Registration Network Family sampling frame stratified for age (12 discrete age groups from 24 to 81 years), sex, and level of occupational achievement (low/high) to have balanced groups in each stratum. At baseline (1993-1996), these participants underwent a comprehensive assessment of medical status, lifestyle, and anthropomorphic and neurocognitive measures, which were repeated 6 and 12 years after baseline. See Appendix 1 for the flowchart of the study design.

\section{Measures}

\section{Obesity}

Obesity was defined by both BMI and WC. BMI was calculated as weight in kilograms divided by height in meters squared $\left(\mathrm{kg} / \mathrm{m}^{2}\right)$. The cut-off point for obesity (BMI $\geq 30.00$ $\mathrm{kg} / \mathrm{m}^{2}$ ) was used according to World Health Organization guidelines. ${ }^{16}$ WC provides an indication of abdominal fat, and obesity is defined by a WC of $>102 \mathrm{~cm}$ (or $>41$ inches) in men and $>88 \mathrm{~cm}$ (or $>36$ inches) in women. ${ }^{16}$ Weight, height and WC were measured with a medical scale, stadiometer and tape measure, respectively. Participants were defined as obese based on BMI (measured at baseline, 6- and 12-year follow-up), WC (measured at baseline and 6-year follow-up) or both.

\section{Cognitive decline}

Neuropsychological tests were administered by psychologists and trained test assistants at baseline and the 6- and 12-year follow-up measurements. The Visual Verbal Learning Test was used to assess verbal memory. ${ }^{17}$ In this test, fifteen non-related monosyllabic words are presented in five consecutive trials on a computer screen, followed by an immediate (after each trial) and delayed (twenty minutes after last trial) recall phase. In the present study, the delayed recall was used. The Concept Shifting Test was used to measure executive function. ${ }^{18}$ In three trials, the participant has to cross out as fast as possible sixteen digits in ascending order (part A), sixteen letters in alphabetic order (part $B$ ), and finally eight digits and eight letters in alternating order (part C). The shifting score is calculated by subtracting the average time needed to complete part A and B from the time needed to complete part C. The Letter Digit Substitution Test was used to assess 
information processing speed. ${ }^{19}$ Using a reference key, the participant has ninety seconds to match specific letters to given numbers as quickly as possible.

\section{Covariates}

Age, sex, and educational level (low, middle and high) were included as demographic covariates. Blood pressure was measured three times at five-minute intervals on the left arm using an automatic sphygmomanometer (Critikon Dinamap 8100). Hypertension was defined as a systolic blood pressure of $\geq 140 \mathrm{mmHG}$ or a diastolic blood pressure of $\geq 90 \mathrm{mmHG}$ averaged over the three measurements, or self-reported antihypertensive medication intake. ${ }^{20}$ Presence of type 2 diabetes was based on a self-reported diagnosis by a physician or use of anti-diabetic medication at or after 40 years of age. Depressive symptoms were assessed using the 16-item depression subscale of the revised Symptom Checklist-90.21 Other variables included self-report of cardiovascular disease (e.g. myocardial infarction, angina pectoris), present or past history of smoking (yes/no), and alcohol abuse (according to World Health Organization guidelines). ${ }^{22}$

\section{Statistical analyses}

Differences between obese and non-obese participants were analyzed using independent samples $t$-test and $X^{2}$-tests. Two data transformations were used for the skewed distributions of the Visual Verbal Learning Test (square root transformation) and the Concept Shifting Test (logarithmic transformation). Random effects models tested the association between obesity and change in cognition over time. We used two inverse probability weights to reduce selection bias: 1) an attrition weight to correct for bias due to selective attrition (e.g. inclusion of individuals with missing follow-up data); and 2) a sampling weight to weight back the estimates to the population from which the MAAS sample was drawn (Registration Network Family Practices database). The attrition weight was constructed using a probit regression on being lost to follow-up at the 6 or 12 year assessment using baseline values for age, gender, education, delayed recall score, depressive symptoms, $\mathrm{BMI}$, alcohol intake, smoking status, and presence of hypertension, cardiovascular disease or diabetes as predictors. The sampling weight was based on a probit regression on the likelihood of being sampled into MAAS from the Registration Network Family Practices sampling frame using age, gender and level of occupational achievement as predictors. The inverse of the probability was used in the analyses, so that participants who were less likely to be sampled or to have follow-up scores were given more weight in the analyses. The models included a random intercept and random slope with an unstructured correlation matrix, as suggested by likelihood ratio tests. Interaction terms between 
obesity and a discrete time variable were included by using dummy variables for the two follow-ups ( 1 = baseline to 6 years; 2 = baseline to 12 years). The obesity-by-time interaction was tested using a $x^{2}$-test with 2 degrees of freedom. First, cognition scores were adjusted for age, age ${ }^{2}$, sex, level of education, and obesity and time, while fullyadjusted model also included baseline alcohol intake, history of smoking, and current (i.e. time-varying) hypertension, type 2 diabetes, depressive symptoms and cardiovascular disease. Analyses were stratified by sex and age group (young: < 65 years; old: $\geq 65$ years). Since the results from crude models differed minimally (see Appendix 2), only the results from fully adjusted models (Model 1 in Table 2 and Table 3 ) are presented. Tests were twosided with an alpha-level of 0.05 and were done in Stata 13.1 (StataCorp, TX).

\section{RESULTS}

Baseline characteristics are summarized in Table 1. Sixteen out of 1,823 participants were excluded due to missing obesity data $(n=7)$ or because they were underweight $(n=9)$. Of the remaining 1,807 participants, 545 (30\%) persons were obese (BMI: $n=329$ (18\%); WC: $\mathrm{n}=494$ (27\%); both: $\mathrm{n}=278$ (15\%). They were on average older, more often female, and had lower education, higher depression scores, and a history of hypertension, type 2 diabetes, and cardiovascular disease than non-obese participants. Of the 1,262 participants without baseline obesity, 238 participants were excluded due to missing obesity data at follow-up. Of the remaining 1,024 participants, 190 (19\%) persons had incident obesity at 6- or 12year follow-up. They were more often women and had a lower educational level.

\section{Step 1: Baseline obesity and cognitive decline}

Baseline cognition in participants with obesity did not differ from non-obese participants, but the former declined faster in all three cognitive domains (Model 1 in Table 2). Comparing slopes across time showed that this was dictated by an accelerated decline from 6- to 12-year follow-up (memory: $\mathrm{x}^{2}=5.03 ; \mathrm{df}=1 ; \mathrm{p}=0.025$; executive function: $\mathrm{x}^{2}=5.80$; $d f=1 ; p=0.016$; processing speed $\left.x^{2}=11.82 ; d f=1 ; p=0.001\right)$. In women, but not in men, obesity was associated with a faster decline in all domains (See Appendix 3).

\section{Step 2: Effect of age and age-related decline}

In persons aged $<65$ years at baseline, obesity was significantly associated with a faster decline in processing speed, but not in memory or executive function. Baseline obesity did not predict cognitive decline later in life ( $\geq 65$ years) (see Appendix 4). To further explore the effect of age, we adjusted for age-related variation in rate of cognitive 
decline by including an age-by-time interaction term in above analyses (Figure 1; Model 2 in Table 2). As expected, being older was associated with a faster decline in all three cognitive domains, yet the association between obesity and cognitive decline became non-significant, suggesting that the association of obesity and cognitive decline was due to the fact that obese individuals tended to be older. The difference in effect estimates between Model 1 and Model 2 (see Table 2) was substantial. For memory this led to 78\% decrease in the estimate, and for executive function and processing speed to a decrease of $70 \%$ and $91 \%$, respectively. The same phenomenon was found in women.

Table 1. Baseline characteristics of the study sample by obesity status at baseline and follow-up

\begin{tabular}{|c|c|c|c|c|c|c|}
\hline \multirow[b]{2}{*}{ Variables $^{a}$} & \multicolumn{3}{|c|}{ Baseline obesity } & \multicolumn{3}{|c|}{ Incident obesity } \\
\hline & $\begin{array}{l}\text { Yes, } \\
n=545\end{array}$ & $\begin{array}{l}\text { No, } \\
n=1,262\end{array}$ & P-value & $\begin{array}{l}\text { Yes, } \\
n=190\end{array}$ & $\begin{array}{l}\text { No, } \\
n=834\end{array}$ & $P$-value \\
\hline Age, mean (SD) & $58.0(15.0)$ & $48.9(16.2)$ & $<0.001$ & $49.0(15.5)$ & $46.7(14.9)$ & 0.060 \\
\hline Male, n (\%) & $227(41.7)$ & $680(53.9)$ & $<0.001$ & 79 (41.6) & $479(57.4)$ & $<0.001$ \\
\hline $\begin{array}{l}\text { Educational level, n (\%) } \\
\text { Low } \\
\text { Middle } \\
\text { High }\end{array}$ & $\begin{array}{l}263(48.4) \\
201(37.0) \\
80(14.7)\end{array}$ & $\begin{array}{l}397(31.5) \\
536(42.5) \\
328(26.0)\end{array}$ & $<0.001$ & $\begin{array}{l}69(36.3) \\
73(38.4) \\
48(25.3)\end{array}$ & $\begin{array}{l}229(27.5) \\
376(45.1) \\
229(27.5)\end{array}$ & 0.049 \\
\hline $\mathrm{BMI}$, mean (SD) & $31.2(3.9)$ & $24.9(2.5)$ & $<0.001$ & $28.7(2.4)$ & $24.8(2.4)$ & $<0.001$ \\
\hline Waist circumference, mean (SD) & $101.3(9.1)$ & $84.6(9.6)$ & $<0.001$ & $98.2(7.3)$ & $86.9(9.1)$ & $<0.001$ \\
\hline History of smoking, n (\%) & $346(67.2)$ & $791(67.5)$ & 0.901 & $107(60.1)$ & $518(66.8)$ & 0.093 \\
\hline Alcohol abuse, $\mathrm{n}(\%)$ & $14(2.6)$ & $37(2.9)$ & 0.669 & $1(0.5)$ & $25(3.0)$ & 0.051 \\
\hline Hypertension, n (\%) & $293(53.8)$ & $365(28.9)$ & $<0.001$ & $59(31.1)$ & $205(24.6)$ & 0.066 \\
\hline Type 2 diabetes, n (\%) & $35(6.4)$ & $33(2.6)$ & $<0.001$ & $4(2.1)$ & $16(1.9)$ & 0.867 \\
\hline Cardiovascular disease, $\mathrm{n}(\%)$ & $83(15.2)$ & $111(8.8)$ & $<0.001$ & $14(7.4)$ & $49(5.9)$ & 0.440 \\
\hline Depression score, mean (SD) & $21.3(6.8)$ & $20.5(6.1)$ & 0.010 & $20.7(5.7)$ & $20.2(5.8)$ & 0.313 \\
\hline
\end{tabular}

Abbreviations: BMI - Body Mass Index; SD - standard deviation.

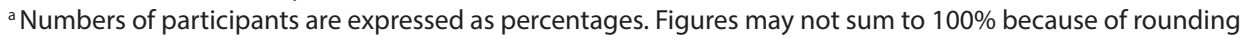
errors. 


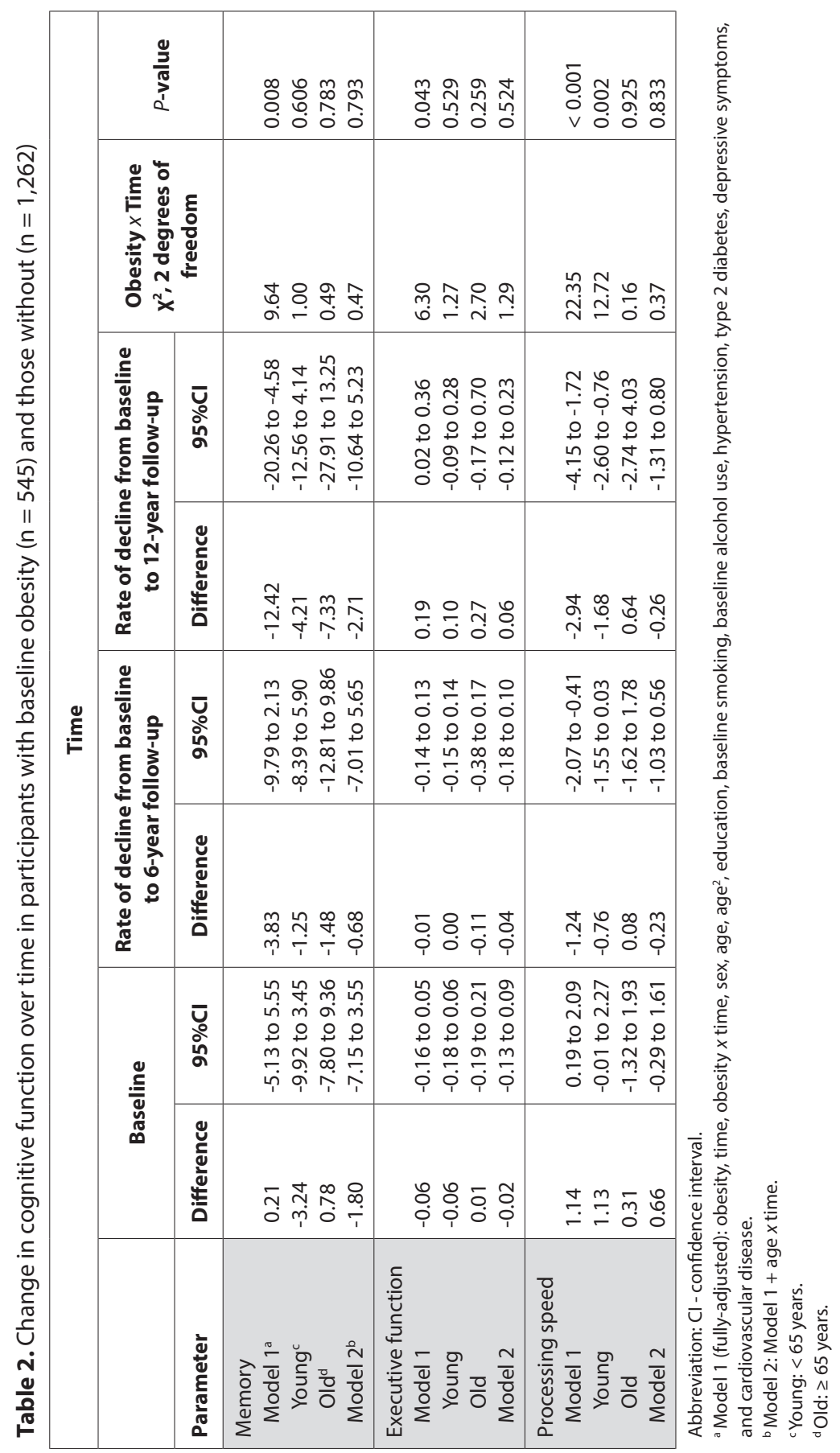



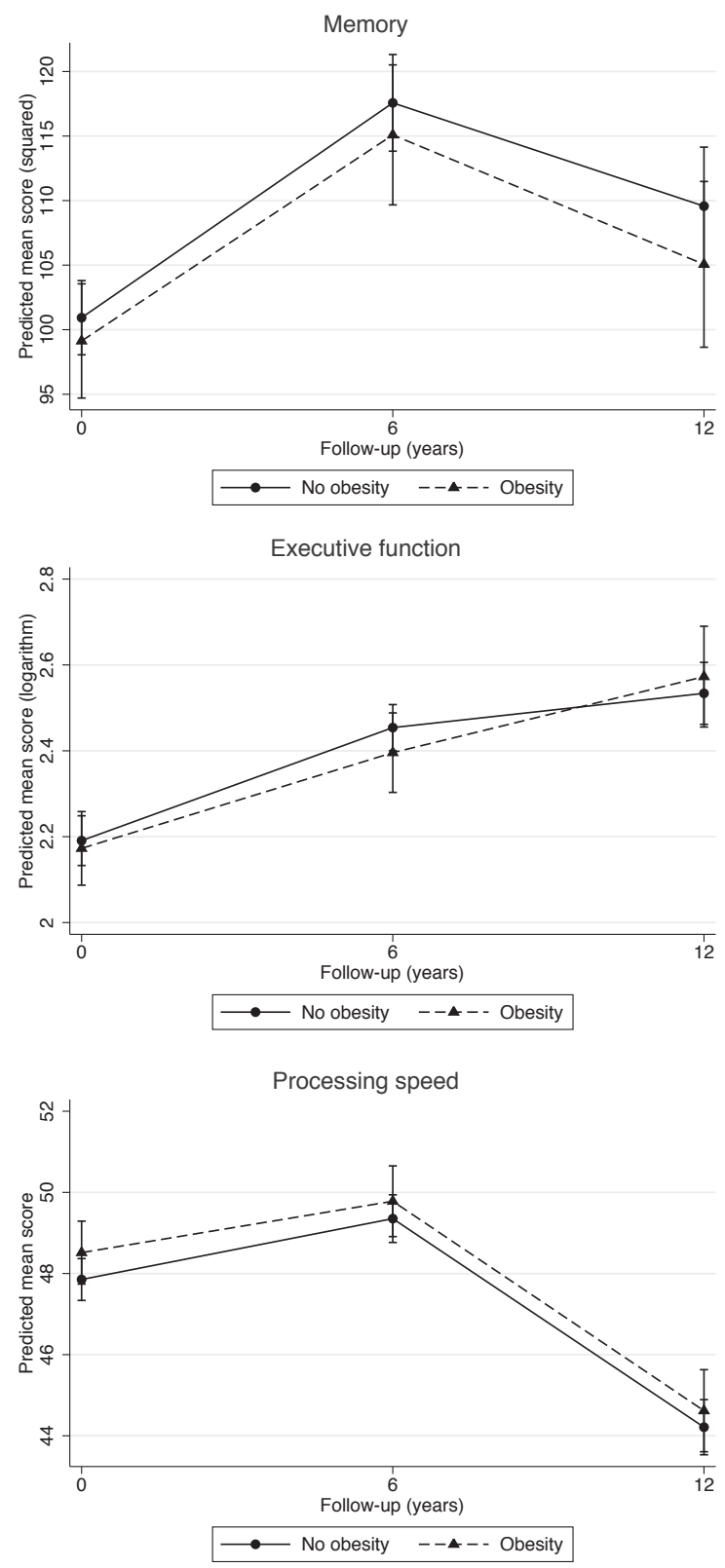

Figure 1. Cognitive trajectories of persons with baseline obesity (dotted line) and those without baseline obesity (solid line)

Adjusted for sex, age, age ${ }^{2}$, education, obesity $x$ time, age $x$ time, baseline smoking, baseline alcohol use, hypertension, type 2 diabetes, depressive symptoms, and cardiovascular disease (Model 2). For memory and processing speed, a higher score indicates better performance. For executive function, a lower score indicates better performance. Predicted mean scores are estimated marginal means of time by obesity status (obesity or no obesity) with all covariates fixed at their means. 


\section{Step 3: Incident obesity and cognitive decline}

Table 3 summarizes the results for the comparisons between participants with incident obesity ( $n=190)$ and those with normal weight $(n=834)$. For executive function, but not for memory and processing speed, the former group performed worse at baseline but showed less decline during the study period in comparison with healthy subjects (Model 1 in Table 3). Sex-stratified analyses showed no significant differences between males and females.

\section{Step 4: Effect of age and age-related decline}

In persons aged $<65$ years, incident obesity was not associated with memory or processing speed. For executive function, persons with incident obesity had lower scores at baseline but showed less decline during the study period compared with healthy participants. Obesity did not predict cognitive decline later in life ( $\geq 65$ years) (Appendix 4). Adjusting for the potential confounding effect of age on rate of decline in the total sample did not change results: incident obese individuals had worse baseline scores but a less steep decline than non-obese participants (Model 2 in Table 3 and Appendix 5). The difference in effect estimates between Model 1 and Model 2 (see Table 3) was considerable. For memory, the estimate was decreased by $26 \%$, and for executive function and processing speed this decrease was $10 \%$ and $70 \%$, respectively.

\section{Step 5: Predictive value of BMI versus WC}

In order to compare the predictive value of BMI and WC, additional analyses for baseline obesity were conducted. Obesity according to BMI predicted a faster decline in processing speed (memory: $x^{2}=3.77 ; d f=2 ; p=0.152$; executive function: $x^{2}=2.97 ; d f=2 ; p=0.226$; processing speed $\left.x^{2}=10.41 ; d f=2 ; p=0.006\right)$. Obesity based on WC was associated with a faster decline in all three cognitive domains (memory: $x^{2}=9.88 ; \mathrm{df}=2 ; \mathrm{p}=0.007$; executive function: $X^{2}=6.30 ; d f=2 ; p=0.043$; processing speed $x^{2}=20.14 ; d f=2 ; p<0.001$ ). Again, after adding the age-by-time interaction term, the effect of obesity on cognitive decline was no longer significant for both measures. 


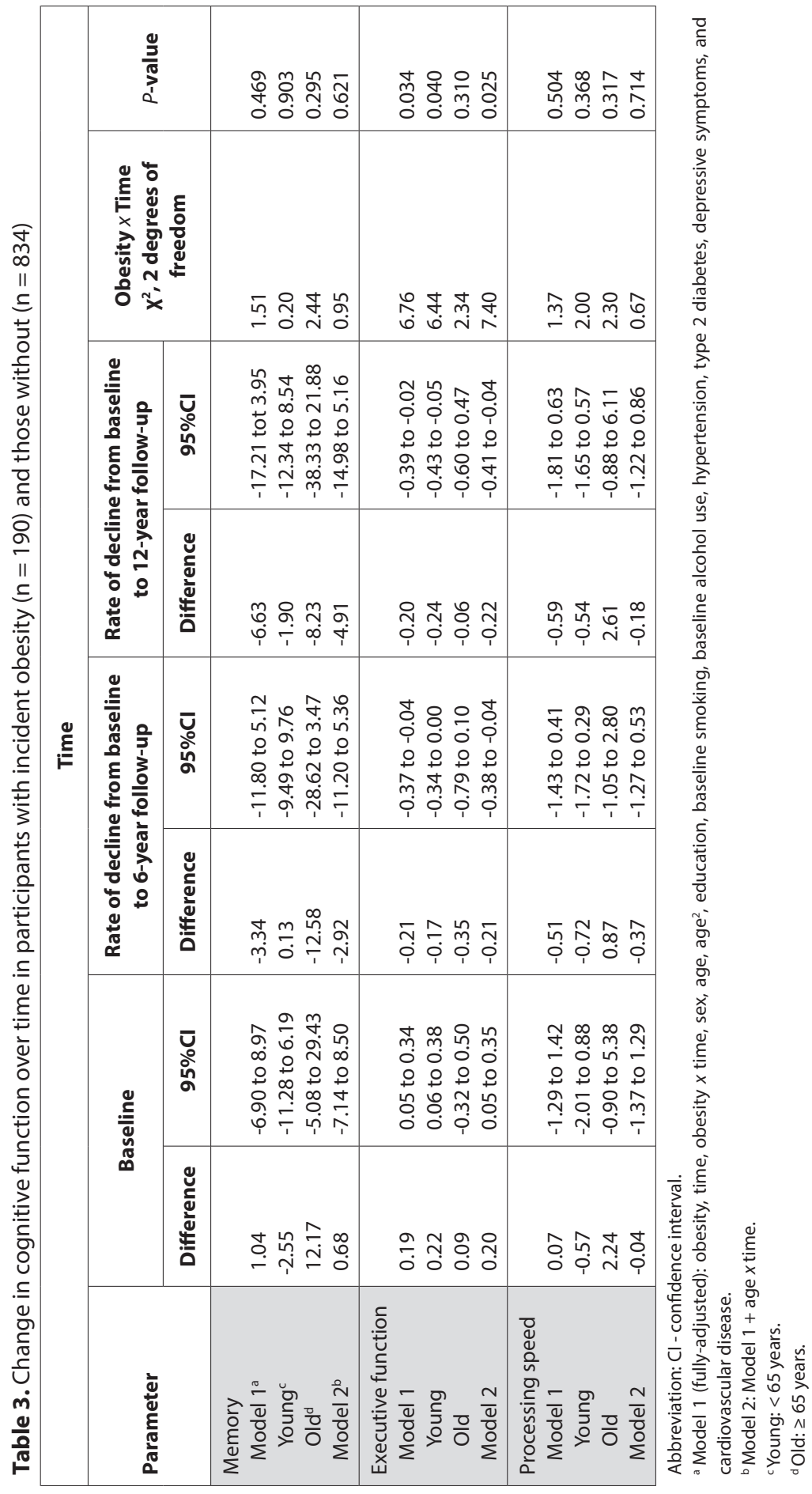




\section{Step 6: Effect of chronic obesity}

To investigate the effects of being obese over a short or a longer period of time we compared persons who were not obese during the study period with two groups: (1) persons who were obese at baseline but not at follow-up ( $n=74)$; and (2) persons who were obese both at baseline and follow-up ( $n=342)$. Individual who were obese only at follow-up (incident obesity) were excluded from this analysis. Compared to non-obese participants, the first group showed a decline in all three cognitive domains, whereas the second group showed decline in memory and processing speed, but not executive function. Again, after adding the age-by-time interaction to the model the associations were no longer significant.

\section{Step 7: Testing for non-linear associations between baseline BMI and cognition}

Finally, we tested for the presence of linear and quadratic (U-shaped) associations between baseline BMI and cognition, re-entering the nine participants with a $\mathrm{BMI}<18.5$. There was no association for executive function (quadratic: $x^{2}=0.56 ; d f=2 ; p=0.755$; linear: $\left.X^{2}=0.80 ; d f=2 ; p=0.670\right)$. For memory, a quadratic next to a linear association was observed (quadratic: $x^{2}=13.97 ; d f=2 ; p=0.001$; linear: $x^{2}=16.17 ; d f=2 ; p<0.001$ ). For processing speed, we only observed a significant linear relation (quadratic: $X^{2}=4.65 ; d f=2 ; p=0.098$; linear: $\left.x^{2}=7.92 ; d f=2 ; p=0.019\right)$. After adding the age-by-time interaction term, the associations for memory were still present. Figure 2 shows the rate of change over twelve year as a function of baseline BMI. The graph suggests a very modest linear decline from the lowest observed baseline BMI of 17 to BMI of 30, followed by a J-shaped trajectory with increasing BMI. Sensitivity analyses suggested that these effects were driven by a very small number of subjects in the lower and upper extremes of BMI with the severely obese group (BMI $\geq 40 ; n=5$ ) showing a significant improvement in memory over the 12-year follow-up in comparison with the healthy weight group $(p<0.001)$. They were older, more often women and had a lower educational level. In addition, they all showed a decrease in bodyweight during the study period. Persons with a BMI between 25 and 35 showed the smallest improvement in memory. When participants with a baseline $\mathrm{BMI} \geq 40$ were excluded, no significant linear $(p=0.129)$ or quadratic $(p=0.192)$ effects of $B M I$ on rate of change were observed. One participant had a remarkably high baseline BMI value (> 50) and also performed poor on all cognitive tests, but exclusion of this participant in sensitivity analyses showed no substantial influence on the analyses. 


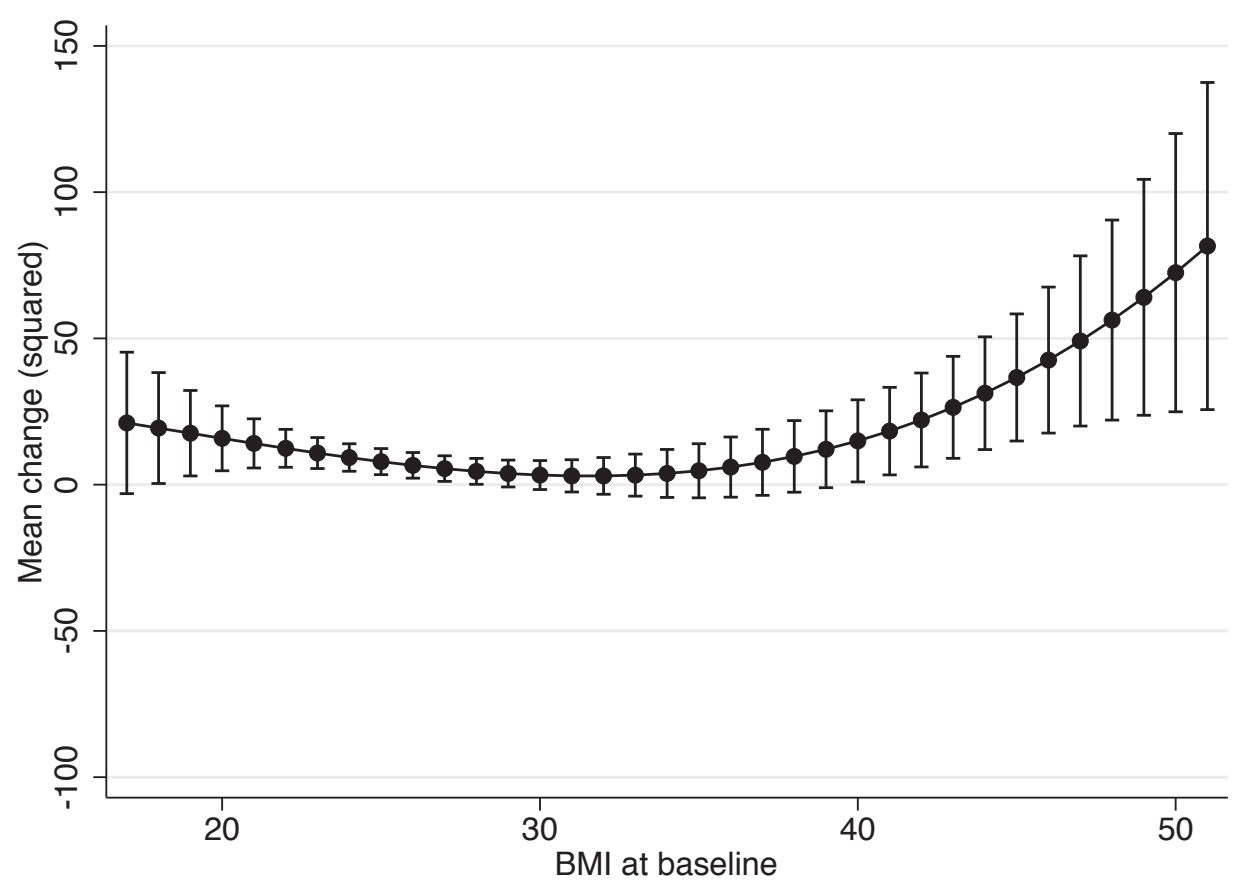

Figure 2. Change in memory performance from baseline to 12-year follow-up

Adjusted for sex, age, age ${ }^{2}$, education, Body Mass Index and time, Body Mass Index ${ }^{2} x$ time, age $x$ time, baseline smoking, baseline alcohol use, hypertension, type 2 diabetes, depressive symptoms, and cardiovascular disease (Model 2).

\section{DISCUSSION}

The present study investigated the association between baseline and incident obesity and cognitive decline over a 12-year follow-up period and potential differences in outcome that are due to methodological choices. Overall, results suggest that age and differences in rate of decline across the adult age range confounded the association between obesity and cognitive decline in this sample.

Initial results were largely congruent with previous reports: baseline (i.e. prevalent) obesity was associated with decline in memory, executive function, and processing speed independently of other cardiovascular risk factors, and more evidently in midlife $(<65$ years at baseline). Persons who developed obesity during the study period (incident obesity) seemed to perform worse on executive function at baseline but showed less decline during the study period in comparison with healthy subjects. In addition, WC as a measure of obesity showed stronger and more widespread association with cognitive 
decline than BMI. However, age-stratification nullified most of the associations. Additional analyses clarified that being older was associated with being obese at baseline or followup and a faster cognitive decline. Adjusting for these age-dependent differences in cognitive decline (in models that already adjusted the slope for obesity-related cognitive decline for linear and squared age effects), the associations of obesity and decline were no longer significant. An isolated effect was observed in the form of a curvilinear association between $\mathrm{BMI}$ and 12-year change in memory. Initial decline in memory from a healthy bodyweight (BMI from 18.5 to 25 ) to obesity (BMI $\geq 30$ ) was followed by memory improvement, but the association was driven by a very small number $(n=5)$ of severely obese persons. It was remarkably that all these persons show a decrease in bodyweight during the study period. Possibly, underlying lifestyle changes are responsible for weight loss and improvement in memory. Unfortunately, we were unable to explore this further. Several studies investigated the association between obesity and cognition or dementia risk longitudinally. ${ }^{7,23}$ The general notion is that of lower cognitive functioning and an increased risk of dementia in obese subjects, but the found associations are in fact rather inconclusive. ${ }^{7,23}$ Out of 14 studies published between October 2009 and December 2012, 7 showed an increased risk for cognitive impairment or dementia, while 2 showed a decreased risk and 5 showed no significant association. ${ }^{7}$ What is more, four recent studies found that obese persons have a lower dementia risk than people with a healthy weight. ${ }^{8-11}$ Results might be inconclusive due to methodological differences (e.g. followup duration, number of participant, measure of cognition/dementia, measure of obesity, obesity cut-offs). In the present study, the associations varied considerably as a function of age-range and sex of the cohort, and the choice of how to measure obesity. In addition, similar prospective studies like the present one found significant associations between midlife overweight/obesity and cognitive functioning in late-life, but they did not adjust for the confounding effect of age on rate of cognitive decline. ${ }^{24-26} \mathrm{~A}$ biological plausible mechanism that links obesity to cognitive impairment still is unknown, even though various pathways have been identified that could play a role in this complex relation. First, obesity is associated with neuroendocrine disturbances, increased presence of adipokines, enhanced pro-inflammatory markers, and hormonal abnormalities, which have deleterious effects on cognition-related brain structures ${ }^{27,28}$ by leading to cerebral atrophy, white matter abnormalities, and damage to the blood-brain barrier. ${ }^{25,28-31}$ Second, obesity is linked to several cardiovascular diseases and diabetes, which, in turn, are associated with an increased risk of cognitive impairment, 7,30,32 and obesity and metabolic abnormalities might have cumulative effects on cognitive decline. ${ }^{33}$ Third, there appears to be a bidirectional relation between obesity and cognition: obese persons 
have an increased risk of developing cognitive impairment, ${ }^{7,23}$ while individuals with low cognitive capacities earlier in life have an increased risk of becoming obese later (reverse causality). ${ }^{34}$ Obviously, more prospective studies on obesity-related brain changes and their correlations with cognitive decline are needed. Given the present results, such studies should look at both low and high BMI, or both under- and overweight, while carefully studying potential age-related effects.

The strengths of our study include the large sample size across the whole adult age range, the prospective design, serial assessments of obesity and cognitive functioning with a comprehensive neuropsychological test battery, and the availability of relevant covariates. Yet, a number of limitations should be mentioned. First, older participants with multiple comorbidities were more likely to drop out of the study. This could have resulted in an underestimation of the association between obesity and cognition in general, and in individuals aged $\geq 65$ years in particular. This is an unfortunate but common phenomenon in aging studies. By choosing random effects models that included covariates related to attrition and using additional attrition weights, we aimed to reduce selection bias. Second, as no information on cholesterol, physical activity, diet, medicine intake and illegal substance abuse was available in MAAS, we were not able to control for these factors. For instance, some studies suggest that dietary factors influence cognitive abilities and that dietary patterns might partly explain the relationship between obesity and lower cognitive functioning. ${ }^{35,36}$ Additionally, future public health policies should focus on healthy diet through nutritional education to reduce the increasing prevalence of obesity. ${ }^{37}$ Third, some of the covariates were assessed by self-report, which may have led to non-differential misclassification. Fourth, due to the non-experimental design of this study we are not able to make causal statements about the relationship between obesity and cognitive decline. The purpose of our explorative analyses was to investigate the influence of a range of methodological choices. For that reason, we did not correct for multiple testing, since this would reduce the chance to find an effect. Fifth, due to insufficient power we were not able to investigate the possible association between underweight $(n=9)$ and cognitive change. A recent retrospective study found that people who are underweight had an increased risk of dementia. ${ }^{11}$ This is partly consistent with our finding of a quadratic association between BMI and decline in memory.

This study indicates that the association between obesity and cognitive decline is not at all straightforward and may be highly dependent on methodological choices made during study design and data analysis. In MAAS, a strong confounding effect of age on rate of decline was present. Adjusting for age-differences in cognitive test scores per wave (i.e. not including a term for the interaction with time in linear mixed models) could not 
control for this. Future studies need to take this into account. Albeit less of an issue if dementia or other binary outcomes are studied, it might be favorable to use age as the time axis to control more rigorously for ageing effects in time-to-event or incidence rates. Also, more studies are needed that investigate biological plausible pathways as well as the complex association between obesity (and BMI and WC) and cognition, leaving room for non-linear relationships and mediating and moderating factors, in order to inform about the probability of obesity being a causal risk factor for decline. 


\section{REFERENCES}

1. Ferri CP, Prince $M$, Brayne $C$, et al. Global prevalence of dementia: a Delphi consensus study. Lancet 2005; 366(9503): 2112-7.

2. Alzheimer's Disease International. Dementia and risk reduction: an analysis of protective and modifiable factors. London: Alzheimer's Disease International, 2014.

3. Barnes DE, Yaffe K. The projected effect of risk factor reduction on Alzheimer's disease prevalence. Lancet Neurol 2011; 10(9): 819-28.

4. Finucane MM, Stevens GA, Cowan MJ, et al. National, regional, and global trends in body-mass index since 1980: systematic analysis of health examination surveys and epidemiological studies with 960 country-years and 9.1 million participants. Lancet 2011; 377(9765): 557-67.

5. Norton S, Matthews FE, Barnes DE, Yaffe K, Brayne C. Potential for primary prevention of Alzheimer's disease: an analysis of population-based data. Lancet Neuro/ 2014; 13(8): 788-94.

6. Stevens G, Singh G, Lu Y, et al. National, regional, and global trends in adult overweight and obesity prevalences. Population Health Metrics 2012; 10(1): 22.

7. Deckers K, van Boxtel MP, Schiepers OJ, et al. Target risk factors for dementia prevention: a systematic review and Delphi consensus study on the evidence from observational studies. Int J Geriatr Psychiatry 2015; 30(3): 234-46.

8. Albanese E, Davis B, Jonsson PV, et al. Overweight and Obesity in Midlife and Brain Structure and Dementia 26 Years Later: The AGES-Reykjavik Study. American Journal of Epidemiology 2015; 181(9): 672-9.

9. Aslan AK, Starr JM, Pattie A, Deary I. Cognitive consequences of overweight and obesity in the ninth decade of life? Age Ageing 2015; 44(1): 59-65.

10. de Bruijn RF, Bos MJ, Portegies ML, et al. The potential for prevention of dementia across two decades: the prospective, population-based Rotterdam Study. BMC Med 2015; 13: 132.

11. Qizilbash N, Gregson J, Johnson ME, et al. BMI and risk of dementia in two million people over two decades: a retrospective cohort study. Lancet Diabetes Endocrinol 2015; 3(6): 431-6.

12. Profenno LA, Porsteinsson AP, Faraone SV. Meta-analysis of Alzheimer's disease risk with obesity, diabetes, and related disorders. Biol Psychiatry 2010; 67(6): 505-12.

13. Whitmer RA, Gunderson EP, Quesenberry CP, Jr., Zhou J, Yaffe K. Body mass index in midlife and risk of Alzheimer disease and vascular dementia. Curr Alzheimer Res 2007; 4(2): 103-9.

14. Jolles J, Houx PJ, van Boxtel MPJ, Ponds RWHM. Maastricht Aging Study. Maastricht: Neuropsych Publishers; 1995.

15. Metsemakers JF, Hoppener P, Knottnerus JA, Kocken RJ, Limonard CB. Computerized health information in The Netherlands: a registration network of family practices. Br J Gen Pract 1992; 42(356): 102-6.

16. World Health Organization. Waist circumference and waist-hip ratio: Report of a WHO expert consultation.: World Health Organization, 2008.

17. Van der Elst W, van Boxtel MP, van Breukelen GJ, Jolles J. Rey's verbal learning test: normative data for 1855 healthy participants aged 24-81 years and the influence of age, sex, education, and mode of presentation. J Int Neuropsychol Soc 2005; 11(3): 290-302.

18. Van der Elst W, Van Boxtel MP, Van Breukelen GJ, Jolles J. The Concept Shifting Test: adult normative data. Psychol Assess 2006; 18(4): 424-32. 
19. van der Elst W, van Boxtel MP, van Breukelen GJ, Jolles J. The Letter Digit Substitution Test: normative data for 1,858 healthy participants aged 24-81 from the Maastricht Aging Study (MAAS): influence of age, education, and sex. J Clin Exp Neuropsychol 2006; 28(6): 998-1009.

20. Guidelines Subcommittee. 1999 World Health Organization-International Society of Hypertension Guidelines for the Management of Hypertension. J Hypertens 1999; 17(2): 15183.

21. Arrindell WA, Ettema JHM. Handleiding Bij Een Multidimensionele Psychopathologie-Indicator [SCL-90. Manual of a Multidimensional Psychopathology Indicator] Lisse, The Netherlands: Swets Test Publishers; 2003.

22. World Health Organization. Problems Related to Alcohol Consumption: Report of WHO Expert Committee. Geneva, Switzerland 1980.

23. Dahl AK, Hassing LB. Obesity and Cognitive Aging. Epidemiologic Reviews 2013; 35(1): 22-32.

24. Dahl A, Hassing LB, Fransson $E$, et al. Being overweight in midlife is associated with lower cognitive ability and steeper cognitive decline in late life. J Gerontol A Biol Sci Med Sci 2010; 65(1): 57-62.

25. Debette $\mathrm{S}$, Seshadri S, Beiser A, et al. Midlife vascular risk factor exposure accelerates structural brain aging and cognitive decline. Neurology 2011; 77(5): 461-8.

26. Hassing LB, Dahl AK, Pedersen NL, Johansson B. Overweight in midlife is related to lower cognitive function 30 years later: a prospective study with longitudinal assessments. Dement Geriatr Cogn Disord 2010; 29(6): 543-52.

27. Hughes TF, Ganguli M. Modifiable Midlife Risk Factors for Late-Life Cognitive Impairment and Dementia. Curr Psychiatry Rev 2009; 5(2): 73-92.

28. Kiliaan AJ, Arnoldussen IAC, Gustafson DR. Adipokines: a link between obesity and dementia? Lancet Neurol 2014; 13(9): 913-23.

29. Debette S, Wolf $\mathrm{C}$, Lambert JC, et al. Abdominal obesity and lower gray matter volume: a Mendelian randomization study. Neurobiol Aging 2014; 35(2): 378-86.

30. Gustafson D. Adiposity indices and dementia. Lancet Neurol 2006; 5(8): 713-20.

31. Whitmer RA. The epidemiology of adiposity and dementia. Curr Alzheimer Res 2007; 4(2): 11722.

32. Plassman BL, Williams JW, Jr., Burke JR, Holsinger T, Benjamin S. Systematic review: factors associated with risk for and possible prevention of cognitive decline in later life. Ann Intern Med 2010; 153(3): 182-93.

33. Singh-Manoux A, Czernichow S, Elbaz A, et al. Obesity phenotypes in midlife and cognition in early old age: the Whitehall II cohort study. Neurology 2012; 79(8): 755-62.

34. Smith E, Hay P, Campbell L, Trollor JN. A review of the association between obesity and cognitive function across the lifespan: implications for novel approaches to prevention and treatment. Obes Rev 2011; 12(9): 740-55.

35. Handing EP, Small BJ, Reynolds SL, Kumar NB. Impact of dietary factors and inflammation on cognition among older adults. J Prev Alz Dis 2015; 2(4): 220-6.

36. Kesse-Guyot $\mathrm{E}$, Andreeva VA, Touvier $\mathrm{M}$, et al. Overall and abdominal adiposity in midlife and subsequent cognitive function. J Nutr Health Aging 2015; 19(2): 183-9.

37. do Nascimento Jacinto de Souza BF, Marín-León L. Living and health conditions associated with overweight and obesity among elderly. J Frailty Aging 2015; 4(4): 198-206. 


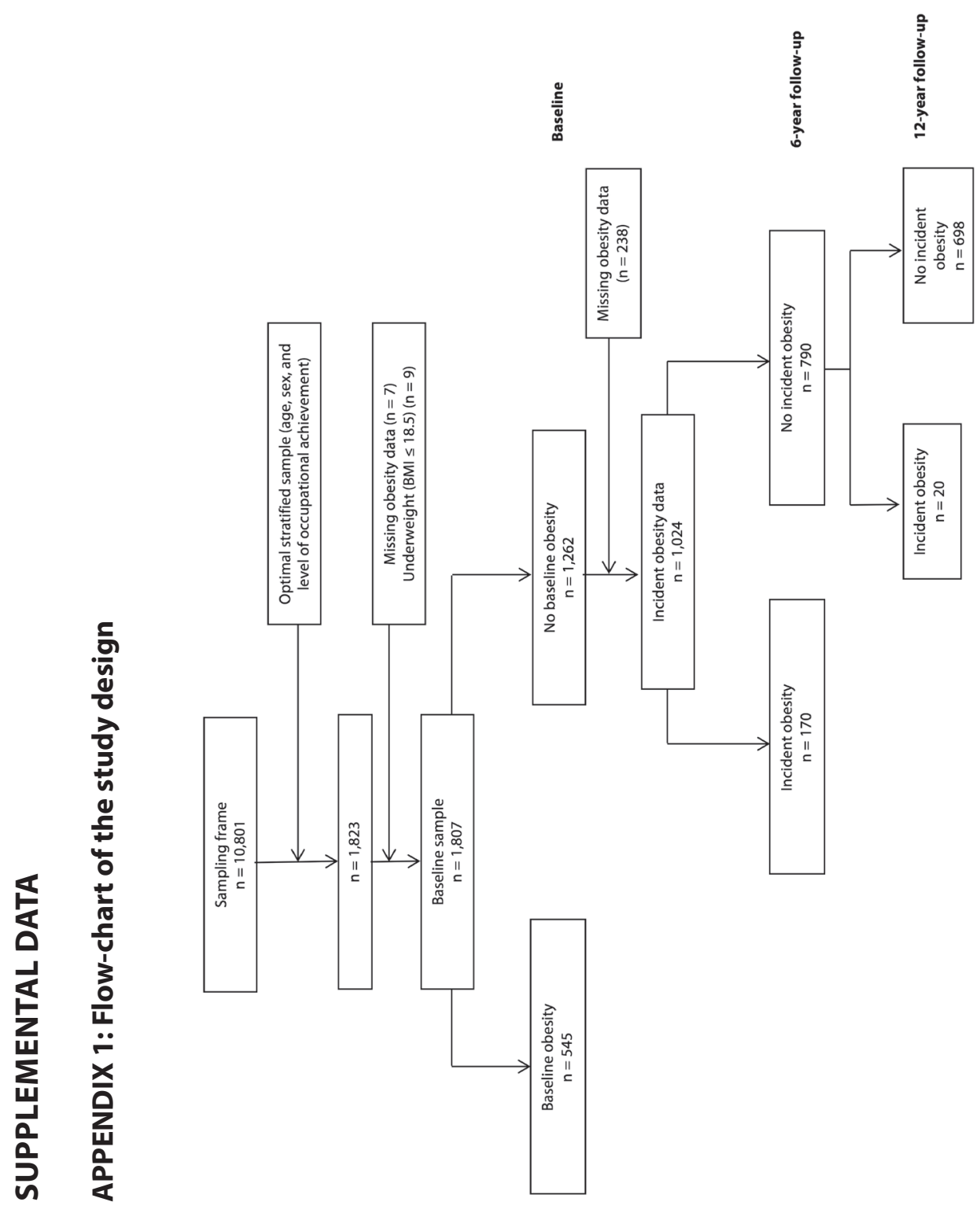




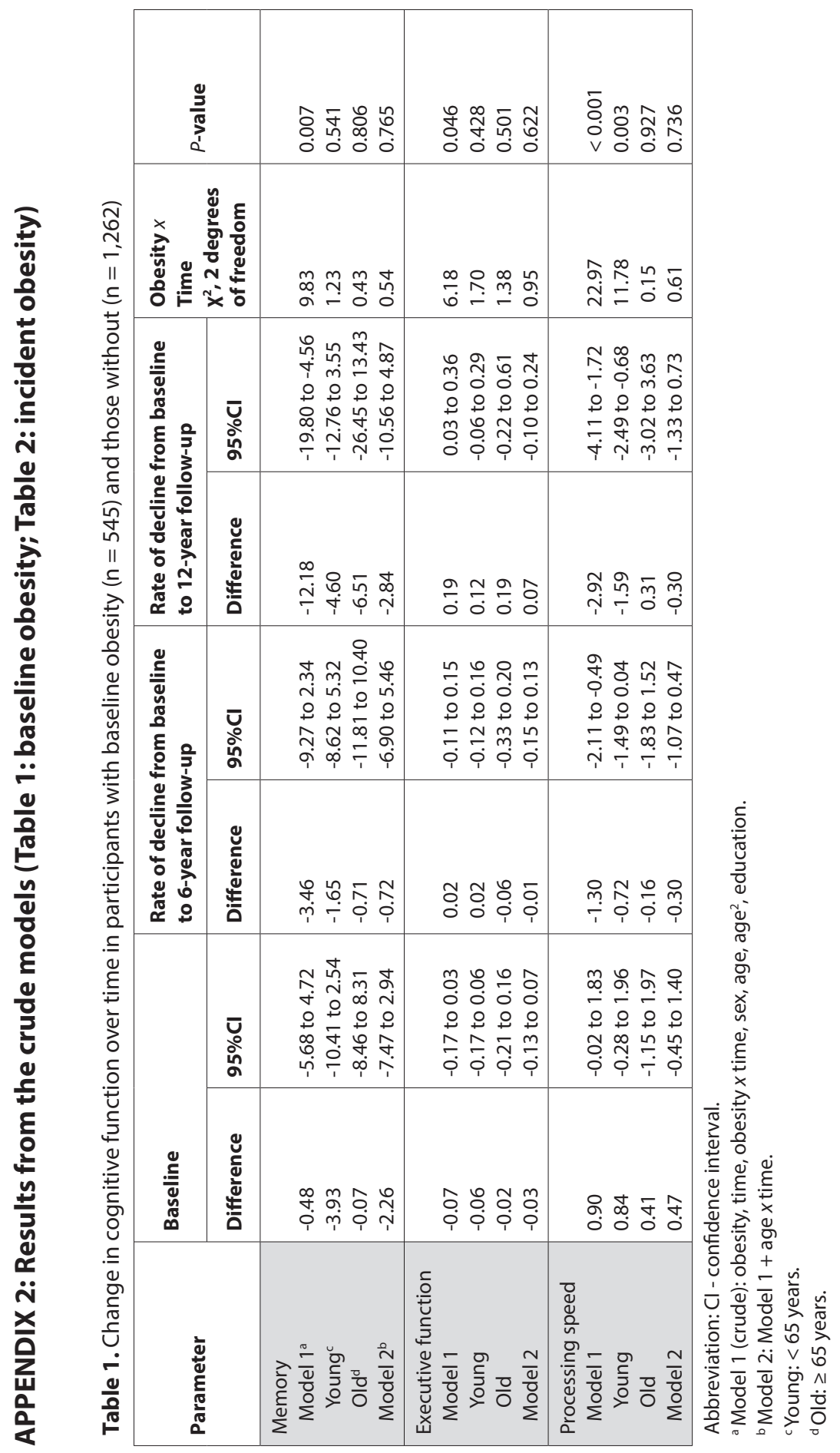




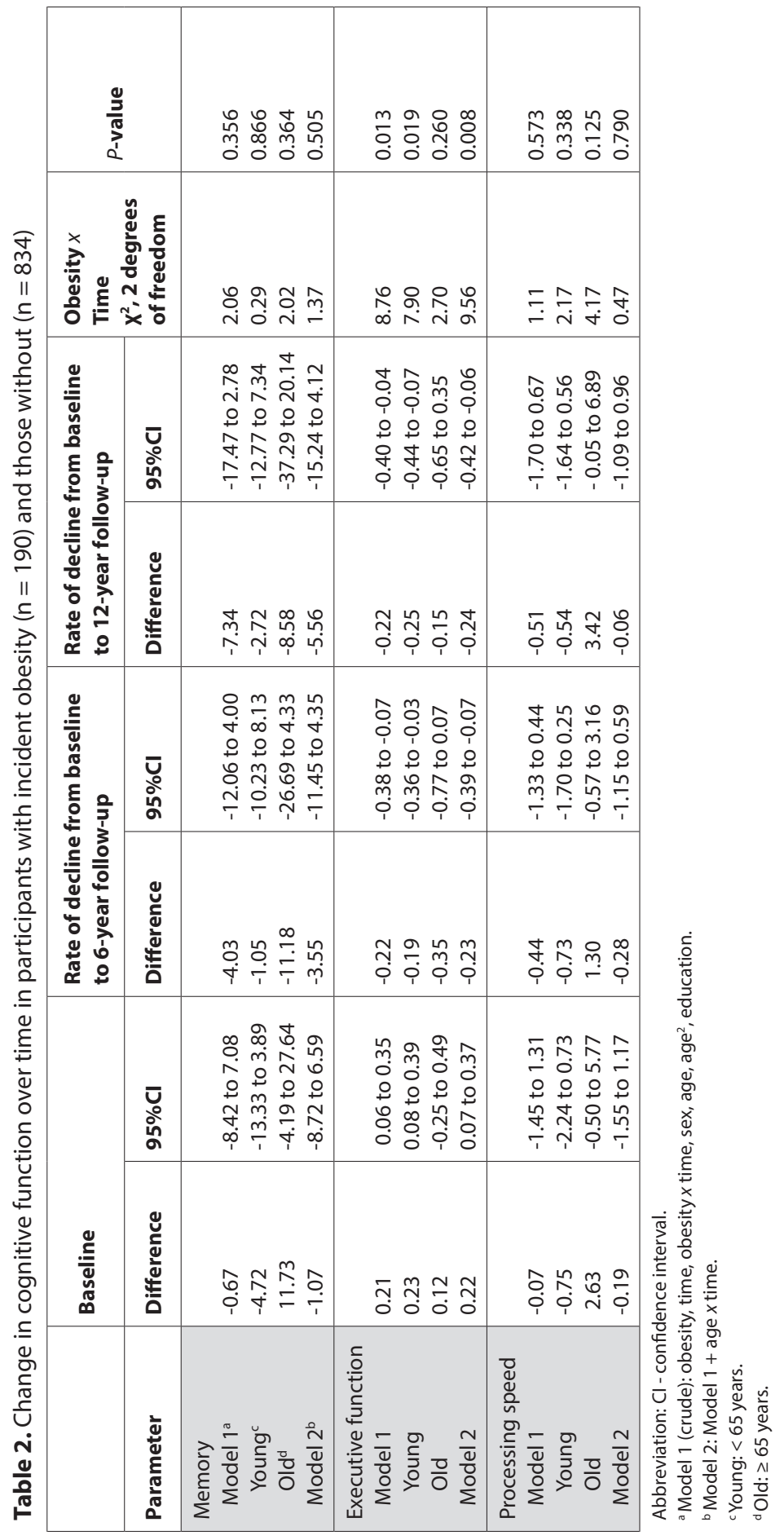




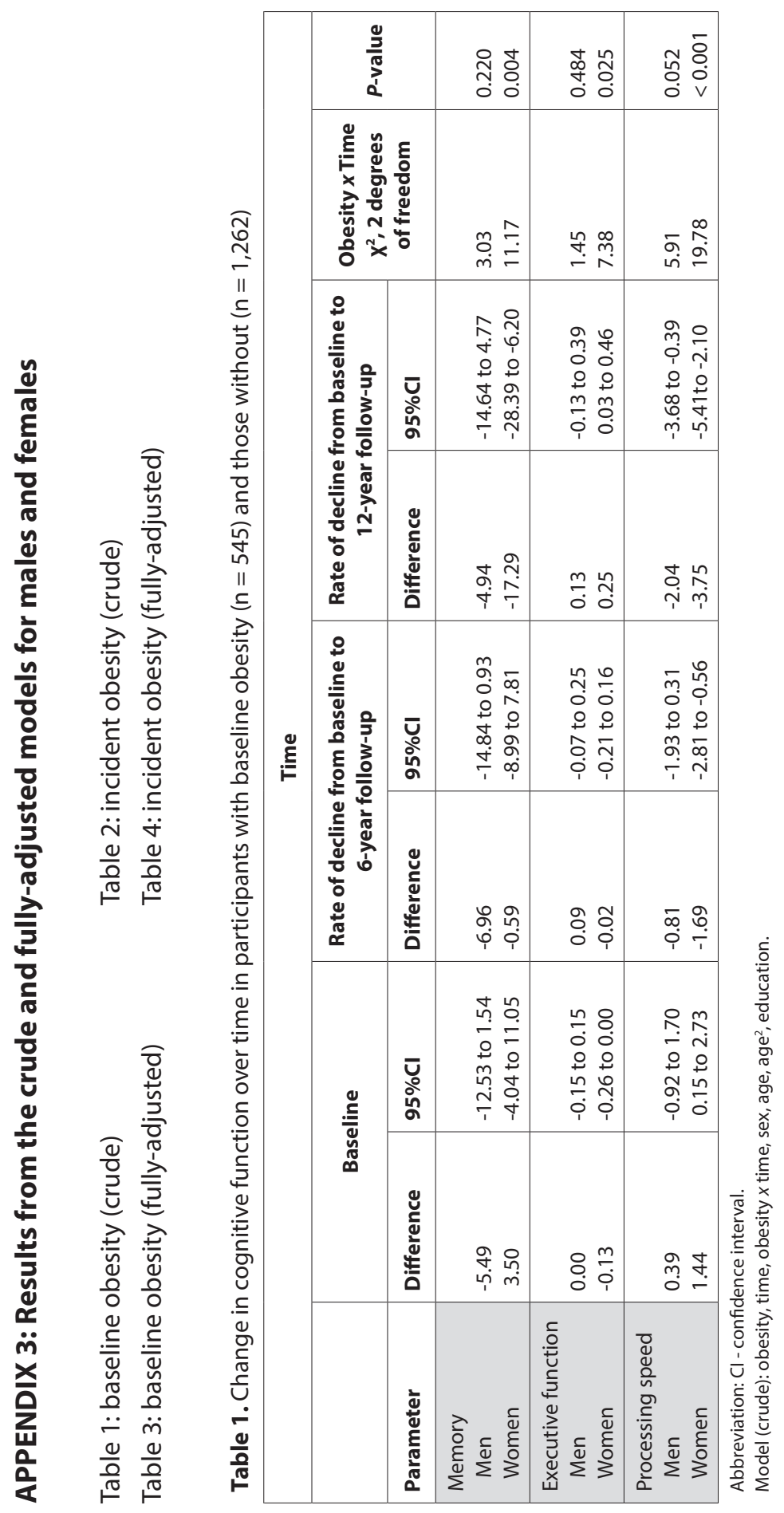




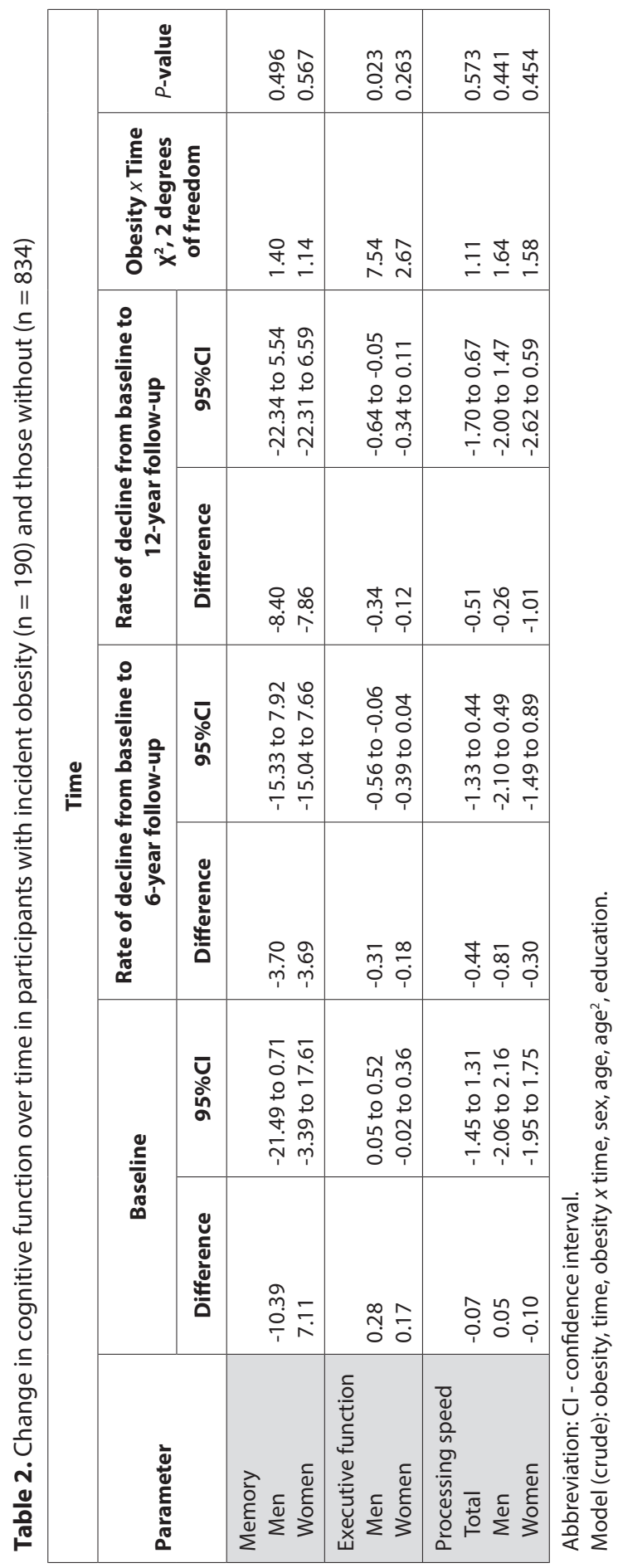




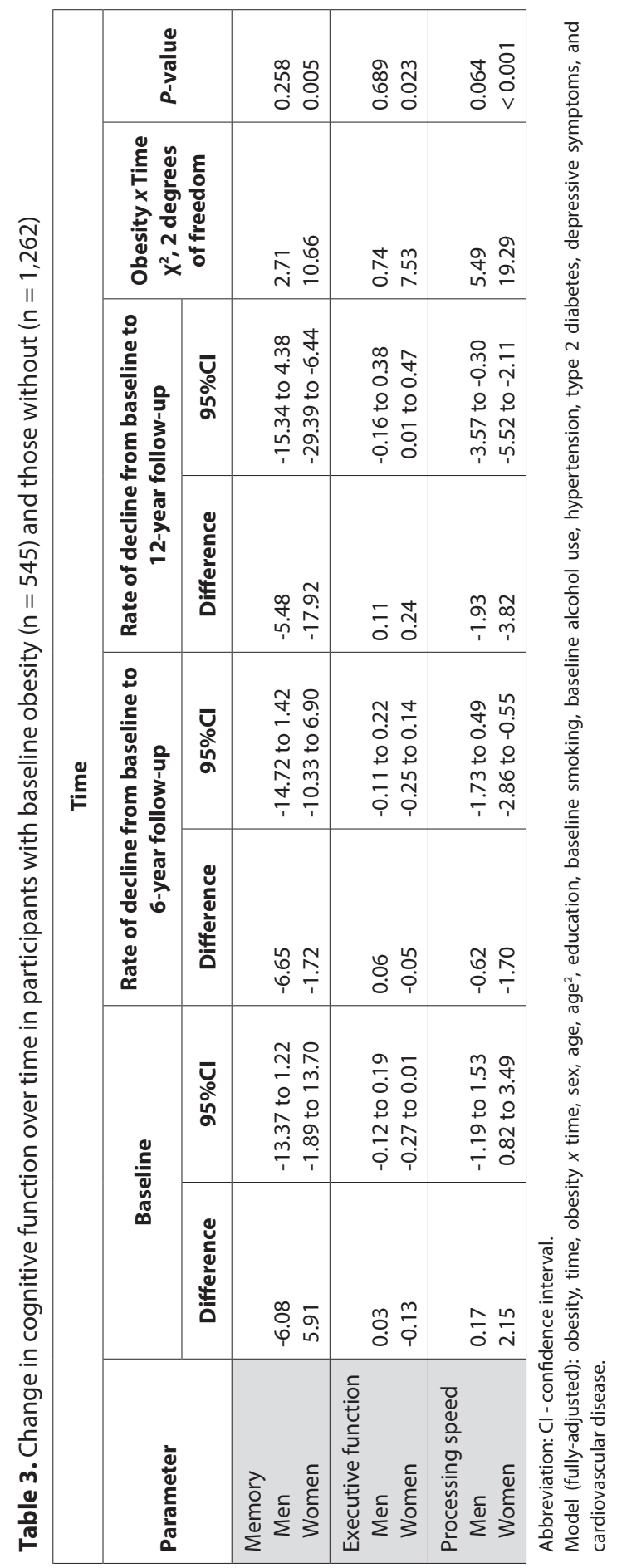




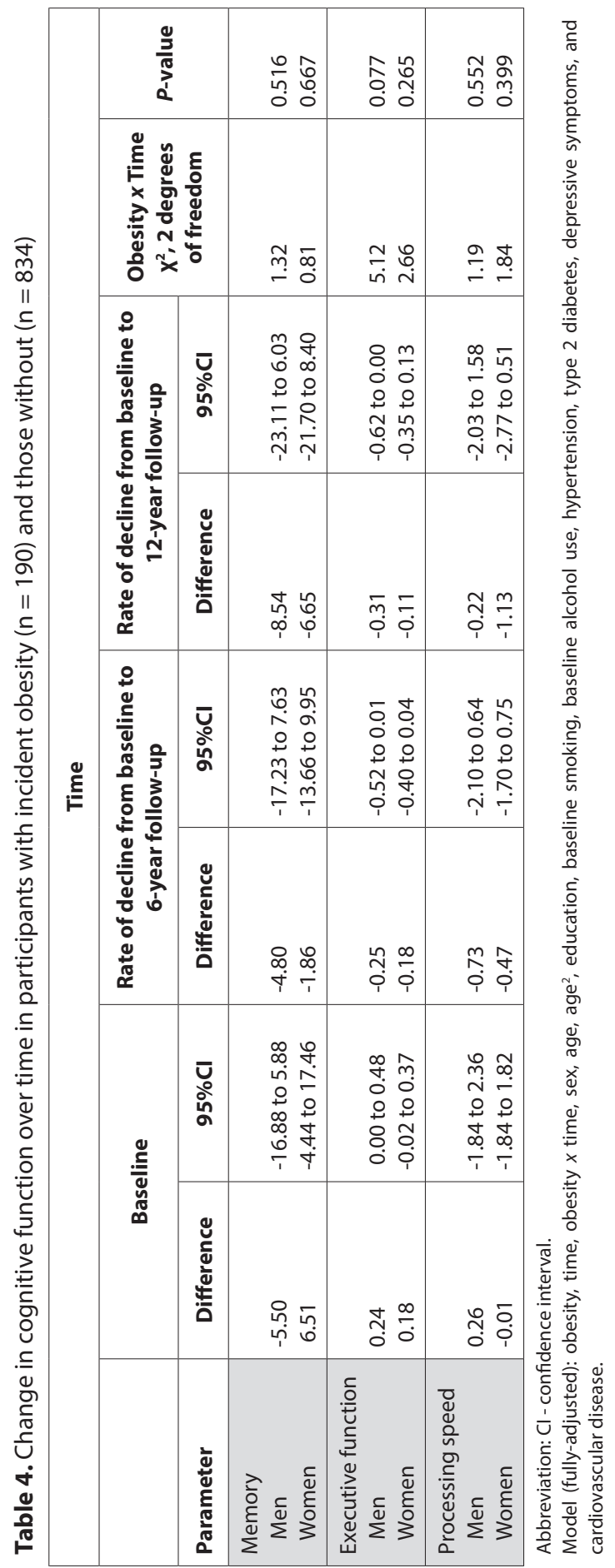




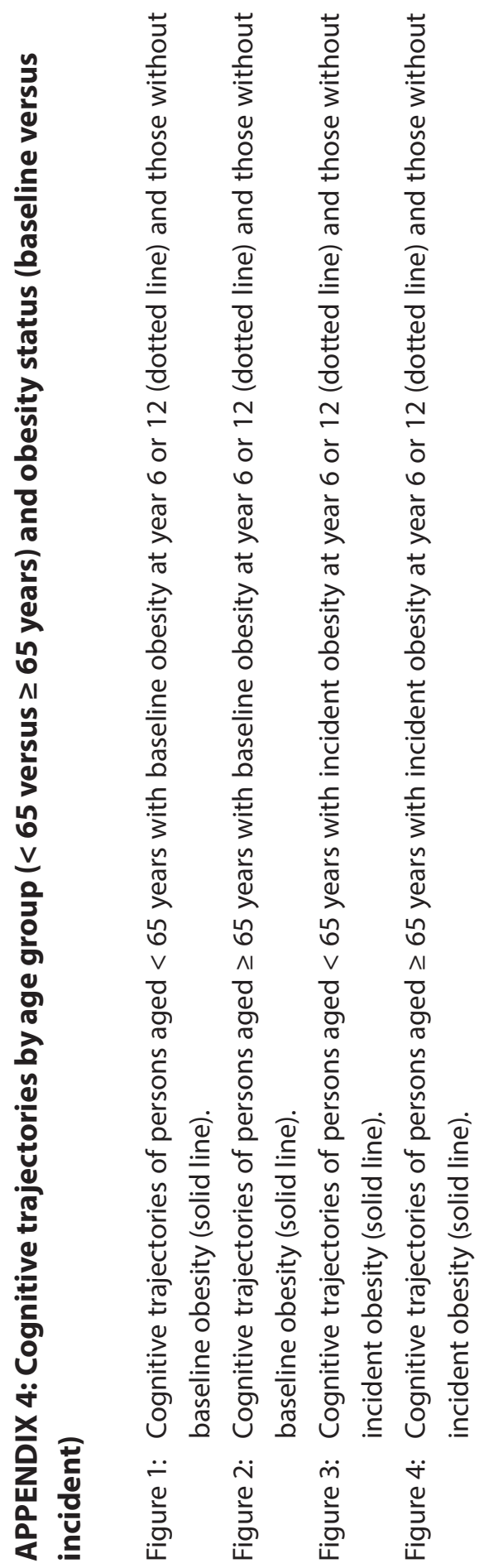



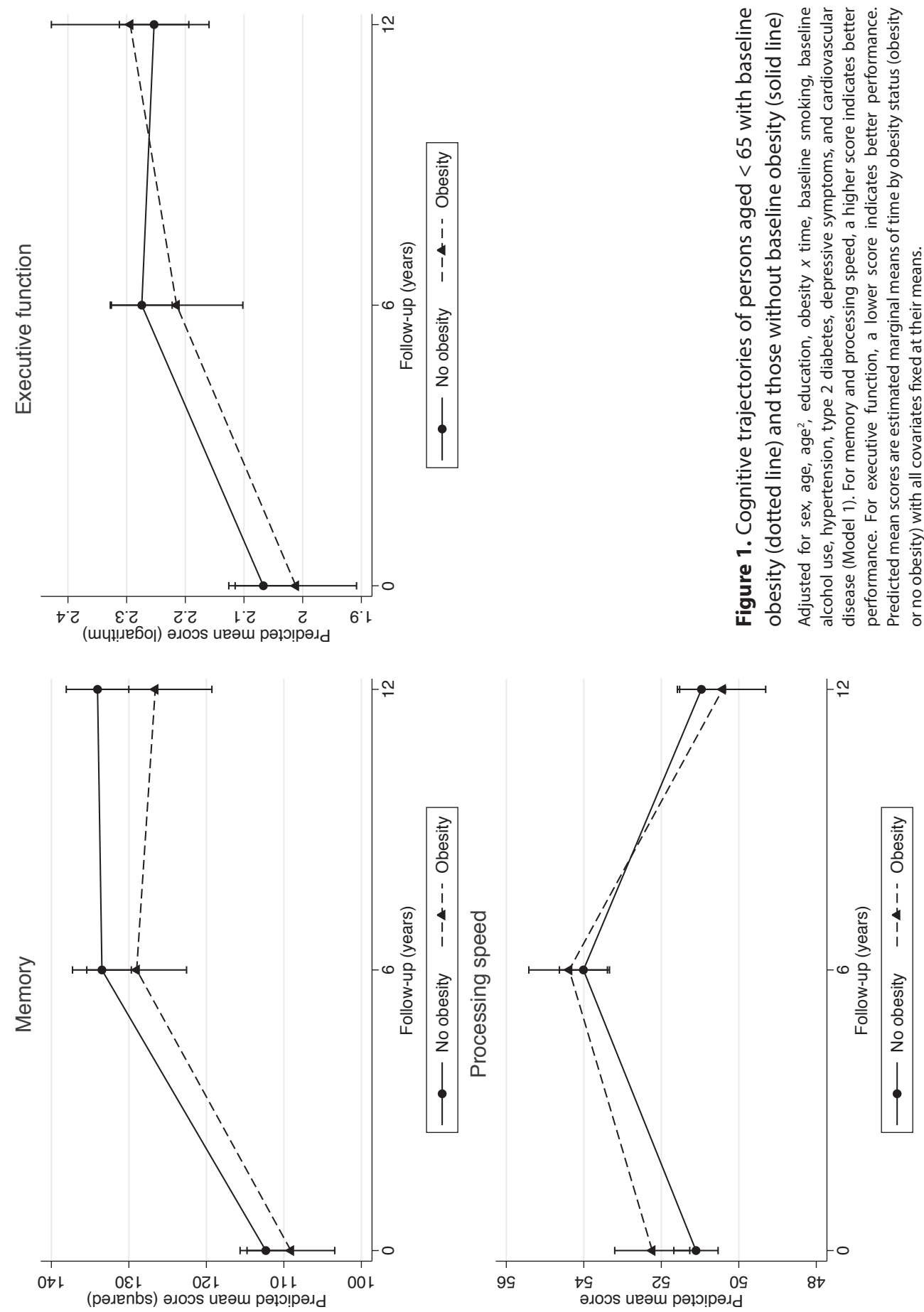

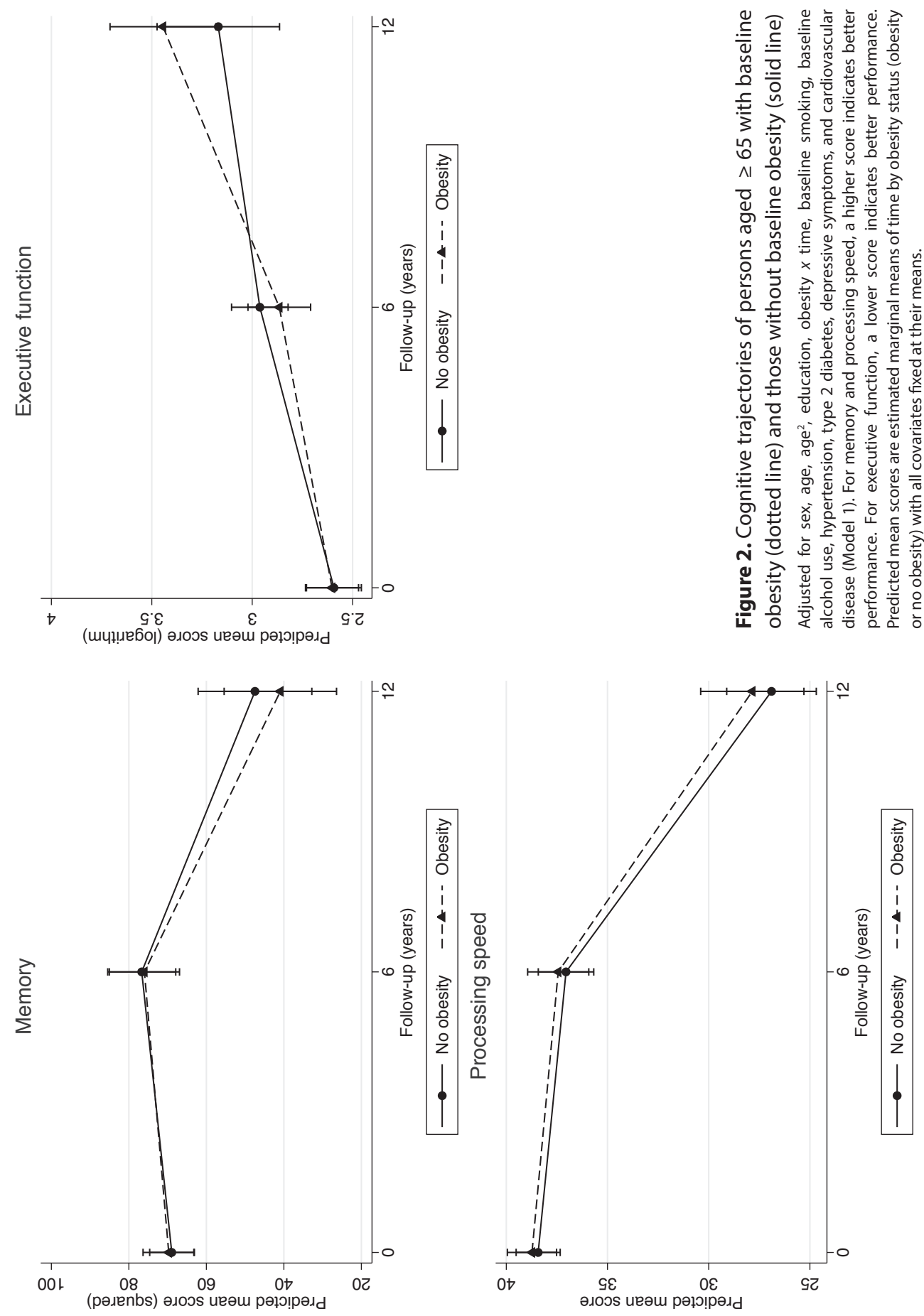

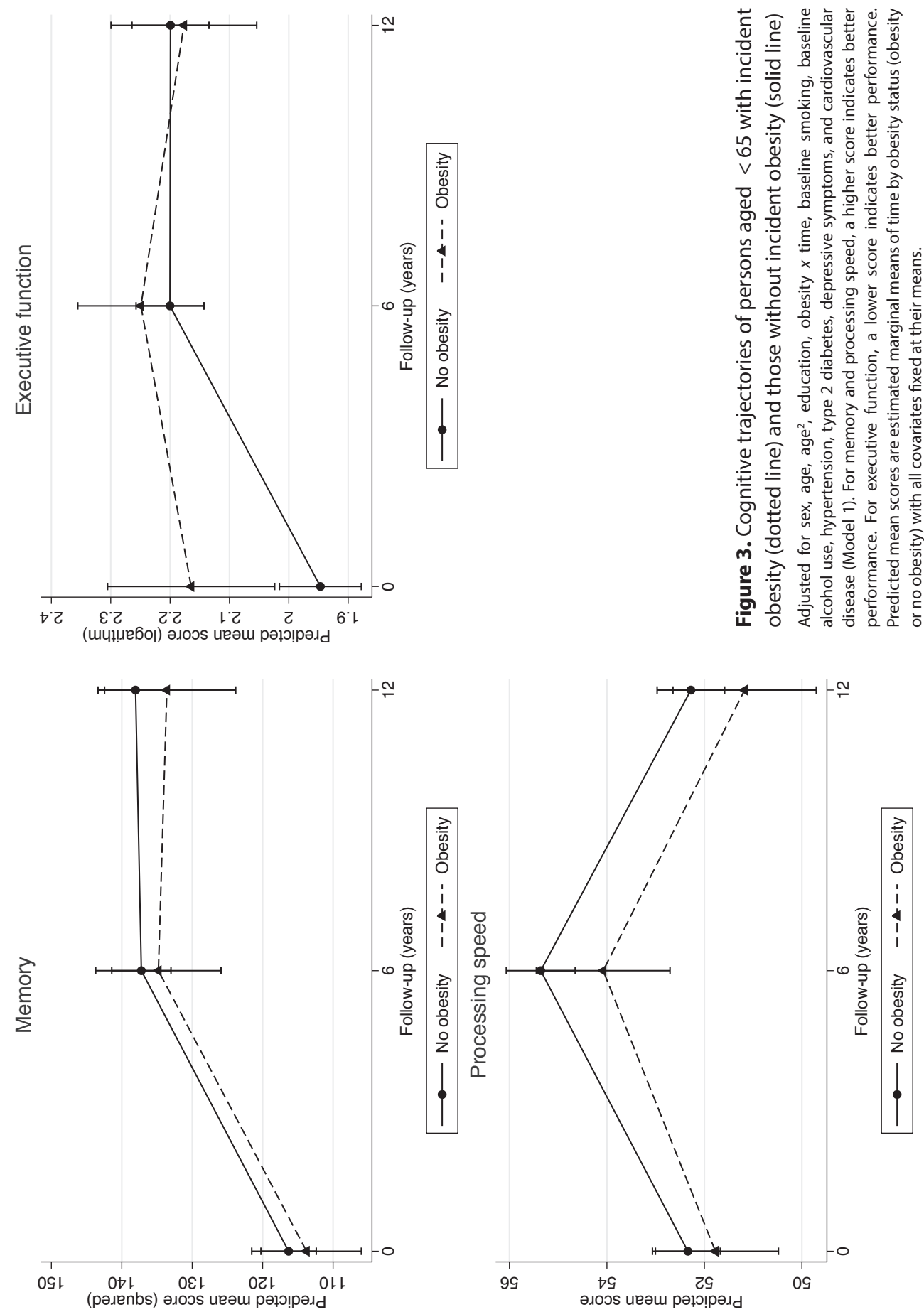

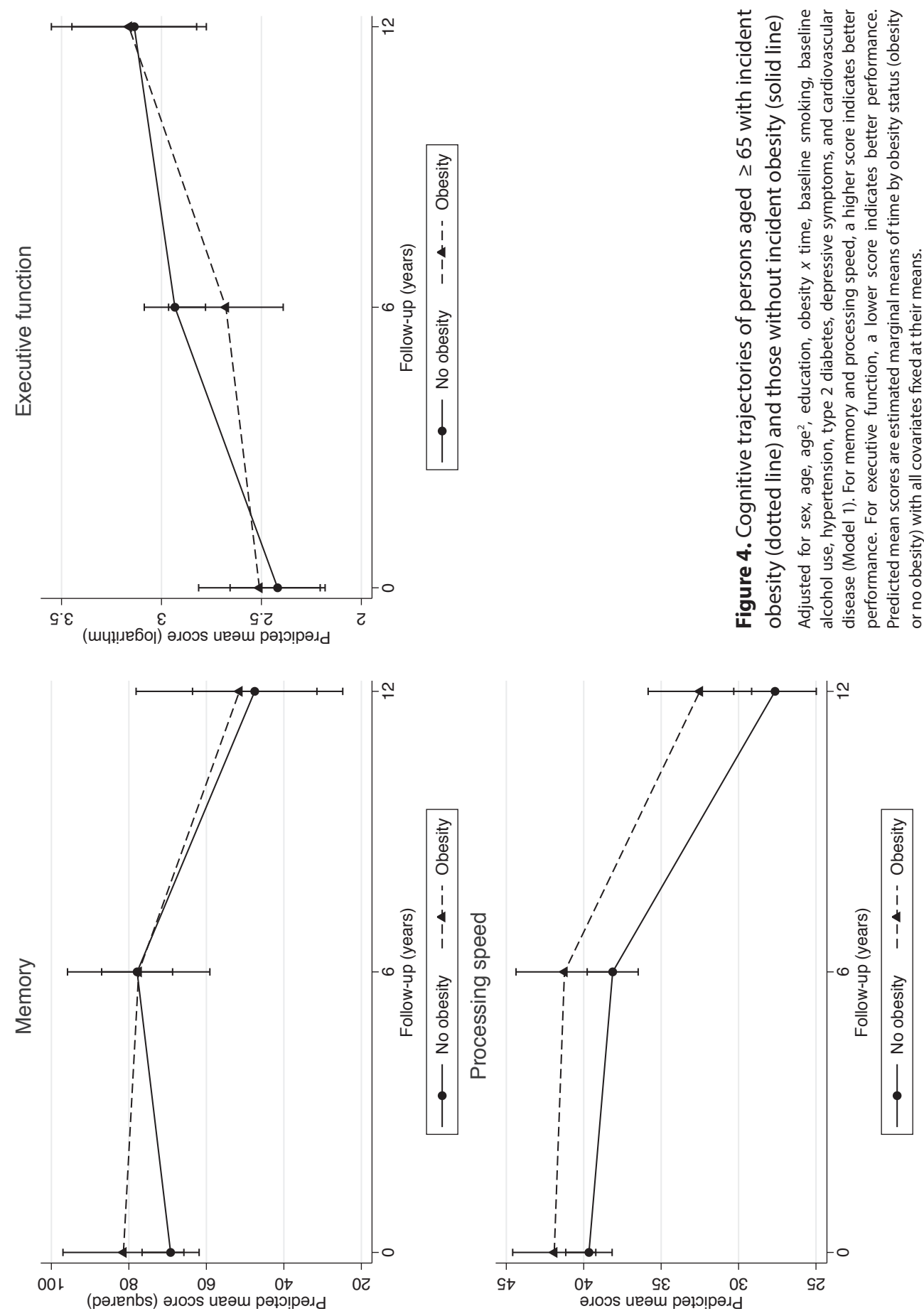

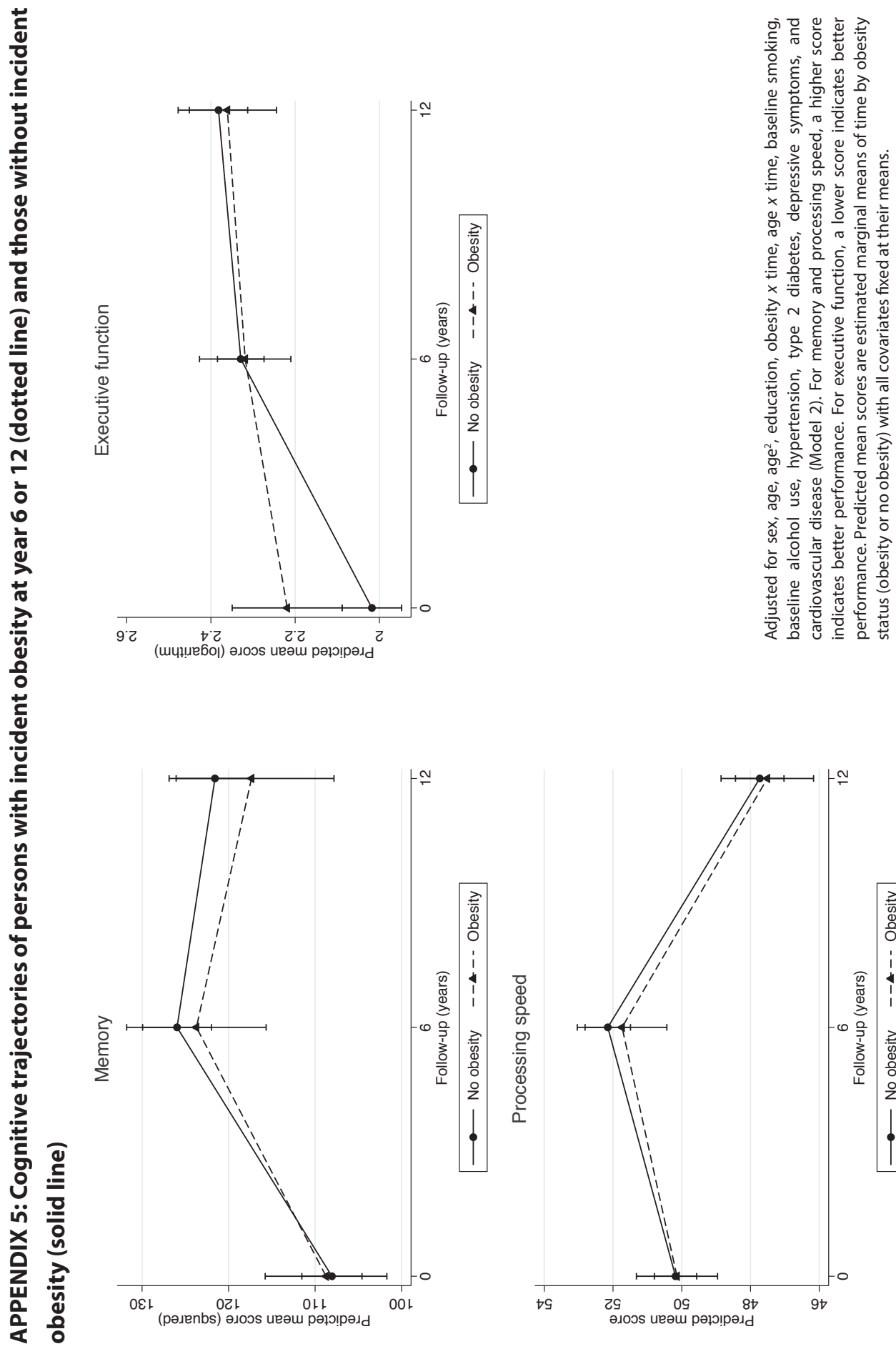

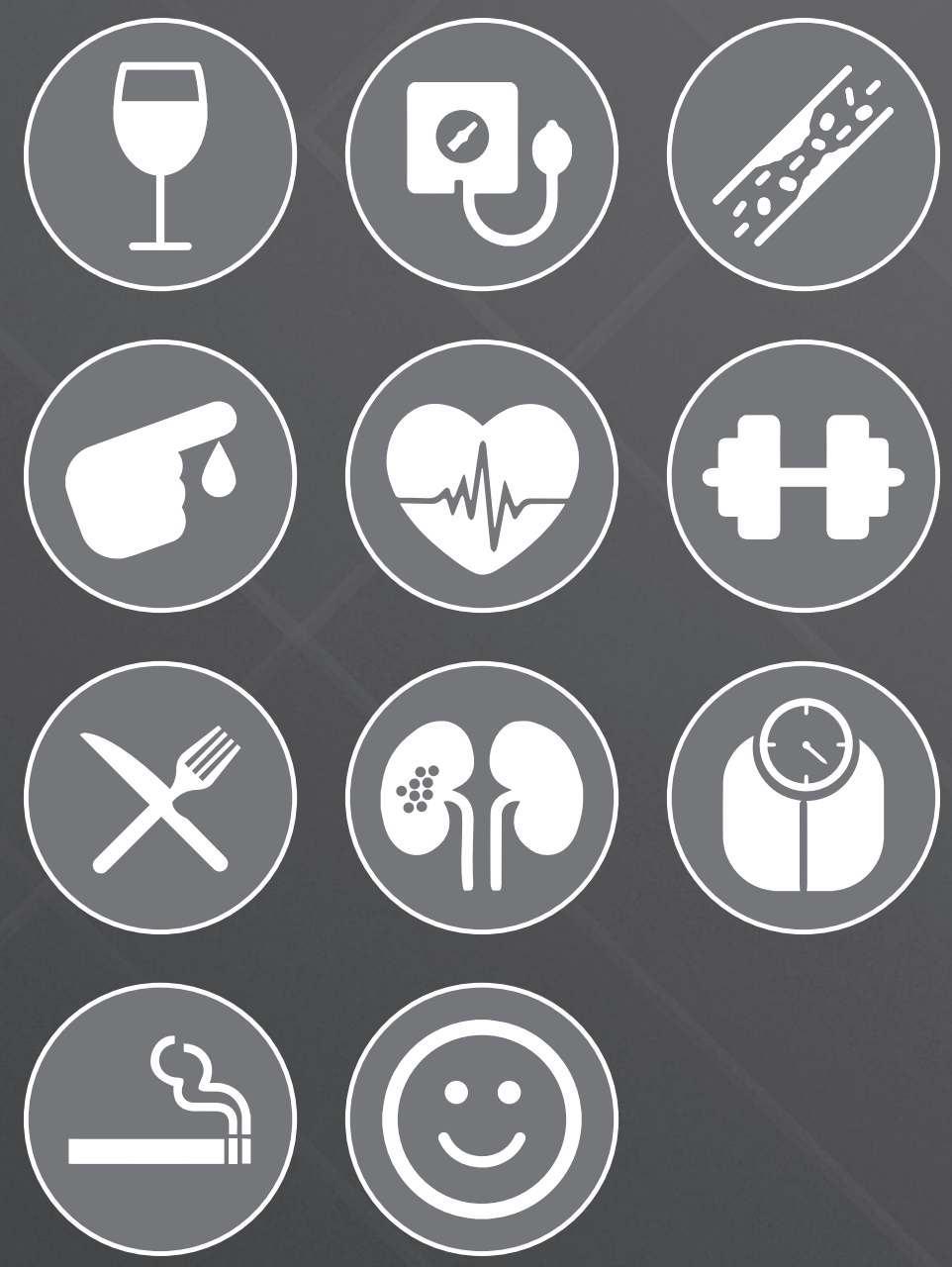


\section{CHAPTER 6}

\section{PREDICTION OF MILD COGNITIVE IMPAIRMENT AND DEMENTIA WITH A MULTIFACTORIAL ENVIRONMENTAL RISK SCORE: A 30 YEAR FOLLOW-UP OF THE CAIDE POPULATION-BASED STUDY}

Submitted

Kay Deckers, Mariagnese Barbera, Sebastian Köhler, Tiia Ngandu, Martin PJ van Boxtel, Minna Rusanen, Tiina Laatikainen, Frans RJ Verhey, Hilkka Soininen, Miia Kivipelto, Alina Solomon 


\section{ABSTRACT}

Background:The LIfestyle for BRAin Health (LIBRA) score, developed based on a systematic review and expert consensus study, reflects an individual's dementia prevention potential and is composed of 12 modifiable risk and protective factors. This study aimed to examine the predictive accuracy of this compound score for dementia and mild cognitive impairment $(\mathrm{MCl})$ in midlife and late-life, and in individuals with high or low genetic risk based on presence of the apolipoprotein (APOE) $\varepsilon 4$ allele.

Methods: Participants in the Finnish Cardiovascular Risk Factors, Aging and Dementia (CAIDE) population-based study were examined in midlife and twice in late-life up to 30 years later. Data on 11 LIBRA factors were available. The study population (participants/ survivors) included 1,024 individuals for associations with LIBRA in midlife (dementia $\mathrm{n}=84, \mathrm{MCI} n=151$ ), and 604 individuals for associations with LIBRA in late-life (dementia $\mathrm{n}=35, \mathrm{MCl} \mathrm{n}=108$ ). Cox proportional hazard regression models were used.

Results: Higher midlife LIBRA score was related to higher risk of dementia (HR 1.31,95\%Cl 1.17-1.46, C-statistic: 0.65 ) and MCI (HR 1.12, 95\%Cl 1.03-1.22, C-statistic: 0.58 ) up to 30 years later. Higher late-life LIBRA score was related to higher risk of $\mathrm{MCl}(\mathrm{HR} 1.14,95 \% \mathrm{Cl}$ 1.02-1.27, C-statistic: 0.60 ), but not dementia. Higher late-life LIBRA score was related to higher dementia risk among APOE $\varepsilon 4$ non-carriers. The LIBRA-APOE interaction was not significant in midlife.

Conclusion: Findings emphasize the importance of modifiable risk and protective factors for dementia prevention. The LIBRA score may be useful for educational/motivational purposes by emphasizing areas amenable to preventive lifestyle measures, and for identifying at-risk individuals who may benefit from lifestyle interventions. 


\section{BACKGROUND}

Dementia is one of the core challenges facing our ageing society. ${ }^{1}$ Prevention is crucial given that there are no treatments available to stop or reverse dementia. ${ }^{2}$ Early identification of persons at risk for dementia, preferably in midlife, makes it possible to target specific risk factors in an early stage. Evidence-based preventive strategies focusing on modifiable risk factors are urgently needed. ${ }^{3}$ Recently, the LIfestyle for BRAin Health (LIBRA) score was developed based on a systematic review and expert consensus study. ${ }^{4}$ The LIBRA score reflects an individual's prevention potential for dementia and consists of twelve modifiable risk and protective factors that are promising targets for preventive strategies. Since there are currently no dementia risk indices purely based on a compound score of modifiable risk and protective factors, it is important to investigate the predictive accuracy of this poly-environmental risk score for mild cognitive impairment $(\mathrm{MCl})$ and dementia in several cohort studies with e.g. different follow-up times, age bands, and risk factor ascertainments in order to evaluate and validate the index objectively. ${ }^{5}$ Therefore, the overall aim of the present study is to investigate the predictive validity of the LIBRA score in the longitudinal population-based Cardiovascular Risk Factors, Aging and Dementia (CAIDE) study. ${ }^{6}$ The first aim is to investigate the performance of the LIBRA score in midlife (40-50 years) and late life (65-79 years) in predicting the risk of subsequent dementia and $\mathrm{MCl}$. The second aim is to investigate potential differences between persons with high and low genetic risk for dementia (apolipoprotein E (APOE) $\varepsilon 4$ carriers versus non-carriers) regarding the relations of the LIBRA score with dementia and $\mathrm{MCl}$ risk.

\section{METHODS}

\section{The CAIDE study}

CAIDE participants were randomly selected from four independent population-based samples of the North Karelia Project and the FINMONICA study. Participants were examined in midlife in $1972,1977,1982$, or $1987 .^{-9}$ In 1998, a random sample of 2,000 individuals aged 65-79 years from the towns and surroundings of Kuopio and Joensuu in Eastern Finland was invited for the first re-examination. ${ }^{6}$ Of these, 1,449 persons (72.5\%) participated. A second re-examination took place between 2005 and 2008. Of the initial 2000 individuals, 1,426 were still alive and living in the target areas in 2005, and $909(63.7 \%)$ attended the re-examination. In total, 1,511 participants attended at least one re-examination, and 750 attended both re-examinations, with completed cognitive assessments. Mean follow-up time (SD) from midlife was 20.9 (4.9) years until the first re- 
examination, and 28.9 (5.0) years until the second re-examination. The study was approved by the local ethics committee of Kuopio University and Kuopio University Hospital, and written informed consent was obtained from all participants.

In both re-examinations, cognitive status was assessed with a three-step protocol (screening, clinical and differential diagnostic phase). Individuals scoring $\leq 24$ on the Mini-Mental State Examination (MMSE) ${ }^{10}$ at screening were referred for additional clinical assessments. In 2005-2008, individuals with $\leq 24$ points or decline $\geq 3$ points on MMSE, $<70 \%$ delayed recall in the CERAD word list, ${ }^{11}$ or an informant expressing concerns about the participant's cognition were referred for more assessments. Both re-examinations had a clinical phase with detailed neuropsychological and medical assessments, and a differential diagnostic phase with blood tests, brain imaging (MRI/CT-scans), electrocardiogram and if needed cerebrospinal fluid analysis. A review board consisting of a senior neurologist, senior neuropsychologist, study physician and study neuropsychologist ascertained the final diagnosis based on all available information. In both re-examinations, diagnosis of $\mathrm{MCl}$ and dementia were made according to established criteria. ${ }^{12-14}$

\section{Design of the present study}

Midlife LIBRA score: the main study population included 1,024 CAIDE participants with available data for the midlife LIBRA score, and who attended at least one re-examination with completed cognitive assessments (see Appendix 1). Outcomes were incident dementia $(n=84)$ or $\mathrm{MCI}(n=151)$ as diagnosed at the CAIDE re-examination visits. Secondary analyses were conducted in an extended study population (1,360 individuals) additionally including non-survivors/non-participants at re-examinations. Outcome was dementia $(n=250)$ as diagnosed at CAIDE visits or recorded in Finnish national registers (Hospital Discharge Register, Drug Reimbursement Register, and Causes of Death Register) until the end of 2008. Due to lack of a specific International Classification of Disease (ICD) code, $\mathrm{MCl}$ could not be ascertained from those registers. Dementia diagnoses in Finnish national registers have been previously validated against CAIDE diagnoses. ${ }^{15}$

Late-life LIBRA score: the main study population included 604 individuals with available 1998 data for the late-life LIBRA score, who were cognitively normal at the 1998 reexamination (i.e. no dementia or $\mathrm{MCl}$ ), and who returned for the 2005-2008 re-examination. Outcomes were incident dementia $(n=35)$ or $\mathrm{MCl}(n=108)$ as diagnosed at the 2005-2008 re-examination. Secondary analyses were conducted in an extended study population (1,022 individuals) additionally including non-survivors/non-participants at the 20052008 re-examination who had been cognitively normal at the 1998 re-examination. 
Outcome was incident dementia $(n=104)$ as diagnosed at CAIDE visits or recorded in Finnish national registers until the end of 2008.

\section{LIBRA score}

The LIBRA score was developed after triangulation of results from a systematic literature review on risk and protective factors for dementia and an expert consensus study, ${ }_{1}^{4}$ as part of the European (FP7) INnovative, Midlife INtervention for Dementia Deterrence (InMINDD) project. ${ }^{16}$ It consists of twelve modifiable risk and protective factors that can be targeted by tailored lifestyle interventions and primary prevention: physical inactivity, smoking, (low-to-moderate) alcohol use, (high) cognitive activity, healthy diet, depression, hypertension, obesity, diabetes, hypercholesterolemia, coronary heart disease, and renal disease. A weight is assigned to each factor, based on the factor's relative risk (Appendix 2). ${ }^{4}$ Weights are then standardised and summed up to yield the final LIBRA score (range from -5.9 to +12.7 ), with higher scores indicating greater risk. A modified version of the LIBRA score was developed for the purpose of validation in older cohorts. It consists of ten factors, excluding the risk factors obesity and hypertension, since these are considered to be major risk factors in midlife only.

\section{LIBRA score assessment in the CAIDE study}

At the midlife examination, assessments and survey methods were standardized and adhered to international guidelines and the World Health Organization (WHO) (Multinational MONItoring of trends and determinants in CArdiovascular disease) MONICA protocol. ${ }^{17}$ CAIDE re-examination surveys were similar to midlife. Surveys involved selfadministered questionnaires on medical history, sociodemographic and psychological factors, and health-related behaviors. A trained nurse verified the answers, and measured height, weight and blood pressure. A venous blood sample was taken to determine serum total cholesterol. APOE genotype was determined from blood leucocytes using polymerase chain reaction and Hhal digestion ${ }^{18}$.

Data were available for 11 of the 12 LIBRA factors. No information on cognitive activity was available. LIBRA factors were dichotomized based on previously used cut-offs (Appendix 2). Hypertension was defined as a systolic blood pressure $\geq 140 \mathrm{mmHg}$ or diastolic blood pressure $\geq 90 \mathrm{mmHg}$. Participants were classified as obese if their Body Mass Index (BMI) exceeded $30 \mathrm{~kg} / \mathrm{m}^{2}$. The cut-off point for hypercholesterolemia was $\geq 6.5 \mathrm{mmol} / \mathrm{L}$. Diabetes and coronary heart disease were based on self-reports of diagnoses made by a physician, and diagnoses from the Finnish Hospital Discharge Register. Renal disease was based solely on diagnoses from the Finnish Hospital Discharge Register. A cut-off point for 
depressive symptoms was created based on the sum scores of two questions related to feelings of hopelessness (Appendix 2). Persons who engaged in physical activity at least twice a week, lasting at least 20 to 30 minutes each occasion, and causing sweating and breathlessness, were regarded as physically active. Low to moderate alcohol consumption was based on categorized frequency of alcohol use. For smoking, participants were divided into ever- and never-smokers. Since information on diet was available for only a small group of approximately 240 participants in midlife, analyses including diet were conducted separately. Adherence to a healthy diet was based on previously used cut-offs of the CAIDE Healthy Diet Index. ${ }^{19}$

\section{Statistical analyses}

To examine differences in risk factors and demographic variables between participants with subsequent dementia, $\mathrm{MCl}$ and controls, one-way analysis-of-variance (ANOVA) and $\mathbf{X}^{2}$-tests were used. Cox proportional hazard regression models were used to test associations between the LIBRA score and dementia or MCI risk. Harrell's concordance rate (C statistic) for censored data was calculated to examine predictive accuracy. Model 1 was unadjusted (except for age as the time scale, see below), and Model 2 was adjusted for the covariates sex and education. In addition, we tested for an interaction between LIBRA score and APOE genotype ( $\varepsilon 4$ carriers versus non-carriers). All analyses were done in Stata 14 (StataCorp, TX) and the level of statistical significance was $p<0.05$.

Midlife LIBRA: stcox was used, with age as time scale and midlife age as origin. In the main study population (participants/survivors), age was measured at the first dementia diagnosis in CAIDE re-examinations, or end of study (date of last available CAIDE reexamination). The same approach was used in analyses with $\mathrm{MCl}$ as outcome (i.e. considering date of first $\mathrm{MCl}$ diagnosis). In the extended study population (including also non-participants/non-survivors), age was measured at the first dementia diagnosis (in CAIDE or registers), or date of death, or end of study (second CAIDE re-examination in 2005-2008 for participants in this re-examination, or December 31, 2008 for the remaining population).

Late-life LIBRA: stcox was used, with age as time scale and age in 1998 as origin. In the main study population, age was measured at the 2005-2008 CAIDE re-examination. In the extended study population, age was measured at the first dementia diagnosis after 1998 (in CAIDE or registers), or date of death, or end of study (second CAIDE re-examination in 2005-2008 for participants in this re-examination, or December 31, 2008 for the remaining population). Participants without cognitive impairment in 1998 who had a dementia diagnosis in any register before 2000 were excluded (i.e. they were too close to dementia onset). 


\section{RESULTS}

\section{Population characteristics}

Characteristics of the main and extended study populations are shown in Table 1. As expected, individuals with dementia were older, had a lower education level and were more often APOE $\varepsilon 4$ carriers (all $p<0.01$ ). Sex distribution was not significantly different between diagnostic groups.

Midlife LIBRA score was higher in participants who subsequently developed dementia in both main and extended study populations (Table 1). Among LIBRA components, elevated systolic and diastolic blood pressure / hypertension, high BMI / obesity and high cholesterol were significantly more common among the subsequent dementia group. A similar pattern was observed in the extended population, where the subsequent dementia group also had higher midlife LIBRA score with diet included.

Differences in late-life LIBRA score between diagnostic groups were less pronounced. In the main population, the subsequent dementia group included a higher percentage of individuals with coronary heart disease, a lower percentage of individuals with hypertension, and had lower blood pressure levels (Table 1). There were no significant differences between dementia and control groups in LIBRA score and components in the extended study population.

\section{Midlife LIBRA, dementia and MCI}

Performance of the LIBRA score in predicting subsequent dementia or $\mathrm{MCl}$ is shown in Table 2 (continuous LIBRA score), Appendix 3 and Figure 1 (quartiles of LIBRA score). Higher midlife LIBRA score was significantly related to elevated dementia risk in both main (HR: 1.27, 95\%Cl 1.13-1.43; C-statistic: 0.67) and extended (HR: 1.13, 95\%Cl 1.05-1.21; C-statistic: 0.58 ) study populations. In addition, higher midlife LIBRA score was significantly associated with elevated $\mathrm{MCl}$ risk (HR: $1.12,95 \% \mathrm{Cl} 1.03-1.22$; C-statistic: 0.58 ), but not after adjustment for sex and education (HR: 1.05, 95\% Cl 0.97-1.16; C-statistic: 0.65) (Table 2). In the small group of participants with available midlife diet data, the LIBRA score including diet was significantly related to dementia risk in the extended study population, but not main population or $\mathrm{MCl}$ risk, although $\mathrm{C}$-statistic values increased (Table 2).

No significant interactions between midlife LIBRA score and APOE $\varepsilon 4$ carrier status were found in any of the models (results not shown). 


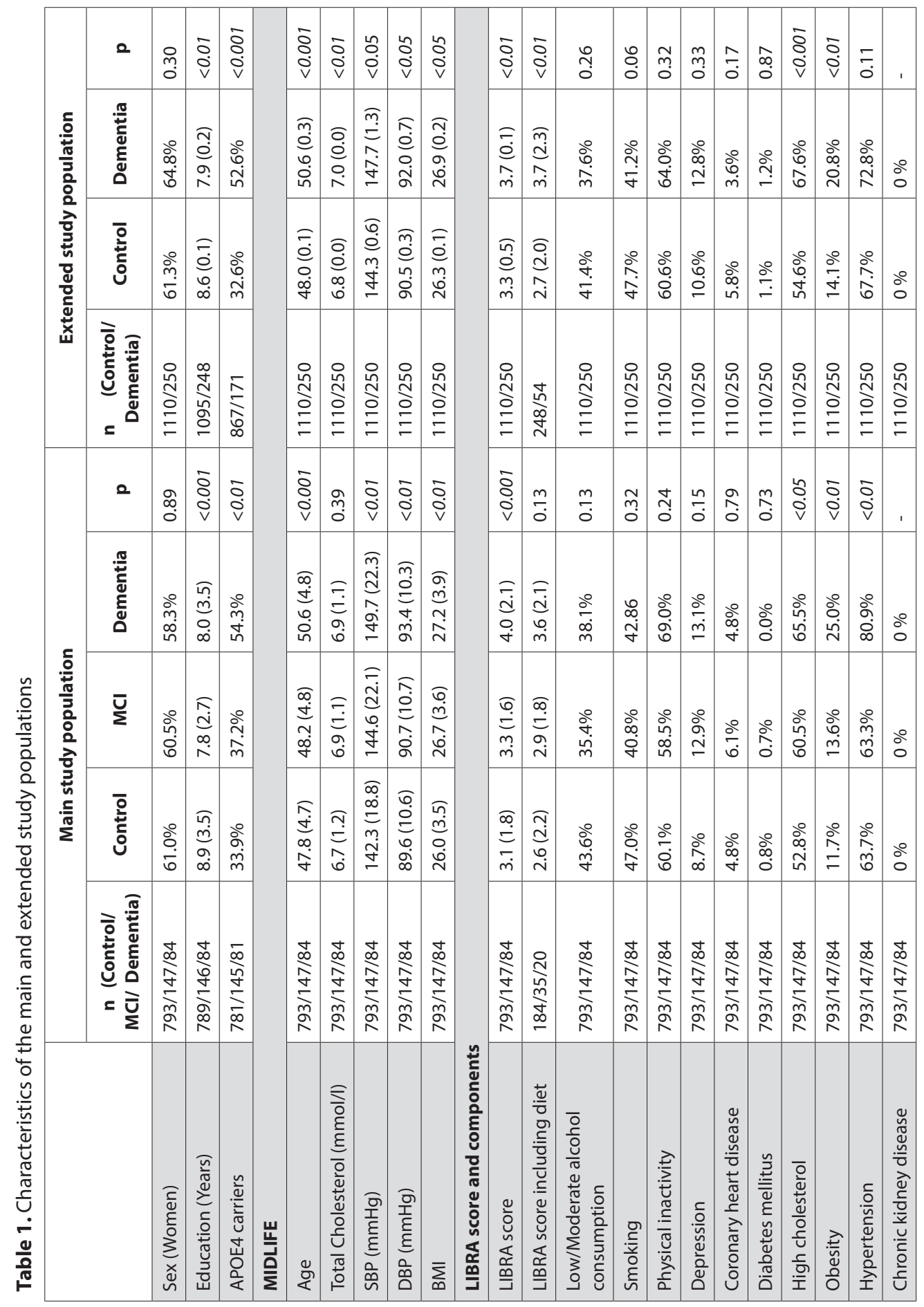




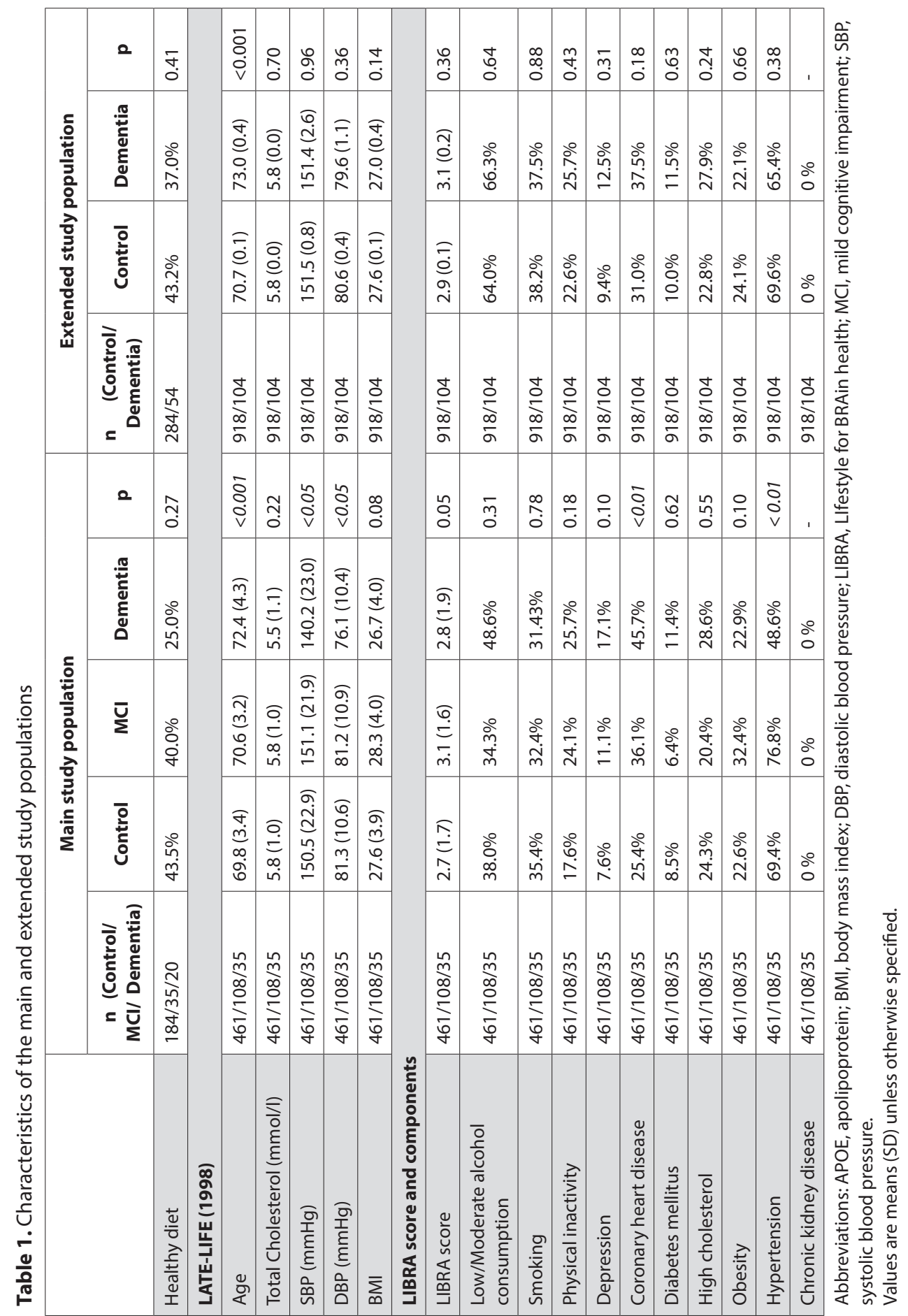




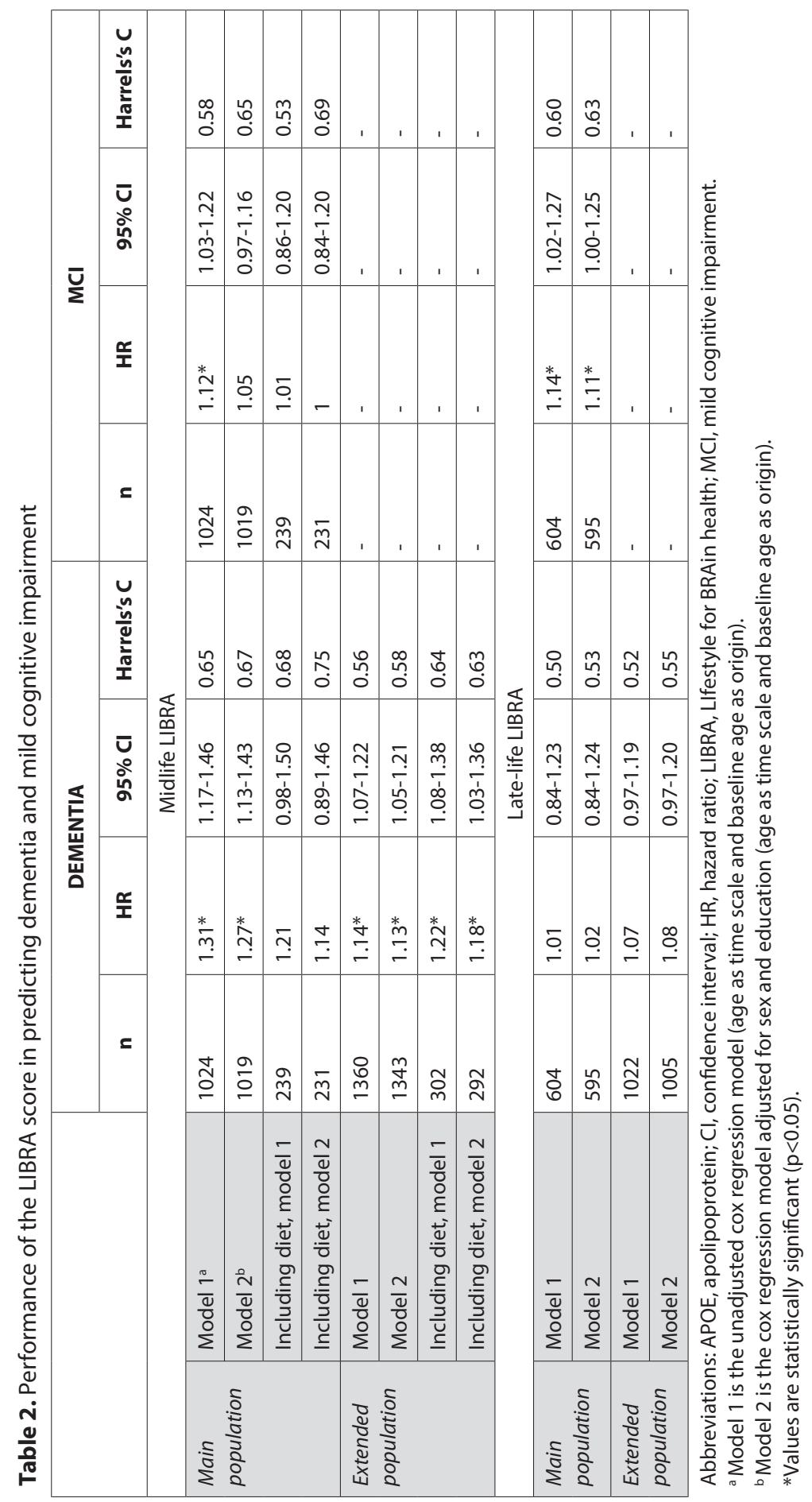



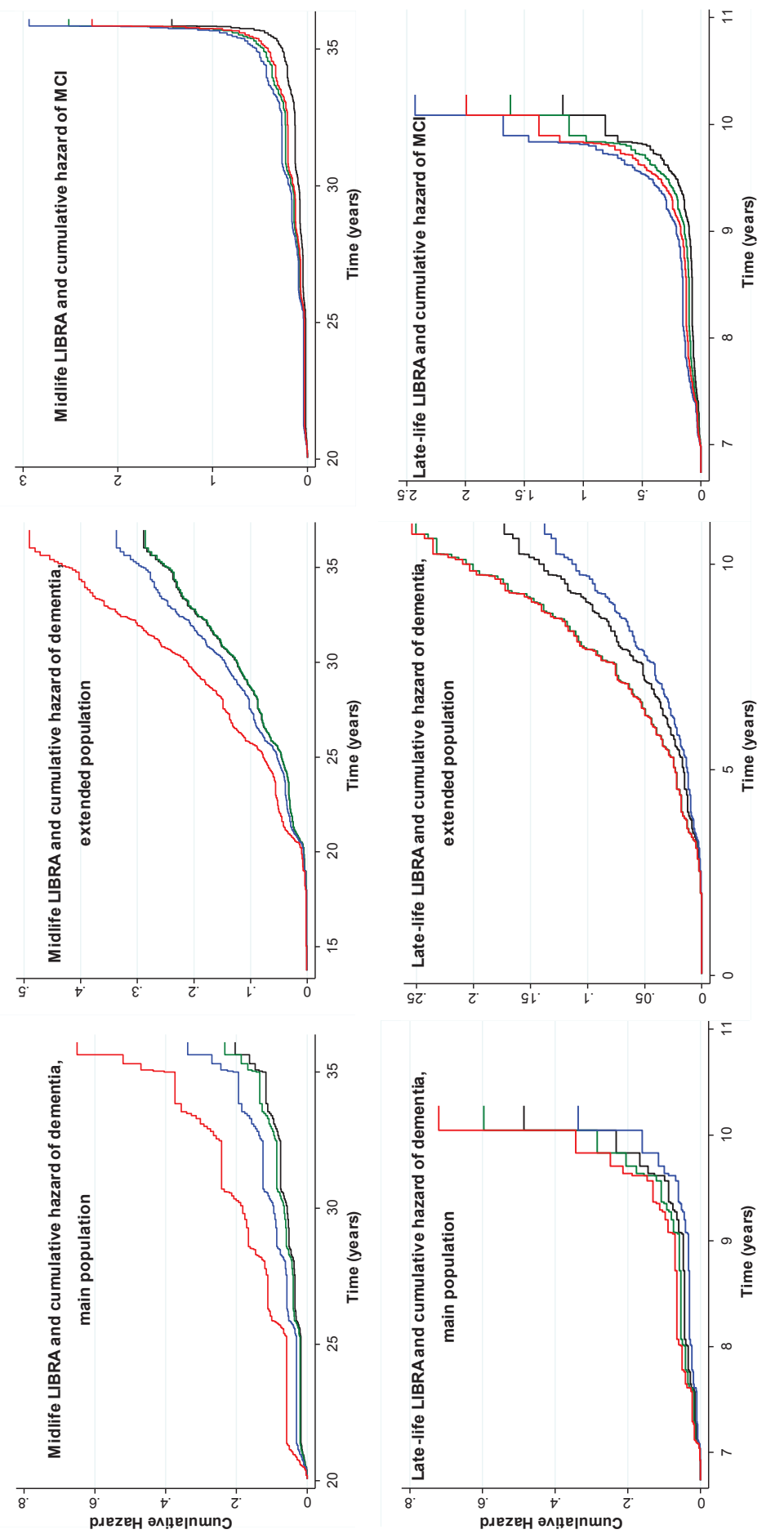

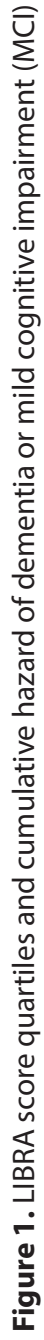




\section{Late-life LIBRA, dementia and $\mathrm{MCI}$}

Late-life LIBRA score was not significantly related to dementia in either main or extended population. However, higher late-life LIBRA score was significantly associated with $\mathrm{MCl}$ risk (HR: 1.11, 95\%Cl 1.00-1.25; C-statistic: 0.63). Significant interactions between late-life LIBRA score and APOE $\varepsilon 4$ carrier status were found in relation to dementia risk $(p=0.011$ in main population; $p=0.025$ in extended population). In the main population, HR (95\% $\mathrm{Cl})$ for dementia were 1.26 (0.96-1.64) among non-carriers, and 0.73 (0.53-1.01) among carriers, and in the extended population these were 1.19 (1.04-1.37) among non-carriers and 0.94 (0.80-1.09) among carriers. No significant interactions between late-life LIBRA score and APOE $\varepsilon 4$ carrier status were found in relation to $\mathrm{MCl}$ risk.

In late-life, higher modified LIBRA scores (excluding midlife risk factors obesity and hypertension) were significant associated with dementia in the extended population (HR: 1.17, 95\% Cl 1.03-1.33), but not in the main population (HR: 1.22, 95\% Cl 0.97-1.53). No significant associations were found for $\mathrm{MCl}$ (data not shown). Additionally, significant interactions between modified late-life LIBRA score and APOE $\varepsilon 4$ carrier status were only found in relation to dementia risk (data not shown).

\section{DISCUSSION}

In a general Finnish population, higher midlife LIBRA score was related to higher risk of developing dementia or $\mathrm{MCl}$ up to 30 years later. Higher late-life LIBRA score was related to higher risk of $\mathrm{MCl}$ up to 10 years later and to higher dementia risk, though the latter was restricted to APOE $\varepsilon 4$ non-carriers. These findings emphasize the role of modifiable risk factors in the development of $\mathrm{MCl}$ and dementia, and the potential usefulness of LIBRA as a tool for facilitating preventive strategies.

The LIBRA score was designed to reflect an individual's prevention potential for dementia, and thus focuses exclusively on modifiable risk/protective factors, yielding a weighted sum score. Available dementia / $\mathrm{MCl}$ risk scores have usually combined modifiable risk/ protective factors with e.g. age, sex, formal education, cognitive performance and/or other biomarkers. ${ }^{5}$ Age and education are strong risk factors for dementia and usually have the highest weights in risk scores they are part of. It is perhaps not surprising that the dementia predictive performance of the LIBRA score was lower than C-statistic or AUC values reported for such risk scores (e.g. 0.75-0.77 for the validated midlife CAIDE Dementia Risk Score versus 0.65 for midlife LIBRA score in the present study). The C-statistic improved after adding diet to the LIBRA score, although the small number of participants with midlife diet data, and lack of late-life diet data limited these analyses. The lack of 
data on cognitive activity in the present study may also have affected the LIBRA score predictive performance, given the growing evidence that high engagement in cognitive activities is associated with lower risk for cognitive impairment or dementia. ${ }^{4}$

Higher midlife LIBRA score was significantly related to higher dementia risk even after taking age, education and sex into account, thus emphasizing the importance of modifiable lifestyle and vascular/metabolic factors for dementia risk, and the importance of early preventive strategies. Given the low public awareness about links between such modifiable factors and dementia risk, ${ }_{1}^{20,21}$ the LIBRA score could be useful for educational and motivational purposes to facilitate lifestyle changes for healthy cognitive aging and dementia prevention. An ongoing 6-month feasibility trial is using the LIBRA score to provide middle-aged individuals in primary care with a personalized profile highlighting areas of already healthy behaviors (to facilitate maintenance), areas of unhealthy behaviors (to facilitate change), and chronic vascular/metabolic conditions (to facilitate appropriate management). ${ }^{16}$ Due to the focus on factors that are easily amenable to interventions, participants can set specific personal goals and self-monitor progress. ${ }^{16}$

In the present study, performance of the midlife LIBRA score was better than the performance of the late-life LIBRA score, suggesting that the significance of modifiable risk factors for dementia/MCI may be different in midlife compared with older ages. This is in line with previous studies showing that dementia risk scores based on midlife risk profiles tend to perform less well in older populations. ${ }^{5,22}$ For example, important midlife vascular risk factors such as hypertension, obesity or hypercholesterolemia tend to be less predictive for dementia at older ages, and some late-life risk scores have even included low blood pressure and/or low BMI as predictors. ${ }^{5}$ Blood pressure, $\mathrm{BMI}$ and cholesterol tend to decline from midlife to late-life in people who develop dementia later on, although the exact mechanisms are not fully clear. ${ }^{23}$ Such changes during the long pre-clinical phase of dementia-related diseases are also a major challenge for longer-term dementia risk monitoring.

The midlife LIBRA score performed better in predicting dementia risk than $\mathrm{MCl}$ risk. This is perhaps not surprising considering the notable heterogeneity of $\mathrm{MCl}$ as defined by older criteria in use at the time of the CAIDE visits. The performance of the late-life LIBRA score in predicting $\mathrm{MCl}$ risk (C statistic 0.60) was similar to the basic prediction model developed in the Mayo Clinic Study of Aging, including education and self-reported memory complaints together with several lifestyle and vascular factors. ${ }^{24}$

While the associations of the midlife LIBRA score with dementia or $\mathrm{MCl}$ risk were not influenced by the APOE $\varepsilon 4$ allele in the present study, a significant interaction with APOE $\varepsilon 4$ carrier status was found for late-life LIBRA index in relation to dementia risk. Higher 
late-life LIBRA score was associated with elevated dementia risk particularly among noncarriers. While some midlife lifestyle/vascular risk factors have been reported to have a more pronounced detrimental impact on dementia risk among APOE $\varepsilon 4$ carriers compared with non-carriers, ${ }^{23}$ it is possible that the impact of such risk factors among carriers may become less pronounced at older ages. APOE $\varepsilon 4$ carriers who survive and do not develop dementia until after the age of 75-80 years represent a highly selected group where other genetic and/or non-genetic risk and protective factors may also be important.

The major strengths of the present study include the population-based design, the long follow-up period starting already in midlife, and detailed assessments at several time points. Analyses in both the main study population (survivors/participants only) and extended population (additional register dementia diagnoses for non-survivors/nonparticipants) accounted at least partly for mortality and non-participation. Mortality and non-participation in longitudinal studies are often linked to poorer health, i.e. people who are more likely to develop dementia, or die before dementia onset. Findings were quite similar in both study populations, with somewhat lower HR and C-statistic values in the extended population, most likely due to lower sensitivity of dementia diagnoses in registers. ${ }^{15}$

While data for most LIBRA factors were available in the CAIDE study, reliance on register diagnoses for some chronic conditions (i.e. only conditions severe enough to require hospitalization) may have affected the predictive performance of the LIBRA score. Also, complete data on pharmacological treatment for the included risk factors/conditions were not available. In addition, interactions between risk factors were not taken into account in the design of the LIBRA score. Information on possible interactions between risk factors is still incomplete in available literature and therefore more research on this matter is needed.

In conclusion, findings from the present study emphasize the role of modifiable risk and protective factors in the development of $\mathrm{MCl}$ and dementia. The LIBRA score may be useful for educational and motivational purposes by emphasizing areas amenable to preventive lifestyle measures, and for identifying at-risk individuals who may benefit from lifestyle interventions. However, it should not be used for diagnostic purposes. The LIBRA score is also not very suitable for identifying individuals who are already close to dementia onset, and who may need referral to specialized clinics for detailed cognitive and other assessments, as well as early initiation of pharmacological treatment. 


\section{REFERENCES}

1. World Health Organization. Dementia: a public health priority. Geneva: World Health Organization, 2012.

2. Scalco MZ, van Reekum R. Prevention of Alzheimer disease. Encouraging evidence. Can Fam Physician 2006; 52: 200-7.

3. Baumgart M, Snyder HM, Carrillo MC, Fazio S, Kim H, Johns H. Summary of the evidence on modifiable risk factors for cognitive decline and dementia: A population-based perspective. Alzheimers Dement 2015; 11(6): 718-26.

4. Deckers K, van Boxtel MP, Schiepers OJ, et al. Target risk factors for dementia prevention: a systematic review and Delphi consensus study on the evidence from observational studies. Int J Geriatr Psychiatry 2015; 30(3): 234-46.

5. Tang EY, Harrison SL, Errington L, et al. Current Developments in Dementia Risk Prediction Modelling: An Updated Systematic Review. PLoS One 2015; 10(9): e0136181.

6. Kivipelto $M$, Helkala EL, Laakso MP, et al. Midlife vascular risk factors and Alzheimer's disease in later life: longitudinal, population based study. BMJ 2001; 322(7300): 1447-51.

7. Puska P, Salonen JT, Nissinen A, et al. Change in risk factors for coronary heart disease during 10 years of a community intervention programme (North Karelia project). Br Med J (Clin Res Ed) 1983; 287(6408): 1840-4.

8. Puska P, Tuomilehto J, Salonen J, et al. Changes in coronary risk factors during comprehensive five-year community programme to control cardiovascular diseases (North Karelia project). BMJ 1979; 2(6199): 1173-8.

9. Vartiainen E, Puska P, Jousilahti P, Korhonen HJ, Tuomilehto J, Nissinen A. Twenty-year trends in coronary risk factors in north Karelia and in other areas of Finland. Int J Epidemiol 1994; 23(3): 495-504.

10. Folstein MF, Folstein SE, McHugh PR. "Mini-mental state". A practical method for grading the Cognitive state of patients for the clinician. J Psychiatr Res 1975; 12(3): 189-98.

11. Morris JC, Heyman A, Mohs RC, et al. The Consortium to Establish a Registry for Alzheimer's Disease (CERAD). Part I. Clinical and neuropsychological assessment of Alzheimer's disease. Neurology 1989; 39(9): 1159-65.

12. American Psychiatric Association. Diagnostic and statistical manual of mental disorders (4th edition). Washington, DC: American Psychiatric Association; 1994.

13. McKhann G, Drachman D, Folstein M, Katzman R, Price D, Stadlan EM. Clinical diagnosis of Alzheimer's disease: report of the NINCDS-ADRDA Work Group under the auspices of Department of Health and Human Services Task Force on Alzheimer's Disease. Neurology 1984; 34(7): 939-44.

14. Petersen RC, Smith GE, Ivnik RJ, et al. Apolipoprotein E status as a predictor of the development of Alzheimer's disease in memory-impaired individuals. JAMA 1995; 273(16): 1274-8.

15. Solomon A, Ngandu T, Soininen H, Hallikainen MM, Kivipelto M, Laatikainen T. Validity of dementia and Alzheimer's disease diagnoses in Finnish national registers. Alzheimers Dement 2014; 10(3): 303-9.

16. O'Donnell CA, Browne S, Pierce $M$, et al. Reducing dementia risk by targeting modifiable risk factors in mid-life: study protocol for the Innovative Midlife Intervention for Dementia Deterrence (In-MINDD) randomised controlled feasibility trial. Pilot and Feasibility Studies 2015; 1(40). 
17. Geographical variation in the major risk factors of coronary heart disease in men and women aged 35-64 years. The WHO MONICA Project. World Health Stat Q 1988; 41(3-4): 115-40.

18. Tsukamoto K, Watanabe T, Matsushima T, et al. Determination by PCR-RFLP of apo E genotype in a Japanese population. J Lab Clin Med 1993; 121(4): 598-602.

19. Eskelinen MH, Ngandu T, Tuomilehto J, Soininen H, Kivipelto M. Midlife healthy-diet index and late-life dementia and Alzheimer's disease. Dement Geriatr Cogn Dis Extra 2011; 1(1): 103-12.

20. Anderson LA, Day KL, Beard RL, Reed PS, Wu B. The public's perceptions about cognitive health and Alzheimer's disease among the U.S. population: a national review. Gerontologist 2009; 49 Suppl 1: S3-11.

21. Smith BJ, Ali S, Quach H. Public knowledge and beliefs about dementia risk reduction: a national survey of Australians. BMC Public Health 2014; 14: 661.

22. Solomon A, Soininen H. Dementia: Risk prediction models in dementia prevention. Nat Rev Neurol 2015; 11(7): 375-7.

23. Solomon A, Mangialasche F, Richard E, et al. Advances in the prevention of Alzheimer's disease and dementia. J Intern Med 2014; 275(3): 229-50.

24. Pankratz VS, Roberts RO, Mielke MM, et al. Predicting the risk of mild cognitive impairment in the Mayo Clinic Study of Aging. Neurology 2015; 84(14): 1433-42. 


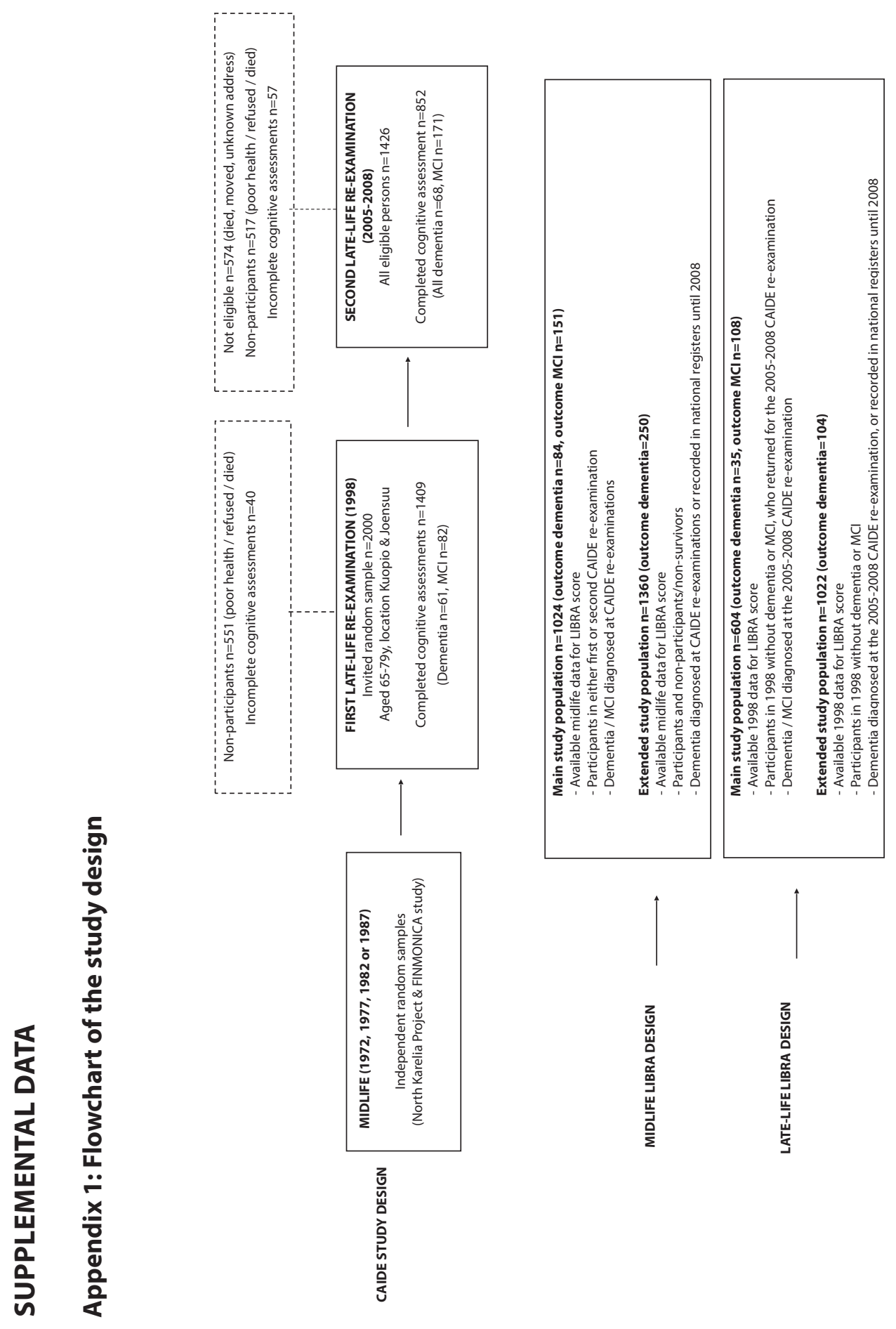




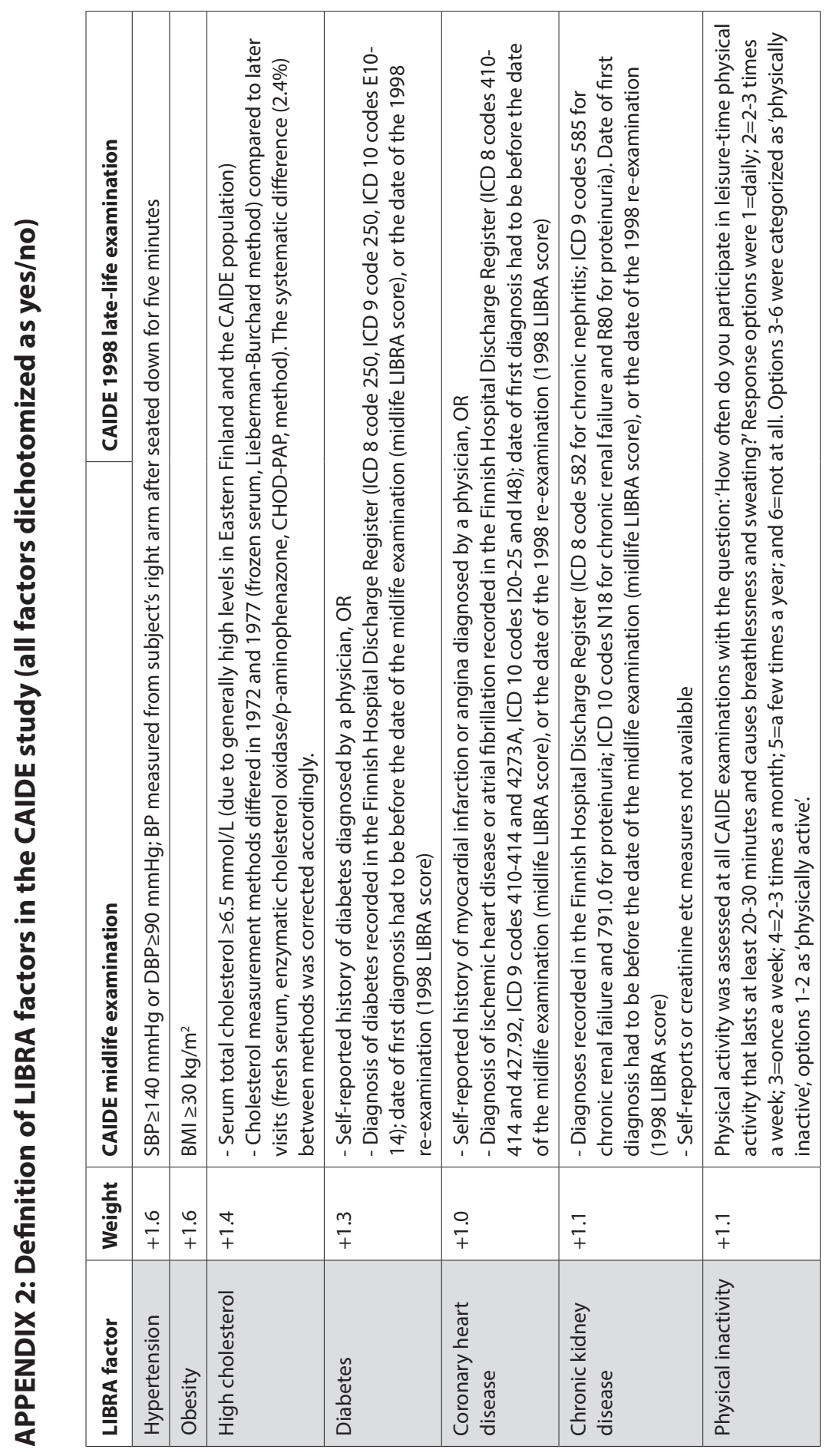




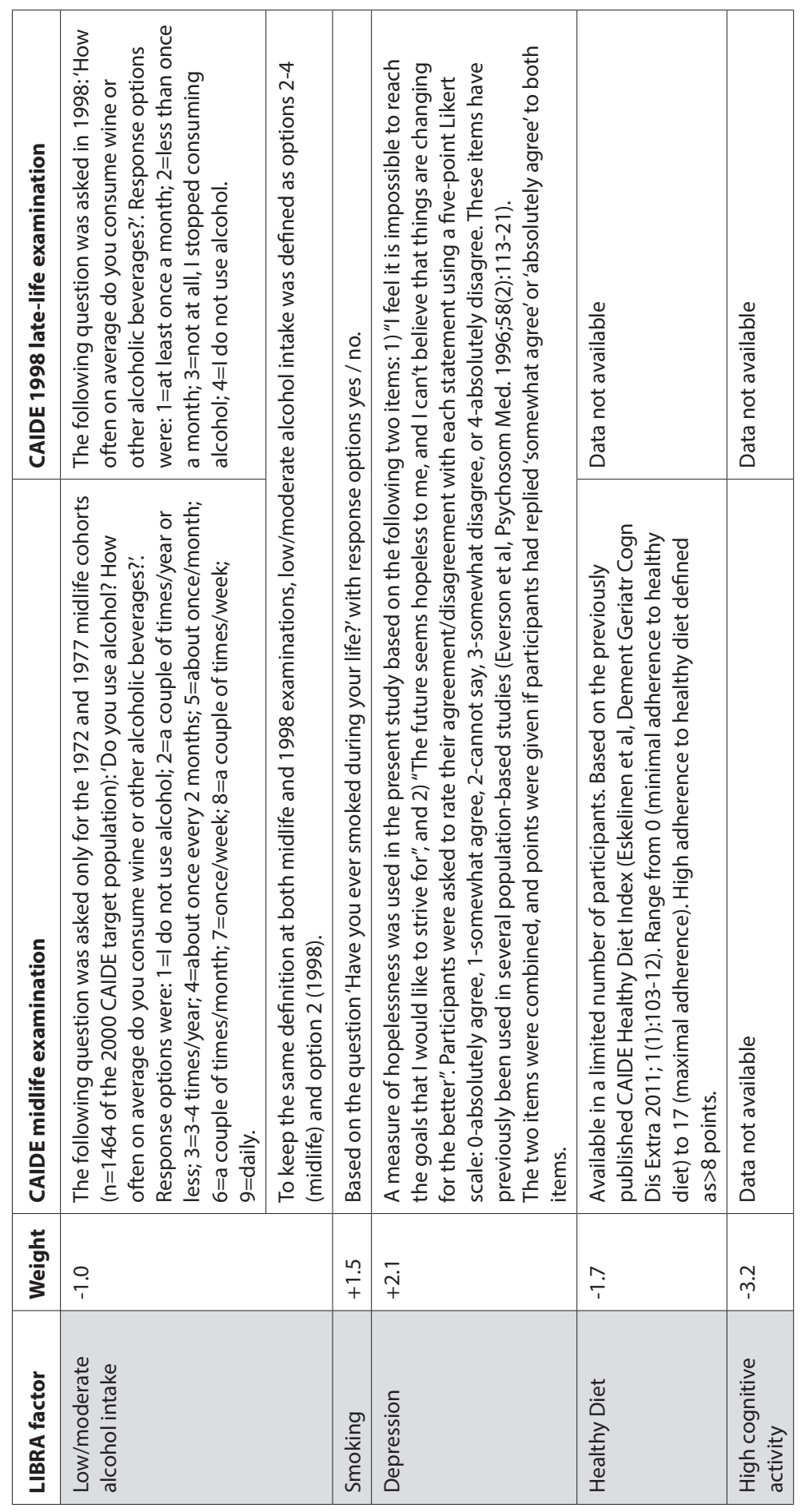




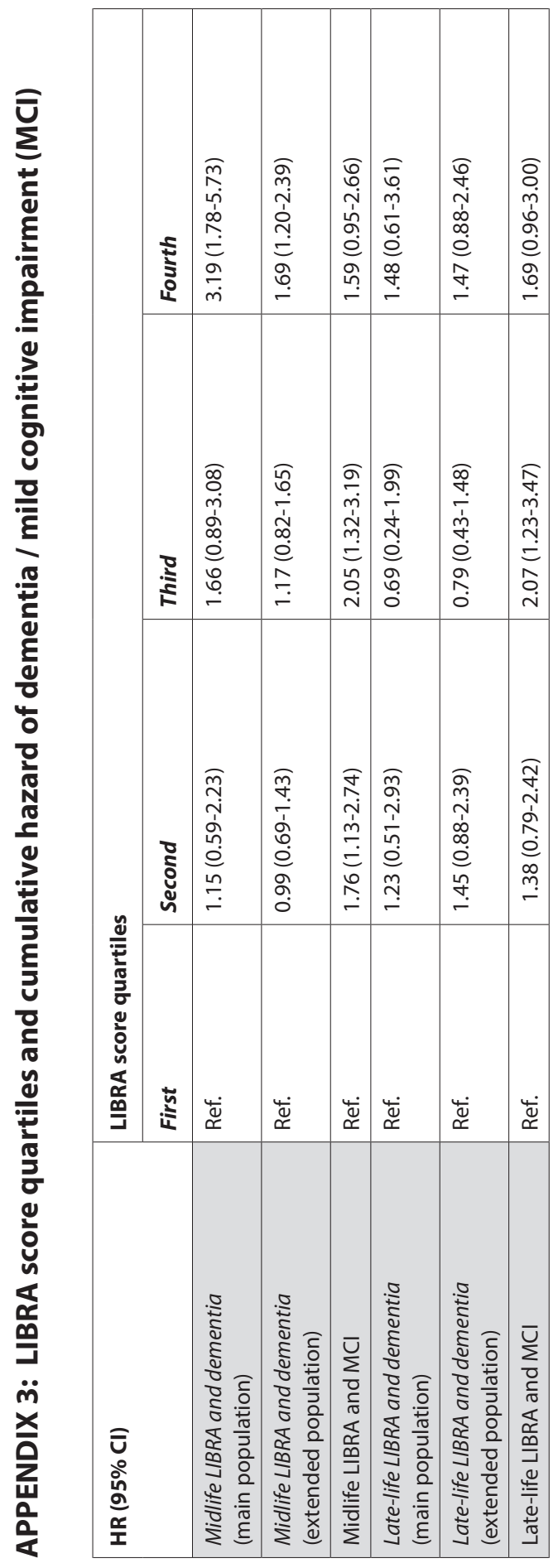




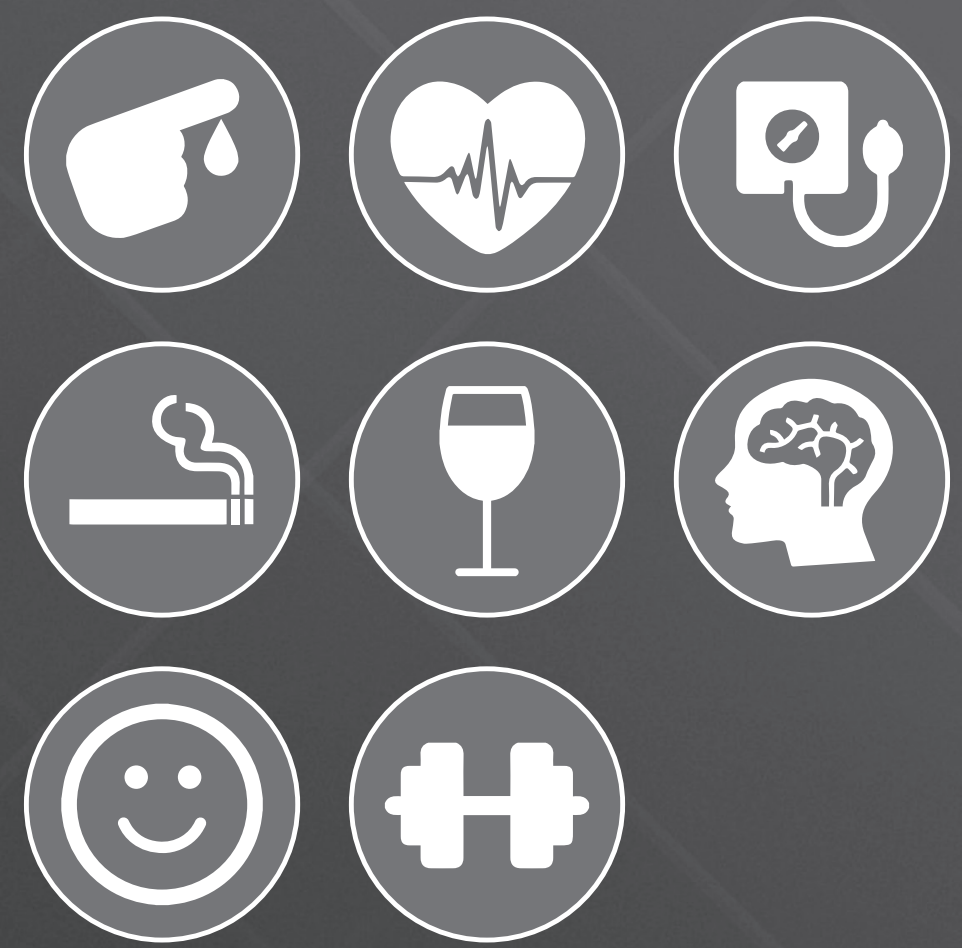


\section{CHAPTER 7}

\section{LACK OF ASSOCIATIONS BETWEEN MODIFIABLE RISK FACTORS AND DEMENTIA IN THE VERY OLD:}

FINDINGS FROM THE CAMBRIDGE CITY OVER-75S COHORT STUDY

Aging \& Mental Health 2017

Kay Deckers, Sebastian Köhler, Martin PJ van Boxtel, Frans RJ Verhey, the CC75C study collaboration, Carol Brayne, Jane Fleming 


\section{ABSTRACT}

Objectives: To investigate the association between modifiable risk and protective factors and severe cognitive impairment and dementia in the very old. Additionally, the present study tests the predictive validity of the 'Llfestyle for BRAin health' (LIBRA) score, an index developed to assess an individual's dementia prevention potential.

Method: Two hundred seventy-eight individuals aged 85 years or older from the population-based Cambridge City over-75s Cohort Study were followed-up until death. Included risk and protective factors were: diabetes, heart disease, hypertension, depression, smoking, low-to-moderate alcohol use, high cognitive activity, and physical inactivity. Incident severe cognitive impairment was based on the Mini-Mental State Examination (score: 0-17) and incident dementia was based on either post-mortem consensus clinical diagnostic assessments or death certificate data. Logistic regressions were used to test whether individual risk and protective factors and the LIBRA score were associated with severe cognitive impairment or dementia after 18 years follow-up.

Results: None of the risk and protective factors or the LIBRA score was significantly associated with increased risk of severe cognitive impairment or dementia. Sensitivity analyses using a larger sample, longer follow-up period, and stricter cut-offs for prevalent cognitive impairment showed similar results.

Conclusion: Associations between well-known midlife risk and protective factors and risk for severe cognitive impairment or dementia might not persist into very old age, in line with suggestions that targeting these factors through lifestyle interventions should start earlier in life. 


\section{INTRODUCTION}

In 2012, dementia was proclaimed a public health priority by the World Health Organization.' Given the current lack of available treatments for dementia, research focus has shifted to prevention strategies. ${ }^{2}$ Even if a future cure for dementia becomes available, primary prevention should arguably remain one of the pillars of public health campaigns to reduce the number of affected individuals or to delay symptom onset. Several studies suggest that targeting modifiable risk factors is essential to reduce dementia risk. ${ }^{3-5}$ Questions still remain as to which factors should be targeted and which period during a person's lifespan would be the window of opportunity for most effective and efficient prevention. Since only a few randomized controlled trials have investigated the effects of single or multivariate risk factor reduction on cognitive decline or dementia incidence, ${ }^{6,7}$ the evidence for most factors comes from observational studies. ${ }^{3,4,8}$ Recent systematic literature reviews and meta-analyses showed consistent support for a wide range of modifiable risk and protective factors associated with dementia, including cardiovascular and metabolic factors (e.g. hypertension, obesity, hypercholesterolemia, diabetes, coronary heart disease), lifestyle factors (e.g. diet, smoking, physical activity, alcohol consumption, cognitive activity) and psycho-social factors (e.g. depression). .-5, $^{2}$ These factors could be targeted by tailored lifestyle interventions, preferably in midlife, when lifestyle adjustments are more feasible and probably most effective by reducing brain damage accumulated during long-term exposure to these factors. ${ }^{9}$ Indeed, previous studies have shown that the effects of certain risk factors vary across the life course. For instance, obesity and hypertension in midlife have more pronounced effects on dementia risk rather than in late life. ${ }^{3,410}$ Additionally, late life studies showed inconsistent results regarding the predictive ability of health and lifestyle factors., ${ }^{30-12}$ There are a few studies that looked at the effects of metabolic syndrome (including obesity, hypertension, diabetes and hypercholesterolemia) towards cognitive decline. The association between metabolic syndrome and cognitive decline, which is found to be positive in younger populations, was not significant in the very old. ${ }^{13,14}$ However, studies investigating the (combined) effects of modifiable risk and protective factors on dementia risk in a very old population (i.e. $85+$ years) are particularly rare.

Therefore, the overall aim of the current study is to investigate the association between known modifiable risk and protective factors and severe cognitive impairment and dementia in individuals aged 85 years and older, as part of the Cambridge City over-75s Cohort (CC75C) Study, a longitudinal study of ageing in the very old..$^{15,16}$ In addition, the study tests the predictive validity of the recently developed 'Llfestyle for BRAin health' 
(LIBRA) score, ${ }^{4}$ a simple summary index that assesses an individual's dementia prevention potential by combining information on major modifiable health and lifestyle factors.

\section{METHODS}

\section{Study population}

The CC75C study is a population-based study originally started in 1985 to measure the prevalence of dementia in people aged 75 years and over from a selection of geographically and socially representative general practices in the city of Cambridge, United Kingdom (UK). ${ }^{15,16}$ From the original sample of 2,610, a total of 2,166 participants from all but one general practice formed the sample that was followed-up every two to four years until the last participant's death after the final survey in 2013 (Year 28). Each survey used a structured interviewer-administered schedule to collect information on socio-demographic variables, activities of daily living, cognitive functioning (Mini-Mental State Examination (MMSE), ${ }^{17}$ health problems, medication, and use of health and social services. After the first survey, proxy informant interviews were sought as needed to minimize loss to follow-up of the frailest individuals. From Survey 2 onwards, participants were asked whether they were willing to participate in the brain donation program. Each study phase was approved by the Cambridge Research Ethics Committee. At Survey 4 (Year 10), the most comprehensive assessment of modifiable risk and protective factors took place and was hence considered the baseline assessment for the present study ( $\mathrm{n}=$ 446 ; age range $=84-102$ ), yielding a maximum follow-up period of 18 years (see Figure 1 ). 


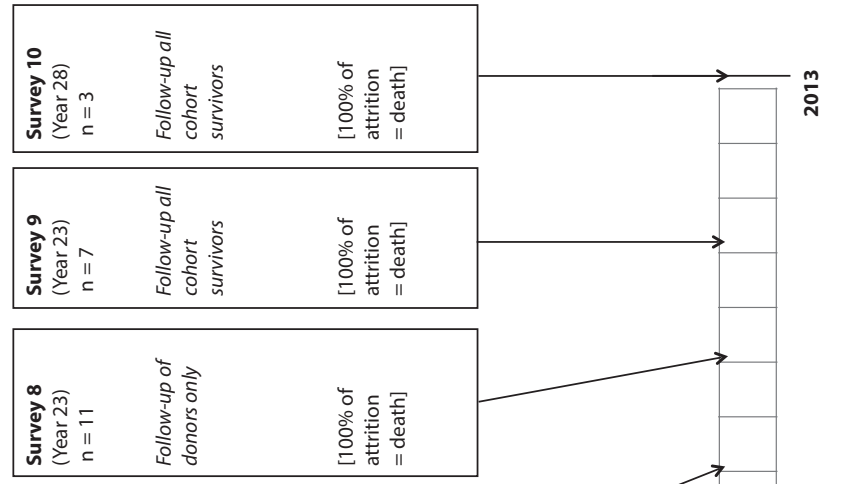

\begin{tabular}{|c|c|c|}
\hline 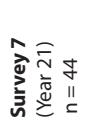 & 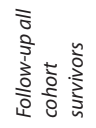 & 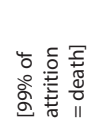 \\
\hline
\end{tabular}

\begin{tabular}{|c|c|c|}
\hline 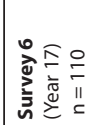 & 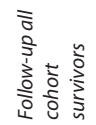 & 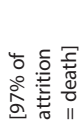 \\
\hline
\end{tabular}

\begin{tabular}{|c|c|c|}
\hline 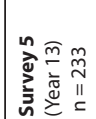 & 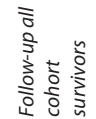 & 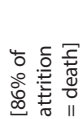 \\
\hline
\end{tabular}

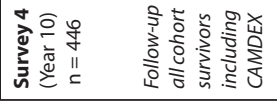

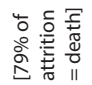
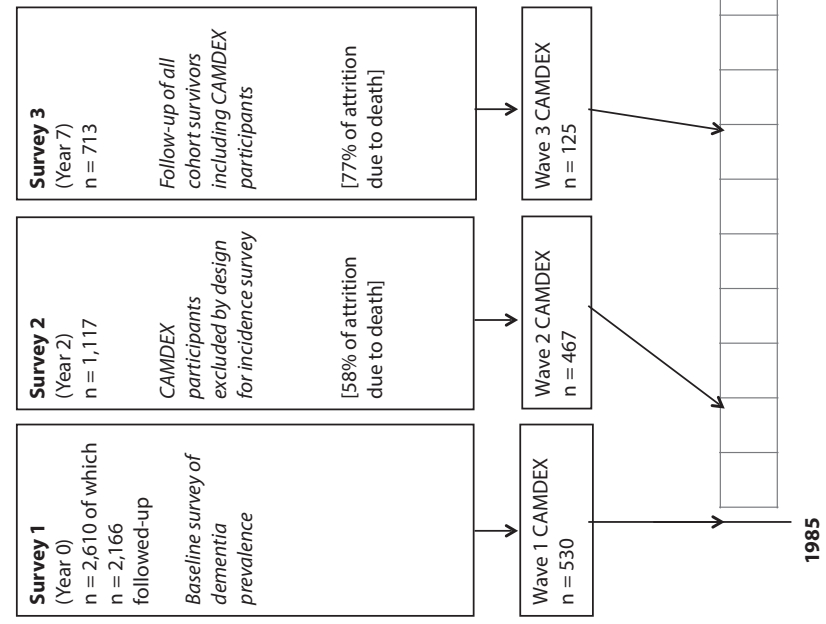

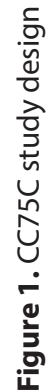




\section{Dementia and severe cognitive impairment diagnosis}

Participants with dementia were identified using three CC75C study data sources: 1) Psychiatrist-administered assessments: the Cambridge Diagnostic Examination for the Elderly (CAMDEX). ${ }^{18}$ In Survey 1, cognitively impaired participants (MMSE scores $\leq 23$ ) and one in three participants with milder cognitive impairment (MMSE scores 24-25) underwent CAMDEX assessments. CAMDEX assessments following Surveys 2 and 3 also included participants with high cognitive scores (MMSE 26-30); 2) Post-mortem consensus clinical diagnostic assessments were conducted to confirm dementia diagnosis or absence of dementia by the time of death for the sub-sample who had donated to the study's brain donation programme; 3) The cohort was flagged for mortality with the Office of National Statistics so the study resource includes cause of death data from death certificates. Prevalent dementia at Survey 4 was defined as dementia diagnosed by latest CAMDEX assessment (all prior to Survey 4) and incident dementia was based on either post-mortem consensus diagnosis or death certificate data, excluding prevalent CAMDEX dementia cases. More than half of Survey 4 participants had undergone at least one CAMDEX assessment (231/446), of whom 94/231 were diagnosed with prevalent dementia. More than a quarter of Survey 4 participants had post-mortem consensus clinical diagnostic assessment (121/446). Of these, 70/121 were diagnosed with dementia, of whom the majority $(51 / 70)$ had incident dementia, i.e. no prior CAMDEX dementia diagnosis. Death certificate data were available for all participants, for whom 66 death certificates mentioned dementia. For 37 of these 66 there had been neither a CAMDEX dementia diagnosis nor any post-mortem clinical consensus diagnostic assessment. This totals 88 cases of incident dementia after Survey 4.

As the $\mathrm{CC} 75 \mathrm{C}$ data sources may not capture all prevalent and incident dementia, we also included severe cognitive impairment in our overall outcome. Individuals with MMSE scores 0-17 were categorized as severely cognitively impaired. ${ }^{19}$ Eighty-five cases of prevalent severe cognitive impairment could be identified based on their MMSE score at Survey 4 and 52 individuals developed incident severe cognitive impairment after Survey 4. Combining these two outcomes resulted in 140 prevalent and 84 incident cases of severe cognitive impairment or dementia (see Figure 2).

\section{Demographics}

Age and sex were confirmed from general practice lists when originally enrolled in the study and educational level was self-reported at baseline through questions on what age the participant left school and years of education after school leaving age. 


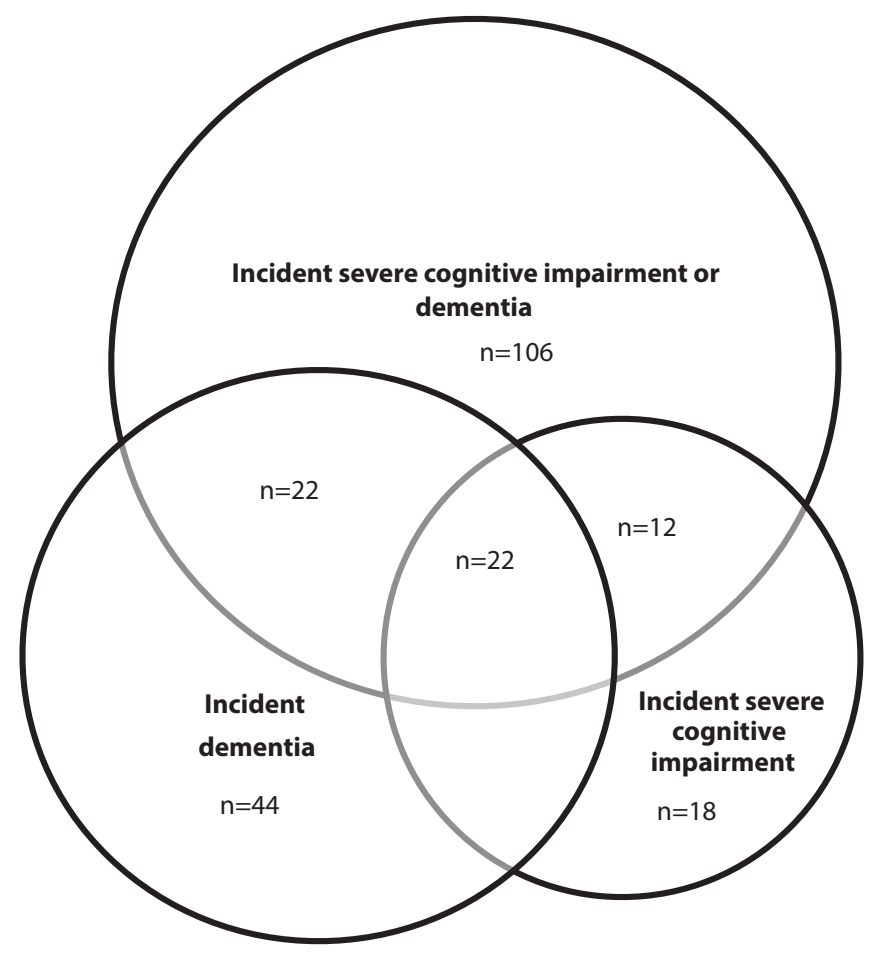

Figure 2. Survey 4 cases of incident severe cognitive impairment or dementia

\section{Modifiable risk and protective factors}

For the present study, data were available on eight out of twelve modifiable risk and protective factors identified in a recent review: diabetes, depression, coronary heart disease, hypertension, alcohol consumption, smoking status, physical activity and cognitive activity. ${ }^{4}$ Risk factors were based on either self-reported or proxy-reported information and were either dichotomized according to cut-offs as described below or rated present or absent. Information from proxy informants was used when participants' cognitive abilities interfered with accurate reporting. The presence of coronary heart disease (angina pectoris or heart attack), diabetes and hypertension were based on self- or proxy-report of a doctor's diagnosis. For smoking, participants were divided into current smokers and non-smokers. Alcohol consumption was based on the reported frequency of current alcohol use, with 1-14 glasses per week considered low-to-moderate, according to recent UK alcohol guidelines. ${ }^{20}$ Individuals were considered depressed if they scored 6 or higher on the ten-item CAMDEX Depressive Symptoms Scale (range 0-11). ${ }^{21}$ The physical activity measure categorized participants as active individuals who engaged in one or 
more forms of physical activity or exercise (e.g. walking, cycling, do-it-yourself, gardening, etc.) during the last week and the inactive who did none of these. For cognitive activity (intellectual engagement), participants were categorized as active or inactive based on reported activities undertaken in the last fortnight (e.g. visits to places of interest, hobbies, reading) and having taken part in education or training in recent years. Engagement in three or more of these activities was considered as cognitively active.

\section{LIBRA-index}

The LIBRA score was developed after triangulation of results from a systematic literature review on risk and protective factors for dementia and an expert consensus study, ${ }^{4}$ as part of the European (FP7) INnovative, Midlife INtervention for Dementia Deterrence (InMINDD) project. ${ }^{22}$ It consists of twelve modifiable risk and protective factors that can be targeted by tailored lifestyle interventions and primary prevention: physical inactivity, smoking, (low-to-moderate) alcohol use, (high) cognitive activity, healthy diet, depression, hypertension, obesity, diabetes, hypercholesterolemia, coronary heart disease, and renal disease. A weight is assigned to each factor, based on the factor's relative risk. ${ }^{4}$ Weights are then standardised and summed to yield the final LIBRA score (range from -5.9 to +12.7), with higher scores indicating greater risk. In contrast to other risk indices, LIBRA is based on modifiable risk and protective factors only, and hence assesses an individual's potential for dementia prevention. A modified version of the LIBRA score was developed for the purpose of validation in older cohorts. It consists of ten factors, excluding the risk factors obesity and hypertension, since these are considered to be major risk factors in midlife only. In CC75C, status information was available for 7 of the 10 factors from the modified LIBRA score (range from -4.2 to + 7.0). No information was available for diet, renal dysfunction and hypercholesterolemia.

\section{Statistical analysis}

Independent samples $t$-tests and $\mathbf{X}^{2}$-tests were used to examine differences in risk factors and demographic variables between participants with incident severe cognitive impairment or dementia and non-affected individuals. Multiple imputation was used to impute missing values for the eight risk and protective factors, but only for participants with less than three missing factors (others were listwise-deleted). Multivariate imputation by chained equations was carried out using all non-missing data on risk and protective factors and sociodemographic covariates (age, sex and educational level). ${ }^{23}$ Ten imputed datasets were created and the results combined using Rubin's rules. ${ }^{24}$ Separate logistic regressions tested whether individual risk and protective factors and the continuous 
LIBRA score were associated with odds for severe cognitive impairment or dementia in crude analyses (Model 1) or after adjustment for age, sex and educational level (Model 2). All analyses were done in Stata 13.1 (StataCorp, College Station, TX, USA), and the level of statistical significance used was $p<0.05$ in two-sided tests.

\section{RESULTS}

\section{Sample characteristics}

After exclusion of 140 cases of prevalent severe cognitive impairment or dementia and 10 individuals with missing MMSE data after Survey 4, the total outcome-free sample at Survey 4 consisted of 296 participants. The mean age was 87.9 (SD 3.2, 84-102) years, and 201 (68\%) were female. During the 18-year follow-up, 84 individuals (28\%) developed severe cognitive impairment or dementia.

\section{Risk and protective factors}

Status information for all eight risk and protective factors was available in 226 participants (76\%). As described above, data were imputed for those participants with one $(n=38)$ or two $(n=14)$ missing factors. From the total of 2368 values for the eight factors, 66 values were imputed (2.8\%). We excluded 18 participants with more than two missing factors from the analyses, of whom 9 (50\%) individuals developed severe cognitive impairment or dementia. This resulted in a total sample of 278 participants with a mean age of 87.8 (SD 3.1, 84-102) years, of whom 189 (68\%) were female. Of these, 75 individuals (27\%) developed severe cognitive impairment or dementia. The characteristics of this sample are illustrated in Table 1. None of the risk or protective factors was significantly associated with severe cognitive impairment or dementia in crude analyses or after adjustment for age, sex and educational level. Similar results were found in separate analyses for dementia and severe cognitive impairment (see Table 2).

\section{LIBRA-index}

Seven of the 8 risk factors from imputed datasets were used to calculate individuals' modified LIBRA scores (hypertension omitted as explained above; range from -0.8 to 2.2). Lower LIBRA scores were significantly associated with increased odds of severe cognitive impairment or dementia, but this association was no longer significant when age, sex and educational level were added as covariates (see Table 2). Separate analyses for dementia showed no significant results, but lower LIBRA scores were significantly associated with higher odds of severe cognitive impairment even after adjustment for sociodemographic covariates. 


\section{Sensitivity analyses}

We performed two sensitivity analyses. First, to further investigate the direction of effects, the same analysis procedure for incident dementia as outcome was repeated with participants in Survey 3 (year 7; $n=560$ after exclusion of 153 cases of prevalent dementia), a larger sample with longer follow-up but with information available on only six risk factors: diabetes, heart disease, hypertension, depression, high cognitive activity, and physical inactivity. Again, data were imputed for those participants with one $(n=78)$ or two $(n=29)$ missing factors (imputation of $4.2 \%$ ). As a result, the sample for these sensitivity analyses totaled 546 participants (mean age $=85.5$ (SD 3.6, 81-103) years; $69 \%$ females; $17 \%$ developed dementia). Individuals with dementia were on average younger and more often female, and they died at a younger age in comparison with participants without dementia. Physical inactivity showed a protective effect and high cognitive activity was associated with an increased risk of incident dementia, but these effects were no longer significant or of only borderline significance when adjusted for age, sex and educational level (data not shown). Second, we studied whether results were due to inclusion of participants with mild or moderate cognitive impairment at Survey 4. For this, we restricted the sample to those with an MMSE score $>21$ and those with an MMSE score $>25$. Results were similar to the full sample analyses (data not shown). 


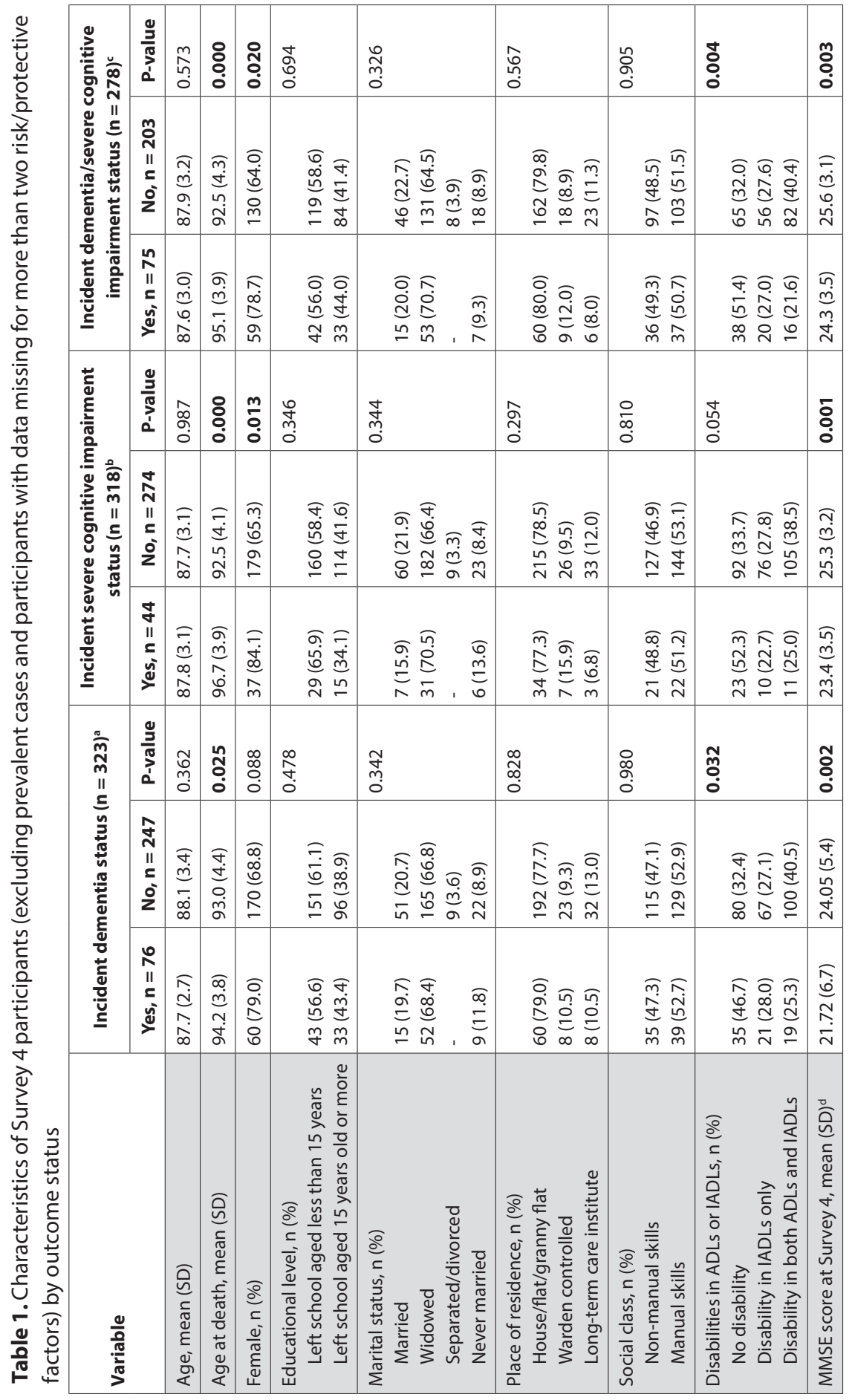




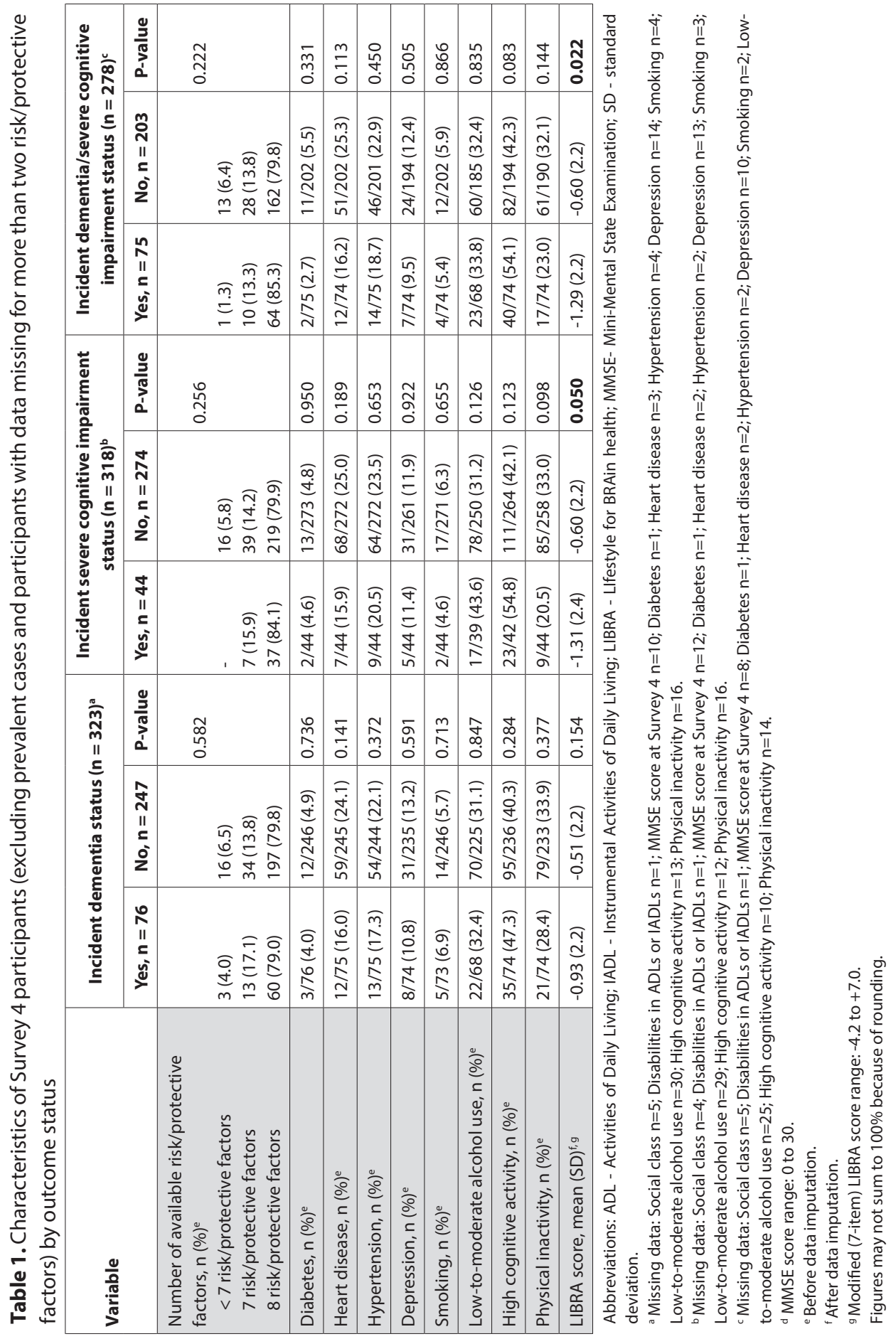




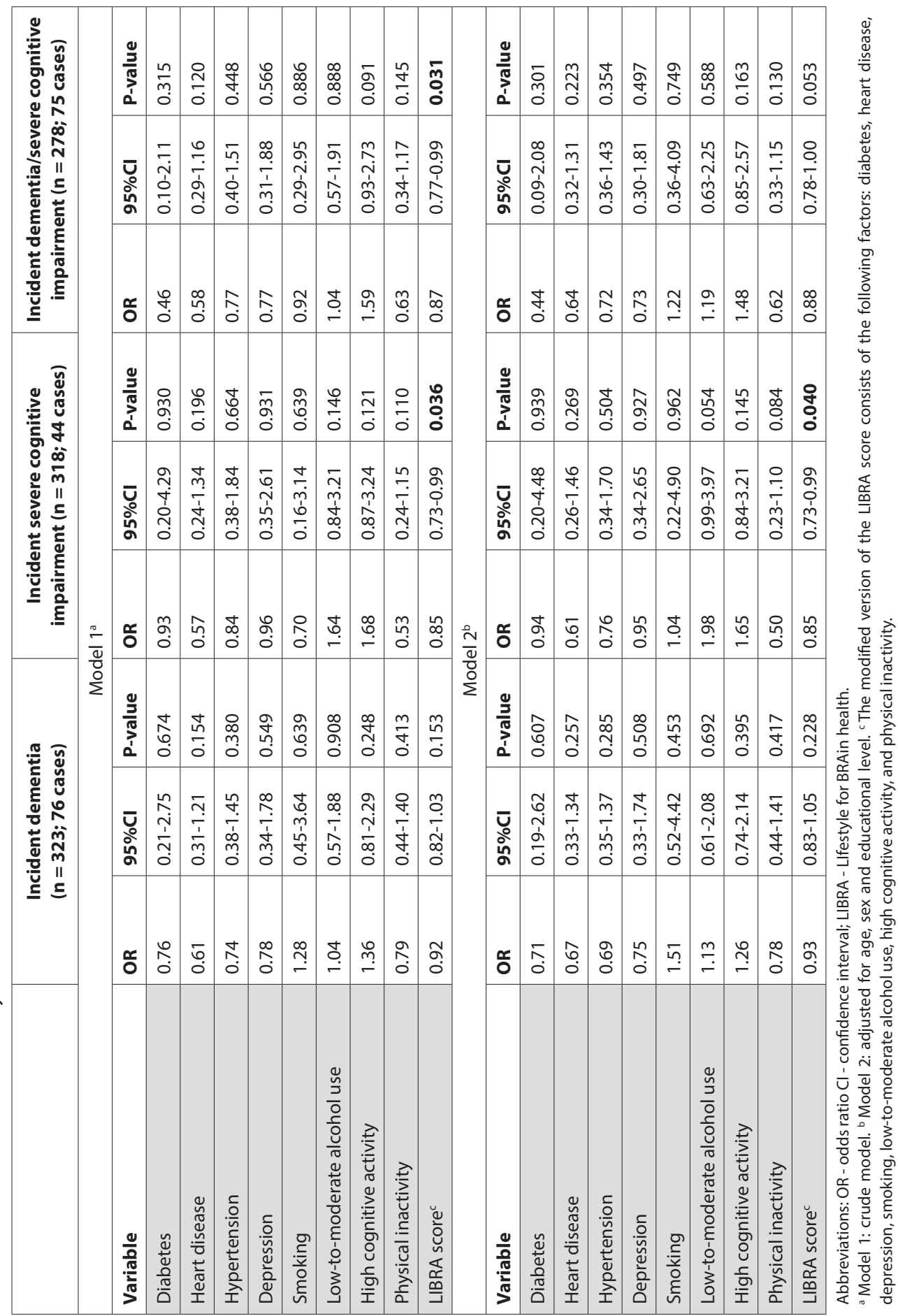




\section{DISCUSSION}

Our study shows that modifiable risk and protective factors did not predict odds of severe cognitive impairment or dementia in the very old, even after adjustment for age, sex and educational level. Similar results were found when severe cognitive impairment and dementia were taken as separate outcomes, when using a larger sample and longer follow-up period (up to 21 years; Survey 3; incident dementia as outcome) and when using stricter cut-offs for prevalent cognitive impairment (MMSE score $>21$ or $>25$ ), though results for physical inactivity and high cognitive activity were less clear and in an unexpected direction. Additionally, higher LIBRA scores did not increase the odds for dementia. It seems that the predictive value of modifiable risk and protective factors for dementia in the very old is poor. Therefore, dementia risk prediction models focusing on very old populations (i.e. $85+$ years) developed to date have included other factors such as age, cognitive test performance, brain imaging measures or apolipoprotein $\mathrm{E}$ genotype. ${ }^{25-27}$ It is important to note that inclusion of these non-modifiable factors will only increase the predictive accuracy of the risk prediction model, but will not provide information regarding an individual's potential for dementia prevention.

These findings suggest that targeting common modifiable risk factors in the very old might not have a serious impact on future dementia risk, and hence a different approach might be more appropriate. Indeed, previous randomized trials focusing on non-midlife populations generally produced negative findings. ${ }^{7,28}$ The HYVET-COG trial showed that antihypertensive treatment did not reduce the incidence of dementia in participants aged 80 years or older. ${ }^{28}$ The multidomain pre-DIVA trial focusing on vascular care in persons aged 70-78 years showed non-significant results, although dementia risk could be reduced by antihypertensive treatment in those not previously treated. ${ }^{7}$ Therefore, the Lancet Neurology Commission recently advised that dementia prevention studies should start in midlife. ${ }^{29}$

It is possible that other risk or protective factors may play a role in the etiology of dementia in the very old. This group of older people has probably survived several morbidities earlier in life and managed to live with chronic conditions like diabetes or coronary heart disease until advanced age. They may possess longevity genes or other resilience factors, which protect them from getting dementia at a higher rate than those unexposed to such risk factors. On the other hand, it is also possible that dementia is an irreversible process in very old adults. In other words, the CC75C study participants who developed incident dementia may have had fairly advanced underlying pathology at baseline already (neurodegenerative, vascular or mixed) but of a slowly-progressive nature that had not 
been diagnosed at an earlier stage. We hypothesize that this degenerative process cannot be reversed by lifestyle adaptations. It is also notable that the direction of most of the effect estimates was counter-intuitive (even in the sensitivity analysis). Inverse associations were found for diabetes, heart disease, hypertension, depression, low-to-moderate alcohol use, high cognitive activity, physical inactivity and the LIBRA score. Based on the above, it could be hypothesized that individuals at high (polygenetic) risk for dementia but with a healthy lifestyle survive longer and therefore have higher odds of developing dementia in late life in comparison with the rest of the survivors. Taken together, these results indicate that more studies are needed that investigate the effects of modifiable risk and protective factors on dementia risk in the very old, including studies aimed at detection of novel candidate risk factors.

The strengths of our study include the prospective study design focused on a representative population of the very old, the long follow-up period (up to 18 years), and the use of interviews with proxy informants to minimize lost to follow-up that could under-represent the frailest elderly and to replace missing data. However, our study has several limitations. First, the sample size was relatively small and, although sizeable for research with this very old age-group, has limited power to detect significant associations. Therefore, a sensitivity analysis with a larger sample and longer follow-up period was conducted to further investigate the direction of effects. Second, some selection bias may have occurred since individuals who were too ill or refused to participate due to medical reasons were more likely to drop out of the study. Third, the ascertainment of exposures was based on self-reported or proxy-reported information which could have led to response bias and non-differential exposure misclassification. Given the old age and physical condition of the study participants and the absence of sufficient resources to conduct neuropsychological and neurological examinations, full examinations of medical records, laboratory test, and brain scans at each survey and for each participant, the structured survey interview was the best option. Fourth, the diagnosis of dementia was partly based on death certificate records. A drawback of such data is the lack of information on how any dementia reported was diagnosed. Moreover, absence of death certificate recorded dementia cannot be taken as confirmation that dementia was absent, with the possibility of non-differential outcome misclassification (e.g. under-reporting). The discrepancy between the prevalence of incident dementia and incident severe cognitive impairment in Survey 4 may reflect inadequate identification of dementia after death and may also reflect non-random missing cognitive data. Participants whose cognitive abilities declined rapidly may not have been interviewed after this downfall, either having died or having only proxy interviews by the next survey, and are therefore 
missing from the severe cognitive impairment category. Fifth, death before follow-up and non-response are likely to be associated with both the outcomes and factors investigated. Additionally, participants with more than two missing factors were excluded from the analyses. Higher proportion of this subsample $(n=18)$ than of the included participants lived in a long-term care institute, were disabled, had dementia, and had missing MMSE data. These issues are likely to influence the investigated associations.

In sum, our results indicate that in the very old the associations between well-known risk and protective factors and subsequent development of dementia are not wellestablished, but further research is required. It supports the idea that the effects of these factors are more pronounced at other life stages such as midlife. Future campaigns should focus their preventive message on these younger age groups in anticipation of long-term health benefit. 


\section{REFERENCES}

1. World Health Organization and Alzheimer's Disease International. Dementia: A Public Health Priority. Geneva: World Health Organization, 2012.

2. Baumgart M, Snyder HM, Carrillo MC, Fazio S, Kim H, Johns H. Summary of the evidence on modifiable risk factors for cognitive decline and dementia: A population-based perspective. Alzheimers Dement 2015; 11(6): 718-26.

3. Barnes DE, Yaffe K. The projected effect of risk factor reduction on Alzheimer's disease prevalence. Lancet Neurol 2011; 10(9): 819-28.

4. Deckers K, van Boxtel MP, Schiepers OJ, et al. Target risk factors for dementia prevention: a systematic review and Delphi consensus study on the evidence from observational studies. Int J Geriatr Psychiatry 2015; 30(3): 234-46.

5. Norton S, Matthews FE, Barnes DE, Yaffe K, Brayne C. Potential for primary prevention of Alzheimer's disease: an analysis of population-based data. Lancet Neurol 2014; 13(8): 788-94.

6. Ngandu T, Lehtisalo J, Solomon A, et al. A 2 year multidomain intervention of diet, exercise, cognitive training, and vascular risk monitoring versus control to prevent cognitive decline in at-risk elderly people (FINGER): a randomised controlled trial. Lancet 2016; 385(9984): 2255-63.

7. van Charante EP, Richard E, Eurelings LS, et al. Effectiveness of a 6-year multidomain vascular care intervention to prevent dementia (preDIVA): a cluster-randomised controlled trial. Lancet 2016; 338(10046): 797-805.

8. Plassman BL, Williams JW, Jr., Burke JR, Holsinger T, Benjamin S. Systematic review: factors associated with risk for and possible prevention of cognitive decline in later life. Ann Intern Med 2010; 153(3): 182-93.

9. Lafortune L, Martin S, Kelly S, et al. Behavioural Risk Factors in Mid-Life Associated with Successful Ageing, Disability, Dementia and Frailty in Later Life: A Rapid Systematic Review. PLoS One 2016; 11(2): e0144405.

10. Anstey KJ, Cherbuin N, Budge M, Young J. Body mass index in midlife and late-life as a risk factor for dementia: a meta-analysis of prospective studies. Obes Rev 2011; 12(5): e426-37.

11. Anstey KJ, Lipnicki DM, Low LF. Cholesterol as a risk factor for dementia and cognitive decline: a systematic review of prospective studies with meta-analysis. Am J Geriatr Psychiatry 2008; 16(5): 343-54.

12. Power MC, Weuve J, Gagne JJ, McQueen MB, Viswanathan A, Blacker D. The association between blood pressure and incident Alzheimer disease: a systematic review and metaanalysis. Epidemiology 2011; 22(5): 646-59.

13. Harrison SL, Stephan BC, Siervo M, et al. Is there an association between metabolic syndrome and cognitive function in very old adults? The Newcastle 85+ Study. J Am Geriatr Soc 2015; 63(4): 667-75.

14. Katsumata Y, Todoriki H, Higashiuesato $Y$, et al. Metabolic Syndrome and Cognitive Decline Among the Oldest Old in Okinawa: In Search of a Mechanism. The KOCOA Project. The Journals of Gerontology Series A: Biological Sciences and Medical Sciences 2012; 67A(2): 126-34.

15. Brayne C, Huppert F, Paykel E, Gill C. The Cambridge Project for Later Life: design and preliminary results. Neuroepidemiology 1992; 11 Suppl 1: 71-5.

16. Fleming J, Zhao E, O'Connor DW, Pollitt PA, Brayne C. Cohort profile: the Cambridge City over75s Cohort (CC75C). Int J Epidemiol 2007; 36(1): 40-6. 
17. Folstein MF, Folstein SE, McHugh PR. "Mini-mental state". A practical method for grading the Cognitive state of patients for the clinician. J Psychiatr Res 1975; 12(3): 189-98.

18. Roth $M$, Tym E, Mountjoy CQ, et al. CAMDEX. A standardised instrument for the diagnosis of mental disorder in the elderly with special reference to the early detection of dementia. $\mathrm{Br} J$ Psychiatry 1986; 149: 698-709.

19. Tombaugh TN, Mclntyre NJ. The mini-mental state examination: a comprehensive review. J Am Geriatr Soc 1992; 40(9): 922-35.

20. Department of Health. Alcohol guidelines review - report from the guidelines development group to the UK Chief Medical Officers: Department of Health, 2016.

21. Girling DM, Huppert FA, Brayne C, Paykel ES, Gill C, Mathewson D. Depressive symptoms in the very elderly—-their prevalence and significance. Int J Geriatr Psychiatry 1995; 10(6): 497-504.

22. O'Donnell CA, Browne S, Pierce $M$, et al. Reducing dementia risk by targeting modifiable risk factors in mid-life: study protocol for the Innovative Midlife Intervention for Dementia Deterrence (In-MINDD) randomised controlled feasibility trial. Pilot and Feasibility Studies 2015; $1:(40)$.

23. White IR, Royston P, Wood AM. Multiple imputation using chained equations: Issues and guidance for practice. Stat Med 2011; 30(4): 377-99.

24. Rubin DB. Multiple Imputation After 18+ Years. Journal of the American Statistical Association 1996; 91 (434): 473-89.

25. Barnes DE, Covinsky KE, Whitmer RA, Kuller LH, Lopez OL, Yaffe K. Predicting risk of dementia in older adults: The late-life dementia risk index. Neurology 2009; 73(3): 173-9.

26. Pekkala T, Hall A, Lotjonen J, et al. Development of a Late-Life Dementia Prediction Index with Supervised Machine Learning in the Population-Based CAIDE Study. J Alzheimers Dis 2017; 55(3): 1055-67.

27. Tang EYH, Harrison SL, Errington L, et al. Current Developments in Dementia Risk Prediction Modelling: An Updated Systematic Review. PLoS One 2015; 10(9): e0136181.

28. Peters R, Beckett N, Forette F, et al. Incident dementia and blood pressure lowering in the Hypertension in the Very Elderly Trial cognitive function assessment (HYVET-COG): a doubleblind, placebo controlled trial. Lancet Neurol 2008; 7(8): 683-9.

29. Winblad B, Amouyel P, Andrieu S, et al. Defeating Alzheimer's disease and other dementias: a priority for European science and society. Lancet Neurol 2016; 15(5): 455-532. 




\section{CHAPTER 8}

GENERAL DISCUSSION SUMMARY

NEDERLANDSE SAMENVATTING (DUTCH SUMMARY) KNOWLEDGE VALORIZATION DANKWOORD (ACKNOWLEDGEMENTS) THESIS DEFENSES FROM MHENS LIST OF PUBLICATIONS CURRICULUM VITAE 



\section{GENERAL DISCUSSION}

Since there are currently no effective disease-modifying drugs for dementia, the focus of dementia research is slowly shifting towards primary prevention by means of risk factor reduction. It is suggested that modifiable risk factors play an important role in the development of dementia. ${ }^{1,2}$ Nevertheless, there are still some uncertainties with respect to the selection of target risk factors, causality claims and the window of opportunity for optimal intervention timing. ${ }^{3}$ Therefore, in this thesis we aimed to investigate the role of modifiable risk and protective factors of dementia in the general population. This was performed by using several study designs including systematic literature reviews, metaanalyses and longitudinal cohort studies.

This chapter discusses the interpretation of our main findings, the methodological issues concerning our studies, the implications for (clinical) practice and policy making, and recommendations for future research.

\section{Main findings}

\section{Risk and protective factors for dementia prevention}

Epidemiological evidence has pointed out that several modifiable risk factors are associated with an increased dementia risk. ${ }^{1,2}$ Yet, their importance for primary prevention of dementia by general practitioners has not been investigated. In a mixed-method approach (Chapter 2) we found strong evidence for depression, (midlife) hypertension, diabetes, (midlife) obesity, smoking, and hypercholesterolemia. For some identified risk and protective factors further validation is required: coronary heart disease (CHD), renal dysfunction, low-to-moderate alcohol consumption, cognitive activity and healthy diet. These findings were used to develop a multi-factorial model for dementia risk reduction, as part of work package 1 (WP1; "Risk Prediction Algorithm") of the INnovative Midlife INterventions for Dementia Deterrence (In-MINDD) project. ${ }^{4}$ This new tool is called the 'LIfestyle for BRAin Health' (LIBRA) score. LIBRA quantifies an individual's potential for dementia prevention and consists of twelve modifiable risk and protective factors that can be targeted by tailored lifestyle interventions and primary prevention: physical inactivity, smoking, low-to-moderate alcohol use, high cognitive activity, healthy diet, depression, hypertension, obesity, diabetes, hypercholesterolemia, CHD, and renal disease. Notably, LIBRA can be further divided into dynamic factors that are amendable to lifestyle changes (e.g. smoking, obesity, healthy diet) and chronic factors that need medical control (e.g. diabetes, CHD, renal disease). LIBRA was calculated according to a previously reported 
and fairly similar approach. ${ }^{5,6}$ First, the natural logarithm (In) of the relative risk (RR) from existing meta-analyses (Chapter 2, Table 4) was calculated for each risk or protective factor. Second, these were standardised by taking the lowest In (RR) as a reference value (i.e. -0.30 for low-to-moderate alcohol consumption) and dividing all other values by this value (see Table 1). This resulted in a weight for each factor and this weight is assigned to the presence or absence of each risk (positive weight) and protective (negative weight) factor. Weights are then summed to yield the final LIBRA score (range from -5.9 to +12.7 ), with higher scores indicating greater risk. The LIBRA score can be updated easily based on recent findings from epidemiological studies (e.g. inclusion of a new identified risk factor or adjustment of a risk estimate based on strong empirical evidence).

Table 1. Development of the LIfestyle for BRAin Health (LIBRA) score

\begin{tabular}{|l|l|l|l|}
\hline LIBRA factors & $\begin{array}{c}\text { Relative risk from the } \\
\text { existing meta-analyses }\end{array}$ & $\begin{array}{c}\text { Beta-coefficient (natural } \\
\text { logarithm of the relative risk) }\end{array}$ & Weight \\
\hline Low-to-moderate alcohol use & $0.74^{7}$ & -0.30 & -1.0 \\
\hline Coronary heart disease ${ }^{a}$ & $1.36^{8}$ & 0.31 & +1.0 \\
\hline Physical inactivity & $1.39^{9}$ & 0.33 & +1.1 \\
\hline Renal disease & $1.39^{10}$ & 0.33 & +1.1 \\
\hline Diabetes & $1.47^{11}$ & 0.39 & +1.3 \\
\hline Hypercholesterolemia & $1.54^{12}$ & 0.43 & +1.4 \\
\hline Smoking & $1.59^{13}$ & 0.46 & +1.5 \\
\hline (Midlife) obesity & $1.60^{1}$ & 0.47 & +1.6 \\
\hline (Midlife) hypertension & $1.61^{1}$ & 0.48 & +1.6 \\
\hline Healthy diet & $0.60^{14}$ & -0.51 & -1.7 \\
\hline Depression & $1.85^{15}$ & 0.62 & +2.1 \\
\hline High cognitive activity & $0.38^{5}$ & -0.97 & -3.2 \\
\hline
\end{tabular}

Abbreviation: LIBRA, LIfestyle for BRAin Health

${ }^{a}$ Meta-analysis on atrial fibrillation

${ }^{\mathrm{b}}$ Meta-analysis on estimated glomerular filtration rate as a marker of renal disease

There are a few existing dementia risk indices including the most widely-known CAIDE (Cardiovascular Risk Factors, Aging, and Incidence of Dementia) Dementia Risk Score ${ }^{6}$ and the ANU-ADRI (Australian National University Alzheimer's Disease Risk Index). ${ }^{5}$ In general, most dementia risk indices are limited to the variables included in the dataset on which they were based (except ANU-ADRI, which used a literature-based selection of risk factors), few indices are externally validated (except CAIDE, ANU-ADRI) and they often include nonmodifiable risk factors (e.g. age, traumatic brain injury) or non-standardized information such as magnetic resonance imaging (MRI) measures or apolipoprotein E genotype, 
which make comparison quite difficult. ${ }^{16}$ These dementia risk indices are maximized for predicting who is at risk, but not who benefits most from prevention. In contrasts, LIBRA has been developed as a result of evidence-based medicine (systematic literature review, Delphi expert consensus study, risk estimates from existing meta-analyses) and only consists of modifiable risk factors that are readily available to health professionals in primary care. Additionally, a modified version of the LIBRA score was used for validation in older cohorts (i.e. late-life and very old). Obesity and hypertension were excluded because their effects are more pronounced in midlife. ${ }^{1,17}$ A limitation of the LIBRA score is that the ascertainment of risk and protective factors in studies is often based on relatively crude (proxy) measures (e.g. cognitive activity based on compound score of a person's educational level, social activities and mental stimulation) or self-reported information (e.g. self-report of a doctor's diagnosis or a validated questionnaire), which can lead to non-differential exposure misclassification or response bias.

At the moment, external validation of LIBRA against several large population-based datasets is ongoing. Pooled risk estimates from these (ongoing) validation studies show that in midlife and late-life, the risk for dementia increased with higher LIBRA scores (adjusted for age, sex and educational level; see Figure 1).

In the very old (i.e. 80+ years), higher LIBRA scores did not increase the risk for dementia. It is important to note that not all LIBRA factors were available for each individual in the various cohort studies. This could have influenced the predictive validity of the LIBRA score, although in general results remained similar when findings from participants with missing factors where compared with participants with all LIBRA factors available. 


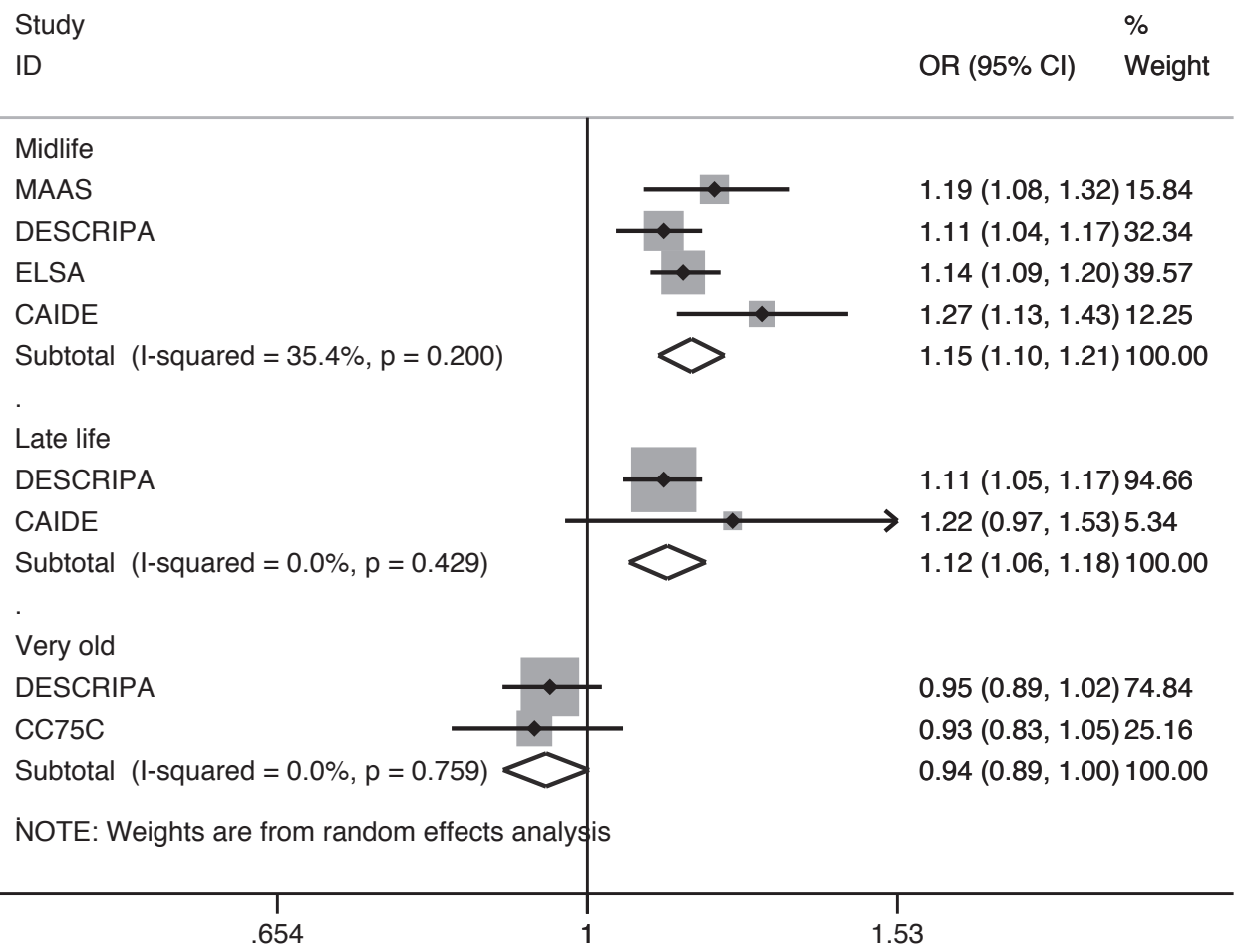

Figure 1. Forest plot of population-based prospective studies assessing the relation between the LIfestyle for BRAin Health (LIBRA) score and dementia risk (adjusted for age, sex and educational level)

Abbreviations: MAAS - Maastricht Ageing Study; DESCRIPA - Development of screening guidelines and criteria for predementia Alzheimer's disease; ELSA - English Longitudinal Study of Ageing; CAIDE - Cardiovascular Risk Factors, Ageing and Dementia; CC75C - Cambridge City over-75s Cohort study

\section{New candidate risk factors}

In Chapter 2, renal disease was considered to be a new candidate risk factor for cognitive impairment or dementia. In our very broad systematic literature review and metaanalysis in Chapter 3 we found overall modest support for an association between renal dysfunction and cognitive impairment or dementia. The debate whether chronic kidney disease is a causal risk factor or a risk state marking microvascular changes is not settled. Future studies looking at shared biological pathways are needed.

CHD also emerged in Chapter 2 as a possible new risk factor for dementia for which more research was needed. In our systematic literature review and meta-analysis investigating the association between CHD (including the most prevalent heart diseases myocardial infarction and angina pectoris) and cognitive impairment or dementia we found that CHD 
was prospectively associated with increased odds of cognitive impairment or dementia. Given the rising incidence rates of both CHD and dementia, mechanistic studies focusing on the biological pathways and shared risk factors underlying the heart-brain connection are needed. Additionally, public health campaigns focusing on these two major public health priorities should joint forces by targeting shared risk factors (e.g. hypertension, smoking, obesity, hypercholesterolemia, physical inactivity) in addition to promoting healthy aging.

\section{Obesity and cognitive decline}

Obesity is one of the risk factors for which the evidence in the literature is rather inconsistent. In Chapter 2 we found that only seven out of fourteen obesity studies found an increased risk for cognitive impairment or dementia, while two studies demonstrated a decreased risk and five studies revealed no significant association (50\% consistency). There are many contradictions in this fast-moving research field. These inconsistencies in findings can be related to several methodological differences between studies (e.g. obesity measurement, obesity cut-offs, exposure time, cognition/dementia measurement, cohort size, and mean age of the sample). In Chapter 5, we found that that the association between obesity and cognitive decline was not as straightforward as initially thought. Most associations were strongly confounded by the effect of age on rate of decline. Future studies examining the relation between obesity and cognitive decline should take this into account. Over the last few years, some studies found no evidence for a link between obesity and dementia risk. ${ }^{18,19}$ One study even found that being underweight was associated with increased dementia risk and being obese was considered to be protective. ${ }^{20}$ Nevertheless, midlife obesity is still considered to be one of the most important risk factors for primary prevention of dementia. ${ }^{21}$ Besides, obesity will always remain one of the main targets of public health strategies given its relation with other risk factors such as physical inactivity, hypertension, cardiovascular disease, diabetes and unhealthy diet.

\section{Window of opportunity}

It is not quite clear which period during a person life would be the ideal timing for effective and efficient prevention of dementia. In Chapter 6, we found that midlife and late-life are suitable life periods to target health and lifestyle factors to reduce dementia risk. These findings indicate that it is already possible to predict future risk of mild cognitive impairment or dementia based upon a compound score of modifiable risk and protective factors measured in midlife. In Chapter 7, we found that targeting modifiable risk and protective factors at a very old age is not a feasible approach to reduce risk for cognitive 
impairment or dementia. Based on these findings, we can conclude that addressing modifiable risk and protective by making lifestyle changes at an early stage, preferably in midlife ('the earlier the better'), is crucial in terms of dementia risk reduction.

\section{Methodological considerations}

\section{Strengths}

Our systematic literature reviews used broad search strategies in order to include all available evidence on the association between modifiable risk factors and risk for cognitive impairment or dementia (Chapter 2-4). By means of meta-analyses, we were able to get insight in the predictive value of new candidate risk factors for cognitive impairment or dementia based on population-based studies with prospective (Chapter 3 \& 4), cross-sectional (Chapter 4) and case-control study designs (Chapter 4). Strengths of our longitudinal studies include (1) the use of large datasets of representative samples of the general population covering midlife (Chapter $5 \& 6$ ), late-life (Chapter $5 \& 6$ ) and very old age (Chapter 7); (2) the inclusion of a rich set of covariates; and ( 3 ) the long followup period up to 12 (Chapter 5), 18 (Chapter 7) and 30 (Chapter 6) years providing us the opportunity to investigate the long-term effects of modifiable risk factors on dementia incidence.

\section{Limitations}

Our studies had several limitations. Our systematic literature reviews mainly focused on observational studies with a follow-up of at least 1 year (Chapter 2-3). In doing so, we might have excluded studies with promising short-term results. The observed heterogeneity in our meta-analyses can be related to several methodological differences across studies (e.g. ascertainment of the predictor variable, assessment of the outcome variable, (possible) adjustment for covariates, variation in study population), although meta-regression analyses (Chapter 4) did not identify any statistically significant source of heterogeneity. We used random-effects meta-analyses to take into account the variability between and within studies. Our longitudinal studies suffered from selection bias due to selective attrition which could have led to an underestimation of any risk association. This is a common phenomenon in ageing research. ${ }^{22}$ We tried to address these issues by using several strategies including multiple imputation to replace missing data, inclusion of data from proxy-informant interviews to minimize loss to follow-up, the use of inverse probability weights to correct for possible selection bias and the inclusion of covariates related to attrition. 


\section{Implications for (clinical) practice and policy}

Although the absolute number of people with dementia is expected to keep rising over the coming decades due to the aging of the population, ${ }^{23-25}$ especially in low- and middleincome countries, ${ }^{23,25}$ several studies report a declining trend in dementia incidence rates and age-standardized prevalence in developed countries, including the Framingham Heart Study ${ }^{26}$ the Rotterdam Study, ${ }^{27}$ the Cognitive Function and Ageing Study (CFAS), ${ }^{28}$ the Kungsholmen Project and Swedish National study on Aging and Care in Kungsholmen ${ }^{29}$, the Danish 1905-Cohort and 1915-Cohort, ${ }_{10}^{30}$ the Monongahela Valley Independent Elders Study and the Monongahela-Youghiogheny Healthy Aging Team Study, ${ }_{1}{ }^{31}$ and the Health and Retirement Study. ${ }^{32}$ This is good news for the field of dementia prevention since this decline in dementia incidence and prevalence might be related to better health awareness, rising levels of education and better management of cardiovascular risk factors (e.g. diabetes, hypercholesterolemia and hypertension). ${ }^{33-35}$ Standard (cardio)vascular risk management is nowadays quite comprehensive in developed countries and could lead to a decrease in vascular complications (e.g. stroke, myocardial infarction, peripheral artery disease) of hypertension, diabetes and hypercholesterolemia, which in turn can lead to a decline in dementia incidence. Better management of cardiovascular risk factors in relation to dementia incidence is confirmed by findings from the Prevention of Dementia by Intensive Vascular Care (preDIVA) trial. ${ }^{36}$ In this 6-year multidomain practice nurse-led cardiovascular intervention aimed at older people (70-78 years) no effect on incident dementia after a median follow-up of 6.7 years was found.$^{37}$ One possible explanation for this null finding was the modest intensity of the intervention. Overall, the effects of the intervention were neutral, with the exception of participants with incident hypertension, participants without cardiovascular disease at baseline, and in a subset of participants who developed vascular dementia. A more intensive and tailored intervention might have resulted in a larger effect. Another explanation might be the high standard of the cardiovascular risk management which is already implemented in the Dutch healthcare system. It is important to note that during the trial period the cardiovascular risk management guideline was updated. ${ }^{38} \mathrm{~A}$ more proactive approach in terms of primary prevention was recommended in individuals aged 70 years and older. As a consequence, the control group received similar lifestyle advice as the intervention group. In the coming years, it would be interesting to investigate whether this change in policy regarding cardiovascular risk management may have induced changes in dementia incidence. In general, this can be nicely summarized by the maxim 'what's good for your heart, is good for your brain'. 
It must be realized that the abovementioned decline in incidence rates and agestandardized prevalence of dementia, due to better management of health and lifestyle factors, was strictly speaking "prevention by accident". At the time of the development of the cardiovascular risk management program, addressing dementia was not one of the primary objectives. This illustrates the large potential of targeting risk and protective factors of dementia in a personalized approach.

Other large dementia prevention initiatives focusing on multivariate risk factor reduction are the Multidomain Alzheimer Preventive Trial (MAPT), ${ }^{39}$ the Finnish Geriatric Intervention Study to Prevent Cognitive Impairment and Disability (FINGER) ${ }^{40}$ trial and the Healthy Aging Through Internet Counselling in the Elderly (HATICE) trial. ${ }^{41}$ In FINGER, potential study participants were selected based on their CAIDE risk score (including non-modifiable factors age and education). ${ }^{6}$ The cut-off of 6 points or higher indicated the presence of some modifiable risk factors. ${ }^{40}$ The intervention group followed an intensive protocol including nutritional guidance, physical exercise, cognitive training, engagement in social activities, and management of metabolic and cardiovascular risk factors, while the control group received general health advice. After two years, significant intervention effects on cognition were established..$^{40} \mathrm{~A} 7$ year extended follow-up will be conducted to investigate the effects on dementia incidence. It is important to note that FINGER participants were either previous participants from the FINRISK study, the Finnish survey database for monitoring of risk factors for chronic disease (1972-2007), or previous participants from the Finnish type 2 diabetes prevention program's population survey (2004 or 2007).42 Although recruitment took place from these previous population-based non-intervention studies, participants might have been more inclined to make sustainable lifestyle changes and complete study participation due to their previous experiences with these non-communicable disease risk factor surveys. This raises the question whether similar findings can be found in various other settings and populations. Nevertheless, these findings are immense from a public health perspective and it seems likely that they would have received much more attention when similar results were found in a dementia drug trial. Results of the completed MAPT trial have not been published so far, while the HATICE trial is still ongoing. These trials focus on older adults (e.g. > 60 years) instead of middle aged individuals mainly because 65 years and older is the optimal window for outcome assessment given the higher incidence rate of cognitive decline and dementia later in life..$^{28,32}$ Yet, midlife seems to be the most suitable period during a person's life in relation to primary prevention of dementia, since lifestyle adaptations from midlife onwards are more effective with regard to feasibility and will decrease the exposure time to risk factors dramatically and thereby its deleterious effects on the brain. ${ }^{43}$ Therefore, a randomized 
controlled feasibility trial into dementia prevention, as part of WP3 ("Feasibility study of the In-MINDD profiler and environment in practice") of the In-MINDD project, assessed the effects of access to a personalized dementia risk profile (LIBRA), online profiler and support environment and focused on middle aged persons. ${ }^{4}$ The study was conducted in general practices across France, Ireland, the Netherlands and Scotland. Inclusion criteria were: aged between 40 and 60 years, at least one of the modifiable risk factors incorporated in LIBRA, and access to the Internet. The LIBRA score was used to monitor progression in terms of dementia risk reduction over a period of 6 months. In addition, qualitative interviews were conducted with participants and health care professionals (e.g. practice nurses and general practitioners) in order to explore their use of the In-MINDD system and their thoughts and understanding of dementia risk reduction. While results of this trial are still to be awaited, some important conclusions can already be drawn from this study. First, personal interviews with health care professionals demonstrated insufficient knowledge regarding dementia preventive strategies. Participant interviews showed that people need more than general health information and health advice to make and sustain healthy lifestyle choices. Tailoring interventions to the resources and preferences of the individual as well as giving support in the form of coaching are thus important.

From a clinical perspective, health care professionals (e.g. general practitioners, practice nurses) should receive training in how to address the difficult and overly remote topic dementia risk reduction in middle aged individuals and how to motivate them to make and more importantly to sustain lifestyle adaptations. Additionally, since approximately $80 \%$ of the risk and protective factors incorporated in LIBRA are also addressed in the cardiovascular risk management program of Dutch general practitioners, it will be a small step to implement the additional risk factor assessment (e.g. renal dysfunction, mental activity, depression) in the general workflow. Health care professionals could give personalized lifestyle advice based on an individual's LIBRA risk factor profile. This could eventually lead to a decrease in health care costs of diseases associated with dementia risk such as heart disease, stroke, depression and obesity. On the long term, this could lead to decrease in workload of health care professionals due to a reduction in the number of medical consultations. Policy makers in the Netherlands might learn from other countries when it comes to dementia prevention strategies. In the United Kingdom, the National Health Service Health Checks program started in 2009, initially aimed at preventing stroke, kidney disease, heart disease and diabetes. ${ }^{44}$ Every British adult between 40 and 74 years without pre-existing diabetes or cardiovascular disease is invited every 5 years by their general practitioner for a free routine structured cardiovascular check. During this health check (20-30 minutes), the health care professional offers advice to promote 
a healthier lifestyle (e.g. treatment of risk factors and providing support for behavioral changes). In 2016, the dementia component was added to this health check and it aims to increase awareness of dementia among people aged 65 to 74 . Health care professionals have access to online training programs focusing on this dementia component. A similar approach seems feasible in the Netherlands.

These above-mentioned findings have also important implications for policy making and public health advice. Policy makers must become aware that dementia risk reduction at an early stage (preferably in midlife) will save costs associated with dementia care by reducing the prevalence of dementia. In the Netherlands, the average annual costs associated with dementia is estimated on $€ 14,056$ per person, whereas the prevalence of dementia is estimated on 210,366 persons. ${ }^{45}$ Thus, a $10 \%$ reduction in dementia prevalence could possibly lead to a decrease of approximately $€ 300$ million per year. Yet, a reduction in the number of people with dementia will lead to longer life expectancy and as a consequence an increase in the costs associated with other diseases in life years gained. We did not correct for this in the abovementioned rough estimation. Simulation studies of dementia risk reduction strategies showed the large potential of these trials in terms of cost-effectiveness. ${ }^{46,47}$ Additionally, preventive strategies will stimulate people to live longer and healthier and thereby staying longer in their jobs, which is important in times of late retirement. Of course, the impact of such a dementia prevention strategy will not be immediately visible. It is a societal investment in our common future. Given the lack of knowledge among the general public regarding dementia risk reduction, ${ }^{48,49}$ future public health campaigns should spread the message that you can do something about your own dementia risk by promoting a healthy lifestyle and give people advice on how to target the involved risk factors. It is still debatable whether future dementia prevention trials should focus on individuals at high risk for dementia (e.g. individuals with most 'room for improvement') or the general population. From a clinical perspective, it can be reasonably argued to reach those at highest risk and most in need, but from a public health perspective you might exclude persons who could also benefit from lifestyle changes. Related to this is the so-called 'prevention paradox' in which a very modest intervention effect can have major consequences at population level, while on an individual level effects are insignificant. For instance, a decrease of 5 or $10 \mathrm{mmHG}$ in diastolic or systolic blood pressure can have substantial effects on dementia incidence, but for the individual the effects are negligible..$^{50}$ 


\section{Future directions}

So far, billions of dollars have been invested in trials focusing on a pharmalogical treatment for dementia. Unfortunately, none of the tested drugs have proven to be effective, yet. ${ }^{51}$ While finding a disease-modifying drug for dementia is an important area of research and would represent a 'game changer', a sole focus on pharmacological options is too narrowminded and ignores the facts presented. Therefore, dementia research should focus more on primary prevention of dementia as an important additional strategy in the fight against dementia. The complex multi-causal etiology of dementia asks for a multifactorial approach to delay or prevent the onset. In the near future, well-designed randomized controlled trials are needed that investigate the effects of targeting simultaneously multiple health and lifestyle-related risk factors on dementia incidence, ideally by following middle aged people over several decades. Besides these efficacy trials, there is also an urgent need for effectiveness trials that test dementia prevention in real life (e.g. In-MINDD). Experiences from (ongoing) prevention trials in other chronic conditions (e.g. diabetes management) should be taken into account in the optimal design of such a multi-domain program. Additionally, available longitudinal datasets focusing on the association between modifiable risk and protective factors and dementia risk must be used to inform the concept and methodology of new dementia prevention trials. For instance, these observational studies should identify specific target groups at high risk of dementia and they should focus on unraveling possible interrelations, interactions and mechanisms between risk and protective factors for cognitive impairment and dementia. Besides, LIBRA might be a useful tool for participant selection/risk stratification (who benefits most from prevention) and as intermediate outcome measurement (change in dementia risk score) in future intervention studies.

Still, there are some hard challenges to the field of dementia prevention and promotion of health behavior change including insufficient general knowledge, selection of target groups (e.g. everybody or only high risk groups), diversity in treatment preferences (e.g. group or individual approach), lack of time, lack of motivation and social support, financial costs, physical restrictions, and entrenched attitudes and behaviors. Unfortunately, most of these issues are particularly pronounced in the 'hard to reach' groups (e.g. low socioeconomic background, low educational level, ethnic minority groups). Unsurprisingly, this is the target audience you want to reach in order to reduce health inequalities. Inequalities in health status due to socioeconomic status, employment, geographical location, ethnicity, and gender are generally considered to be unacceptable, but they still exist and need to be put on research and policy agendas by priority. 
Based on the findings of this thesis and lessons learned from the In-MINDD project and previous dementia prevention trials as described above, a new project called the 'MyBraincoach' project was started very recently in Limburg, a province in the south of the Netherlands. The overall aim of this project is to raise understanding about dementia risk reduction/brain health. A dementia awareness campaign will be launched in collaboration with local authorities and municipal health services. As part of this campaign, an e-health application will be developed and tested to raise more public awareness about dementia risk reduction. This e-health application contains a personal action plan for improving individual brain health by taking into account an individual's 'room for improvement' (based on the LIBRA score) and treatment preferences. Next, motivational e-coaching and local health service mapping will be implemented to attain individual goals. The duration of this project will be 2.5 years, after which the impact will be evaluated.

In sum, the future of dementia prevention research requires a number of actions: (1) overcome key barriers (e.g. identify the optimal window of opportunity where risk factors have the best potential to positively or negatively affect brain health; tackling of methodological challenges of multi-domain intervention trials); (2) a personalized approach to convince and motivate people to make sustainable lifestyle changes; (3) improving infrastructure and sharing of knowledge by facilitating more international collaboration between research groups (e.g. use and sharing of data); and (4) translation of research findings into effective public and professional messaging (e.g. go for 'low hanging fruit' - promoting lifestyle changes that potentially have the biggest influence on dementia risk).

\section{Conclusions}

The thesis improves our understanding about the relation between health and lifestylerelated risk factors and dementia and highlights the large potential for dementia prevention by means of risk reduction. Taken together, it is now time for a (inter)national strategy on dementia prevention in order (1) to raise public awareness that dementia risk can indeed be modified and that a healthy lifestyle supports long-term brain health; and (2) to decrease the (future) prevalence of dementia and its associated burden for individuals and for society as a whole, and related health care costs. 


\section{REFERENCES}

1. Barnes DE, Yaffe K. The projected effect of risk factor reduction on Alzheimer's disease prevalence. Lancet Neurol 2011; 10(9): 819-28.

2. Plassman BL, Williams JW, Jr., Burke JR, Holsinger T, Benjamin S. Systematic review: factors associated with risk for and possible prevention of cognitive decline in later life. Ann Intern Med 2010; 153(3): 182-93.

3. Baumgart M, Snyder HM, Carrillo MC, Fazio S, Kim H, Johns H. Summary of the evidence on modifiable risk factors for cognitive decline and dementia: A population-based perspective. Alzheimers Dement 2015; 11(6): 718-26.

4. O'Donnell CA, Browne S, Pierce $M$, et al. Reducing dementia risk by targeting modifiable risk factors in mid-life: study protocol for the Innovative Midlife Intervention for Dementia Deterrence (In-MINDD) randomised controlled feasibility trial. Pilot and Feasibility Studies 2015; 1(1): 40.

5. Anstey KJ, Cherbuin N, Herath PM. Development of a New Method for Assessing Global Risk of Alzheimer's Disease for Use in Population Health Approaches to Prevention. Prevention Science 2013; 14(4): 411-21.

6. Kivipelto $M$, Ngandu T, Laatikainen T, Winblad B, Soininen $H$, Tuomilehto J. Risk score for the prediction of dementia risk in 20 years among middle aged people: a longitudinal, populationbased study. Lancet Neurol 2006; 5(9): 735-41.

7. Anstey KJ, Mack HA, Cherbuin N. Alcohol consumption as a risk factor for dementia and cognitive decline: meta-analysis of prospective studies. Am J Geriatr Psychiatry 2009; 17(7): 54255.

8. Kalantarian S, Stern TA, Mansour M, Ruskin JN. Cognitive impairment associated with atrial fibrillation: a meta-analysis. Ann Intern Med 2013; 158(5 Pt 1): 338-46.

9. Hamer $M$, Chida Y. Physical activity and risk of neurodegenerative disease: a systematic review of prospective evidence. Psychol Med 2009; 39(1): 3-11.

10. Etgen T, Chonchol M, Forstl H, Sander D. Chronic kidney disease and cognitive impairment: a systematic review and meta-analysis. Am J Nephrol 2012; 35(5): 474-82.

11. Lu FP, Lin KP, Kuo HK. Diabetes and the risk of multi-system aging phenotypes: a systematic review and meta-analysis. PLoS One 2009; 4(1): e4144.

12. Anstey KJ, Lipnicki DM, Low LF. Cholesterol as a risk factor for dementia and cognitive decline: a systematic review of prospective studies with meta-analysis. Am J Geriatr Psychiatry 2008; 16(5): 343-54.

13. Peters R, Poulter R, Warner J, Beckett N, Burch L, Bulpitt C. Smoking, dementia and cognitive decline in the elderly, a systematic review. BMC Geriatr 2008; 8: 36.

14. Psaltopoulou T, Sergentanis TN, Panagiotakos DB, Sergentanis IN, Kosti R, Scarmeas N. Mediterranean diet, stroke, cognitive impairment, and depression: A meta-analysis. Ann Neurol 2013; 74(4): 580-91.

15. Diniz BS, Butters MA, Albert SM, Dew MA, Reynolds CF, 3rd. Late-life depression and risk of vascular dementia and Alzheimer's disease: systematic review and meta-analysis of community-based cohort studies. Br J Psychiatry 2013; 202(5): 329-35.

16. Tang EY, Harrison SL, Errington L, et al. Current Developments in Dementia Risk Prediction Modelling: An Updated Systematic Review. PLoS One 2015; 10(9): e0136181. 
17. Anstey KJ, Cherbuin N, Budge M, Young J. Body mass index in midlife and late-life as a risk factor for dementia: a meta-analysis of prospective studies. Obes Rev 2011; 12(5): e426-37.

18. Albanese E, Davis B, Jonsson PV, et al. Overweight and Obesity in Midlife and Brain Structure and Dementia 26 Years Later:The AGES-Reykjavik Study. Am J Epidemiol 2015; 181(9): 672-9.

19. de Bruijn RF, Bos MJ, Portegies ML, et al. The potential for prevention of dementia across two decades: the prospective, population-based Rotterdam Study. BMC Med 2015; 13: 132.

20. Qizilbash N, Gregson J, Johnson ME, et al. BMI and risk of dementia in two million people over two decades: a retrospective cohort study. Lancet Diabetes Endocrinol 2015; 3(6): 431-6.

21. Norton S, Matthews FE, Barnes DE, Yaffe K, Brayne C. Potential for primary prevention of Alzheimer's disease: an analysis of population-based data. Lancet Neurol 2014; 13(8): 788-94.

22. Weuve J, Proust-Lima C, Power MC, et al. Guidelines for reporting methodological challenges and evaluating potential bias in dementia research. Alzheimers dement 2015; 11(9): 1098-109.

23. Ferri $C P$, Prince $M$, Brayne $C$, et al. Global prevalence of dementia: a Delphi consensus study. Lancet 2005; 366(9503): 2112-7.

24. Hebert LE, Weuve J, Scherr PA, Evans DA. Alzheimer disease in the United States (2010-2050) estimated using the 2010 census. Neurology 2013; 80(19): 1778-83.

25. Prince M, Bryce R, Albanese E, Wimo A, Ribeiro W, Ferri CP. The global prevalence of dementia: a systematic review and metaanalysis. Alzheimers Dement 2013; 9(1): 63-75 e2.

26. Satizabal CL, Beiser AS, Chouraki V, Chene G, Dufouil C, Seshadri S. Incidence of Dementia over Three Decades in the Framingham Heart Study. N Engl J Med 2016; 374(6): 523-32.

27. Schrijvers EM, Verhaaren BF, Koudstaal PJ, Hofman A, Ikram MA, Breteler MM. Is dementia incidence declining?: Trends in dementia incidence since 1990 in the Rotterdam Study. Neurology 2012; 78(19): 1456-63.

28. Matthews FE, Arthur A, Barnes LE, et al. A two-decade comparison of prevalence of dementia in individuals aged 65 years and older from three geographical areas of England: results of the Cognitive Function and Ageing Study I and II. Lancet 2013; 382(9902): 1405-12.

29. Qiu C, von Strauss E, Backman L, Winblad B, Fratiglioni L. Twenty-year changes in dementia occurrence suggest decreasing incidence in central Stockholm, Sweden. Neurology 2013; 80(20): 1888-94.

30. Christensen K, Thinggaard M, Oksuzyan A, et al. Physical and cognitive functioning of people older than 90 years: a comparison of two Danish cohorts born 10 years apart. Lancet 2013; 382(9903): 1507-13.

31. Dodge HH, Zhu J, Lee CW, Chang CC, Ganguli M. Cohort effects in age-associated cognitive trajectories. J Gerontol A Biol Sci Med Sci 2014; 69(6): 687-94.

32. Langa KM, Larson EB, Crimmins EM, et al. A Comparison of the Prevalence of Dementia in the United States in 2000 and 2012. JAMA Intern Med 2016.

33. Gerstorf D, Hulur G, Drewelies J, et al. Secular changes in late-life cognition and well-being: Towards a long bright future with a short brisk ending? Psychol Aging 2015; 30(2): 301-10.

34. Larson EB, Yaffe K, Langa KM. New Insights into the Dementia Epidemic. New England Journal of Medicine 2013; 369(24): 2275-7.

35. Wu YT, Fratiglioni L, Matthews FE, et al. Dementia in western Europe: epidemiological evidence and implications for policy making. Lancet Neurol 2016; 15(1): 116-24.

36. Richard E, Van den Heuvel E, Moll van Charante EP, et al. Prevention of dementia by intensive vascular care (PreDIVA): a cluster-randomized trial in progress. Alzheimer Dis Assoc Disord 2009; 23(3): 198-204. 
37. Moll van Charante EP, Richard E, Eurelings LS, et al. Effectiveness of a 6-year multidomain vascular care intervention to prevent dementia (preDIVA): a cluster-randomised controlled trial. Lancet 2016; 388(10046): 797-805.

38. Dutch College of General Practitioners. Guideline on cardiovascular risk management (first revision). Huisarts Wet 2012; 55: 14-28.

39. Gillette-Guyonnet S, Andrieu S, Dantoine T, Dartigues J-F, Touchon J, Vellas B. Commentary on "A roadmap for the prevention of dementia II. Leon Thal Symposium 2008." The Multidomain Alzheimer Preventive Trial (MAPT): A new approach to the prevention of Alzheimer's disease. Alzheimers Dement 2009; 5(2): 114-21.

40. Kivipelto M, Solomon A, Ahtiluoto S, et al. The Finnish Geriatric Intervention Study to Prevent Cognitive Impairment and Disability (FINGER): study design and progress. Alzheimers Dement 2013; 9(6): 657-65.

41. Richard E, Jongstra S, Soininen $\mathrm{H}$, et al. Healthy Ageing Through Internet Counselling in the Elderly: the HATICE randomised controlled trial for the prevention of cardiovascular disease and cognitive impairment. BMJ Open 2016; 6(6).

42. Ngandu T, Lehtisalo J, Levälahti E, et al. Recruitment and Baseline Characteristics of Participants in the Finnish Geriatric Intervention Study to Prevent Cognitive Impairment and Disability (FINGER)-A Randomized Controlled Lifestyle Trial. International Journal of Environmental Research and Public Health 2014; 11(9): 9345-60.

43. Lafortune L, Martin S, Kelly S, et al. Behavioural Risk Factors in Mid-Life Associated with Successful Ageing, Disability, Dementia and Frailty in Later Life: A Rapid Systematic Review. PLoS One 2016; 11(2): e0144405.

44. Robson J, Dostal I, Sheikh A, et al. The NHS Health Check in England: an evaluation of the first 4 years. BMJ Open 2016; 6(1).

45. Gustavsson A, Svensson M, Jacobi F, et al. Cost of disorders of the brain in Europe 2010. Eur Neuropsychopharmacol 2011; 21(10): 718-79.

46. Lin PJ, Yang Z, Fillit HM, Cohen JT, Neumann PJ. Unintended benefits: the potential economic impact of addressing risk factors to prevent Alzheimer's disease. Health Aff (Millwood) 2014; 33(4): 547-54.

47. Zhang Y, Kivipelto M, Solomon A, Wimo A. Cost-effectiveness of a health intervention program with risk reductions for getting demented: results of a Markov model in a Swedish/Finnish setting. J Alzheimers Dis 2011; 26(4): 735-44.

48. Low LF, Anstey KJ. Dementia literacy: recognition and beliefs on dementia of the Australian public. Alzheimers Dement 2009; 5(1): 43-9.

49. Marcinkiewicz A, Reid S. Attitudes to dementia: Findings from the 2015 Britisch Social Attitudes survey. London: NatCen Social Research, 2016.

50. Rose G. Sick Individuals and Sick Populations. International Journal of Epidemiology 1985; 14(1): 32-8.

51. Mangialasche F, Solomon A, Winblad B, Mecocci P, Kivipelto M. Alzheimer's disease: clinical trials and drug development. Lancet Neurol 2010; 9(7): 702-16. 



\section{SUMMARY}

Dementia is a global public health problem given its rise in absolute numbers and associated health care costs. In view of the absence of a disease-modifying drug for dementia, primary prevention of dementia is receiving more attention in these days. In this thesis, we aimed to obtain deeper insights in the potential of dementia prevention by investigating the role of modifiable risk factors of dementia in the general population. In Part l, we summarized the available evidence regarding modifiable risk and protective factors of cognitive impairment or dementia. In Part II, we prospectively examined the (combined) effects of modifiable risk and protective factors on incident cognitive impairment or dementia.

In Chapter 2, we provided a systematic review and Delphi consensus study which identified and ranked modifiable risk and protective factors based on their importance for primary prevention of dementia by general practitioners. Strong support was found for depression, (midlife) hypertension, physical inactivity, diabetes, (midlife) obesity, high cholesterol and smoking, while other factors like renal dysfunction, coronary heart disease, (healthy) diet and cognitive activity needed further validation. Based on the findings of this chapter, the 'LIfestyle for BRAin Health' (LIBRA) score was developed. LIBRA consists of the abovementioned health and lifestyle factors and assesses a person's potential for dementia prevention.

In Chapter 3, we investigated the prospective association between markers of renal dysfunction and development of cognitive impairment or dementia in a systematic review and meta-analysis. Overall, the evidence for this association was modest, with sufficient evidence for albuminuria, mixed results for estimated glomerular filtration rate (eGFR), tentative evidence for serum creatinine and creatinine clearance, and insufficient support for cystatin C. Pooled results showed that individuals with albuminuria have a $35 \%$ increased risk of developing cognitive impairment or dementia.

In Chapter 4, we examined the relation between coronary heart disease and risk for cognitive impairment or dementia in a systematic review and meta-analysis of all available population-based studies. Meta-analyses of prospective studies showed that coronary heart disease was associated with a $45 \%$ increased risk of cognitive impairment or dementia. Separate meta-analyses of individual predictors (myocardial infraction and angina pectoris) showed similar results. Meta-analyses of cross-sectional and case-control studies were inconclusive, probably due to the moderate to substantial heterogeneity among studies and the low number of included studies. 
In Chapter 5, we investigated the association between obesity and cognitive decline in 1,807 individuals of the Maastricht Ageing Study (MAAS). At first inspection results were rather straightforward. Baseline obesity was associated with a decline in memory, executive function and processing speed over a 12 year follow-up period independent of other cardiovascular risk factors. However, age stratification and subsequent model adjustments showed that most of the associations were confounded by the effect of age on the rate of decline. The findings of this study confirmed the importance of the methodological choices made during study design and data analysis.

In Chapter 6, we used the population-based Cardiovascular Risk Factors, Aging and Dementia (CAIDE) study to examine the predictive accuracy of the LIBRA score for mild cognitive impairment and dementia in midlife (40-50 years) and late-life (65-79 years), in individuals with high or low genetic risk based on presence of the apolipoprotein $\varepsilon 4$ allele. Higher midlife LIBRA scores were associated with higher risk of mild cognitive impairment and dementia, whereas higher LIBRA scores in late-life were associated with an increased risk of mild cognitive impairment only. Higher late-life LIBRA score was related to higher dementia risk among APOE $\& 4$ non-carriers. The LIBRA-APOE interaction was not significant in midlife. These findings indicate that it is possible to predict future risk of mild cognitive impairment or dementia based upon a compound score of modifiable risk and protective factors measured in midlife.

In Chapter 7, we studied the association between well-known modifiable risk and protective factors and severe cognitive impairment or dementia in 278 individuals aged 85 years or older from the population-based Cambridge City over-75s Cohort (CC75C) Study. None of the risk and protective factors were associated with risk of severe cognitive impairment or dementia after 18 years of follow-up. These findings indicate that the association between well-established (midlife) risk and protective factors and subsequent severe cognitive impairment or dementia may not persist into very old age.

In Chapter 8, we provided a general discussion. Furthermore, this last chapter is followed by a summary of the findings, a description of knowledge valorization, acknowledgements, a list of publications, and information about the author.

Overall, the studies in this thesis improved our understanding about the role of modifiable risk and protective factors in the etiology of dementia, led to the development of a promising innovative tool for dementia prevention, and made positive contributions toward the significance of primary prevention of dementia in the general population, and specifically in middle-aged persons. 


\section{NEDERLANDSE SAMENVATTING (DUTCH SUMMARY)}

Wereldwijd vormt dementie een toenemend volksgezondheidsprobleem vanwege de stijgende aantallen mensen met een vorm van dementie en toenemende zorgkosten. Aangezien er momenteel nog steeds geen causale behandeling voor dementie beschikbaar is, bestaat er de laatste jaren meer belangstelling voor primaire preventie van dementie. In deze dissertatie, hebben we geprobeerd om meer inzicht te krijgen in het potentieel van primaire preventie van dementie door middel van onderzoek naar de rol van modificeerbare risico- en beschermende factoren van dementie in de algemene bevolking. Deel I vat de beschikbare evidentie met betrekking tot modificeerbare risicoen beschermende factoren van cognitieve achteruitgang of dementie samen. Deel II onderzoekt prospectief de (gecombineerde) effecten van modificeerbare risico- en beschermende factoren op incidente cognitieve achteruitgang of dementie.

In Hoofdstuk 2 hebben we een literatuuronderzoek en Delphi-studie gepresenteerd waarin de belangrijkste risico- en beschermende factoren met betrekking tot hun belang voor de primaire preventie van dementie geïdentificeerd en gerangschikt zijn. Sterk bewijs werd gevonden voor depressie, hypertensie (op middelbare leeftijd), onvoldoende lichaamsbeweging, diabetes, obesitas (op middelbare leeftijd), verhoogd cholesterol en roken, terwijl er meer validatie nodig is voor factoren zoals nierziekten, coronaire hartziekten, (gezond) dieet en mentale stimulatie. Op basis van de resultaten van dit hoofdstuk is de 'Llfestyle for BRAin Health' (LIBRA; leefstijl voor een gezond brein) score ontwikkeld. LIBRA bestaat uit de bovengenoemde gezondheids- en leefstijlfactoren en reflecteert een individu's potentieel voor dementie preventie.

In Hoofdstuk $\mathbf{3}$ hebben we de prospectieve associatie tussen verschillende maten voor nierfunctie en het ontwikkelen van een cognitieve stoornis of dementie onderzocht in een literatuuronderzoek en meta-analyse. In het algemeen was het bewijs voor deze associatie bescheiden, met voldoende bewijs voor albuminurie, gemengde resultaten voor estimated glomerular filtration rate (eGFR), voorzichtig bewijs voor serum creatinine en creatinineklaring, en onvoldoende bewijs voor cystatin C. Gepoolde resultaten lieten zien dat mensen met albuminurie een verhoogd risico van 35\% hebben op het ontwikkelen van een cognitieve stoornis of dementie.

In Hoofdstuk 4 werd de relatie tussen coronaire hartziekten en het risico op een cognitieve stoornis of dementie onderzocht in een literatuuronderzoek en meta-analyse van alle beschikbare bevolkingsonderzoeken. Meta-analyses van prospectieve studies lieten zien dat coronaire hartziekten zijn geassocieerd met een $45 \%$ verhoogde kans op het krijgen van een cognitieve stoornis of dementie. Separate meta-analyses van individuele 
voorspellers (angina pectoris, myocard infarct) toonden vergelijkbare resultaten. Metaanalyses van cross-sectionele studies en patiënt-controle onderzoek waren niet conclusief, waarschijnlijk door de matige tot substantiële heterogeniteit tussen studies en het laag aantal geïncludeerde studies.

In Hoofdstuk 5 werden de effecten van obesitas op cognitieve achteruitgang onderzocht in 1,807 deelnemers van de Maastricht Ageing Study (MAAS). Bij een eerste beschouwing leken de resultateneenduidig geïnterpreteerd te kunnen worden. Bijvoorbeeld, obesitas bij aanvang van de studie was geassocieerd met een achteruitgang in geheugen, executief functioneren en verwerkingssnelheid over een periode van 12 jaar, onafhankelijk van andere cardiovasculaire factoren. Echter, leeftijd-stratificatie liet zien dat het merendeel van de gevonden associaties vertekend werden door het effect van leeftijd op de mate van cognitieve achteruitgang. De bevindingen van deze studies laten het belang van methodologische keuzes zien tijdens het opzetten van een studie als deze en het analyseren van de data.

In Hoofdstuk 6 hebben we de prospectieve Cardiovascular Risk Factors, Aging and Dementia (CAIDE) cohortstudie gebruikt om de voorspellende waarde van de LIBRA score, gemeten op middelbare leeftijd (40-50 jaar oud) en op latere leeftijd (65-79 jaar oud), voor een milde cognitieve stoornis of dementie onderzocht in personen met een hoog of laag genetisch risico op dementie op basis van de aanwezigheid van het APOE $\varepsilon 4$ allel. Over een periode van maximaal 30 jaar bleken hogere LIBRA scores op middelbare leeftijd geassocieerd te zijn met een hogere kans op een milde cognitieve stoornis of dementie, terwijl hogere LIBRA scores op latere leeftijd geassocieerd waren met alleen een verhoogd risico op een milde cognitieve stoornis. Een hogere LIBRA score op latere leeftijd was gerelateerd aan een hogere kans op dementie in niet-dragers van het APOE $\varepsilon 4$ allel. De interactie tussen LIBRA en APOE genotype was daarentegen niet significant op middelbare leeftijd. Deze bevindingen laten zien dat het mogelijk is om op basis van een samengestelde score van modificeerbare risico- en beschermende factoren, gemeten bij een individu op middelbare leeftijd, het toekomstig risico op het krijgen van een milde cognitieve stoornis of dementie met een zekere nauwkeurigheid te voorspellen.

In Hoofdstuk 7 hebben we de relatie tussen welbekende modificeerbare risico- en beschermende factoren en een ernstige cognitieve stoornis of dementie bestudeerd in 278 deelnemers van 85 jaar of ouder van de prospectieve Cambridge City over-75s Cohort (CC75C) Study. Over een periode van 18 jaar was geen enkele van deze risico- en beschermende factoren geassocieerd met een ernstige cognitieve stoornis of dementie. Deze resultaten tonen aan dat de associaties tussen welbekende risico-en beschermende 
factoren en daaropvolgende cognitieve stoornissen of dementie op hoge leeftijd niet meer gevonden kunnen worden.

Hoofdstuk 8 bevat een algemene discussie van onze bevindingen en plaatst deze in een bredere, maatschappelijke context. Tenslotte bevat deze dissertatie een samenvatting van de resultaten, een beschrijving van kennisvalorisatie, een dankwoord, een publicatielijst, en informatie over de auteur.

In het algemeen hebben de studies in deze dissertatie beter inzicht gegeven in de rol van modificeerbare risico- en beschermende factoren in de etiologie van dementie, hebben zij geleid tot de ontwikkeling van een veelbelovend en innovatief instrument voor de preventie van dementie, en hebben zij positief bijgedragen aan de discussie over het nut van primaire preventie van dementie in de algemene bevolking, met name bij mensen van middelbare leeftijd. 



\section{KNOWLEDGE VALORIZATION}

The aim of this thesis was to investigate the role of modifiable risk and protective factors of dementia in the general population. This valorization paragraph addresses the societal relevance and implementation opportunities of the results described in this thesis.

Mrs. Robinson is a 50 year old woman, slightly overweight and a heavy smoker, who lives together with her husband in one of the suburbs of Maastricht. After a visit to her 90-year old aunt who suffers from dementia, she wonders about her own dementia risk. She realizes that her lifestyle is not that healthy and could potentially lead to cardiovascular problems, but she wonders whether there is also a relation between lifestyle and dementia risk. She makes an appointment with her general practitioner to discuss this issue.

\section{Societal relevance}

The steady increase in dementia incidence is one of the core challenges facing our aging society. Estimations show that the number of people living with dementia will double in the next 15 years and may even triple in the coming 35 years. Additionally, the costs associated with dementia are predicted to only rise further in the coming decades. If the global societal economic costs of dementia were the expenditure of a country, it would be comparable with a ranking in the 20 largest economies in the world. Next to societal costs, the impact on the quality of life of the person with dementia and their caregivers, families and friends are immense. For these reasons, the World Health Organization (WHO) made dementia a global public health priority.

Identification of risk and protective factors of dementia is of importance since there are no curable treatments for dementia at present. It is shown that targeting modifiable risk factors will potentially decrease the risk of dementia or delay its onset. Surveys in the United Kingdom and Australia among the general public have shown that most people are unaware that there is an association between modifiable risk and protective factors and dementia. The general idea is that there is nothing that one can do to decrease one's own dementia risk. This seems to be a misconception based on the findings of recent studies. Seven modifiable risk factors (e.g. diabetes, midlife hypertension, midlife obesity, smoking, depression, low educational attainment and physical inactivity) are responsible for around 30\% (9.6 million cases) of all dementia cases worldwide. Estimations show that a $10 \%$ reduction per decade in the prevalence of these seven modifiable risk factors could eventually lead to a reduction of the global prevalence of dementia of $8.3 \%$ in 2050 (8.8 million cases). Likewise, delaying the onset of dementia by 5 years would lead to reduce 
the number of cases by a third and alleviate economic costs by $36 \%$. In other words, there is a huge potential for dementia prevention.

Studies in this thesis identified (new) risk factors that can be used in dementia prevention programs. Additionally, more systematic evidence was provided for some risk factors for which more research was needed. Furthermore, findings in this thesis confirm that individuals with multiple health and lifestyle-related risk factors have an increased risk of dementia.

\section{Target groups}

The findings described in this thesis are relevant for the general public (and more specifically individuals at high risk for dementia), health care professionals, public health advocates, researchers and policy makers.

Our results are relevant for all people who are interested to know how they could reduce their own dementia risk. More specifically, persons at high risk (e.g. presence of more health and lifestyle related risk factors) of dementia could benefit most from these findings by making suitable lifestyle adjustments. Targeting risk factors in an early phase (e.g. midlife) is probably more feasible and most effective since this will decrease the duration of exposure to risk factors and its accumulated effects on the brain. Health care professionals (e.g. general practitioners, practice nurses) could also benefit from this knowledge since the link between modifiable risk factors and dementia risk is not generally known. Based on a patient's risk factor profile they could give tailored lifestyle advice. This could eventually lead to substantial cost-reductions due to a reduction in the number of medical consultations and improved management of chronic disease like diabetes, stroke, coronary heart disease, obesity, depression and renal dysfunction. The products emerging from this thesis as described below are relevant for researchers in the field of dementia prevention and dementia epidemiology. These can be useful for participant selection/risk stratification (who benefits most from prevention) and as intermediate outcome measurement (change in dementia risk score) in intervention studies. Policy makers must become aware that early identification and targeting of risk factors is important to decrease future dementia risk. Future public health campaigns have to incorporate the findings of this thesis into their messages.

\section{Products}

Based on the studies in this thesis, the 'Llfestyle for BRAin Health (LIBRA)' score was developed, an instrument that assesses an individual's potential for dementia prevention. This multifactorial environmental risk tool consists of twelve modifiable risk and 
protective factors that can be addressed by making lifestyle changes. The LIBRA score has been used as a personalized score of brain health in a European multicenter trial into dementia prevention as part of the In-MINDD (Innovative Midlife Intervention for Dementia Deterrence) project. Based on the LIBRA score, an on-line profiler and support environment was developed to calculate an individual's dementia risk modification profile and to support access to health information and goal setting, respectively. The effects of the LIBRA score (as a proxy outcome) and online support environment has been tested in a lifestyle intervention feasibility trial in primary care across France, Ireland, the Netherlands and Scotland. The results of this trial are expected in the coming months.

\section{Innovation}

In comparison with already existing dementia risk indices LIBRA is based on evidencebased medicine and contains only modifiable risk factors instead of pre-determined risk factors like age and particular genotypes. Other risk indices are maximized for predicting who is at risk and not who benefits from prevention. Additionally, they are often developed based on a single dataset and in most cases have not been validated in external datasets. Currently, several validation studies with LIBRA are ongoing. International and national collaborations (including United States, Australia, United Kingdom, France and Sweden) have been started to investigate the predictive validity of LIBRA in large population-based datasets.

\section{Implementation}

In this thesis a strong case was made for an early start of dementia prevention. We have made the first steps to initiate a prevention campaign. The findings of this thesis will be implemented in the 'MyBraincoach' project that started very recently. In this project, a dementia awareness campaign will be launched in Limburg, a province in the south of the Netherlands, in collaboration with local authorities and municipal health services. The overall aim of this campaign is to communicate the message that dementia risk can be modified and that a healthy lifestyle supports long-term brain health. In tandem, an e-health application will be developed and tested to raise more public knowledge about dementia risk reduction. This e-health application can propose a personal action plan for improving individual brain health by taking into account an individual's 'roomfor-improvement' (based on the LIBRA score) and treatment preferences. Next, active e-coaching and local health service mapping will be implemented to attain individual goals. 
Back to Mrs. Robinson. Based on the ongoing dementia awareness campaign by Maastricht University, her general practitioner became interested in the subject and asked for a copy of this thesis. He found out that his initial thoughts about the relation between lifestyle and dementia risk after years of suspicious were confirmed. He pointed her to the website of 'MyBraincoach', where she could discover more about her personal possibilities to improve her brain health and download an app to help her making sustainable lifestyle choices. 


\section{DANKWOORD (ACKNOWLEDGEMENTS)}

De afgelopen vier jaar zijn voorbij gevlogen. Het was een hele mooie en leerzame periode. De afwisselende werkzaamheden (data analyseren, artikelen schrijven, onderwijs geven, proefpersonen testen), de prettige sfeer op de afdeling, de congresbezoeken en buitenlandse tripjes (o.a. Brussel, Heidelberg, Londen, Cambridge, Glasgow, Dublin, Nice, Athene, en Beijing) hebben hier enorm aan bijgedragen.

Maar zoals zoveel dingen in het leven kun je het nooit helemaal alleen doen. Het is belangrijk om een aantal mensen te bedanken die direct of indirect hebben bijgedragen aan de totstandkoming van dit proefschrift.

Allereest wil ik graag mijn promotieteam bestaande uit prof. dr. Frans Verhey, dr. Martin van Boxtel en dr. Sebastian Köhler bedanken.

Frans, ik wil je bedanken voor de kans die jij mij vier jaar geleden geboden hebt om me te ontwikkelen als de onderzoeker die ik nu ben. Bedankt voor jouw vertrouwen, jouw belangstelling voor mij als persoon, het delen van jouw kennis over allerlei onderwerpen buiten de dementiewereld, jouw kritische blik op mijn onderzoek en vooral bedankt voor jouw (droge) humor. Ik kijk elke keer uit naar onze overleggen en ik leer enorm van je.

Martin, ik kan jou het beste beschrijven als de pater familias van de afdeling. Je straalt een bepaalde rust uit die zeer inspirerend is en zeer prettig (samen)werken is. Toen ik in 2007 startte met de studie Psychologie was jij een van de eerste personen van wie ik college kreeg. Alle studenten (waaronder mijn eigen persoon) keken echt tegen jou op. Wie had dat gedacht dat ik mij anno 2017 (met trots) jouw collega mag noemen. Ik wil je eveneens bedanken voor het delen van jouw analytisch vermogen en voor het feit dat ik altijd bij jou terecht kon/kan met vragen. Onze samenwerking krijgt gelukkig met het MijnBreincoach project een vervolg.

Seb, je bent en blijft mijn voorbeeld. Waar moet ik beginnen......Je hebt mij vier jaar geleden spreekwoordelijk als groentje onder je hoede genomen en vier jaar later afgeleverd als volwaardig wetenschappelijk onderzoeker. Je hebt mij vanaf het begin het volste vertrouwen gegeven om mijzelf te ontplooien. Zo mocht ik van jou tijdens alle InMINDD consortium meetings de presentaties verzorgen en zorgde jij ervoor dat ik ook echt alle credits kreeg. Bedankt voor het delen van jouw netwerk, jouw epidemiologische 
kennis en passie voor de wetenschap. Daarnaast heb ik enorm veel respect hoe jij jouw drukke privéleven combineert met je wetenschappelijke ambities. Ik hoop dat we nog lang mogen samenwerken!

Via deze weg wil ik ook alle leden van de beoordelingscommissie bedanken voor het lezen en beoordelen van dit proefschrift.

All co-authors of my articles, many thanks for your insightful comments, which provided significant contributions to the quality of this dissertation. Special thanks to Alina and Miia for giving me the opportunity to work with CAIDE.

Many thanks to Marly, lleana and Mercedes for their hard work, nice conversations and support during data acquisition.

Hartelijk dank aan alle mensen die hebben deelgenomen aan het wetenschappelijk onderzoek dat is benoemd in deze dissertatie. Dit zijn echt een heleboel mensen (misschien wel meer dan één miljoen.....). Om maar een paar voorbeelden te noemen: alle deelnemers van de populatiestudies MAAS, CC75C en CAIDE. Natuurlijk mogen alle deelnemers van het In-MINDD project en alle medewerkers van de deelnemende huisartsenpraktijken (Medisch Centrum Ubachsberg, Medisch Centrum Dammerich, Huisartsenpraktijk Daalhof, Huisartsenpraktijk Swijgman en Huisartsenpraktijk Heerlerbaan) niet ontbreken. Bedankt voor de hartelijke ontvangst, fijne samenwerking en de lekkere koffie!

Many thanks to all the members of the In-MINDD consortium. It was a real honor working with you. Special thanks to Kate (Irving) and Kate (O'Donnell) for their support during the In-MINDD years. Marjan, bedankt voor jouw visie op de huisartswereld.

Rudolf, mijn mentor. Jij hebt je sinds 2011 ontfermt over mij en ik ben je hier ontzettend dankbaar voor. Je bent niet alleen ontzettend belangrijk geweest voor mijn wetenschappelijke carrière, maar je wees mij er altijd haarfijn op dat ik mij ook op de klinische kant van het vak moest richten. Met als resultaat dat ik ook alle klinische aantekeningen heb behaald. Ik durf best te stellen dat zonder jouw (carrière) adviezen dit proefschrift er waarschijnlijk (in deze vorm) niet was geweest. Gelukkig werken we nog steeds samen!

Marjolein, bedankt voor de adviezen die je de afgelopen 4 jaar (naast als je wetenschappelijke, klinische en managementtaken) aan mij hebt gegeven. Je hebt mij 
onder andere op gewezen op de mogelijkheden tot de aanvraag van een exchange fellowship. Nogmaals dank hiervoor. Je bent een voorbeeld voor velen!

Via deze weg wil ik ook Alzheimer Nederland, de Alzheimer's Society UK en hun donateurs bedanken voor de unieke mogelijkheid die zij mij hebben geboden om een aantal maanden onderzoek te mogen verrichten bij een tweetal topinstituten in het Verenigd Koninkrijk. Speciale dank gaat dan ook uit naar Marco, Dinant, Erlen en Ellen.

Astrid Nooyens, bedankt dat jij mij wegwijs hebt gemaakt in het Doetinchem cohort!

Carol and Jane, many thanks for the amazing two months in Cambridge. I really enjoyed your hospitality and being part of the department. Thanks for the excellent supervision. I am looking forward to our future collaborations.

Andrew and Dorina, many thanks for giving me the opportunity to work with ELSA. I learned a lot during my stay in London. I hope that our work will result in an excellent publication.

Daarnaast zijn er nog een aantal belangrijke personen die ik van ganser harte wil bedanken aangezien zij aan de basis van mijn carrière hebben gestaan en hebben bijgedragen aan mijn persoonlijke ontwikkeling: Elly Kersten, Wim Meulders, Wilma Noteborn, Ingrid Weijnen en Dymphie in de Braek. Jullie zijn toppers!

Daarnaast wil ik graag alle collega's bedanken voor de fijne tijd. Veel dank gaat uit naar mijn (oud)kamergenootjes Syenna, Inge, Babette en Elles. Jullie hebben het vast heel zwaar met mij gehad. Syenna, de spontaniteit spat er bij jou vanaf en je bent altijd bereid om te sparren over wetenschappelijke vraagstukken. Wat hebben wij een bekijks gehad in Beijing toen ik je de trappen van de metro op en af moest helpen. Inge, met verbazing heb ik moeten constateren dat jij (in vergelijking met de andere kamergenoten) verreweg het meeste Chinees eten op krijgt. Bedankt voor je nuchtere Kerkraadse blik op de wereld. Babette, wat hebben wij vaak in een deuk gelegen om jouw opmerkingen (Is dat Hindi?). Elles, bedankt voor je altijd ongenuanceerde meningen. Liselot, samen naar de middelbare school en nu collega's, je bent altijd dezelfde lieve Lot gebleven. Leonie, bedankt voor al je inzet en hulp bij het MVV-project. Danielle, bedankt voor al jouw hulp op het administratieve vlak. Nico en Els, kort en krachtig: jullie zijn helden! Willemijn en Els, het samen organiseren van het (succesvolle) ACL Jubileumsymposium was een feest op zich! 
Rick en Hamza, onze vriendschap gaat al heel wat jaren terug. Van voetballen in de hondenpoep op het Burgemeester Dohmenplein tot het mij alleen op een kamer laten slapen bij een freak in Bergamo. Ik geniet elke keer van jullie grappen en grollen, maar gelukkig kunnen we ook hele serieuze gesprekken voeren. Ik hoop jullie nog jaren aan mijn zijde te hebben staan!

Stefan en Tamara, bedankt voor de heerlijke etentjes, de gezellige spellenavonden en fijne gesprekken. Jullie vriendschap is verrijkend.

Karel, Monique en Danielle. Bedankt voor alle afleiding de afgelopen jaren. De zeer uitgebreide ontbijtjes op zondagochtend, de heerlijke barbecues in de zomer, de uitstapjes naar het wielrennen en de klusprojecten zijn maar een paar van de vele voorbeelden. Het klinkt cliché, maar ik kan geen betere schoonfamilie wensen.

Tom, Thijn en Toke, bedankt voor de nodige afleiding de afgelopen jaren. Thijn en Toke, het ravotten (lees: strikte commando's opvolgen) met jullie in de weekenden heeft gelukkig voor heel wat ontspanning gezorgd.

Dienja, Aris en Nina, de liefste inwoners van Tiel. Bedankt voor de bezoekjes, uitstapjes en fijne gesprekken de afgelopen jaren. Het hoogtepunt was toch wel onze rondreis door West-Amerika. Drie weken heerlijk rondrijden in onze 'MUF', maar geen tijd hebben voor zeeolifanten. Fabulicious!

Huub en Ine, jullie hebben mij gevormd tot de persoon die ik nu ben. De vastberadenheid en daadkracht van Ma en het doorzettingsvermogen en de kalmte van Pa dragen hier aanzienlijk aan bij. Ik ben een mooie mix van jullie beiden. Hartelijk dank hiervoor. Eveneens bedankt voor jullie luisterend oor en de interesse in mijn werk de afgelopen jaren. Ik ben ontzettend blij met jullie als ouders.

Als laatste de allerbelangrijkste persoon in mijn leven. Lieve Clau, wat ben ik blij dat ik je 6 jaar geleden heb ontmoet. Bedankt voor al je liefde en onvoorwaardelijke steun de afgelopen jaren. Je bent een godsgeschenk. We gaan een mooie toekomst tegemoet in Schinnen. Ik wil heel oud met je worden, maar vooral samen genieten van de kleine dingen in het leven!

Op het leven! And to be continued..... 


\section{THESIS DEFENSES FROM MHENS - SCHOOL FOR MENTAL HEALTH AND NEUROSCIENCE}

\section{3}

Rob Havermans: Bipolar disorder in daily life; Mood and cortisol responses to naturally occurring events. Supervisor: Prof.dr. M. de Vries; Co-Supervisor: Dr. N. Nicolson.

Véronique Moers-Hornikx: Deep brain stimulation and the cerebellum. Supervisors: Prof.dr. J. Vles / Prof.dr. Y. Temel; Co-Supervisor: Dr. G. Hoogland.

Nicole Veldhorst-Janssen: Intranasal delivery of rapid acting drugs. Supervisors: Prof.dr. M. Marcus / Prof.dr. C. Neef; Co-Supervisor: Dr. P.H. van der Kuy.

Stéphanie Knippenberg:Vitamin D and Multiple Sclerosis: immunological and clinical outcome. Supervisor: Prof.dr. J. CohenTervaert; Co-Supervisors: Dr. J. Damoiseaux / Dr. Y. Bols.

Erik D. Gommer: Dynamic Cerebral Autoregulation: from methodology towards clinical application. Supervisors: Prof.dr. W.H. Mess / Prof.dr. R.B. Panerai, UK; Co-Supervisor: Dr.ir. J.P.H. Reulen.

Olga A.H. Reneerkens: Can PDE inhibition improve cognition ? Translational insights. Supervisor: Prof.dr. H.W.M. Steinbusch; CoSupervisor: Dr. J. Prickaerts;.

Lyzel S. Elias-Sonnenschein: Clinical and biomarker correlates of genetic risk factors for Alzheimer's disease. Supervisor: Prof.dr. F.R.J. Verhey; Co-Supervisor: Dr. P.J. Visser.

Diego F. Mastroeni: Epigenetic Dysregulation and the Pathophysiology of Alzheimer's Disease. Supervisors: Prof.dr. H.W.M. Steinbusch / Prof.dr. P.D. Coleman, Sun City, Arizona; Co-Supervisors: Dr. B.P.F. Rutten / Dr. D.L.A. van den Hove.

Leonidas Chouliaras: Epigenetic Regulation in Aging and Alzheimer's disease: A translational perspective. Supervisor: Prof. dr. H.W.M. Steinbusch; Co-Supervisors: Dr. B.P.F. Rutten / Dr. D.L.A. van den Hove.
Liesbeth Knaepen: Perinatal events and altered pain sensitivity in later life. Supervisors: Prof.dr. E.A.J. Joosten / Prof.dr. D. Tibboel, EUR; Co-Supervisor: Dr. J. Patijn.

Marisela Martinez-Claros: Hippocampal plasticity and corticosterone: From dendrites to behaviour. Supervisor: Prof.dr. H.W.M. Steinbusch; CoSupervisors: Dr. J.L. Pawluski / Dr. J. Prickaerts.

Marcus D. Lancé: A circle of improvement in bleeding management: from laboratory to clinic and back. Supervisors: Prof.dr. M.A.E. Marcu / Prof.dr. J.W.M. Heemskerk; Co-Supervisor: Dr. Y.M.C. Henskens.

Hilde Braakman: Imaging the brain; neuronal correlates of cognitive impairment in children with frontal lobe epilepsy. Supervisors: Prof.dr. A.P. Aldenkamp / Prof.dr. J.S.H. Vles; Co-Supervisors: Dr.ir. W.H. Backes / Dr. P.A.M. Hofman.

Willem H.van Zwam: Aneurysmal subarachnoid hemorrhage: imaging strategies and cost-effectiveness aspects in diagnostic work-up and post-therapeutic followup. Supervisors: Prof.dr. J.T. Wilmink / Prof.dr. J.E. Wildberger; Co-Supervisor: Dr. P.A.M. Hofman.

Klara De Cort: The Pathogenesis of Panic Disorder. Supervisors: Prof.dr. I. MyinGermeys / Prof.dr. E.J.L. Griez; CoSupervisors: Dr. K.R.J. Schruers / Dr. I. Van Diest, Leuven.

Kim van Wijck: Mind the Gap; experimental studies on splanchnic hyperfusion and gastrointestinal integrity loss in man. Supervisors: Prof.dr. W.A. Buurman / Prof.dr. C.H.C. Dejong; Co-Supervisor: Dr. K. Lenaerts.

Yvette Roke: Antipsychotic-induced hyperprolactinemia in children and adolescents with mainly autism spectrum 
disorders. Prevalence, symptoms, clinical consequences and genetic risk factors. Supervisors: Prof.dr. P.N. van Harten / Prof. dr. J.K. Buitelaar (RUN); Co-Supervisor: Dr. A. Boot (UMCG).

Fleur Goezinne: Retinal detachment surgery: pre and postoperative prognostic factors. Supervisors: Prof.dr. F. Hendrikse / Prof.dr. C.A.B. Webers; Co-Supervisor: Dr. E.C. La Heij (Amsterdam).

Ralph L.J.G. Maassen: The Merits of Videolaryngoscopy during Glottic Visualisation for Endotracheal Intubation. Supervisors: Prof.dr. M. Marcus / Prof.dr. A. van Zundert (University of Queensland).

Maria J. de Sousa Guerreiro: The role of sensory modality in age-related distraction. Supervisor: Prof.dr. C.M. van Heugten; CoSupervisor: Dr. P.W.M. van Gerven.

Ine Rayen: Effects of developmental fluoxetine exposure on neurobehavioral outcomes. Supervisor: Prof.dr. H.W.M. Steinbusch; Co-Supervisors: Dr. J.L. Pawluski / Dr. T.D. Charlier (Ohio University, USA).

Nynke M.G. Bodde: Psychogenic non-epileptic seizures; a separate disorder or part of a continuum? Supervisors: Prof.dr. R. van Oostenbrugge / Prof.dr. K. Vonck (UZ Gent); Co-Supervisors: Dr. R. Lazeron / Dr. A. de Louw (Epilepsiecentrum Kempenhaeghe, Heeze).

Alejandro M. Gomez: Novel strategies for making myasthenia less gravis: targeting plasma cells and the neuromuscular junction. Supervisor: Prof.dr. M.H. De Baets; Co-Supervisors: Dr. M. Losen / Dr. P. MartinezMartinez.

Mohammad S. Rahnama'i: Prostaglandins and Phosphodiesterases in the Urinary Bladder Wall. Supervisors: Prof.dr. Ph. Van Kerrebroeck / Prof.dr. S. de Wachter (Universiteit Antwerpen); Co-Supervisor: Dr. G. van Koeveringe.

Mariken B. de Koning: Studying biomarkers in populations at genetic and clinical high risk for psychosis. Supervisors: Prof.dr. T.
Amelsvoort / Prof.dr. J. Booij (AMC).

Fabien Boulle: Epigenetic regulation of BDNF/

TrkB signaling in the pathophysiology and treatment of mood disorders. Supervisors: Prof.dr. H.W.M. Steinbusch / Prof.dr. L. Lanfumey (Universiteit Parijs); Co-Supervisors: Dr. D. van den Hove / Dr. G. Kenis.

\section{4}

Iris Nowak-Maes: Tinnitus; assessment of quality of life \& cost-effectiveness. Supervisors: Prof.dr. M. Peters / Prof.dr. B. Kremer; Co-Supervisors: Dr. M. Joore / Dr. L. Anteunis.

Marjolein Huijts: Cognitive function in patients with cerebral small vessel disease. Supervisor: Prof.dr. R.J. van Oostenbrugge; Co-Supervisors: Dr. A.A. Duits / Dr. J. Staals.

Markus Gantert: Fetal inflammatory injury as origin of long term disease: Lessons from animal models. Supervisors: Prof. dr. B. Kramer / Prof.dr. L. Zimmermann; CoSupervisor: Dr. A. Gavilanes.

Elke Kuypers: Fetal development after antenatal exposures: Chorioamnionitis and maternal glucocorticoids. Supervisors: Prof.dr. B.W. Kramer / Prof.dr. H.W. Steinbusch / Prof.dr. Suhas G. Kallapur (University of Cincinnati, Ohio, USA).

Pieter Kubben: Ultra low-field strength intraoperative MRI for Glioblastoma Surgery. Supervisor: Prof.dr. J.J. van Overbeeke; Co-Supervisor: Dr. H. van Santbrink.

Laura Baijens: Surface electrical stimulation of the neck for oropharyngeal dysphagia in Parkinson's disease: therapeutic aspects and reliability of measurement. Supervisor: Prof.dr. B. Kremer; Co-Supervisor: Dr. R. Speyer, Townsville.

Janneke Hoeijmakers: Small fiber neuropathy and sodium channels; a paradigm shift. Supervisor: Prof.dr. R.J. van Oostenbrugge; Co-Supervisors: Dr. C.G. Faber / 
Dr. I.S.J. Merkies.

Stephanie Vos: The Role of biomarkers in preclinical and prodromal Alzheimer's disease. Supervisor: Prof.dr. F.R. Verhey; CoSupervisor: Dr. P.J. Visser.

Muriël Doors: The Value of Optical Coherence Tomography in Anterior Segment Surgery. Supervisors: Prof.dr. R.M. Nuijts / Prof.dr. C.A. Webers; Co-Supervisor: Dr.T.T.J.M. Berendschot.

Anneke Maas: Sleep problems in individuals with genetic disorders associated with intellectual disability. Supervisors: Prof.dr. I. Curfs / Prof.dr. R. Didden.

Sebastiaan van Gorp: Translational research on spinal cord injury and cell-based therapies; a focus on pain and sensorimotor disturbances. Supervisors: Prof.dr. B. Joosten / Prof.dr. M. van Kleef; Co-Supervisors: Dr. J. Patijn /Dr. R. Deumens, KU Leuven.

Andrea Sannia: High risk newborns and brain biochemical monitoring. Supervisor: Prof.dr. J.S.H. Vles; Co-Supervisors: Dr. D. Gazzolo, Alessandria, Italy / Dr. A.W.D. Gavilanes.

Julie A.D.A. Dela Cruz: Dopamine mechanisms in learning and memory: Evidence from rodent studies. Supervisors: Prof.dr. H.W.M. Steinbusch / Prof.dr. R.J. Bodnar, New York; Co-Supervisor: Dr. B.P.F. Rutten.

René Besseling: Brain wiring and neuronal dynamics; advances in MR imaging of focal epilepsy.Supervisors:Prof.dr.A.P.Aldenkamp / Prof.dr.ir. W.H. Backes; Co-Supervisor: dr. J.F.A. Jansen.

Maria Quint-Fens: Long-term care after stroke; development and evaluation of a long-term intervention in primary care. Supervisors: Prof.dr. J.F.M. Metsemakers / Prof.dr. C.M. van Heugten / Prof.dr. M. Limburg, Almere; Co-Supervisor: dr. G.H.M.I. Beusmans.

Veronique Moulaert: Life after survival of a cardiac arrest; the heart of the matter. Supervisors: Prof.dr. J.A. Verbunt / Prof. dr. C.M. van Heugten / Prof.dr. D.T. Wade,
Oxford, UK.

Feikje Smeets: The hallucinatory-delusional state: a crucial connection in the psychosis symptom network. Supervisor: Prof.dr. J. van Os; Co-Supervisor: Dr. T. Lataster.

Lies Clerx: Alzheimer's disease through the MR-eye; novel diagnostic markers and the road to clinical implementation". Supervisor: Prof.dr. F.Verhey; Co-Supervisors: Dr. P.J. Visser / P. Aalten.

Sonny Tan: The subthalamic nucleus in Parkinson's disease. Supervisors: Prof. dr. Y. Temel / Prof.dr. H.W.M. Steinbusch / Prof.dr. T. Sharp, Oxford, UK / Prof.dr. V. Visser-Vandewalle, Koln.

Koen van Boxem: The use of pulsed radiofrequency in the management of chronic lumbosacral radicular pain. Supervisors: Prof.dr. M. van Kleef / Prof.dr. E.A.J. Joosten; Co-Supervisor: Assoc. Prof.dr. J. van Zundert.

Jérôme Waterval: Hyperostosis cranialis interna. Supervisors: Prof.dr. J.J. Manni / Prof.dr. R.J. Stokroos.

Sylvie Kolfschoten-van der Kruijs: Psychogenic non-epileptic seizures; the identification of neurophysiological correlates. Supervisors: Prof.dr. A.P. Aldenkamp / Prof.dr. K.E.J. Vonck, Universiteit Gent; Co-Supervisors: Dr. J.F.A. Jansen / Dr. R.H.C. Lazeron, Kempenhaeghe.

Wouter Pluijms: Spinal cord stimulation and pain relief in painful diabetic: polyneuropathy, a translational approach. Supervisors: Prof.dr. M. van Kleef / Prof.dr. E.A. Joosten; Co-supervisor: Dr. C.G. Faber.

Ron Handels: Health technology assessment of diagnostic strategies for Alzheimer's disease. Supervisors: Prof.dr. F.R.J. Verhey / Prof.dr. J.L. Severens (EUR); Co-Supervisor: Dr. M.A. Joore / Dr. C.A.G. Wolfs.

Evelyn Peelen: Regulatory $\mathrm{T}$ cells in the pathogenesis of Multiple Sclerosis: potential targets for vitamin D therapy. Supervisors: Prof.dr. R.M.M. Hupperts 
/ Prof.dr. J.W. Cohen Tervaert; CoSupervisor: Dr. J.G.M.C. Damoiseaux / Dr. M.M.G.L.Thewissen, Diepenbeek.

Reint Jellema: Cell-based therapy for hypoxicischemic injury in the preterm brain. Supervisors: Prof.dr. B.W.W. Kramer / Prof. dr. H.W.M. Steinbusch; Co-Supervisor: Dr. W.T.V. Germeraad / Dr. P. Andriessen, Veldhoven.

Maria Wertli: Prognosis of Chronic Clinical Pain Conditions: The Example of Complex Regional Pain Syndrome 1 and Low Back Pain. Supervisors: Prof.dr. M. van Kleef; Co-Supervisor: Dr. F. Brunner, Zürich / Dr. R. Perez, VUmc.

Dagmar Zeef: An experimental model of Huntington's disease: Validation \& Stimulation. Supervisors: Prof.dr. Y. Temel / Prof.dr. H.W.M. Steinbusch; Co-supervisor: Dr. A. Jahanshahi.

Jeroen Decoster: Breaking Down Schizophrenia into phenes, genes and environment. Supervisors: Prof.dr. I. Myin-Germeys / Prof. dr. M. De Hert, KU Leuven; Co-Supervisor: Dr. R. van Winkel.

Eaja Anindya Sekhar Mukherjee: Fetal Alcohol Spectrum Disorders: exploring prevention and management. Supervisor: Prof.dr. L.M.G. Curfs; Co-Supervisor: Prof. S. Hollins, St. George's University of London, UK.

Catherine van Zelst: Inside out; On stereotype awareness, childhood trauma and stigma in psychosis. Supervisors: Prof.dr. Ph. Delespaul / Prof.dr. J. van Os.

Ibrahim Tolga Binbay: Extended Psychosis Phenotype in the Wider Social Environment. Supervisor: Prof.dr. J. van Os; Co-Supervisor: Dr. M. Drukker.

Frank Van Dael: OCD matters in psychosis. Supervisors: Prof.dr. J. van Os / Prof.dr. I. Myin-Germeys.

Pamela Kleikers: NOXious oxidative stress: from head toe too and back. Supervisors: Prof.dr. H.H.H.W. Schmidt / Prof.dr. H.W.M. Steinbusch; Co-Supervisor: Dr. B. Janssen.

José Luis Gerardo Nava: In vitro assay systems in the development of therapeutic interventions strategies for neuroprotection and repair. Supervisors: Prof.dr.med. J. Weis / Prof.dr. H.W.M Steinbusch; Co-Supervisor: Dr. G.A. Brook, RWTH Aachen.

Eva Bollen: Cyclic nucleotide signaling and plasticity. Supervisors: Prof.dr. H.W.M. Steinbusch / Prof.dr. R. D'Hooge, KU Leuven; Co-Supervisor: Dr. J. Prickaerts.

\section{5}

Jessica A. Hartmann: A good laugh and a long sleep; Insights from prospective and ambulatory assessments about the importance of positive affect and sleep in mental health. Supervisor: Prof.dr. J. van Os; Co-Supervisors: C.J.P. Simons / Dr. M. Wichers.

Bart Ament:Frailty in old age; conceptualization and care innovations. Supervisors: Prof.dr. G.I.J.M. Kempen / Prof.dr. F.R.J. Verhey; CoSupervisor: Dr. M.E. de Vugt.

Mayke Janssens: Exploring course and outcome across the psychosis-continuum. Supervisor: Prof.dr. I. Myin-Germeys; CoSupervisor: Dr. T. Lataster.

Dennis M.J. Hernaus: Dopayours is not dopamine: genetic, environmental and pathological variations in dopaminergic stress processing. Supervisor: Prof.dr. I. Myin-Germeys; Co-Supervisors: Prof.dr. F.M Mottaghy / Dr. D. Collip.

Ingrid M.H. Brands: The adaptation process after acquired brain injury Pieces of the puzzle. Supervisors: Prof.dr. C.M. van Heugten / Prof.dr. D.T. Wade, Oxford UK Co-Supervisors: Dr. S.Z. Stapert / Dr. S. Köhler.

Francesco Risso: Urinary and salivary S100B monitoring in high risk infants. Supervisor: Prof.dr. J.S.H. Vles; Co-Supervisors: Dr. D. Gazzolo, Genoa,Italy / Dr. A.W.D. Gavilanes. Alessandro Borghesi: Stem and Progenitor 
Cells in Preterm Infants: Role in the Pathogenesis and Potential for Therapy. Supervisor: Prof.dr. L. Zimmermann; Prof.dr. B. Kramer; Co-Supervisors: Dr. D. Gazzolo, Genoa,Italy / Dr. A.W.D. Gavilanes.

Claudia Menne-Lothmann: Affect dynamics; A focus on genes, stress, and an opportunity for change. Supervisor: Prof.dr. J. van Os; CoSupervisors: Dr. M. Wichers / Dr. N. Jacobs.

Martine van Nierop: Surviving childhood new perspectives on thelink between childhood trauma and psychosis. Supervisors: Prof. dr. I. Myin-Germeys / Prof.dr. J. van Os; Co-Supervisor: Dr. R. van Winkel.

Sylvia Klinkenberg: VNS in children; more than just seizure reduction. Supervisors: Prof.dr. J. Vles / Prof.dr. A. Aldenkamp; CoSupervisor: Dr. H. Majoie.

Anouk Linssen: Considerations in designing an adult hearing screening programme. Supervisor: Prof.dr. B. Kremer; CoSupervisors: Dr. L. Anteunis / Dr. M. Joore. Janny Hof: Hearing loss in young children; challenges in assessment and intervention. Supervisors: Prof.dr. B. Kremer / Prof. dr. R. Stokroos / Prof.dr. P. van Dijk, RUG; Co-Supervisor: Dr. L. Antheunis.

Kimberly Cox-Limpens: Mechanisms of endogenous brain protection; Clues from the transcriptome. Supervisors: Prof.dr. J. Vles/Prof.dr. L.Zimmermann;Co-Supervisor: Dr. A. Gavilanes.

Els Vanhoutte: Peripheral Neuropathy outcome measures; Standardisation (PeriNomS) studypart2:Getting consensus.Supervisors: Prof.dr. C. Faber / Prof.dr. P. van Doorn; Co-Supervisor: Dr. I. Merkies, Spaarne ziekenhuis Hoofddorp.

Mayienne Bakkers: Small fibers, big troubles; diagnosis and implications of small fiber neuropathy. Supervisors: Prof.dr. C. Faber / Prof.dr. M. de Baets; Co-Supervisor: Dr. I. Merkies, Spaarne ziekenhuis Hoofddorp.

Ingrid Kramer: Zooming into the micro-level of experience:Anapproach for understanding and treating psychopathology.

Supervisor: Prof.dr. J. van Os; Co-Supervisors: Dr. M. Wichers, UMC Groningen / Dr. C. Simons.

Esther Bouman: Risks and Benefits of Regional Anesthesia in the Perioperative Setting. Supervisors: Prof.dr. M. van Kleef / Prof.dr. M. Marcus, HMC, Qatar / Prof.dr. E. Joosten; CoSupervisor: Dr. H. Gramke.

Mark Janssen: Selective stimulation of the subthalamic nucleus in Parkinson's disease; dream or near future. Supervisors: Prof.dr. Y. Temel / Prof.dr. V. Visser-Vandewalle, Keulen / Prof.dr. A. Benazzouz, Bordeax, France.

Reina de Kinderen: Health Technology Assessment in Epilepsy; economic evaluations and preference studies. Supervisors: Prof.dr. S. Evers / Prof.dr. A. Aldenkamp; Co-Supervisor:Dr. H. Majoie / Dr. D. Postulart, GGZ O-Brabant.

Saskia Ebus: Interictal epileptiform activity as a marker for clinical outcome. Supervisors: Prof.dr. A. Aldenkamp / Prof.dr. J. Arends, TUE / Prof.dr. P. Boon, Universiteit Gent, België.

Inge Knuts: Experimental and clinical studies into determinants of panic severity. Supervisor: Prof.dr. I. Myin-Germeys; CoSupervisor: Dr. K. Schruers; Influencing panic.

NienkeTielemans: Proactive coping post stroke:

The Restored4Stroke Self-Management study. Supervisors: Prof.dr. C. van Heugten / Prof.dr. J. Visser-Meily, UMC Utrecht; Co-Supervisor: Dr. V. Schepers, UMC Utrecht. Tom van Zundert: Improvements Towards Safer Extraglottic Airway Devices. Supervisors: Prof.dr. A.E.M. Marcus / Prof.dr. W. Buhre / Prof.dr. J.R. Brimacombe, Queensland, Australia / Prof.dr. C.A. Hagberg.

Tijmen van Assen: Anterior Cutaneous Nerve Entrapment Syndrome Epidemiology and surgical management. Supervisors: Prof.dr. G.L. Beets / Prof.dr. M. van Kleef / Dr. R.M.H. Roumen / Dr. M.R.M. Scheltinga, MMC Veldhoven. 
Rohit Shetty: Understanding the Clinical, Immunological and Genetic Molecular Mechanisms of Keratoconus. Supervisors: Prof.dr. R.M.M.A. Nuijts / Prof.dr. C.A.B. Webers.

Christine van der Leeuw: Blood, bones and brains; peripheral biological endophenotypes and their structural cerebral correlates in psychotic disorder. Supervisor: Prof.dr. J. van Os; Co-supervisor: Dr. M. Marcelis.

Sanne Peeters: The Idle Mind Never Rests; functional brain connectivity across the psychosis continuum. Supervisor: Prof.dr. J. van Os; Co-supervisor: dr. M. Marcelis.

Nick van Goethem: a7 nicotinic acetylcholine receptors and memory processes: mechanistic and behavioral studies. Supervisor: Prof.dr. H.W.M. Steinbusch; Cosupervisor: Dr. J. Prickaerts.

Nicole Leibold: A Breath of fear; a translational approach into the mechanisms of panic. Supervisor: Prof.dr. H.W.M. Steinbusch; Cosupervisors: Dr. K.R.J. Schruers / Dr. D.L.A. van den Hove.

Renske Hamel: The course of mild cognitive impairment and the role of comorbidity. Supervisor: Prof.dr. F.R.J. Verhey; Cosupervisors: Dr. I.H.G.B. Ramakers / Dr. P.J. Visser.

Lucia Speth: Effects of botulinum toxin A injections and bimanual task-oriented therapy on hand functions and bimanual activities in unilateral Cerebral Palsy. Supervisors: Prof.dr. J. Vles; Prof.dr. R. Smeets; Co-supervisor: Dr. Y. Janssen-Potten, Adelante Hoensbroek.

Yuan Tian: The effects of Lutein on the inflammatory pathways in age-related macular degeneration (AMD). Supervisors: Prof.dr. C. Webers; Prof.dr. A. Kijlstra, WUR; Co-supervisor: Dr. M. Spreeuwenberg; Dr. H. Tange.

Peggy Spauwen: Cognition and Type 2 diabetes; the interplay of risk factors. Supervisors: Prof.dr. F. Verhey; Prof.dr. C.
Stehouwer; Co-supervisor: Dr. M. van Boxtel Marc Hilhorst: Crescentic glomerulonephritis in ANCA associated vasculitis. Supervisors: Prof.dr. J. Cohen-Tervaert; Co-supervisor: Dr. P. van Paassen

Martin Gevonden: The odd one out: exploring the nature of the association between minority status and psychosis. Supervisors: Prof.dr. J-P. Selten; Prof.dr. J. Booij, Uva; Prof dr. I. Myin-Germeys

Bart Biallosterski: Structural and functional aspects of sensory-motor Interaction in the urinary bladder. Supervisors: Prof.dr. Ph. Van Kerrebroeck; Prof.dr. S. De Wachter, UvAntwerpen; Co-supervisors: Dr. G. van Koeveringe; Dr. M. Rahnama'i.

Alexandra König: The use of information and communication technologies (ICT) for the assessment of patients with Alzheimer's Disease and related disorders. Supervisors: prof.dr. F. Verhey; prof.dr. Ph. Robert, Nice, Fr; Co-supervisors: dr. P. Aalten; dr. R. David, Nice. Fr.

Michelene Chenault: Assessing Readiness for Hearing Rehabilitation. Supervisors: prof dr. M.P.F. Berger; prof.dr. B. Kremer; Cosupervisor: dr. L.J.C. Anteunis.

Anand Vinekar: Retinopathy of Prematurity. Recent advances in tele-medicine screening, risk factors and spectral domain optical coherence tomography imaging Supervisor: prof.dr. C.A.B. Webers; Cosupervisor: dr. N.J. Bauer

Fleur van Dooren: Diabetes and Depression: exploring the Interface between Pathophysiological and Psychological factors. Supervisors: prof.dr. F.R.J. Verhey; prof.dr. J.K.L. Denollet, UvT; prof.dr. F. Pouwer, UvT; Co-supervisor: dr. M.T. Schram.

Gabriëlla Pons van Dijk: Taekwondo and physical fitness components in middleaged healthy volunteers; the Sekwondo study. Supervisors: prof.dr. J. Lodder; prof.dr. H. Kingma; Co-supervisor: dr. A.F. Lenssen.

Yara Pujol López: Development and psychoneuroimmunological mechanisms 
in depression. Supervisor: prof.dr. H.W.M. Steinbusch; Co-supervisors: Dr. G. Kenis; Dr. D. van den Hove; Dr. Aye Mu Myint, München.

Romina Gentier: $\mathrm{UBB}^{+1}$; an important switch in the onset of Alzheimer's disease. Supervisors: Prof. H. Steinbusch; Prof. D. Hopkins; Co-supervisor: Dr. F. van Leeuwen.

Sanne Smeets: Insights into insight: studies on awareness of deficits after acquired brain injury. Supervisor: Prof. C. van Heugten; Prof. R. Ponds; Co-supervisor: Dr. I. Winkens

Kim Beerhorst: Bone disease in chronic epilepsy: fit for a fracture. Supervisor: Prof. A. Aldenkamp; Prof. R. van Oostenbrugge; Co-supervisor: Dr. P. Verschuure.

Alex Zwanenburg: Cerebral and cardiac signal monitoring in fetal sheep with hypoxicischemic encephalopathy. Supervisor: Prof. T. Delhaas; Prof. B. Kramer; Co-supervisors: Dr. T. Wolfs; Dr. P. Andriessen, MMC.

Ismail Sinan Guloksuz: Biological mechanisms of environmental stressors in psychiatry. Supervisor: Prof. J. van Os; Co-supervisors: Dr. B. Rutten; Dr. M. Drukker.

Seyed Ehsan Pishva MD: Environmental Epigenetics in mental health and illness. Supervisor: Prof.dr. J. van Os; Co-supervisors: Dr. B.P.F. Rutten; Dr. G. Kenis.

Ankie Hamaekers: Rescue ventilation using expiratory ventilation assistance; innovating while clutching at straws. Supervisors: Prof.dr. W.F. Buhre; Prof.dr. M. van Kleef.

Rens Evers. 22q11.2 deletion syndrome: intelligence, psychopathology and neurochemistry at adult age. Supervisors: Prof.dr. L.M.G. Curfs; Prof.dr. T. v. Amelsvoort.

Sarah-Anna Hescham. Novel insights towards memory restoration. Supervisor: Prof.dr. Y. Temel; Co-supervisor: Dr. A. Blokland; Dr. A. Jahanshahi.

João P. da Costa Alvares Viegas Nunes. Insulin receptor sensitization improves affective pathology in various mouse models. Supervisor: Prof.dr. H.W.M. Steinbusch; Co- supervisors: Dr. K-P. Lesch; Dr. T. Strekalova; Dr.B.H. Cline, Oxford.

Yanny Ying-Yee Cheng. Clinical Outcomes After Innovative Lamellar Corneal Transplantation Surgery. Supervisor: Prof.dr. R.M.M.A. Nuijts; Co-supervisor: Dr. J.S.A.G. Schouten.

\section{6}

Oliver Gerlach. Parkinson's disease, deterioration during hospitalization. Supervisor: Prof.dr. R. van Oostenbrugge; Co-supervisor: Dr. W. Weber.

Remo Arts. Intracochlear electrical stimulation to suppress tinnitus. Supervisor: Prof.dr. R.J. Stokroos; Cosupervisor: Dr. E.L.J. Georg.

Mitchel van Eeden. The $€$ - Restore4stroke study: Economic evaluation of stroke care in the Netherlands. Supervisors: Prof.dr.mr. S.M.A.A. Evers; Prof.dr. C.M. v. Heugten; Cosupervisor: dr. G.A.P. van Mastrigt.

Pim Klarenbeek. Blood pressure and cerebral small vessel disease. Supervisor: Prof.dr R.J. van Oostenbrugge; Co-supervisor: Dr. J. Staals.

Ramona Hohnen. Peripheral pharmacological targets to modify bladder contractility. Supervisor: Prof.dr. Ph.E.V. van Kerrebroeck Co-supervisors: Dr. G.A. van Koeveringe; Dr. M.A. Sahnama'i; Dr. C. Meriaux.

Ersoy Kocabicak. Deep brain stimulation of the subthalamic nucleus: Clinical and scientific aspects. Supervisors: Prof.dr. Y. Temel; Prof dr. K. van Overbeeke; Co-supervisor: Dr. A. Jahanshahi.

Sven Akkerman. Temporal aspects of cyclic messenger signaling in object recognition memory; a pharmalogical approach. Supervisor: Prof.dr. H.W.M. Steinbusch, Co-supervisors: dr. J. Prickaerts; dr. A. Blokland.

Anja Moonen. Emotion and Cognition in Parkinson's disease; etiology and neurobiological mechanisms. Supervisor: 
Prof.dr. F.R.J.Verhey; Co-supervisor: dr. A.F.G. Leentjens.

Anna Schüth. Three-dimensional bladder tissue morphology. Supervisors: Prof.dr. G.A. van Koeveringe; Prof.dr. M. v. Zandvoort, Aachen; Prof.dr. Ph. V. Kerrebroeck.

Elisabeth van der Ven. Ethnic minority position as risk indicator for autism-Spectrum and psychotic disorders. Supervisors: Prof.dr. J.P. Selten; Prof.dr. J. van Os.

Zuzana Kasanova. Environmental reactivity for better or worse; The impact of stress and reward on neurochemistry, affect and behavior across the psychosis continuum. Supervisor: Prof.dr. I. Myin-Germeys, KU Leuven/UM; Co-supervisor: dr. D. Collip.

Danielle Lambrechts. Ketogenic diet therapies; treatment for children and adults with refractory epilepsy. Supervisors: Prof.dr. H.J.M. Majoie; Prof.dr. J.S.H. Vles; Prof.dr. A.P. Aldenkamp; Co-supervisor: dr. A.J.A. de Louw, Kempenhaghe, Heeze.

Frank van Bussel. Advanced MRI in diabetes; cerebral biomarkers of cognitive decrements. Supervisors: Prof.dr.ir. W.H. Backes; Prof.dr. P.A.M. Hofman; Cosupervisor: dr. J.F.A. Jansen.

Lisa Schönfeldt. Neurostimulation to treat brain injury? Supervisors: Prof.dr. Y. Temel; Prof.dr. S. Hendrikx, Hasselt; Co-supervisor: dr. A. Jahanshahi.

Rianne Geerlings. Transition in patients with childhood-onset epilepsy; a long way to adulthood. Supervisor: Prof.dr. A.P. Aldenkamp;Co-supervisors:dr.A.J.A.deLouw, dr. L.M.C. Gottmer, Kempenhaeghe.

Nele Claes. B cells as multifactorial players in multiple sclerosis pathogenesis: insights from therapeutics. Supervisors: Prof.dr. V. Somers, Hasselt; Prof.dr. R. Hupperts. Co-supervisors: Prof.dr. P. Stinissen, dr. J. Fraussen, Hasselt.

Olaf Schijns. Epilepsy surgery and biomarkers from history to molecular imaging. Supervisors: Prof.dr. J.J. van Overbeeke; Prof. dr. H. Clustermann, Aachen; Co-supervisors: dr. G. Hoogland; dr. M.J.P. v. Kroonenburgh.

Lizzy Boots. Balanced and Prepared; development and evaluation of a supportive e-health intervention for caregivers of people with early-stage dementia. Supervisors: Prof.dr. F.R.J. Verhey; Prof.dr. G.I.J.M. Kempen; Co-supervisor: dr. M.E. de Vugt.

Wouter Donders. Towards patient-specific (cerebro-) vascular model applications. Supervisors: Prof.dr. T. Delhaas; Prof.dr.ir. F.N. van de Vosse, TUE; Co-supervisor: dr.ir. W. Huberts.

Sizzle Vanterpool. The implications of intrauterine invasion by microbes for placental Pathology and the occurrence of adverse pregnancy outcomes. Supervisor: Prof.dr. B.W. Kramer. Co-supervisors: dr. J.V. Been, Erasmus MC Rotterdam, dr. U von Rango.

Manuela Heins. The Relationship between Social Adversity, Psychosis, and Depression across an Individual's Life Span. Supervisor: Prof.dr. I. Myin-Germeys.

Christianus van Ganzewinkel. NEONATAL PAIN; Out of Sight, Out of Mind? Supervisor: Prof.dr. B.W.W. Kramer; Co-supervisor: dr. P. Andriessen, MMC Veldhoven.

Anne-Hilde Muris. Hype or hope? Vitamin D in multiple sclerosis; A clinical and immunological perspective. Supervisor: Prof.dr. R.M.M. Hupperts; Co-supervisor: dr. J.G.M.C. Damoiseaux.

Gerard Bode. The link between ceramide transporters, innate Immunity and Alzheimer's disease. Supervisor: Prof. dr. M.H.V. de Baets; Co-supervisors: dr. P. Martinez, dr. M. Losen.

Jo Stevens. Advanced diagnostics and therapeutics for Alzheimer's disease. Supervisor: Prof.dr. M. de Baets; Cosupervisors: dr. M. Losen, dr. P. MartinezMartinez.

Rosan Luijcks. Stress and pain in muscles and 
brain; developing psychophysiological paradigms to examine stress and pain interactions. Supervisors: Prof.dr. J.J.van Os; Prof.dr.ir. H.J. Hermens, UT; Co-supervisor: dr. R. Lousberg.

Harmen Jan van de Haar. Microvascular and blood-brain barrier dysfunction in Alzheimer's disease. Supervisor: Prof.drir. W. Backes; Prof.dr. F. Verhey; Co-supervisor: Dr. J. Jansen; Dr.ir. M. v. Osch,LUMC.

Coenraad Itz. Chronic low back pain, considerations about: Natural Course, Diagnosis, Interventional Treatment and Costs. Supervisor: Prof.dr. M. van Kleef; Prof. dr. F. Huygen, EUR; Co-supervisor: Dr. B. Ramaekers.

Willemijn Jansen. The Path of Alzheimer's disease: from neuropathology to clinic. Supervisor: Prof.dr. F.Verhey; Co-supervisors: Dr. P.J. Visser; Dr. I. Ramakers.

Ligia dos Santos Mendes Lemes Soares. Phosphodiesterase inhibitors: a potential therapeutic approach for ischemic cerebral injury. Supervisor: Prof.dr. H.W.M. Steinbusch; Co-supervisors: Dr. R.M. Weffort de Oliveira, Brazil; Dr. J. Prickaerts

Martijn Broen. Anxiety and depression in Parkinson's disease. Supervisor: Prof.dr. R.J. van Oostenbrugge; Co-supervisors: Dr. A.F.G. Leentjens; Dr. M.L. Kuijf.

Sandra Schipper. Extrasynaptic receptors as a treatment target in epilepsy. Supervisor: Prof.dr. J.H.S. Vles; Co-supervisors: Dr. G. Hoogland; Dr. S. Klinkenberg; Dr. M.W. Aalbers, RUG.

João Casaca Carreira. Making sense of Antisense Oligonucleotides Therapy in Experimental Huntington's disease. Supervisor: Prof.dr. Y. Temel; Co-supervisors: Dr. A. Jahanshahi; Dr. W. van Roon-Mom, LUMC.

Dominique IJff. Trick or Treat? Cognitive side-effects of antiepileptic treatment. Supervisors: Prof.dr. A.P. Aldenkamp; Prof.dr. M. Majoie; Co-supervisors: Dr. J. Jansen; Dr. R. Lazeron, Kempenhaeghe.
Alfredo Ramirez. Neurogenetic approach in neurodegenerative disorders. Supervisors: Prof.dr. B.P.F. Rutten; Prof.dr. H.W.M. Steinbusch; Prof.dr. M.M. Nöthen, University of Bonn.

Nienke Visser. Toric Intraocular lenses in cataract surgery. Supervisor: Prof.dr. R.M.M.A. Nuijts; Co-supervisor: Dr. N.J.C. Bauer.

Jakob Burgstaller. Prognostic indicators for patients with degenerative lumbar spinal stenosis. Supervisor: Prof.dr. M. van Kleef; Co-supervisors: Dr. M.M. Wertli, University of Zurich; Dr. H.F. Gramke.

Mark van den Hurk. Neuronal Identity and Maturation: Insights from the SingleCell Transcriptome. Supervisors: Prof.dr. H.W.M. Steinbusch; Prof.dr. B.P.F. Rutten; Co-supervisors: Dr. G. Kenis; Dr. C. Bardy, Adelaide.

Maria Nikiforou. Prenatal stress and the fetal gut. Potential interventions to prevent adverse outcomes. Supervisors: Prof.dr. B.W. Kramer; Prof.dr. H.W. Steinbusch; Cosupervisor: Dr. T.G. Wolfs.

Janneke Peijnenborgh. Assessment of cognition, time perception, and motivation in children. Supervisors: Prof.dr. J.S.H. Vles; Prof.dr. A.P. Aldenkamp; Co-supervisors: Dr. J. Hendriksen; Dr. P. Hurks.

Joany Millenaar. Young onset dementia; towards a better understanding of care needs and experiences. Supervisors: Prof. dr. F. Verhey; Prof.dr. R. Koopmans, RUN; Cosupervisors: Dr. M. de Vugt; Dr. C. Bakker, RUN.

\section{7}

Adriana Smits: Perinatal factors and hearing outcome. Supervisors: Prof.dr. R.J. Stokroos; Prof.dr. B.W. Kramer; Prof.dr. B. Kremer.

Angela Bouwmans: Transcranial sonography in parkinsonian disorders: clear window or blurred vision. Supervisor: Prof.dr. W.H. 
Mess; Co-promotores: Dr. W.E.J. Weber; Dr. A.F.G. Leentjens.

Björn K. Stessel: Patient centred care after day surgery: scope for improvement. Supervisors: Prof.dr. W. Buhre; Prof.dr. B. Joosten. Co-supervisor: Dr. A.H. Gramke.

Jan Guy Bogaarts: Quantitative EEG and machine learning methods for the detection of epileptic seizures and cerebral asymmetry. Supervisor: Prof.dr. W.M. Mess; Co-supervisor: Dr.ir. J.P.H. Reulen; Dr.ir. E.D. Gommer.
Martin M. Müller: Pregnancy derived products for treatment of perinatal brain injuries. Supervisors: Prof.dr. B.W.W. Kramer; Prof.dr. D. Surbek, Bern; Co-supervisors: Dr. T. Wolfs; Dr. G. Gavilanes.

Rosalie van Knippenberg: Experience sampling in dementia care - An innovative intervention to support caregivers in daily life. Supervisors: Prof.dr. F.R.J. Verhey; Prof. dr. R.W.H.M. Ponds; Prof.dr. I. Myin-Germeys, KU Leuven ; Co-supervisor: Dr. M.E. de Vugt. 


\section{PUBLICATIONS}

\section{International Journals}

Schiepers OJG, Köhler S, Deckers K, Irving K, O'Donnell CA, Van den Akker M, Verhey FRJ, Vos SJB, de Vugt ME, van Boxtel MPJ. Lifestyle for Brain Health (LIBRA): a new model for dementia prevention. International Journal of Geriatric Psychiatry 2017; DOI: 10.1002/gps.4700.

Deckers K, Köhler S, van Boxtel MPJ, Verhey FRJ, Brayne C, Fleming J. Lack of associations between modifiable risk factors and dementia in the very old: Findings from the Cambridge City over75s Cohort Study. Aging \& Mental Health 2017; DOI: 10.1080/13607863.2017.1280767.

Deckers K, Camerino I, van Boxtel MPJ, Verhey FRJ, Irving K, Brayne C, Kivipelto M, Starr JM, Yaffe K, de Leeuw $P$, Köhler $S$. Dementia risk in renal dysfunction: a systematic review and meta-analysis of prospective studies. Neurology 2017; 88(2):198-208.

Deckers K, van Boxtel MPJ, Verhey FRJ, Köhler S. Obesity and cognitive decline in adults: Effect of methodological choices and confounding by age in a longitudinal study. Journal of Nutrition, Health and Aging 2016; DOI: 10.1007/s12603-016-0757-3.

O'Donnell CA, Browne S, Pierce M, McConnachie A, Deckers K, van Boxtel MPJ, Manera V, Köhler S, Redmond M, Verhey FRJ, van den Akker M, Power K, Irving K. Reducing dementia risk by targeting modifiable risk factors in mid-life: study protocol for the Innovative Midlife Intervention for Dementia Deterrence (In-MINDD) randomised controlled feasibility trial. Pilot and Feasibility studies 2015; 1:40; DOI: 10.1186/s40814-015-0035-x.

Deckers K, van Boxtel MPJ, Schiepers OJG, de Vugt ME, Munoz JL, Anstey KJ, Brayne C, Dartigues JF, Engedal K, Kivipelto M, Ritchie K, Starr JM, Yaffe K, Irving K, Verhey F, Köhler S. Target risk factors for dementia prevention: a systematic review and Delphi consensus study on the evidence from observational studies. International Journal of Geriatric Psychiatry 2015; 30(3):234-246.

\section{National Journals}

Noteborn MWJ, Sanderson RAM, Deckers K, Jansen op de Haar MMBB, van Alphen SPJ. Alcoholproblematiek bij ouderen. GZ-Psychologie 2014; 6(3):10-15.

Noteborn MWJ, Sanderson RAM, Zwanikken H, Deckers K, van Alphen SPJ. Meer aandacht in de huisartsenpraktijk voor alcoholproblematiek bij ouderen. Huisarts \& Wetenschap 2013; 5:214218.

\section{Submitted}

Deckers K, Schievink SHJ, Rodriquez MMF, van Oostenbrugge RJ, van Boxtel MPJ, Verhey FRJ, Köhler S. Coronary heart disease and risk for cognitive impairment or dementia: a systematic review and meta-analysis.

Deckers K, Barbera M, Köhler S, Ngandu T, van Boxtel MPJ, Rusanen M, Laatikainen T, Verhey FRJ, Soininen $\mathrm{H}$, Kivipelto $M$, Solomon A. Prediction of mild cognitive impairment and dementia with a multifactorial environmental risk score: a 30-year follow-up of the CAIDE populationbased study. 
Schievink SHJ, van Boxtel MPJ, Deckers K, van Oostenbrugge RJ, Verhey FRJ, Köhler S. Cognitive changes in prevalent and incident cardiovascular disease: a 12-year follow-up in the Maastricht Aging Study (MAAS).

Vos SJB, van Boxtel MPJ, Schiepers OJG, Deckers K, de Vugt ME, Carrière I, Dartigues JF, Peres K, Artero S, Ritchie K, Galluzzo L, Scafato E, Frisoni GB, Huisman M, Comijs HC, Sacuiu SF, Skoog I, Irving K, O'Donnell CA, Verhey FRJ, Visser PJ, Köhler S. Modifiable risk factors for prevention of dementia in midlife, late life and the oldest-old: validation of the LIBRA index. 


\section{CURRICULUM VITAE}

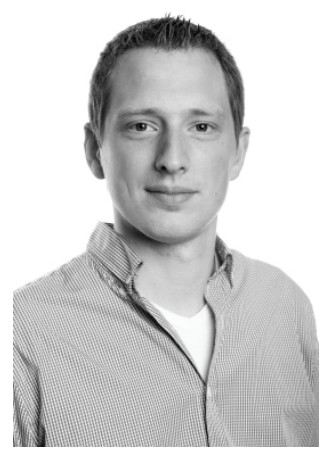

Kay Deckers was born in Brunssum on November 101988 and grew up in Kerkrade. After graduating from high school (College Rolduc, Kerkrade) in 2007 he started to study Psychology at Maastricht University. In 2010, Kay started the two-year Research Master Neuropsychology, for which he performed a research and clinical internship at Mondriaan Zorggroep, $\mathrm{U}$-center and the memory clinic of the Maastricht University Medical Centre. He graduated in 2012 and worked as a researcher/psychologist at U-center and the Maastricht University Medical Centre. In 2013 he started working as a PhD candidate at the Alzheimer Centre Limburg (Department of Psychiatry and Neuropsychology of Maastricht University). As part of his PhD project he worked for two months at the Cambridge Institute of Public Health (University of Cambridge) and two months at the Institute of Epidemiology and Health Care (Department of Epidemiology and Public Health; University College London). Currently, Kay is working as a postdoctoral researcher at the Alzheimer Centre Limburg.

Kay Deckers is geboren in Brunssum op 10 november 1988 en groeide op in Kerkrade. In 2007 haalde hij zijn gymnasiumdiploma aan College Rolduc te Kerkrade. Hierna begon hij aan de studie Psychologie aan de Universiteit Maastricht. In 2010 startte hij met de tweejarige onderzoeksmaster Neuropsychologie en rondde deze in 2012 af. Als onderdeel van deze master heeft hij stage gelopen bij Mondriaan Zorggroep, U-center en de geheugenpoli van het Maastricht Universitair Medisch Centrum. Hierna heeft Kay gewerkt als onderzoeker/basispsycholoog bij U-Center en het Maastricht Universitair Medisch Centrum. In 2013 is hij gaan werken als promovendus bij het Alzheimer Centrum Limburg verbonden aan de afdeling Psychiatrie en Neuropsychologie van de Universiteit Maastricht. Als onderdeel van zijn promotieproject heeft Kay twee maanden gewerkt aan het Cambridge Institute of Public Health (University of Cambridge) en twee maanden aan het Institute of Epidemiology and Health Care (Department of Epidemiology and Public Health; University College London). Kay werkt momenteel als postdoc onderzoeker bij het Alzheimer Centrum Limburg. 

